NUREG/CR-6196

TMI V(93)EG01

EGG-2733

\title{
Calculations to Estimate the \\ Margin to Failure in the \\ TMI-2 Vessel
}

RECEIVED

APR 12 1994

OSTI

Prepared by L. A. Stickler, J. L. Rempe, S. A. Chadvez, G. L. Thinnes, S. D. Snow, R. J. Witt, M. L. Corradini, J. A. Kos

Idaho National Engineering Laboratory

EG\&G Idaho, Inc.

Prepared for

U.S. Nuclear Regulatory Commission 


\section{AVAILABILITY NOTICE}

Availability of Reterence Materials Cited in NRC Publications

Most documents clted in NRC publications will be avallable from one of the following sources:

1. The NRC Public Document Room, 2120 L Street, NW., Lower Level, Washington, DC 20555-0001

2. The Superintendent of Documents, U.S. Government Printing Office, Mail Stop SSOP, Washington, DC $20402-9328$

3. The National Technical Information Service, Springfield, VA 22161

Although the listing that follows represents the majority of documents cited in NRC publications. it is not intended to be exhaustive.

Referenced documents available for inspection and copying for a fee from the NRC Public Document Room include NRC correspondence and internal NRC memoranda: NRC bulletins. circulars. information notices, inspection and investigation notices: licensee event reports; vendor reports and correspondence: Commission papers: and applicant and licensee documents and correspondence

The following documents in the NUREG series are available for purchase from the GPO Sales Program: formal NRC staff and contractor reports, NRC-sponsored conference proceedings, international agreement reports. grant publications, and NRC booklets and brochures. Also available are regulatory guides. NRC regulations in the Code of Federal Regulations, and Nuclear Regulatory Commission Issuances.

Documents available from the National Technical Information Service include NUREG-series reports and technical reports prepared by other Federal agencies and reports prepared by the Atomic Energy Commission. forerunner agency to the Nuclear Regulatory Commission.

Documents available from public ard special technical libraries include all open literature items, such as books, journal articles, and transactions. Federal Register notices. Federal and State legislation, and congressional reports can usually be obtained from these libraries.

Documents such as theses, dissertations, foreign reports and translations, and non-NRC conference proceedings are available for purchase from the organization sponsoring the publication cited.

Single copies of NRC draft reports are available free, to the extent of supply, upon written request to the Office of Administration. Distribution and Mail Services Section, U.S. Nuclear Regulatory Commission, Washington. DC 20555-0001.

Copies of industry codes and standards used in a substantive manner in the NRC regulatory process are maintained at the NRC Library, 7920 Norfolk Avenue. Bethesda. Naryland, for use by the public. Codes and standards are usually copyrighted and may be purchased from the originating organization or, if they are American National Standards, from the American National Standards Institute, 1430 Broadway. New York. NY 10018.

\section{DISCLAIMER NOTICE}

This report was prepared as an account of work sponsored by an agency of the United States Government. Neither the United States Government nor any agency thereof, or any of their employees, makes any warranty, expressed or implied, or assumes any legal liability of responsibility for any third party's use, or the results of such use, of any information, apparatus, product or process disclosed in this report, or represents that its use by such third party would not infringe privately owned rights. 


\section{Calculations to Estimate the Margin to Failure in the TMI-2 Vessel}

Manuscript Completed: February 1994

Date Published: March 1994

Prepared by L. A. Stickler, J. L. Rempe, S. A. Chavez, G. L. Thinnes, S. D. Snow, R. J. Witt, ${ }^{*}$ M. L. Corradini, ${ }^{*}$ J. A. Kos*

Idaho National Engineering Laboratory

Managed by the U.S. Department of Energy

EG\&G Idaho, Inc.

Idaho Falls, ID 83415

\section{Prepared for}

Division of Systems Research

Office of Nuclear Regulatory Research

U.S. Nuclear Regulatory Commission

Washington, DC 20555-0001

NRC FIN A6899

Under DOE Contract No. DE-AC07-76ID0-1570

\section{DISCLAIMER}

This report was prepared as an account of work sponsored by an agency of the United States Government. Neither the United States Government nor any agency thereof, nor any of their employees, makes any warranty, express or implied, or assumes any legal liability or responsibility for the accuracy, completeness, or usefulness of any information, apparatus, product, or process disclosed, or represents that its use would not infringe privately owned rights. Reference herein to any specific commercial product, process, or service by trade name, trademark, manufacturer, or otherwise does not necessarily constitute or imply its endorsement, recommendation, or favoring by the United States Government or any agency thereof. The views and opinions of authors expressed herein do not necessarily state or reflect those of the United States Government or any agency thereof.

\footnotetext{
* University of Wisconsin-Madison

1500 Johnson Drive

Madison, WI 53706
} 


\begin{abstract}
As part of the OECD-sponsored Three Mile Island Unit 2 (TMI-2) Vessel Investigation Project (VIP), margin-to-failure calculations for mechanisms having the potential to threaten the integrity of the vessel were performed to improve understanding of events that occurred during the TMI-2 accident. Analyses considered four failure mechanisms: tube rupture, tube ejection, global vessel failure, and localized vessel failure. Calculational input was based on data from the TMI-2 VIP examinations of the vessel steel samples, the instrument tube nozzles, and samples of the hard layer of debris found on the TMI-2 vessel lower head. Sensitivity studies were performed to investigate the uncertainties in key parameters for these analyses.
\end{abstract}




\section{CONTENTS}

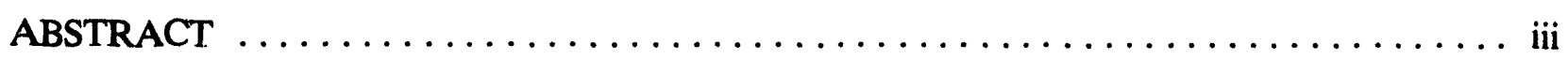

LIST OF FIGURES $\ldots \ldots \ldots \ldots \ldots \ldots \ldots \ldots \ldots \ldots \ldots \ldots \ldots \ldots \ldots \ldots \ldots \ldots \ldots$ ix

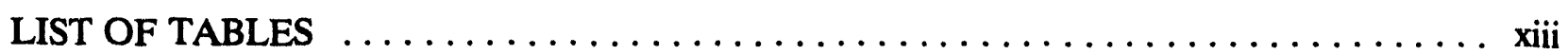

EXECUTIVE SUMMARY $\ldots \ldots \ldots \ldots \ldots \ldots \ldots \ldots \ldots \ldots \ldots \ldots \ldots \ldots \ldots \ldots \ldots$ xv

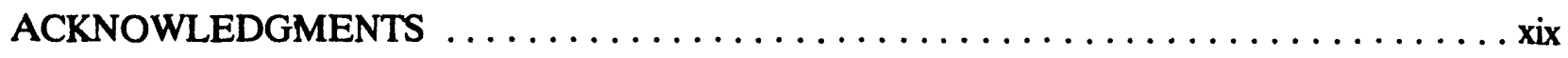

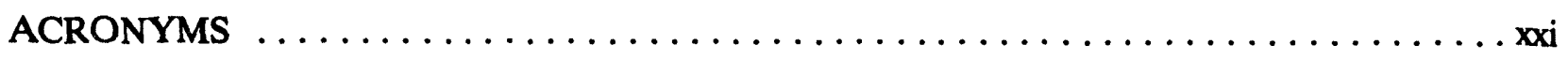

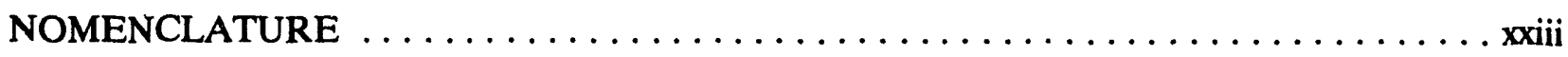

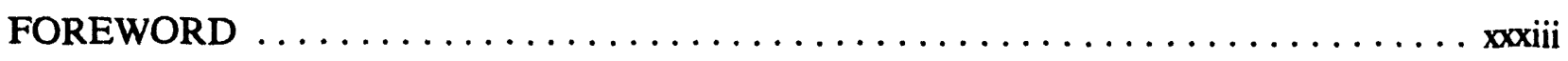

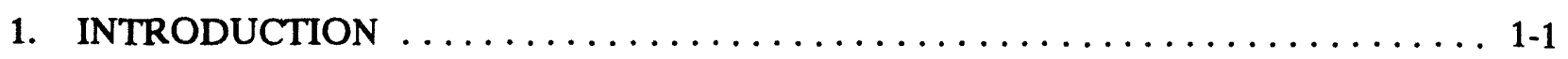

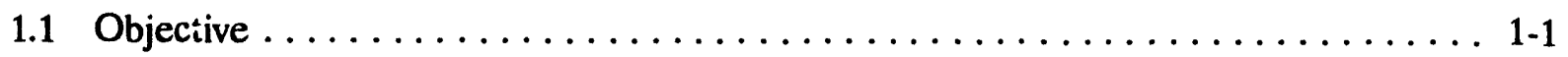

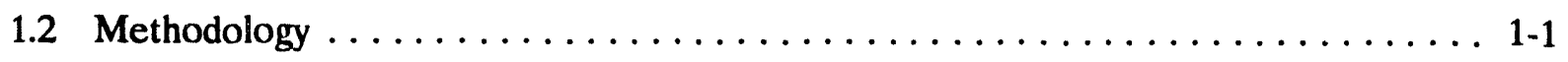

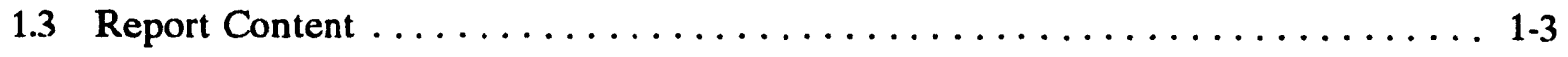

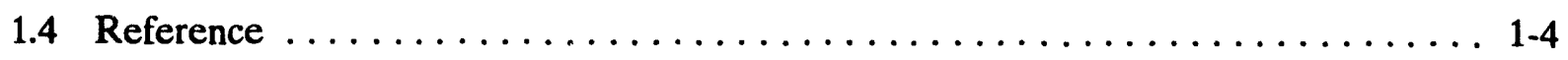

2. TMI-2 ACCIDENT DATA AND RELOCATION SCENARIO DESCRIPTION $\ldots \ldots$ 2-1

2.1 Measured Plant Data and Examination Data $\ldots \ldots \ldots \ldots \ldots \ldots \ldots \ldots \ldots \ldots \ldots \ldots$

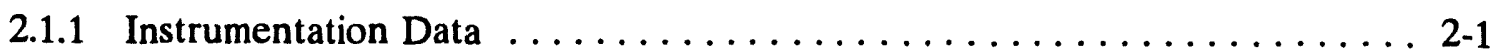

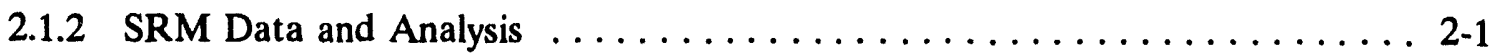

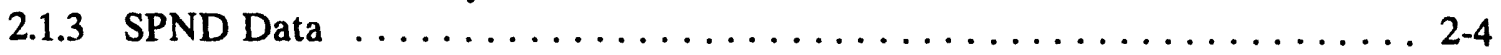

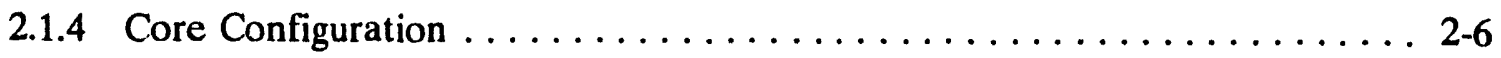

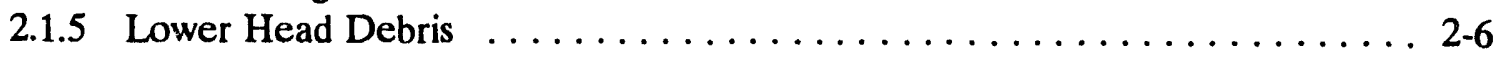

2.1.6 TMI-2 Lower Head Video Inspection $\ldots \ldots \ldots \ldots \ldots \ldots \ldots \ldots \ldots .2-8$

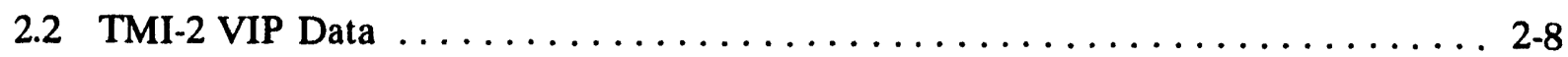

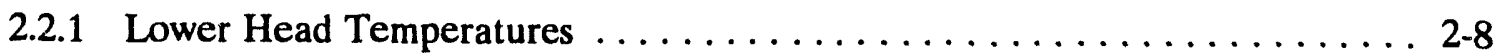

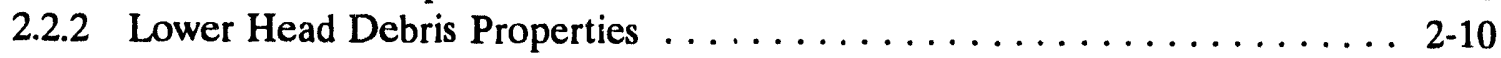

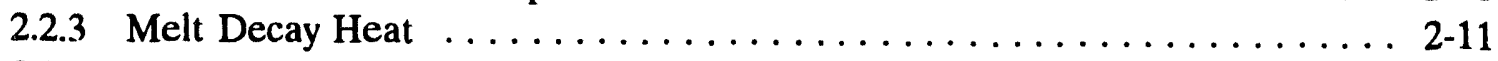

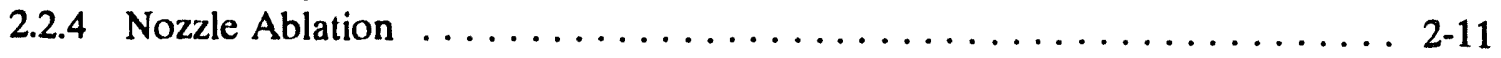

2.2.5 Composition of Melt Attached to Nozzles ................ 2-11 
2.2.6 Melt Flow Through Nozzles $\ldots \ldots \ldots \ldots \ldots \ldots \ldots \ldots \ldots \ldots \ldots . \ldots \ldots$

2.2.7 Nozzle Temperatures $\ldots \ldots \ldots \ldots \ldots \ldots \ldots \ldots \ldots \ldots \ldots \ldots \ldots .2-17$

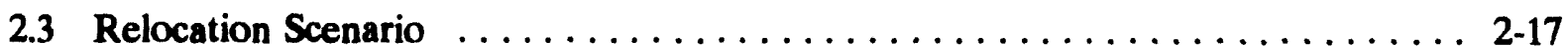

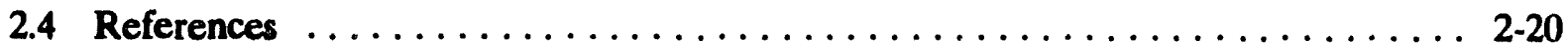

3. SCOPING CALCULATIONS FOR MELT RELOCATION AND THERMAL RESPONSE $\ldots \ldots \ldots \ldots \ldots \ldots \ldots \ldots \ldots \ldots \ldots \ldots \ldots \ldots \ldots \ldots \ldots \ldots \ldots \ldots \ldots, 1$

3.1 Study of Melt Penetration through TMI-2 Instrumentation Nozzles $\ldots \ldots \ldots \ldots$ 3-1

3.1.1 TMI-2 Instrumentation Nozzles $\ldots \ldots \ldots \ldots \ldots \ldots \ldots \ldots \ldots \ldots \ldots \ldots$ 3-1

3.1.2 Model Selection .......................... $3-3$

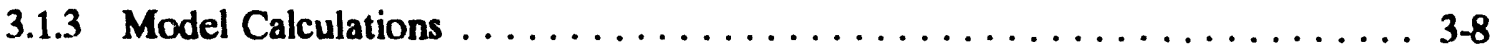

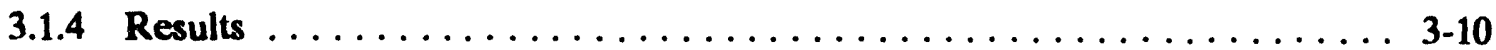

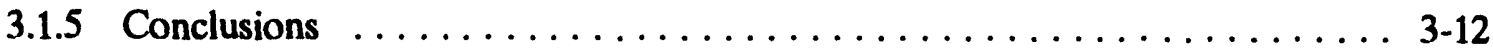

3.2 Jet Impingement and Thermal Response Calculations $\ldots \ldots \ldots \ldots \ldots \ldots$ 3-13

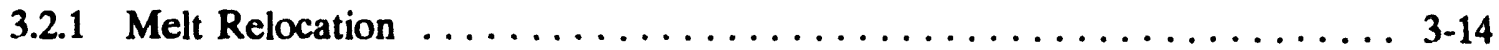

3.2.2 Jet Impingement and Vessel Thermal Response . . . . . . . . . . . 3-17

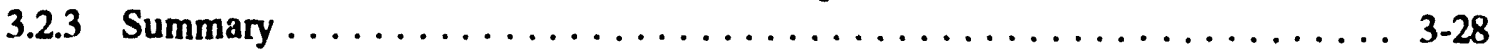

3.3 Summary for Melt Relocation and Thermal Response Calculations . . . . . . 3-31

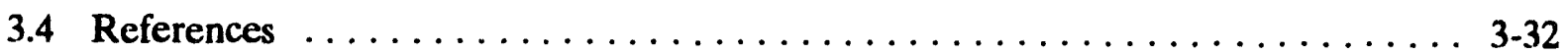

4. SCOPING CALCULATIONS FOR STRUCTURAL RESPONSE AND MARGIN-TOFAILURE ESTIMATES $\ldots \ldots \ldots \ldots \ldots \ldots \ldots \ldots \ldots \ldots \ldots \ldots$

4.1 Margin-to-Failure Background $\ldots \ldots \ldots \ldots \ldots \ldots \ldots \ldots \ldots \ldots \ldots \ldots \ldots \ldots$

4.2 Scoping Analysis for TMI Penetration Tube Weld Failure $\ldots \ldots \ldots \ldots \ldots$. . . 4-2

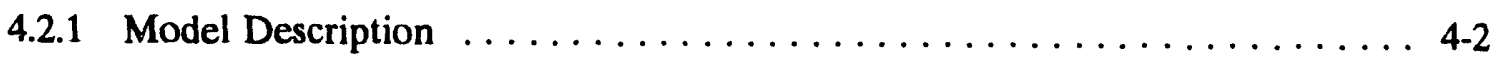

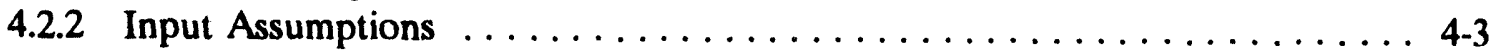

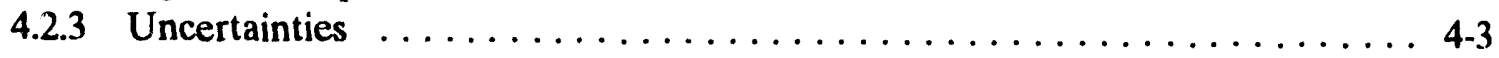

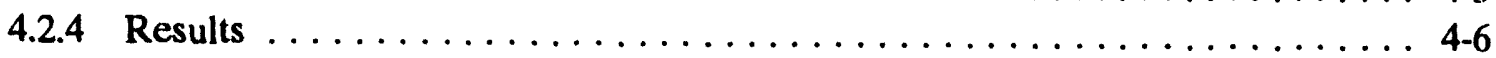

4.2 .5 Discussion $\ldots \ldots \ldots \ldots \ldots \ldots \ldots \ldots \ldots \ldots \ldots \ldots \ldots \ldots \ldots \ldots \ldots$

4.3 Ex-Vessel Instrument Tube Failure $\ldots \ldots \ldots \ldots \ldots \ldots \ldots \ldots \ldots \ldots \ldots$

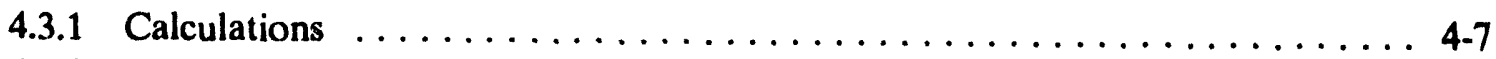

4.3.2 Results $\ldots \ldots \ldots \ldots \ldots \ldots \ldots \ldots \ldots \ldots \ldots \ldots \ldots \ldots \ldots \ldots$ 
4.4 Global Vessel Rupture $\ldots \ldots \ldots \ldots \ldots \ldots \ldots \ldots \ldots \ldots \ldots \ldots \ldots \ldots$

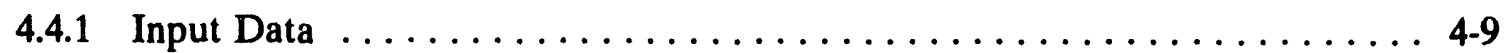

4.4.2 Model Description ........................ 4-10

4.4.3 Global Rupture Analysis Results . . . . . . . . . . . . . . . . . 4-14

4.4.4 Conclusions from the Global Rupture Analysis . . . . . . . . . . 4-17

4.5 Localized Vessel Failure $\ldots \ldots \ldots \ldots \ldots \ldots \ldots \ldots \ldots \ldots \ldots \ldots \ldots \ldots$

4.5.1 Thermal Model $\ldots \ldots \ldots \ldots \ldots \ldots \ldots \ldots \ldots \ldots \ldots \ldots \ldots \ldots \ldots \ldots$

4.5.2 Structural Model . . . . . . . . . . . . . . . . . . . . . 4-22

4.5.3 Results of Thermal and Structural Response .............. 4-25

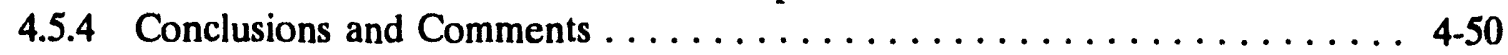

4.6 Conclusions from Margin-to-Failure Calculations $\ldots \ldots \ldots \ldots \ldots \ldots \ldots \ldots$

4.7 References $\ldots \ldots \ldots \ldots \ldots \ldots \ldots \ldots \ldots \ldots \ldots \ldots \ldots \ldots \ldots \ldots \ldots \ldots \ldots \ldots$

5. SCOPING CALCULATIONS TO INVESTIGATE DEBRIS COOLING AND

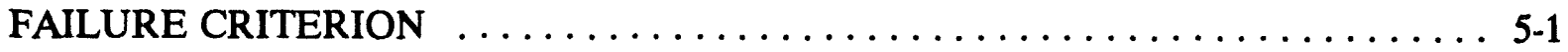

5.1 Slow and Rapid Cooling Analyses $\ldots \ldots \ldots \ldots \ldots \ldots \ldots \ldots \ldots \ldots \ldots \ldots \ldots \ldots$

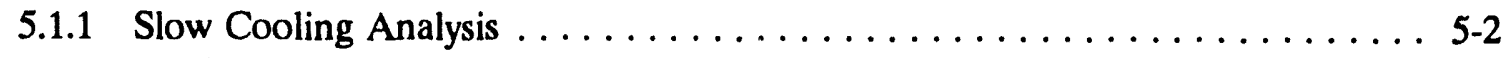

5.1 .2 Rapid Cooling Analysis . . . . . . . . . . . . . . . . . 5-11

5.1.3 Debris Configurations to Obtain Required Cooling Rates . . . . . . . . . 5 5-22

5.1.4 Changes in Lower Head Debris Internal Energy after Relocation . . . . . . 5-37

5.2 Mechanical Instability Failure Criterion Analyses $\ldots \ldots \ldots \ldots \ldots \ldots \ldots$

5.2 .1 Effects of Including Tertiary Creep . . . . . . . . . . . . . $5-46$

5.2.2 Effects of Failure Criterion on Slow Cooling Analysis Results . . . . . . . . 5 5-47

5.2.3 Effects of Failure Criterion on Rapid Cooling Case Results . . . . . . . . 5-58

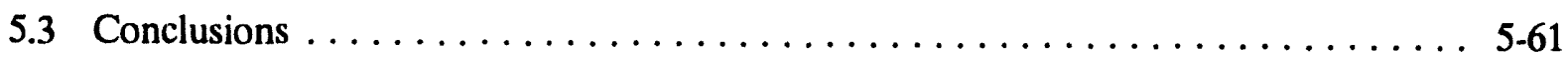

5.4 References $\ldots \ldots \ldots \ldots \ldots \ldots \ldots \ldots \ldots \ldots \ldots \ldots \ldots \ldots \ldots \ldots$

6. SUMMARY AND CONCLUSIONS $\ldots \ldots \ldots \ldots \ldots \ldots \ldots \ldots \ldots \ldots \ldots \ldots$

6.1 Summary of Results $\ldots \ldots \ldots \ldots \ldots \ldots \ldots \ldots \ldots \ldots \ldots \ldots \ldots \ldots$

6.2 Insights from Calculations and Severe Accident Implications $\ldots \ldots \ldots \ldots \ldots$

Appendix A-Modeling Input $\ldots \ldots \ldots \ldots \ldots \ldots \ldots \ldots \ldots \ldots \ldots \ldots \ldots \ldots \ldots$

Appendix B-Supporting Information for Melt Penetration Çalculations . . . . . . . . B-1 
Appendix C-TMI Model Description $\ldots \ldots \ldots \ldots \ldots \ldots \ldots \ldots \ldots \ldots \ldots \ldots \ldots \ldots$ Appendix D-Best Estimate Calculations for Tube Weld Failure $\ldots \ldots \ldots \ldots \ldots \ldots$ D-1 Appendix E-Results from Verification Calculations for Localized Effects Model . . . . . . E-1 


\section{LIST OF FIGURES}

1-1. Flow diagram of scoping calculations $\ldots \ldots \ldots \ldots \ldots \ldots \ldots \ldots \ldots \ldots \ldots$

2-1. RCS pressure with timing of significant events noted $\ldots \ldots \ldots \ldots \ldots \ldots \ldots$

2-2. RCS pressure from reactor scram to 17 hours $\ldots \ldots \ldots \ldots \ldots \ldots \ldots \ldots$

2-3. Cold leg temperatures from 0 to 17 hours $\ldots \ldots \ldots \ldots \ldots \ldots \ldots \ldots$

2-4. Cold leg temperatures between $220-230$ minutes $\ldots \ldots \ldots \ldots \ldots \ldots \ldots$

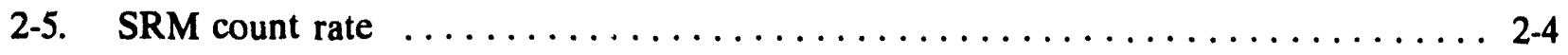

2-6. Elevations of SPND levels within the core $\ldots \ldots \ldots \ldots \ldots \ldots \ldots \ldots$

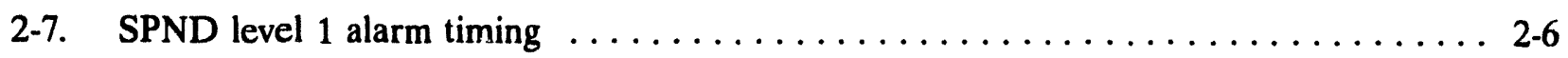

2-8. End state core configuration $\ldots \ldots \ldots \ldots \ldots \ldots \ldots \ldots \ldots \ldots \ldots \ldots \ldots \ldots$

2-9. Depth of hard layer of solidified debris. (Contour lines designate distance between a "hard stop" from probe tests and the bowl-shaped lower head.) . . . . . . . . 2-9

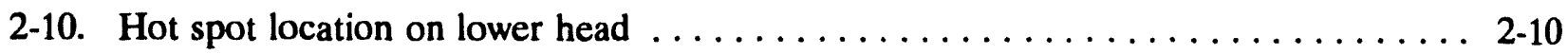

2-11. Three-dimensignal figure of nozzle end state in the lower head $\ldots \ldots \ldots \ldots . \ldots 2$

2-12. Lower head core support assembly $\ldots \ldots \ldots \ldots \ldots \ldots \ldots \ldots \ldots \ldots \ldots$

3-1. TMI-2 instrumentation nozzle $\operatorname{map} \ldots \ldots \ldots \ldots \ldots \ldots \ldots \ldots \ldots \ldots \ldots$

3-2. Area of debris versus distance from nozzle base for nozzles D10, E11, H5, H8, L6,

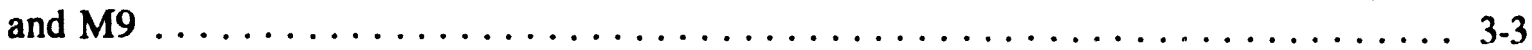

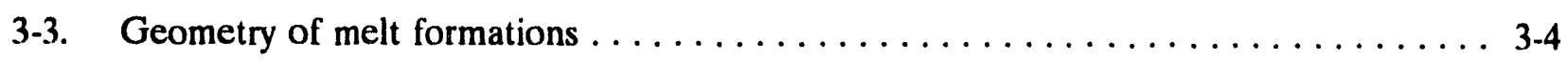

3-4. Melt penetration model geometries $\ldots \ldots \ldots \ldots \ldots \ldots \ldots \ldots \ldots \ldots \ldots$

3-5. Melt velocity plotted as a function of dimensionless penetration distance $\ldots \ldots \ldots$ 3-10

3-6. Thermal loading from jet impingement $\ldots \ldots \ldots \ldots \ldots \ldots \ldots \ldots \ldots$

3-7. Model for TMI-2 thermal analysis $\ldots \ldots \ldots \ldots \ldots \ldots \ldots \ldots \ldots \ldots \ldots$

3-8. Case 2 vessel inner surface temperatures $(0$ to 200 seconds $) \ldots \ldots \ldots \ldots$. . . . .

3-9. Case 2 vessel inner surface temperatures $(0$ to 21,600 seconds $) \ldots \ldots \ldots$. $\ldots \ldots$ 
3-10. Case 2 vessel inner surface temperatures as a function of angle at 21,600 seconds . . $3-25$

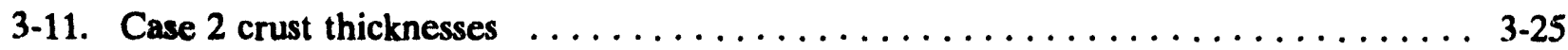

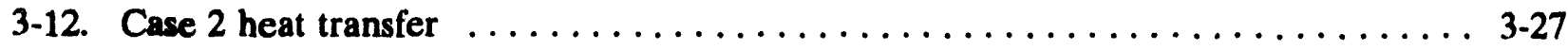

3-13. Case 2 heat fluxes at centerline $(0$ degrees from the vertical) $\ldots \ldots \ldots \ldots$. . . . $3-27$

3-14. Nominal case results $\ldots \ldots \ldots \ldots \ldots \ldots \ldots \ldots \ldots \ldots \ldots \ldots \ldots \ldots$

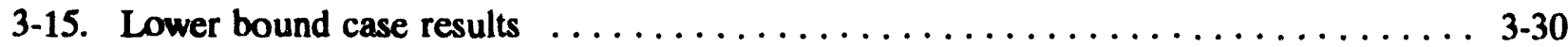

4-1. Schematic of instrument tube penetration $\ldots \ldots \ldots \ldots \ldots \ldots \ldots \ldots \ldots$

4-2. Schematic of instrument tube and vessel showing location of unistrut support $\ldots \ldots$ 4-5

4-3. Schematic of instrument tube penetration showing applied loads, shear stress and weld

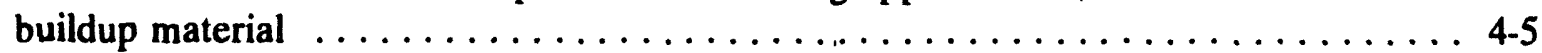

4-4. Schematic of configuration used to evaluate ex-vessel tube rupture $\ldots \ldots \ldots \ldots \ldots$

4-5. Force equilibrium for vessel internal pressure $\ldots \ldots \ldots \ldots \ldots \ldots \ldots \ldots \ldots \ldots$

4-6. Creep damaged vessel capacity $\ldots \ldots \ldots \ldots \ldots \ldots \ldots \ldots \ldots \ldots \ldots \ldots \ldots$

4-7. Global creep rupture model flow diagram $\ldots \ldots \ldots \ldots \ldots \ldots \ldots \ldots \ldots \ldots \ldots$

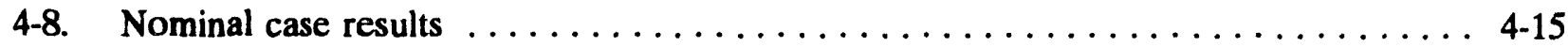

4-9. Lower-bound case results $\ldots \ldots \ldots \ldots \ldots \ldots \ldots \ldots \ldots \ldots \ldots \ldots \ldots \ldots$

4-10. Global failure times predicted for constant pressure and temperatures . . . . . . 4-17

4-11. Mesh of two-dimensional continuum axisymmetric finite element model for determining time-dependent temperature distributions in the reactor vessel wall ... 4-19

4-12. Two-dimensional thermal analysis boundary conditions $\ldots \ldots \ldots \ldots \ldots \ldots \ldots \ldots$ 4-21

4-13. Temperature distribution associated with lower-bound background heat fluxes . . . . 4-26

4-14. Distributions of $100 \%$ damaged ligaments at various times after debris relocation in the lower-bound background temperature problem $\ldots \ldots \ldots \ldots \ldots \ldots \ldots \ldots \ldots$ 4-28

4-15. Distribution of $100 \%$ damaged ligaments just prior to failure (1.91 hours after debris relocation) in the lower-bound background temperature problem . . . . . . . 4-29

4-16. Lower-bound background temperature problem results $\ldots \ldots \ldots \ldots \ldots \ldots \ldots$ 4-30 
4-17. Temperature distribution associated with hot spot on cool $(600 \mathrm{~K})$ background . . . 4-35

4-18. Hot spot on cool $(600 \mathrm{~K})$ background problem results $\ldots \ldots \ldots \ldots \ldots \ldots$. . . . . .

4-19. Distribution of $100 \%$ damaged ligaments at 1,000 hours after debris relocation into hot spot on cool $(600 \mathrm{~K})$ background transient $\ldots \ldots \ldots \ldots \ldots \ldots \ldots \ldots \ldots \ldots \ldots \ldots$

4-20. MF-1 calculation for hot spot on cool background problem results $\ldots \ldots \ldots$ 4-43

4-21. Distribution of $100 \%$ damaged ligaments at 1,000 hours after debris relocation into

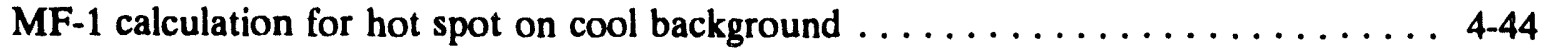

4-22. MF-2 calculation for hot spot on cool background problem results $\ldots \ldots \ldots$. . . .

4-23. Distribution of $100 \%$ damaged ligaments just prior to failure (10 hours after debris relocation) in MF-2 calculation for hot spot on cool $(600 \mathrm{~K})$ background . . . . 4-46

4-24. MF-3 calculation for hot spot on cool background problem results $\ldots \ldots \ldots$. . . 47

4-25. Distribution of $100 \%$ damaged ligaments just prior to failure ( 82 hours after debris relocation) in MF-3 calculation for hot spot on cool $(600 \mathrm{~K})$ background $\ldots \ldots \ldots$ 4-48

4-26. Temperature distribution associated with hot spot on lower-bound background at 2 hours after debris relocation into transient $\ldots \ldots \ldots \ldots \ldots \ldots \ldots \ldots \ldots \ldots$

4-27. Distribution of $100 \%$ damaged ligaments just prior to failure (1.5 hours after debris relocation) in hot spot on lower-bound background problem ......... 4-49

5-1. Temperature distribution of hot spot on $50 \%$ of nominal background heat fluxes $\ldots . .5$

5-2. Results for case with hot spot on $50 \%$ of nominal background heat fluxes $\ldots \ldots \ldots 5-4$

5-3. Distribution of $100 \%$ damaged ligaments at various times for the hot spot on $50 \%$ of nominal background heat fluxes $\ldots \ldots \ldots \ldots \ldots \ldots \ldots \ldots \ldots \ldots \ldots \ldots$

5-4. Temperature distribution of hot spot on $25 \%$ of nominal background heat fluxes . . . 5-6

5-5. Results for case with hot spot on $25 \%$ of nominal background heat fluxes $\ldots \ldots \ldots 5-7$

5-6. Distribution of $100 \%$ damaged ligaments at various times for the hot spot $25 \%$ of nominal background heat fluxes $\ldots \ldots \ldots \ldots \ldots \ldots \ldots \ldots \ldots \ldots \ldots \ldots \ldots$

5-7. Results for case with hot spot on $25 \%$ of nominal background heat fluxes when pressure depression is absent $\ldots \ldots \ldots \ldots \ldots \ldots \ldots \ldots \ldots \ldots \ldots \ldots \ldots \ldots$

5-8. Change in damage distribution when pressure depression is absent $\ldots \ldots \ldots \ldots$. $\ldots$ 
5-9. Temperature distribution of hot spot on $33 \%$ of nominal background heat fluxes . . 5-12

5-10. Results for case with hot spot on $33 \%$ of nominal background heat fluxes $\ldots \ldots \ldots 5-13$

5-11. Distribution of $100 \%$ damaged ligaments at various times for the hot spot on $33 \%$ of nominal background heat fluxes $\ldots \ldots \ldots \ldots \ldots \ldots \ldots \ldots \ldots \ldots \ldots \ldots \ldots \ldots \ldots \ldots$

5-12. Heat flux history in hot spot region for rapid cooling cases $\ldots \ldots \ldots \ldots \ldots \ldots$

5-13. Surface temperature underneath hot spot following initiation of rapid cooling $\ldots \ldots$ 5-16

5-14. Evolution of temperature profile in vessel following initiation of rapid cooling $\ldots \ldots$ 5-17

5-15. Results for case with rapid cooling of hot spot on $33 \%$ of nominal background heat

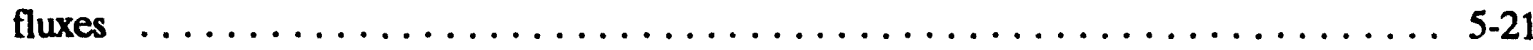

5-16. Results for case with rapid cooling of hot spot on $50 \%$ of nominal background heat

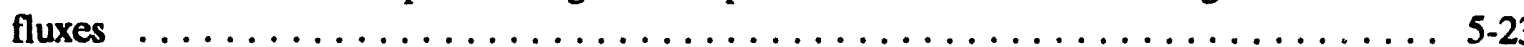

5-17. Distribution of $100 \%$ damaged ligaments at various times for rapid cooling of hot spot on $50 \%$ of nominal background heat fluxes

5-18. Debris geometry for estimating crack and gap cooling $\ldots \ldots \ldots \ldots \ldots \ldots \ldots$

5-19. Control volume for internal energy calculations $\ldots \ldots \ldots \ldots \ldots \ldots \ldots \ldots$

5-20. Combined high pressure injection and makeup flow into the RCS $\ldots \ldots \ldots . . \ldots 51$

5-21. Letdown flow rate of coolant $\ldots \ldots \ldots \ldots \ldots \ldots \ldots \ldots \ldots \ldots \ldots \ldots \ldots$

5-22. Pilot-operated relief valve flow rate $\ldots \ldots \ldots \ldots \ldots \ldots \ldots \ldots \ldots \ldots \ldots$

5-23. Change in debris internal energy versus coolant quality $\ldots \ldots \ldots \ldots \ldots \ldots \ldots$

5-24. Comparison of results obtained with and without tertiary creep for the nominal case

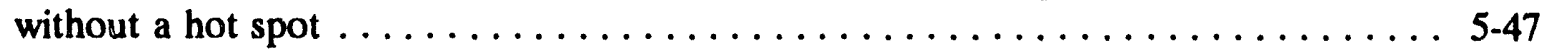

5-25. Distribution of ligaments experiencing tertiary creep at various times for the nominal case without a hot spot $\ldots \ldots \ldots \ldots \ldots \ldots \ldots \ldots \ldots \ldots \ldots \ldots \ldots \ldots \ldots$

5-26. Comparison of results for cases with a hot spot on various nominal heat fluxes . . . 5-49

5-27. Comparison of results for cases with a hot spot on $50 \%$ and $62.5 \%$ nominal heat fluxes 5-49

5-28. Distribution of ligaments experiencing tertiary creep at various times for the $100 \%$

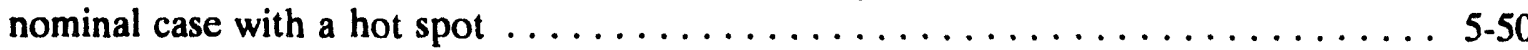


5-29. Distribution of ligaments experiencing tertiary creep at various times for the $75 \%$ nominal case with a hot spot $\ldots \ldots \ldots \ldots \ldots \ldots \ldots \ldots \ldots \ldots \ldots \ldots \ldots \ldots$

5-30. Distribution of ligaments experiencing tertiary creep 'at various times for the $62.5 \%$

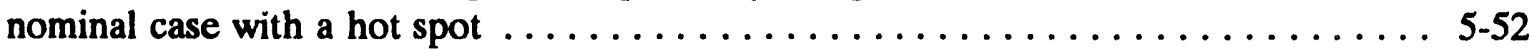

5-31. Distribution of ligaments experiencing tertiary creep at various times for the $50 \%$ nominal case with a hot spot $\ldots \ldots \ldots \ldots \ldots \ldots \ldots \ldots \ldots \ldots \ldots \ldots \ldots$

5-32. Comparison of results with and without rapid cooling for a $62.5 \%$ nominal case with a hot spot

5-33. Comparison of resulis with and without rapid cooling for a $75 \%$ nominal case with a hot spot

5-34. Results for a $80 \%$ nominal case with a hot spot and rapid cooling

5-35. Comparison of results for rapid cooling on various nominal heat fluxes with a hot spot 5-55

5-36. Distribution of ligaments experiencing tertiary creep at various times for the $62.5 \%$ nominal case with a hot spot and rapid cooling $\ldots \ldots \ldots \ldots \ldots \ldots \ldots \ldots \ldots \ldots$

5-37. Distribution of ligaments experiencing tertiary creep at various times for the $75 \%$ nominal case with a hot spot and rapid cooling

5-38. Distribution of ligaments experiencing tertiary creep at various times for the $80 \%$ nominal case with a hot spot and rapid cooling

6-1. Flow diagram illustrating margin-to-failure calculations performed in this study

\section{LIST OF TABLES}

2-1. Composition of debris in contact with nozzles

2-2. Melt constituents on nozzle surfaces

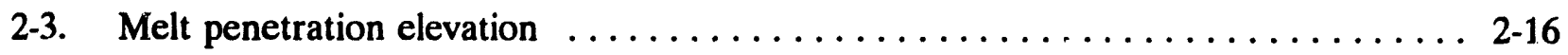

2-4. Wire probe test results $\ldots \ldots \ldots \ldots \ldots \ldots \ldots \ldots \ldots \ldots \ldots \ldots \ldots \ldots \ldots$

2-5. Microhardness measurements $\ldots \ldots \ldots \ldots \ldots \ldots \ldots \ldots \ldots \ldots \ldots \ldots \ldots$

3-1. Comparison of measured melt penetration and model predictions $\ldots \ldots \ldots$ 3-12

3-2. Maximum model predictions of melt penetration distance $\ldots \ldots \ldots \ldots \ldots \ldots$

3-3. TEXAS calculational results $\ldots \ldots \ldots \ldots \ldots \ldots \ldots \ldots \ldots \ldots \ldots \ldots \ldots \ldots$ 
3-4. Vessel thermal response calculation results $\ldots \ldots \ldots \ldots \ldots \ldots \ldots \ldots \ldots \ldots \ldots$

4-1. Ultimate strength margin to failure for instrument tube weld failure $\ldots \ldots \ldots \ldots$ 4-6

4-2. Time to creep failure for instrument tube weld failure $\ldots \ldots \ldots \ldots \ldots \ldots \ldots$

4-3. Time step selection in thermal analysis versus time interval $\ldots \ldots \ldots \ldots \ldots \ldots$

4-4. Comparison of stress status at shell bottom (node 1) and most heavily damaged region (node 120) at 1.44 hours into lower-bound transient $\ldots \ldots \ldots \ldots \ldots \ldots \ldots \ldots$ 4-31

4-5. Stress states in most heavily damaged region (node 120 ) at 1.91 hours into lower-

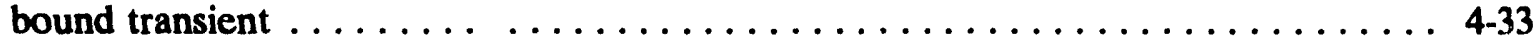

4-6. Peak temperatures of inner surface nodes in high heat flux region $\ldots \ldots \ldots \ldots$ 4-33

4-7. Stress distributions at bottom of shell at various times during transient (hot spot on

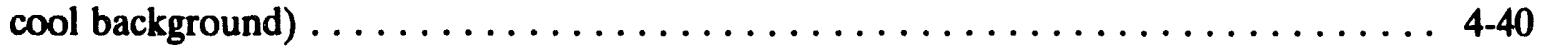

5-1. Summary of input assumptions for enhanced cooling calculations $\ldots \ldots \ldots \ldots$

5-2. Results for estimating the number of cracks to cool TMI-2 debris $\ldots \ldots \ldots \ldots$ 5-35

5-3. Results for estimating heat transfer coefficient through a debris-to-vessel gap . . . . 5-36

5-4. Results for estimating change in debris internal energy $\ldots \ldots \ldots \ldots \ldots \ldots \ldots$ 


\section{EXECUTIVE SUMMARY}

As part of the Three Mile Island Unit 2 (TMI-2) Vessel Investigation Project (VIP), marginto-failure calculations were performed to increase understanding of events that occurred during the TMI-2 accident. Because there is considerable uncertainty in input parameters for these calculations, analyses relied upon methods with closed-form or simplified numerical solution techniques so that a large number of cases could be evaluated.

Calculations were performed to consider tube and vessel failure mechanisms. Results from these calculations illustrate uncertainties in the ability of current models to predict debris behavior and vessel response during a severe accident. Results from thermal and structural response calculations combined with the relatively rapid vessel cooling indicated by metallurgical examinations indicate that debris cooling occurred that was not evident from companion sample examinations and that is not currently considered in severe accident analysis models. In addition, analysis results suggest that a stress-based failure criterion may be too conservative for predicting failure. Furthermore, the large uncertainty in methods for predicting vessel failure precluded an accurate assessment of the margin to failure during the TMI-2 event. Little, if any, validation has been performed on methods used to predict melt/water interaction, molten pool behavior, cooling in debris that solidifies after relocation, and structural creep failure in a severe accident. Therefore, analysis results should only be viewed as providing insight into areas, such as assessing what failure mechanisms were plausible during the TMI-2 event, quantifying for which failure mode there existed the smallest margin during the TMI-2 event, and emphasizing areas where additional research is needed in severe accident analysis. Major conclusions and insights from these calculations are listed below.

- Tube failures have been eliminated as potential failure mechanisms during the TMI-2 event.

Melt penetration calculations indicate that ceramic melt would not penetrate below the vessel head. Therefore, ex-vessel tube rupture calculations were performed assuming tube temperatures consistent with the vessel coolant temperatures. Because such temperatures were expected to result in very high margins to failure, a constant upper system pressure of $15 \mathrm{MPa}$ was applied in the tube failure calculations. Results indicate that the margin to failure for this mechanism was very high.

Prior to performing a tube ejection analysis, a weld failure analysis was performed to determine if the weld holding the nozzle to the vessel failed. Since it is not known if the hot spot temperatures occurred at the same time that the RCS was repressurized to $15 \mathrm{MPa}$,'weld failure calculations were conservatively performed assuming that peak temperatures and pressures occurred simultaneously. Results indicate that even for these very conservative assumptions, there was considerable margin in the weld's integrity. Therefore, there was no need for a tube ejection analysis.

- Debris cooling occurred within the first 2 hours after debris relocation.

Vessel thermal response calculation results indicate that only a case with "lower-bound" input assumptions for parameters, such as debris decay heat, vessel outer heat transfer 
coefficient, and debiis-to-vessel gap resistance resulted in global peak temperature predictions consistent with the boat sample examination data, namely that vessel temperatures remain below values where the material undergoes a transition from ferritic to austenitic steel. However, temperatures for this lower-bound case do not reflect the 10 to $100 \mathrm{~K} / \mathrm{min}$ cooling rate deduced from boat sample examination data.

The potential for the vessel to experience a global failure was evaluated for vessel temperature distributions based upon nominal and lower-bound input assumptions consistent with companion sample data. Global failure was predicted to occur at 1.7 hours after relocation for the nominal case and 2.3 hours after relocation for the lowerbound case. Subsequent parametric studies indicate that failure will be predicted for global vessel temperatures above 700 to $800 \mathrm{~K}$, if the reactor vessel is maintained at pressures near the operating pressure. Although the magnitude of cooling required was decreased when a stress-based failure criterion was replaced with a mechanical instability failure criterion, analyses indicate that debris cooling must have occurred within approximately 2 hours after debris relocation in order to prevent global failure.

Finally, an energy balance based on parameters directly measured or inferred from data measured during the accident indicates that the debris must have cooled after relocation. Calculations were conservatively performed by neglecting heat losses to the vessel and internal structures. Input parameters, such as debris decay heat, coolant injection rates, and relief valve flow rates were quantified based upon data measured during the accident or inferred from data measured during the accident. For all of the cases evaluated, which included upper-bound and lower-bound estimates on debris decay heat and mass flow rates, the debris is predicted to cool in the time period between debris relocation and vessel repressurization.

- Enhanced debris cooling may have occurred via coolant traveling in channels within the debris and in channels between the debris and the vessel.

Although there are insufficient TMI-2 data to determine the exact mechanisms that caused the debris to cool, scoping calculations were performed to quantify the magnitude of cooling needed in order to obtain results consistent with metallurgical examination data. Results indicate that both "slow" cooling (via coolant flowing through channels within the debris bed) and "rapid" cooling (via coolant flowing between the debris and the vessel) were needed in order for the vessel thermal response to be consistent with metallurgical examination data. Calculations indicate that coolant traveling through a negligible volume of channels within the debris bed (i.e., much less than $1 \%$ of the debris bed volume) and a very small gap thickness (e.g., as small as $1 \mathrm{~mm}$ ) would provide sufficient cooling.

- It is possible for the vessel to withstand the hot spot temperatures and durations inferred from the vessel metallurgical examinations if the balance of the vessel remains relatively cool.

Jet impingement calculations indicate that the magnitude and duration of hot spot temperatures estimated in TMI vessel examinations were not due to debris from an 
impinging jet. This is due to the fact that peak temperatures from an impinging jet could not be sustained for more than about 1 minute. The limited area estimated to have experienced hot spot temperature suggests that this region was subjected to a longer term localized heat source, such as might occur with a nonhomogeneous debris bed or a localized region with enhanced debris-to-vessel contact.

The potential for the vessel to experience a localized failure was evaluated by imposing hot spot temperatures on two background distributions, which were selected to bound possible background temperature distributions predicted by metallurgical examinations. Results for the background case with higher temperatures indicate that the presence of a hot spot reduces the predicted time to vessel failure. However, results from the case with lower background temperatures indicate that the vessel is capable of surviving local hot spots in the temperature range and of the duration inferred from the metallurgical examinations if the balance of the shell remains relatively cool.

Localized and global vessel failure calculations indicate that the background temperature behavior, which is highly dependent upon the heat load from relocated debris in the lower head, is key to predicting failure from either of these mechanisms. However, data from companion sample examinations were not sufficient to quantify the timing and rate of cooling that actually reduced this heat load.

The importance of results from these calculations may not be limited to TMI-2 specific applications. Rather, insights from these analyses provide another step toward answering severe accident questions. 


\section{ACKNOWLEDGMENTS}

We would like to express our gratitude to several individuals who contributed to this report. First, we would like to thank Drs. A. Rubin and C. Serpan of the U.S. NRC for their helpful suggestions and guidance on this research project. We would also like to express our appreciation to members of the Structural Mecahanics Peer Review Group: Dr. Y. Rashid (chairman), Dr. R. Dodds, Dr. R. Huddleston, Dr. A. Combescure, Mr. K. Hashimoto, Dr. B. Turland, Dr. B. Sturm, and Prof. E. Vitale. As documented within this report, the comments received from this group were instrumental in completing this analysis effort. 


\section{ACRONYMS}

$\begin{array}{ll}\text { ANL } & \text { Argonne National Laboratory } \\ \text { ANS } & \text { American Nuclear Society } \\ \text { DOE } & \text { U.S. Department of Energy } \\ \text { FCI } & \text { fuel-coolant interaction } \\ \text { HPI } & \text { high pressure injection } \\ \text { INEL } & \text { Idaho National Engineering Laboratory } \\ \text { L/D } & \text { jet length-to-jet diameter } \\ \text { LMP } & \text { Larsen-Miller parameter } \\ \text { MF } & \text { margin to failure } \\ \text { NRC } & \text { U.S. Nuclear Regulatory Commission } \\ \text { OECD } & \text { Organization for Economic Cooperation and Development } \\ \text { PORV } & \text { pilot operated relief valve } \\ \text { PWR } & \text { pressurized water reactor } \\ \text { RCS } & \text { reactor coolant system } \\ \text { SEM } & \text { scanning electron microscopy } \\ \text { SPND } & \text { self-powered neutron detector } \\ \text { SRM } & \text { source range monitor } \\ \text { TMI-2 } & \text { Three Mile Island Unit 2 } \\ \text { VIP } & \text { Vessel Investigation Project }\end{array}$




\section{NOMENCLATURE}

a

b Temperature-dependent constant used in Bailey-Norton creep equations (dimensionless)

c

Temperature-dependent constant used in Bailey-Norton creep equations (dimensionless)

$c_{p} \quad$ Specific heat capacity; may be further designated by the subscript, $d$ for debris, $f$ for bulk coolant temperature, $g$ for coolant in vapor phase, $l$ for coolant in liquid phase, $p$ for molten pool material, jet for impinging jet material, or $v$ for pressure vessel steel (J/kg-K)

$d_{e} \quad$ Effective diameter for melt flow (cm)

$d_{i} \quad$ Nozzle inner diameter $(\mathrm{cm})$

$d_{s o} \quad$ Instrument string outer diameter $(\mathrm{cm})$

$f(\varphi) \quad$ Function indicating variation of heat flux as function of angle, $\varphi$ (dimensionless)

$f_{f} \quad$ Fanning friction factor (dimensionless)

$g \quad$ Acceleration due to gravity $\left(\mathrm{m} / \mathrm{s}^{2}\right)$

$h \quad$ Heat transfer coefficient $\left(\mathrm{W} / \mathrm{m}^{2} \mathrm{~K}\right)$

$h \quad$ Height of debris in lower head (m)

$h_{\text {cond }} \quad$ Heat transfer coefficient through the outer half of the pressure vessel $\left(\mathrm{W} / \mathrm{m}^{2} \mathrm{~K}\right)$

$h_{\text {conv }} \quad$ Component of the heat transfer coefficient on the outer surface of the vessel due to natural convection $\left(\mathrm{W} / \mathrm{m}^{2} \mathrm{~K}\right)$

$h_{\text {crus }} \quad$ Heat transfer coefficient through the crust $\left(W / m^{2} K\right)$

$h_{\text {din }} \quad$ Heat transfer coefficient due to jet impingement $\left(\mathrm{W} / \mathrm{m}^{2} \mathrm{~K}\right)$

$h_{d c} \quad$ Convective heat transfer coefficient from the molten pool to the lower crust $\left(\mathrm{W} / \mathrm{m}^{2} \mathrm{~K}\right)$

$h_{f b, r} \quad$ Heat transfer coefficient for film boiling and radiation from the crust to the coolant $\left(\mathrm{W} / \mathrm{m}^{2} \mathrm{~K}\right)$

$h_{f g} \quad$ Coolant latent heat of vaporization $(\mathrm{J} / \mathrm{kg})$ 
$h_{\text {in }} \quad$ Coolant enthalpy at the inlet $(\mathrm{J} / \mathrm{kg})$

$h_{i n t} \quad$ Debris to structure gap heat transfer coefficient $\left(W / \mathrm{m}^{2} \mathrm{~K}\right)$

$h_{\text {out }} \quad$ Coolant enthalpy at the exit $(\mathrm{J} / \mathrm{kg})$

$h_{p v} \quad$ Effective heat transfer coefficient for the pressure vessel $\left(\mathrm{W} / \mathrm{m}^{2} \mathrm{~K}\right)$

$h_{\text {pvo }} \quad$ Heat transfer coefficient on the outside of the pressure vessel $\left(W / m^{2} \mathrm{~K}\right)$

$h_{\text {rad }} \quad$ Radioactive component of the heat transfer coefficient on the outside of the vessel $\left(\mathbf{W} / \mathrm{m}^{2} \mathrm{~K}\right)$

$h_{\text {sat }} \quad$ Saturated liquid coolant enthalpy for a given pressure $(\mathrm{J} / \mathrm{kg})$

$h_{t d} \quad$ Heat transfer coefficient between tube wall and debris $\left(W / \mathrm{m}^{2} \mathrm{~K}\right)$

$h_{\mu c} \quad$ Convective heat transfer coefficient from the molten pool to the upper crust $\left(\mathrm{W} / \mathrm{m}^{2} \mathrm{~K}\right)$

$h_{w d} \quad$ Heat transfer coefficient between coolant and debris $\left(\mathrm{W} / \mathrm{m}^{2} \mathrm{~K}\right)$

$k \quad$ Thermal conductivity; may be further designated by the subscript, crust for crust material, $d$ for debris material, $f$ for liquid coolant, jet for impinging jet material, por for porous material, $s$ for nonporous material, or $v$ for vessel material $(\mathrm{W} / \mathrm{mK})$

$l_{t} \quad$ Distance melt must travel through nozzle to outer vessel surface (m)

$m$ Temperature-dependent constant used in Bailey-Norton creep equations (dimensionless)

$m$ Temperature-dependent material constant used in low temperature $(<922 \mathrm{~K})$ creep strain relations (dimensionless)

$\dot{m} \quad$ Mass flow rate of impinging jet $(\mathrm{kg} / \mathrm{s})$

$\dot{m}$ Coolant mass flow rate in Section 5, may be further designated by the subscript, crack, for flow through a crack, in, for flow entering the vessel, out, for flow exiting the vessel, and tot, for flow through all debris cracks

$m_{d} \quad$ Debris mass $(\mathbf{k g})$

$m_{\text {satl }} \quad$ Mass of saturated coolant $(\mathrm{kg})$

$n \quad$ Exponent used in power law hardening relation (dimensionless)

$n \quad$ Number of cracks in a debris bed $(m)$ 
$p_{i} \quad$ Reactor system pressure (MPa)

$q^{\prime \prime} \quad$ Heat flux from debris to vessel $\left(\mathrm{W} / \mathrm{m}^{2}\right)$

$q^{\prime \prime} \quad$ Film boiling heat flux $\left(\mathrm{W} / \mathrm{m}^{2}\right)$

$q^{\prime \prime} f b r$ Combined film boiling and radiative heat flux up from the pool $\left(\mathrm{W} / \mathrm{m}^{2}\right)$

$q^{\prime \prime}{ }_{f b, s u b}$ Film boiling heat flux to subcooled coolant $\left(\mathrm{W} / \mathrm{m}^{2}\right)$

$q^{\prime \prime}$ nom Heat flux for nominal case $\left(\mathrm{W} / \mathrm{m}^{2}\right)$

$q^{\prime \prime}, \quad$ Radiative heat flux to coolant $\left(\mathrm{W} / \mathrm{m}^{2}\right)$

$q_{\text {remove }} \quad$ Heat that must be removed by coolant in the debris to vessel gap to obtain cooling rates consistent with metallurgical examinations (W)

$q_{\text {sink }} \quad$ Heat that must be removed by coolant flowing through the cracks to prevent vessel failure (W)

$q^{\prime \prime}$ NB Nucleate boiling heat flux to coolant $\left(\mathrm{W} / \mathrm{m}^{2}\right)$

$q^{\prime \prime} N C$ Natural convection heat flux $\left(\mathrm{W} / \mathrm{m}^{2}\right)$

$q^{\prime \prime \prime} \quad$ Volumetric heat generation rate $\left(\mathrm{W} / \mathrm{m}^{3}\right)$

$r \quad$ Radial distance from the center of curvature of the vessel (m). In Hookes' Law equations, it specifies the radial direction.

$r_{h} \quad$ Horizontal distance from the vertical axis/centerline of the spherical head for use in calculating $x(m)$

$r_{i} \quad$ Inner vessel radius $(\mathrm{m})$

$r_{j} \quad$ Mean radius of segment of vessel head (m)

$r_{m} \quad$ Mean wall radius of vessel head (m)

$r_{0} \quad$ Outer vessel radius (m)

$t \quad$ Time (s or h)

$t_{\text {drain }} \quad$ Time required for jet to drain (s) 
Gap thickness, (m)

$t_{r} \quad$ Rupture time (s or h)

$t_{\text {sol }} \quad$ Time required for melt to solidify while traveling through tube (s)

$t_{v} \quad$ Vessel thickness (m)

$\boldsymbol{u}$

$u_{d}$

$u_{l}$

$v_{d}$

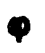

$x$

$\boldsymbol{x}$

$x_{p}$

$z_{\text {crack }}$

$z_{\text {debris }}$

$\boldsymbol{A}$

$\boldsymbol{A}$

$A_{\text {crack }}$

$A_{\text {down }}$
Radial displacement (m)

Debris internal energy; may be further designated by the subscript, 1 or 2 , to denote an initial or final state, respectively $(\mathrm{J} / \mathrm{kg})$

Coolant internal energy; may be further designated by the subscript, 1 or 2 , to denote an initial or final state, respectively $(\mathrm{J} / \mathrm{kg})$

Melt velocity $(\mathrm{m} / \mathrm{s}, \mathrm{cm} / \mathrm{s})$

Angle between the vertical and point along the inner surface of the vessel in Appendix $\mathrm{C}$ and Appendix E; may be modified with subscript $O$ to define undeformed configuration (radians)

Fraction of the effective cross-section area covered by debris (dimensionless)

Quality in the RCS (may be further designated by the subscript, 1 or 2 to denote an initial or final state, respectively)

Melt penetration distance $(\mathrm{cm})$

Effective height for a crack in the debris (m)

Effective height for a crack in the debris (m)

Temperature-dependent constant used in Bailey-Norton creep equations (dimensionless)

Contact area; may be further designated by the subscript, dcrust for area between bottom of molten pool and crust; pvi for area between molten pool and vessel inner surface, pvo for outer surface area of the vessel, $t d$ for area between tube and debris, top for area between upper crust and coolant, ucrust for area between top of molten pool and crust, or $w d$ for area between coolant and debris $\left(\mathrm{m}^{2}\right)$

Surface area in a crack $\left(\mathbf{m}^{2}\right)$

Surface area of debris facing vessel $\left(\mathrm{m}^{2}\right)$ 
$A_{\text {flow }}$ Cross-sectional flow area $\left(\mathrm{m}^{2}\right)$

$C_{i} \quad$ Structural capacity (N)

D Creep damage based on time to rupture (dimensionless)

D. Effective diameter for a crack in the debris (m)

$D_{j a} \quad$ Jet diameter $(\mathbf{m})$

E Young's modulus $(\mathrm{MPa})$

$F_{d} \quad$ Deadweight load (N)

$F_{p} \quad$ Pressure load (N)

$F_{\text {botal }} \quad$ Total force on weld (N)

Fo Fourier number (dimensionless)

Gr Grashof number (may be further designated with the subscript, $f$, to designate that it be evaluated at the bulk coolant temperature) (dimensionjess)

$J_{1} \quad$ First stress invariant (MPa)

K Entrance loss coefficient (dimensionless)

$L \quad$ Latent heat of fusion; may be further designated by the subscript, $d$ in Section 3 for debris or the subscript, crust in Appendix C for debris crust (J/kg)

$L_{\text {cher }} \quad$ Characteristic length (m)

$L_{i} \quad$ Applied load (N)

LMP Larson-Miller parameter (dimensionless)

$M \quad$ Mass; may be further designated by the subscript, $p$ for pool material or $v$ for pressure vessel material $(\mathrm{kg})$

$M_{c} \quad$ Coolant mass in the RCS (may be further designated by the subscript, 1 or 2 to denote an initial or final state, respectively) (kg)

$M_{d} \quad$ Debris mass in hard layer (may be further designated by the subscript, 1 or 2 to denote an initial or final state, respectively) $(\mathbf{k g})$

$M_{\text {drot }} \quad$ Total debris mass in the vessel $(\mathrm{kg})$ 


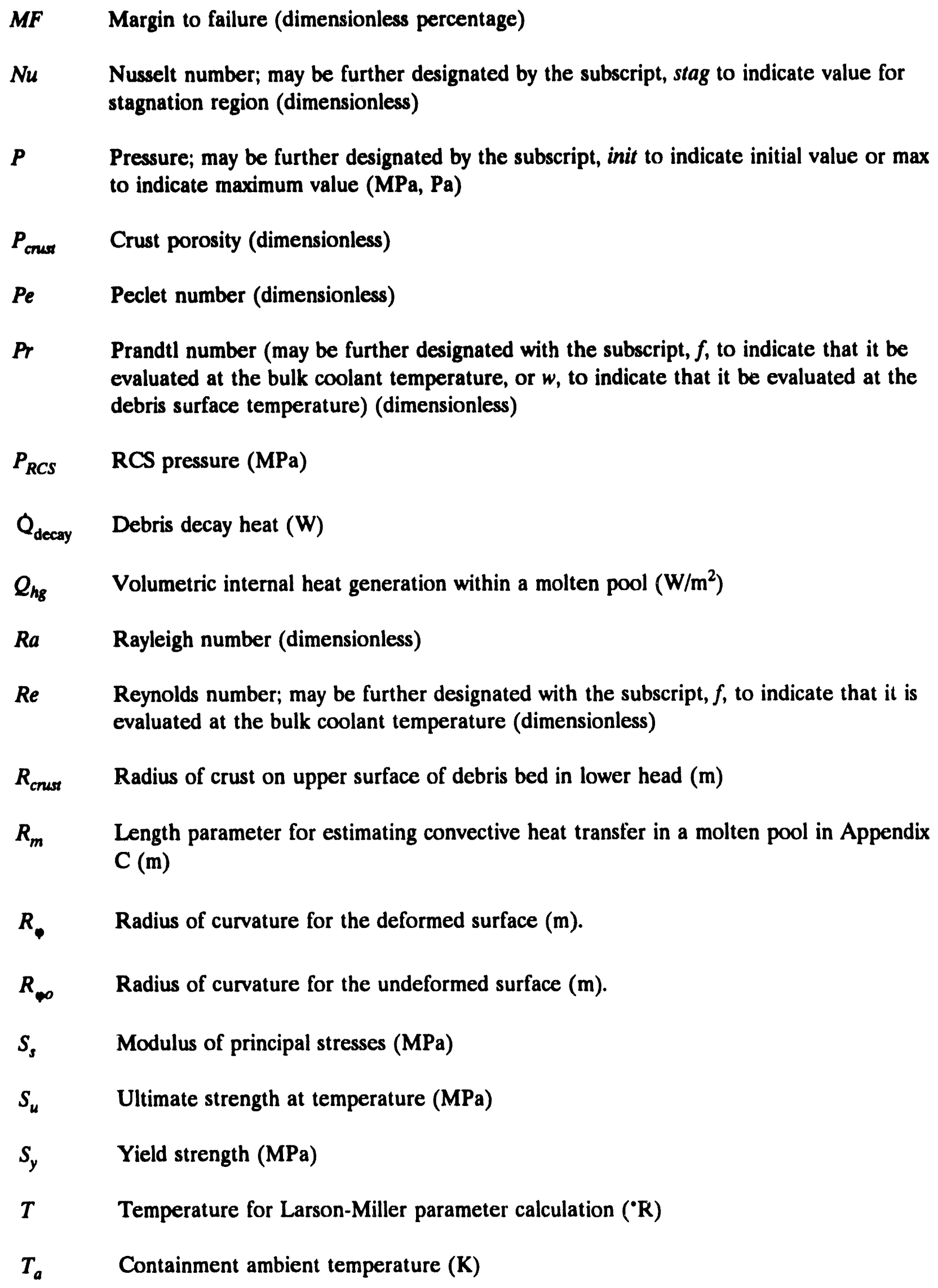

Re Reynolds number; may be further designated with the subscript, $f$, to indicate that it is evaluated at the bulk coolant temperature (dimensionless)

$R_{\text {crust }} \quad$ Radius of crust on upper surface of debris bed in lower head (m)

$R_{m} \quad$ Length parameter for estimating convective heat transfer in a molten pool in Appendix $\mathrm{C}(\mathrm{m})$

$R_{\text {. }} \quad$ Radius of curvature for the deformed surface $(\mathrm{m})$.

$R_{\infty} \quad$ Radius of curvature for the undeformed surface $(\mathrm{m})$.

$S_{s} \quad$ Modulus of principal stresses (MPa)

$S_{u} \quad$ Ultimate strength at temperature $(\mathrm{MPa})$

$S_{y} \quad$ Yield strength $(\mathrm{MPa})$

$T$ Temperature for Larson-Miller parameter calculation $\left({ }^{\circ} \mathrm{R}\right)$

$T_{a} \quad$ Containment ambient temperature (K) 
$T_{\text {bulk }} \quad$ Bulk coolant temperature (K)

$T_{c} \quad$ Coolant temperature (K)

$T_{d} \quad$ Debris temperature (K)

$T_{\text {debris }} \quad$ Initial debris temperature (K)

$T_{i} \quad$ Initial coolant temperature (K)

$T_{\text {in }} \quad$ Coolant inlet temperature (K)

$T_{\text {in }} \quad$ Inside shell surface temperature (K)

$T_{\text {int }} \quad$ Interface temperature between the coolant and the crust upper surface (K)

$T_{\text {jet }} \quad$ Jet temperature (K)

$T_{m p} \quad$ Debris melting temperature (K)

$T_{m p, p} \quad$ Melting temperature of material within pool (K)

$T_{\text {out }} \quad$ Coolant exit temperature (K)

$T_{\text {out }} \quad$ Outside shell surface temperature (K)

$T_{p} \quad$ Temperature within molten pool (K)

$T_{\text {peak }} \quad$ Peak temperature for hot spot temperature definitions (K)

$T_{\text {sat }} \quad$ Coolant saturation temperature (K)

$T_{\text {sub }} \quad$ Subcooled coolant temperature (K)

$T_{\text {sup }} \quad$ Superheated coolant temperature (K)

$T_{t} \quad$ In-vessel tube temperature (K)

$T_{L E V} \quad$ Ex-vessel tube temperature (K)

$T_{\text {tinnerface }}$ Tube temperature at vessel/tube interface (K)

$T_{R C S} \quad$ Reactor coolant system temperature (K)

$T_{v} \quad$ Vessel temperature (K)

$T_{\text {wall }} \quad$ Melt cup wall temperature (K) 
$U$ Overall heat transfer coefficient; may be further designated by the subscript down to indicate transfer from the pool downward to the vessel, up to indicated transfer from the pool upward to the coolant, or out to indicate transfer from the vessel to the surroundings $\left(\mathrm{W} / \mathrm{m}^{2} \mathrm{~K}\right)$

$V \quad$ Volume; may be further designated by the subscript, dcrust to indicate volume of crust on lower pool surface ucrust to indicate volume of curst on upper pool surface $\left(\mathrm{m}^{3}\right)$

$V_{\text {coolant }}$ Reactor coolant system volume (may be further designated by the subscript, 1 or 2 to denote an initial or final state, respectively) $\left(\mathrm{m}^{3}\right)$

$X_{s} \quad$ Solid fraction (dimensionless)

a Thermal expansion coefficient $\left(\mathrm{K}^{-1}\right)$

$\alpha$ Thermal diffusivity; may be further designated by the subscript $p$ for pool material, $d$ for melt; or $\mathrm{v}$ for vessel material $\left(\mathrm{m}^{2} / \mathrm{s}\right)$

$\boldsymbol{\alpha}_{s f} \quad$ Shape factor (dimensionless)

$a_{\mathrm{tr}} \quad$ Vessel thermal diffusivity $\left(\mathrm{m}^{2} / \mathrm{s}\right)$

Shell rotation relative to its original configuration (radians)

B Thermal expansion coefficient (may be further designated with the subscript, $f$, to designate that it be evaluated at the bulk coolant temperature) $\left(\mathrm{K}^{-1}\right)$

B $\quad$ Coefficient of thermal expansion of melt in a molten pool $\left(\mathrm{K}^{-1}\right)$

$\beta_{c} \quad$ Coefficient of thermal expansion for coolant $\left(K^{-1}\right)$

$\gamma \quad$ Material rotation from normal to the deformed middle surface (radians)

$\gamma^{\prime} \quad d \gamma / d \xi$ (radians)

$\Delta t_{i} \quad$ Time increment used in creep damage calculations (h)

$\Delta t_{v} \quad$ Incremental width of a vessel segment (m)

$\Delta \quad$ Time step; may 'e further designated by the subscript, creep to indicate that step was selected based apon creep strain rates, press to indicate time step to next time at which a pressure st $x$.e is defined, or temp to indicate time step to next time at which a temperature distribution is defined (seconds) 
$\Delta T \quad$ Temperature increment; may be further designated by the subscript, $p$ to indicate amount that pool temperature is incremented or $v$ to indicate amount that vessel temperature is incremented $(\mathbf{K})$

$\Delta x \quad$ Mesh size (m)

8 Crust thickness; may be further designated by the subscript dcrust to indicate lower crust thickness or ucrust to indicate upper crust thickness (m)

- Strain; maybe modified with the subscripts $y, p l c r, T, a v, m, \omega 0$, and $r$ to define yield, plastic, creep, thermal, average, at the middle surface, and/or strain component directions (dimensionless)

$\widetilde{E} \quad$ Effective, or equivalent, strain; may be modified with the subscript $c r$ to define effective creep strain $(\mathrm{m} / \mathrm{m})$.

$\varepsilon_{\text {crust }} \quad$ Crust emissivity (dimensionless)

$\varepsilon_{\text {ves }} \quad$ Vessel emissivity (dimensionless)

6 Distance between shell material and midplane, measured normal to the middle surface, between $-t / 2$ and $+t / 2(m)$

$\lambda_{c} \quad$ Melt solidification constant (dimensionless)

H Temperature-dependent material constant used in low temperature $(<922 \mathrm{~K})$ creep strain relations (dimensionless)

$\mu \quad$ Viscosity; may be further designated by the subscript $\boldsymbol{g}$ for coolant vapor, jet for molten jet material, $p$ for pool material, $f$ for the bulk coolant temperature (Pa-s)

$\checkmark \quad$ Poisson's ratio (dimensionless)

$v_{p} \quad$ Melt kinematic viscosity in a molten pool $\left(\mathrm{m}^{2} / \mathrm{s}\right)$

(5) Parametric variable used to define the shell model meridian, $0 \leq \xi \leq 1, \xi^{2}=\mathrm{r} / \mathrm{b}$ (dimensionless)

P Density; may be further designated by the subscript crust, to indicate crust density, $d$ to indicate melt density, $f$ to indicate liquid coolant density, $g$ to indicate vapor coolant density, $p$ to indicate pool material density, sat $t_{g}$ to indicate density for saturated vapor phase of coolant, sat, to indicate density for saturated liquid phase of coolant, sub to indicate subcooled coolant density, or sup to indicate superheated coolant density $\left(\mathrm{kg} / \mathrm{m}^{3}\right)$ 
- Stress; may be modified with the subscripts y, $\theta, 0, r$ or $1,2,3$ to define yield, or stress component directions or principal stresses $(\mathrm{MPa})$

б Effective or equivalent stress (MPa). Note: Mises effective stress $\left(\sigma_{m}\right)$ is defined separately

o $\quad$ Crust thickness (cm)

$\sigma_{f} \quad$ Surface tension for liquid coolant $(\mathrm{N} / \mathrm{m})$

$\sigma_{m} \quad$ Temperature-dependent material constant used in low temperature $(<922 \mathrm{~K})$ creep strain relations (dimensionless)

$\sigma_{s b} \quad$ Stefan Boltzmann constant $\left(5.672 \times 10^{-8} \mathrm{~W} / \mathrm{m}^{2} \mathrm{~K}^{4}\right)$

$\sigma_{v m} \quad$ Mises effective stress $(\mathrm{MPa})$

Characteristic time used in creep strain relationship (hours)

$v_{l} \quad$ Saturated liquid specific volume (may be further designated by the subscript, 1 or 2 to denote an initial or final state, respectively) $\left(\mathrm{m}^{3} / \mathrm{kg}\right)$

$v_{g} \quad$ Saturated vapor specific volume (may be further designated by the subscript, 1 or 2 to denote an initial or final state, respectively) $\left(\mathrm{m}^{3} / \mathrm{kg}\right)$

$d \varphi / d \xi$ in Appendix E (radians) 


\section{FOREWORD}

The contents of this report were developed as part of the Three Mile Island Unit 2 Vessel Investigation Project. This project is jointly sponsored by eleven countries under the auspices of the Nuclear Energy Agency of the Organization for Economic Cooperation and Development. The twelve sponsoring organizations are:

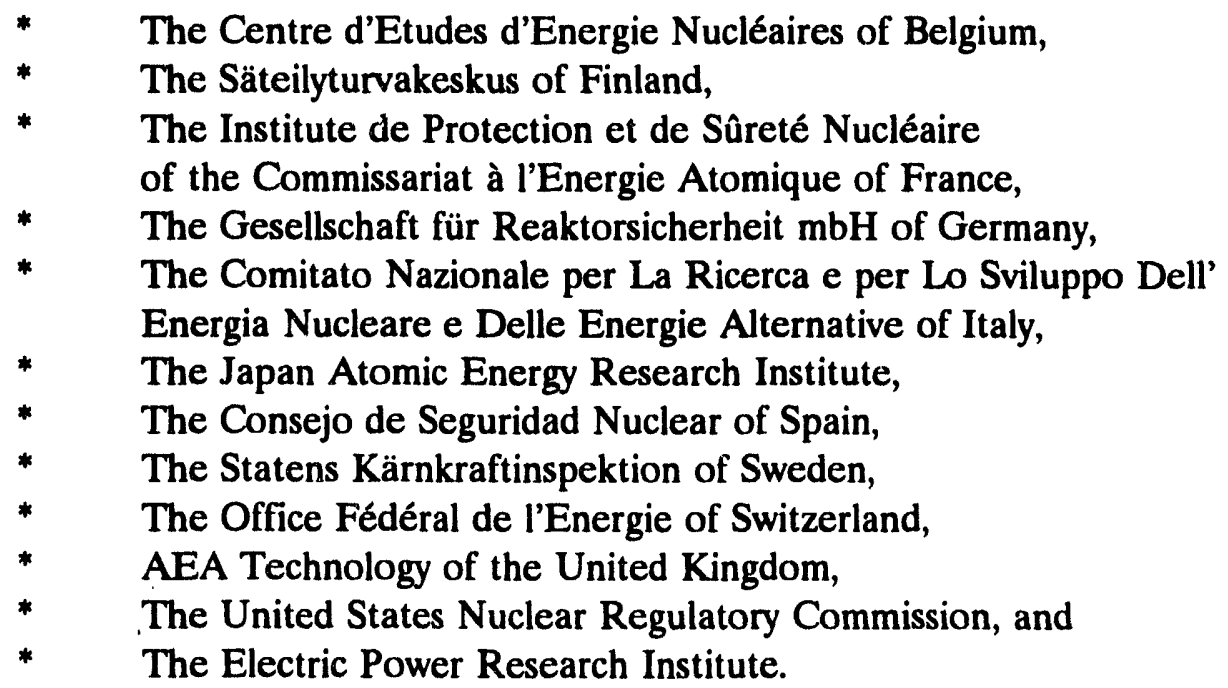

The primary objectives of the Nuclear Energy Agency (NEA) are to promote cooperation between its Member governments on the safety and regulatory aspects of nuclear development, and on assessing the future role of nuclear energy as a contributor to economic progress.

This is achieved by:

- encouraging harmonisation of governments' regulatory policies and practices in the nuclear field, with particular reference to the safety of nuclear installations, protection of man against ionising radiation and preservation of the environment, radioactive waste management, and nuclear third party liability and insurance;

- keeping under review the technical and economic characteristics of nuclear power growth and of the nuclear fuel cycle, and assessing demand and supply for the different phases of the nuclear fuel cycle and the potential future contribution of nuclear power to overall energy demand;

- developing exchanges of scientific and technical information on nuclear energy, particularly through participation in common services;

- setting up international research and development programmes and undertakings jointly organized and operated by OECD countries.

In these and related tasks, NEA works in close collaboration with the International Atomic Energy Agency in Vienna, with which it has concluded a Cooperation Agreement, as well as with other international organizations in the nuclear field. 


\section{Calculations to Estimate the Margin to Failure in the TMI-2 Vessel}

\section{INTRODUCTION}

\subsection{Objectlve}

This report describes the calculations performed to estimate the margin to failure (MF) of the Three Mile Island Unit-2 (TMI-2) pressure vessel lower head. Scoping calculations were performed to quantify the margin to failure of several mechanisms that might have caused failure of the lower head. These mechanisms include tube ejection, tube rupture, and localized or global vessel failure. Several models, using closed-form analytical or simplified numerical solution techniques, were used to determine the thermal and mechanical response of the lower head to the molten core material that relocated from the core to the lower plenum. Although it is recognized that the uncertainty in many input parameters for these calculations is large, an attempt was made to estimate the margin to failure for each failure mechanism, and results were compared to determine which mechanism had the smallest margin to failure.

Rather than obtaining a definitive answer related to the margin to failure that existed in the vessel during the TMI-2 accident, results from these calculations illustrate uncertainties in the ability of current models to predict debris behavior and vessel response during a severe accident. As will be discussed within this report, thermal response calculation results indicate that debris cooling occurred that was not evident from companion sample examinations and that is not currently considered in severe accident analysis models. Furthermore, the large uncertainty in methods for predicting vessel failure precluded an accurate assessment of the margin to failure during the TMI-2 event. Little, if any, validation has been performed on methods used to predict melt/water interaction, molten pool behavior, cooling in debris that solidifies after relocation, and structural creep failure in a severe accident. Therefore, analysis results should only be viewed as providing insight into areas, such as assessing what failure mechanisms were plausible during the TMI-2 event, quantifying the failure mode with the smallest margin during the TMI-2 event, and emphasizing areas where additional research is needed in severe accident analysis.

\subsection{Methodology}

Failure of the TMI-2 pressure vessel lower head due to relocation of approximately 19 tonnes of debris to the lower head could have resulted from one of several mechanisms. These failure mechanisms include tube ejection, tube rupture, localized vessel failure, and global vessel failure. Scoping calculations for each mechanism were performed to determine for which mechanism there existed the smallest margin to failure. Figure 1-1 presents a flow diagram of the scoping calculations performed to accomplish this task. Scoping calculations for failure mechanisms are shown in bold ellipses in Figure 1-1. 


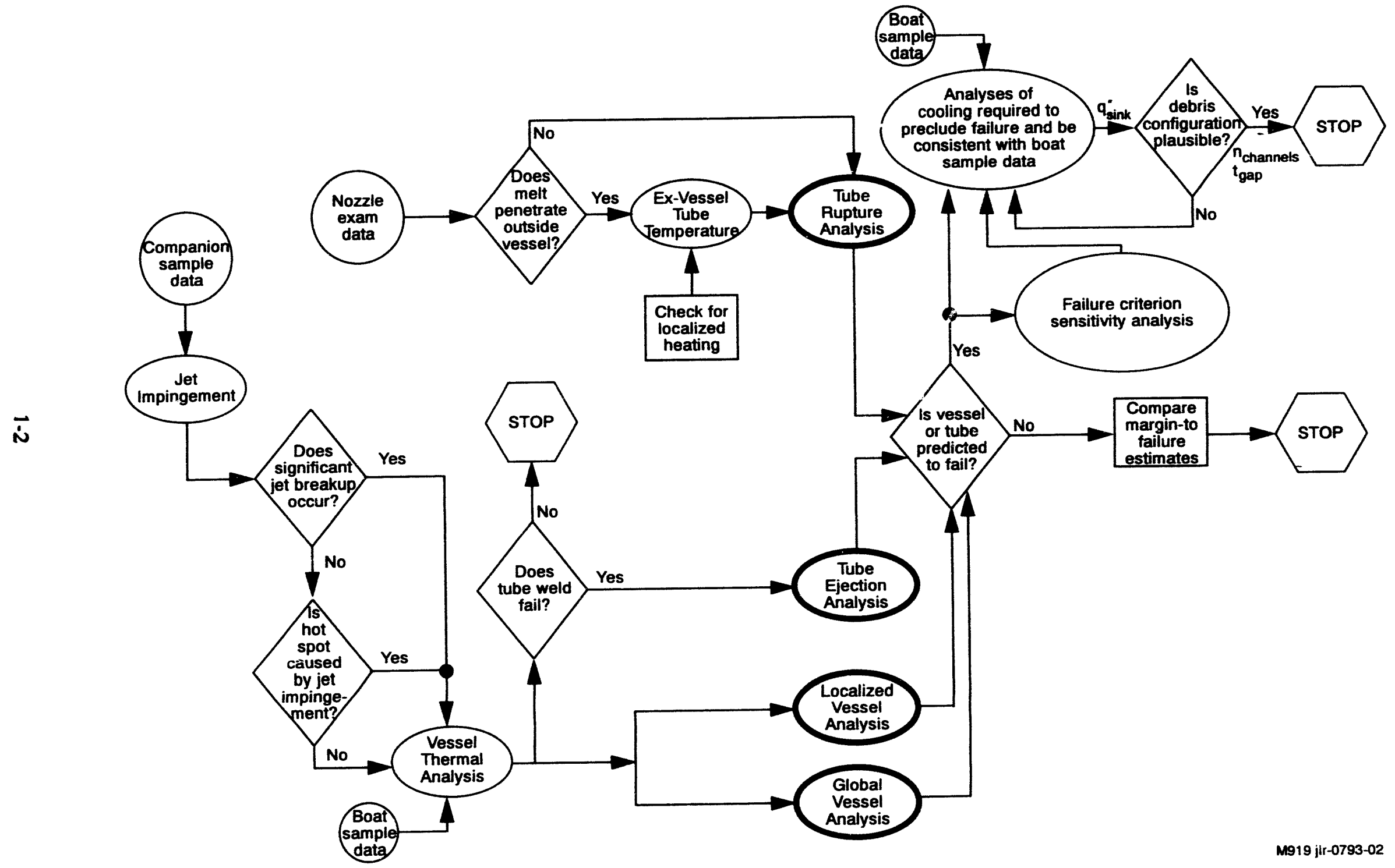

Figure 1-1. Flow diagram of scoping calculations. 
The margin to failure for each of the mechanisms was quantified on the basis of both ultimate strength and creep effects. Failure of a nozzle or the vessel by exceeding the ultimate strength of the material reflects the instantaneous response of the material to temperature/load combinations over a given time period. Failure by creep reflects the cumulative damage of the temperature/load over the entire time period. Creep failure occurs at or before an ultimatestrength failure; thus, creep produces the lowest margin to failure.

As shown in Figure 1-1, several preliminary calculations provide input to the failure analyses. These calculations modeled melt penetration, jet impingement, and the thermal response of the vessel and vessel components. Melt penetration calculations were completed to determine if melt that penetrated into the instrument tubes traveled beyond the vessel lower head. Results provided a basis for determining the effective tube temperature to be used for a tube rupture analysis. Jet impingement calculations were used to determine if the thermal load from a coherent jet would cause the hot spot temperatures observed in Vessel Investigation Project (VIP) metallurgical examinations. This information was used in global vessel thermal response calculations. The vessel temperature distribution information was used in the weld failure analysis and the localized and global vessel failure analyses. Because the weld between the instrument tube nozzle and the vessel must fail prior to tube ejection occurring, results from a weld failure analysis determine the need for a tube ejection analysis.

As indicated in Figure 1-1, these calculations rely upon three major sources of VIP examination data: nozzle examination data for characterizing melt composition and penetration distances within instrument tubes; companion sample examination data for characterizing debris properties, such as decay heat and material composition; and reactor vessel steel, "boat sample," examination data for characterizing peak vessel temperatures, duration of peak temperatures, and vessel cooling rate. As will be illustrated by results within this report, calculation results indicate that some of the companion sample data were inconsistent with boat sample examination cooling rates (namely that the debris underwent a slow cooling). When results based upon companion sample data indicated that vessel failure would occur, irrespective of which failure criterion was selected, it was postulated that cooling, not indicated by companion sample data, needed to be modeled. Hence, calculations were performed to quantify the magnitude of this cooling and the debris configuration required to support this cooling. Calculations were also performed to verify the existence of this cooling based upon plant thermal-hydraulic parameters.

Many of the models used in the scoping calculations are extensions of models developed and/or applied under the U.S. Nuclear Regulatory Commission (NRC)-sponsored Lower Head Failure Analysis Program. ${ }^{1}$ These models were modified according to the geometry of the TMI-2 vessel and operating conditions during the accident.

\subsection{Report Content}

Many of the parameters used in these calculations depend upon the manner, quantity, and timing of debris relocation to the lower head. Plant data available to quantify details related to accident progression are summarized in Section 2. In addition, Section 2 presents several possible scenarios for the manner in which molten debris relocated to the lower head. Sections 3 and 4 describe initial scoping calculations that were performed based upon VIP examination data. Section 3 describes results from thermal analyses that provide input to the failure analyses. 
Failure analyses and margin-to-failure estimates for each failure mechanism are documented in Section 4. Results from these initial scoping calculations illustrate uncertainties in the ability of current models to predict debris behavior and vessel response during a severe accident. Two areas of uncertainty, the amount of cooling that occurred within the debris after relocation and the criterion used for predicting vessel failure, were investigated in more detail. Section 5 summarizes results from these additional scoping calculations. Conclusions from these calculations are discussed in Section 6.

\subsection{Reference}

1. J. L. Rempe et. al., Light Water Reactor Lower Head Failure Analysis, NUREG/CR-5642, EGG-2618, October 1993. 


\section{TML2 ACCIDENT DATA AND RELOCATION SCENARIO DESCRIPTION}

Prior to performing the margin-to-failure analyses, it was necessary to have a clear understanding of the information avalable for reconstructing the TMI-2 event. To assist in this understanding, plant instrumentation data, previous examination data and TMI-2 Vessel Investigation Program (VIP) data were reviewed, with associated analyses of these data. Results from this review and a description of possible relocation scenarios based upon current underatanding of these data are provided in this section.

\subsection{Measured Plant Data and Examination Data}

Data from online instrumentation and the subsequent analysis of these data assisted in identifying the possible sequence of events that took place within the reactor vessel during the accident. Instrumentation information was used to set input parameters in the thermal analyses and scoping calculations. Most data discussed in this section were used in margin-to-failure calculations. In some cases, additional data have been included for completeness.

\subsubsection{Inotrumentation Deta}

Online instrumentation recorded reactor coolant system (RCS) pressure, coolant temperatures, source range monitor (SRM) count rate, and self-powered neutron detector (SPND) response during the TMI-2 accident. Figure 2-1 shows the RCS pressure, with significant events overlaid up to the time when a major relocation was postulated to occur. ${ }^{1}$ Figure $2-2$ shows the pressure from reactor scram to 17 hours. ${ }^{2}$ The pressurizer block valve was repeatedly cycled between 6 and 8 hours, in an attempt to establish RCS flow (see Figure 2-2). Figure 2-3 shows cold leg temperatures from 0 to 17 hours. Figure 2-4 shows the cold leg temperatures between 220 and 230 minutes.

\subsubsection{SAM Data and Analyois}

Source range monitors provided the only time-dependent data to estimate core liquid levels and changes in core geometry. Figure 2-5 shows the source range count rate during the accident with reactions to significant events highlighted. The data were interpreted using neutronic analysis and assumptions of the core configuration and coolant distribution in the core and downcomer. ${ }^{2}$ Initial core uncovery occurred between 114 to 120 minutes. At 140 minutes, the coolant level was estimated to be at midcore. By 165 minutes, coolant covered approximately 1.0 $\mathrm{m}$ of the core. The core was completely covered with water after emergency cooling was injected at 200 minutes. The relocation of 10 to 19 tonnes of molten fuel is substantiated by the sharp increase in the count rate between 224 and 226 minutes. Based on analysis of the count rate, molten fuel continued to drain onto the upper control support assembly after the major relocation at 224 minutes, although in much smaller amounts. 


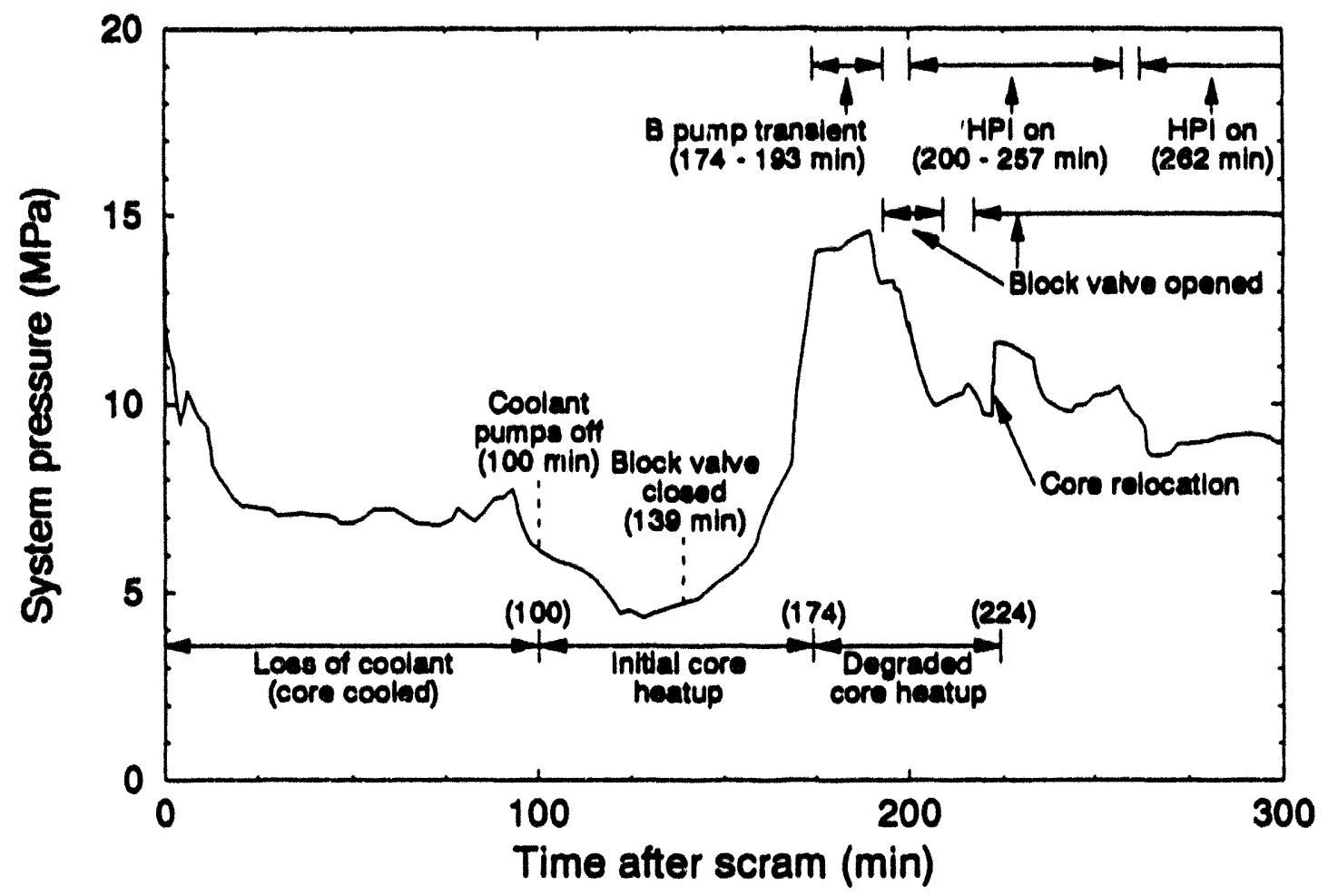

Figure 2-1. RCS pressure with timing of significant events noted.

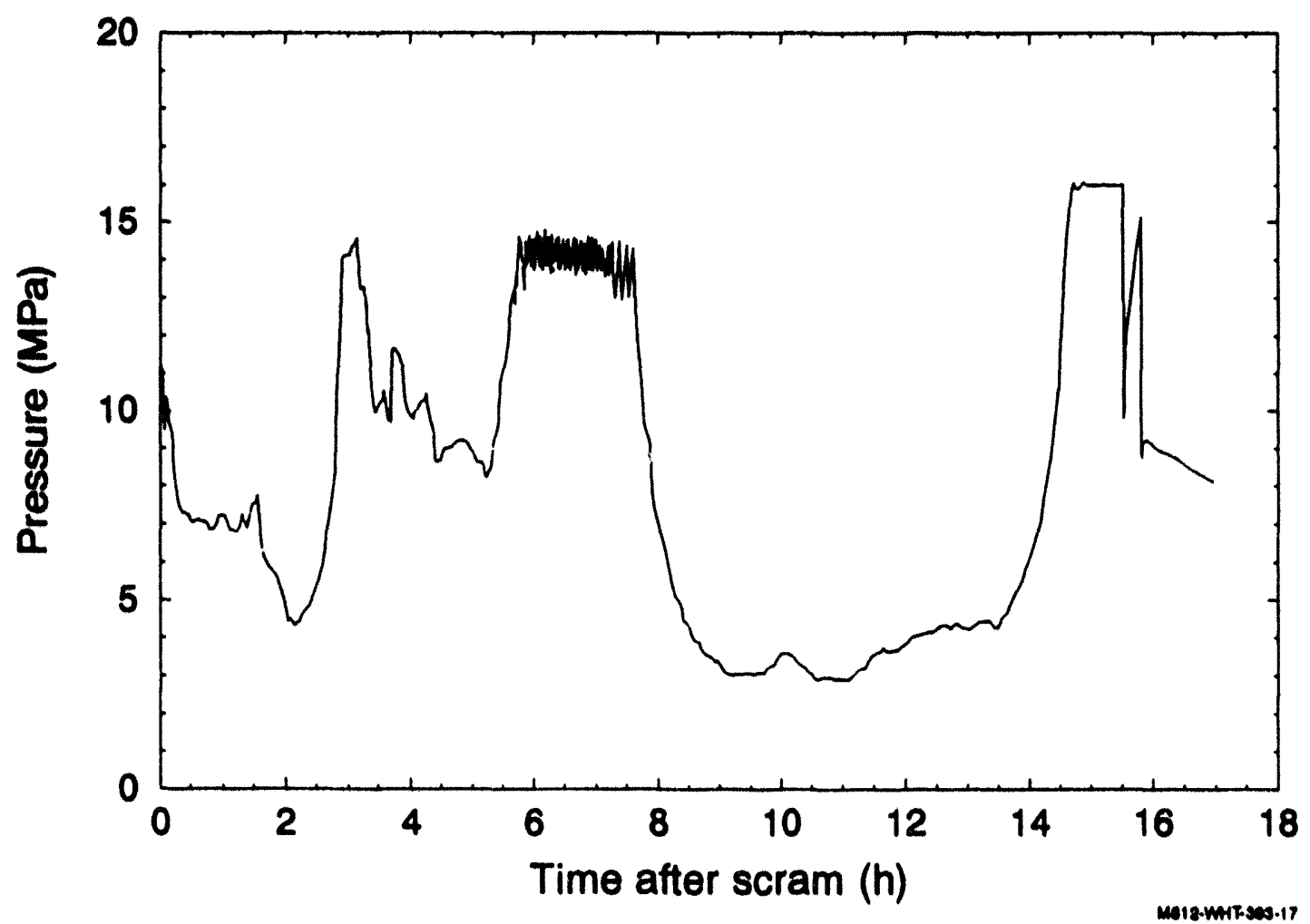

Figure 2-2. RCS pressure from reactor scram to 17 hours. 


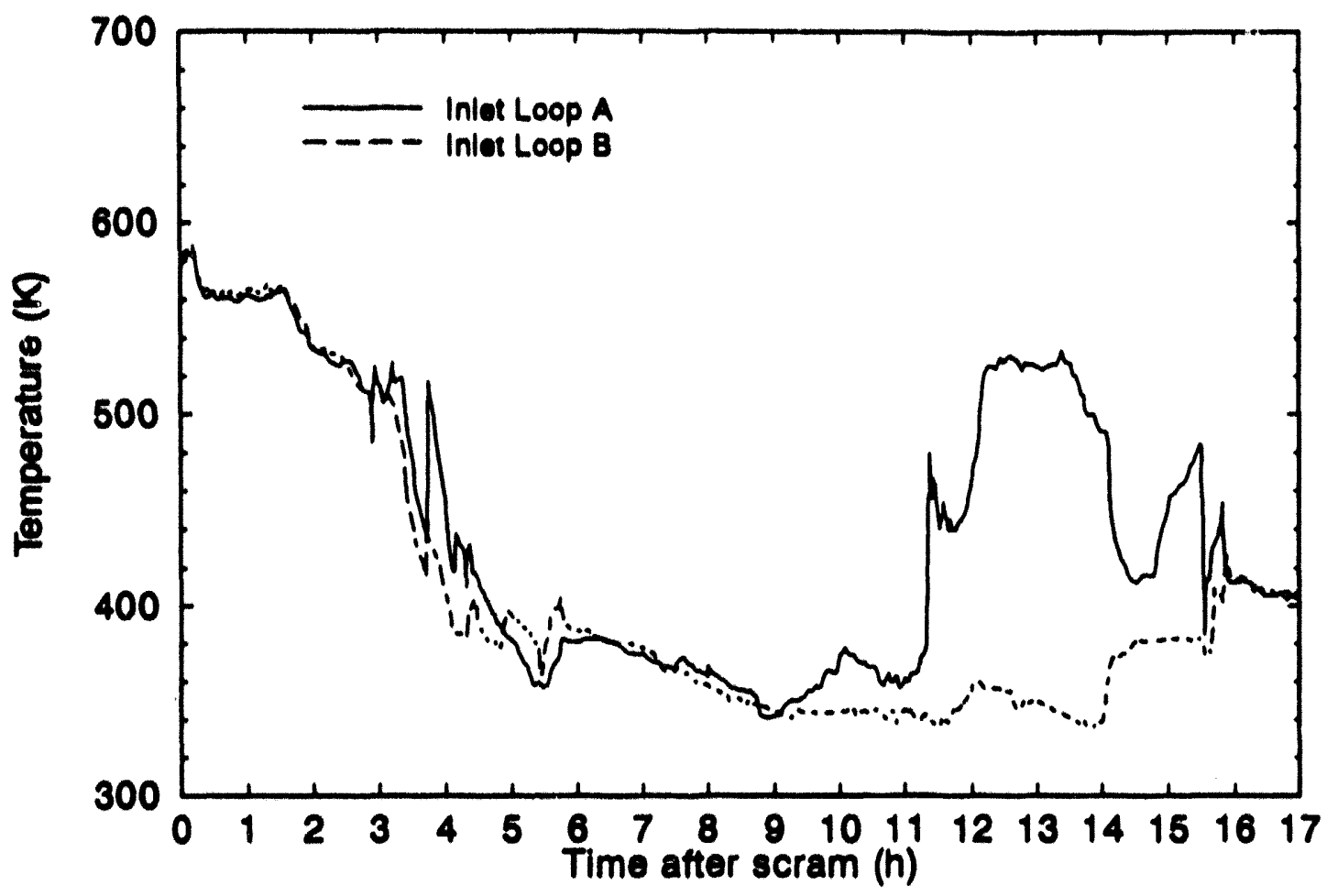

Figure 2-3. Cold leg temperatures from 0 to 17 hours.

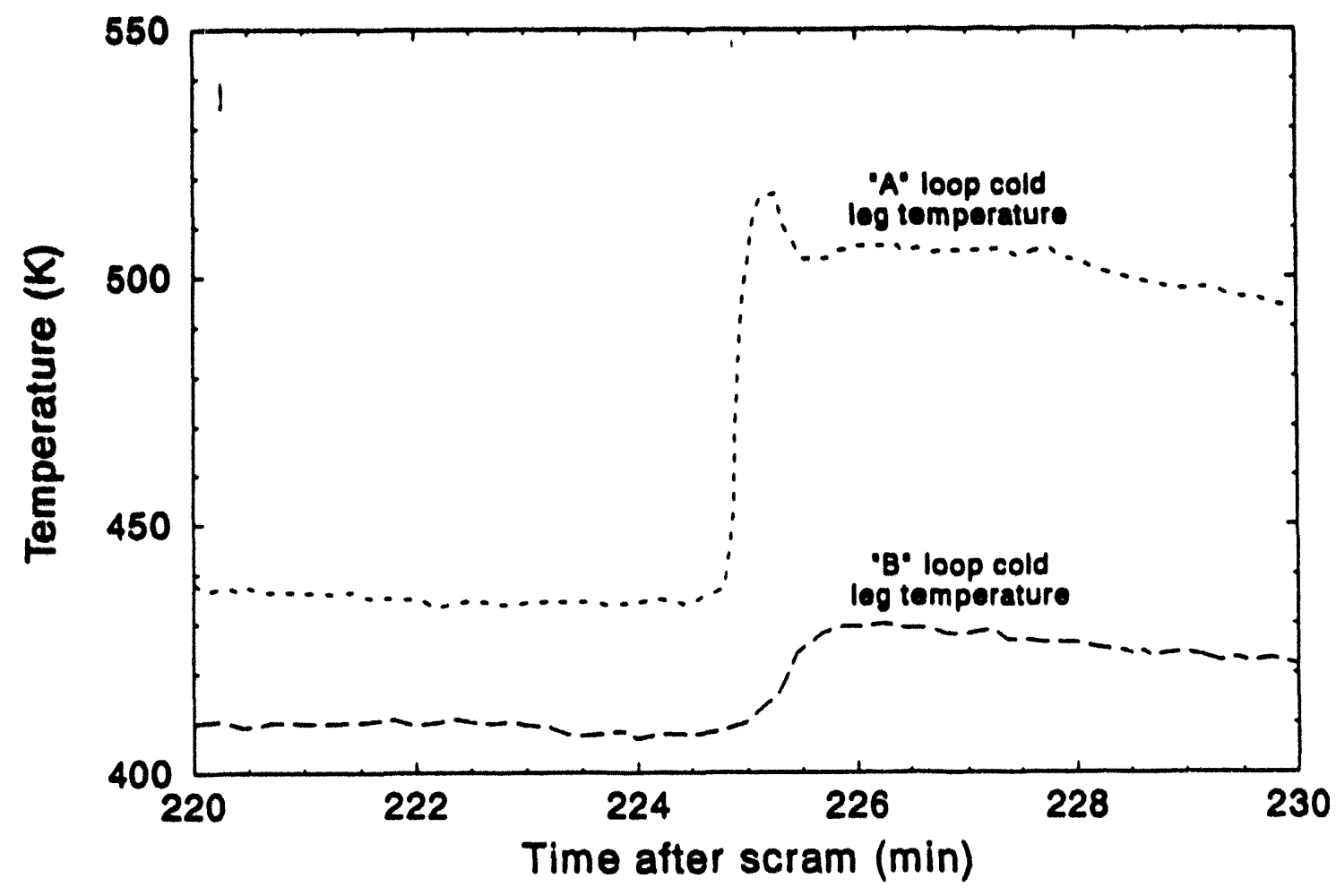

Figure 2-4. Cold leg temperatures between 220-230 minutes. 


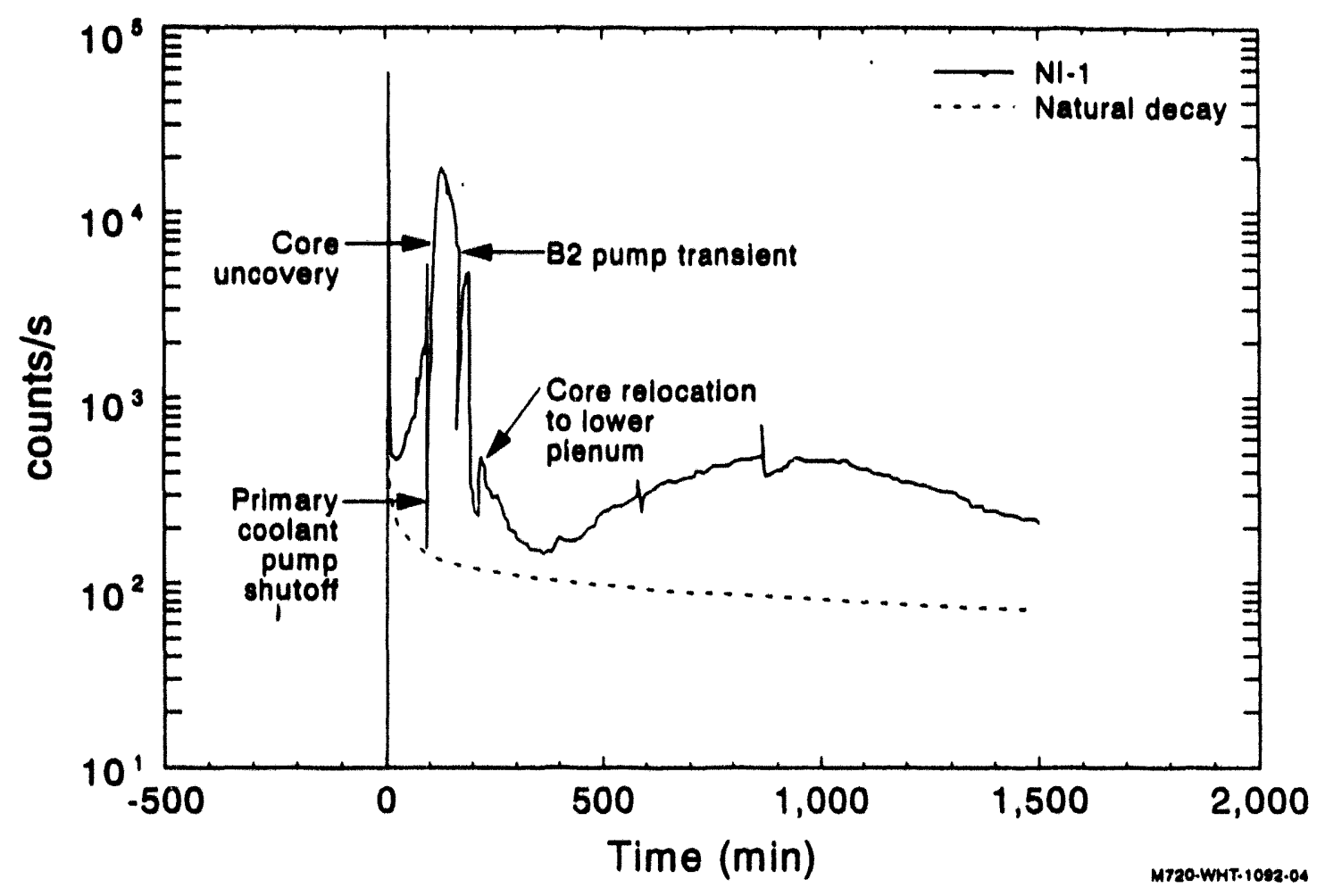

Figure 2-5. SRM count rate.

\subsubsection{SPND Data}

SPND data provided information relative to core heatup. The sources of SPND data included the alarm system data, which indicated a departure from the normal operating range for any of the 364 SPNDs, and a strip chart recorder monitoring output from 18 SPNDs. Figure 2-6 shows the elevations of SPND levels within the core. Correlation of SPND response with local temperatures by experimental analysis has produced two major conclusions. ${ }^{3}$ First, local temperatures can be deduced only when a signal changes polarity. Second, two threshold temperatures, $850 \mathrm{~K}$ and $1,350 \mathrm{~K}$, can be identified. In experimental analysis, SPNDs generated negative signals when they reached $850 \mathrm{~K}$ and positive signals at $1,350 \mathrm{~K}$. At temperatures around $1,350 \mathrm{~K}$, rapid oxidation of fuel rod cladding would increase the fuel rod temperatures enough to melt the cladding and eventually the $\mathrm{UO}_{2}$ pellets.

SPND data indicated that temperatures of $850 \mathrm{~K}$ were reached within the core at 135 minutes. At 150 minutes, level 6 SPNDs in the upper region of the core indicated temperatures of $1,350 \mathrm{~K}$. At 167 minutes, approximately $33 \%$ of the SPNDs at the lower elevations, as low as level 2, alarmed. Along the periphery of the core, SPND measurements indicated temperatures reached $1,350 \mathrm{~K}$ by 180 minutes. At 224 minutes, SPNDs at almost all levels at core locations E7, F7, F8, G6, G9, H5, and M9 indicated temperatures of $1,350 \mathrm{~K}$. Simultaneous SPND alarms at all levels in each of the core locations suggest a common damage point to the instrumentation, which may have occurred in the lower plenum. Molten debris 


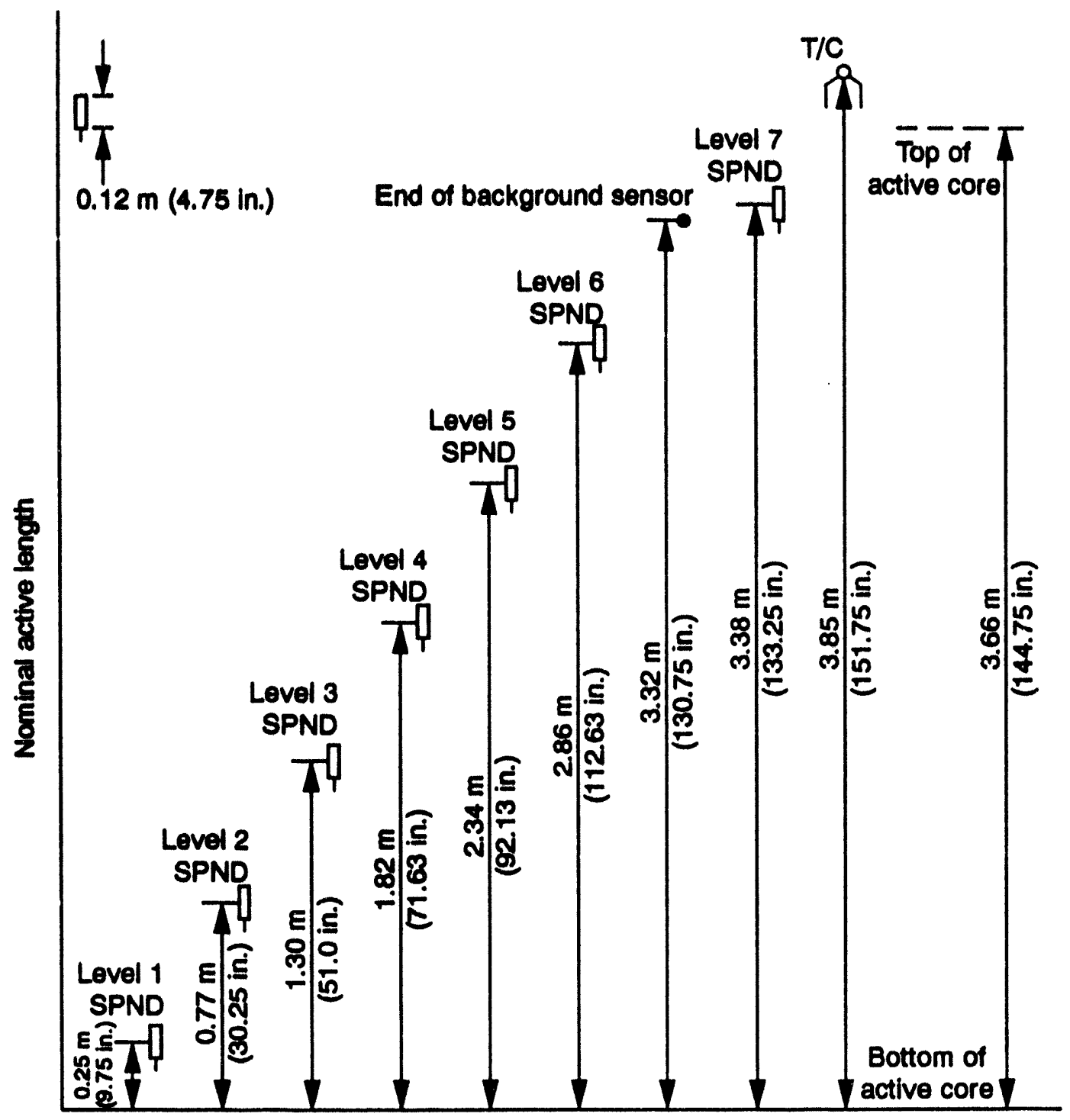

Reference plane

M757-WHT-1192-17

Figure 2-6. Elevations of SPND levels within the core.

flowing across the lower plenum may have heated the SPND leadwires inside the instrument tubes to temperatures high enough to generate thermoelectric currents which would set off the SPND alarms. ${ }^{3}$ The timing sequence of level 1 SPND alarms in the vessel between 224 and 226 minutes is mapped in Figure 2-7. The first level 1 alarms occurred at locations P6 and R7 in the southeast quadrant of the vessel. Subsequent alarms moved toward the core center. Level 1 SPND alarms at core locations E9 and H9 alarmed positive between 228 and 232 minutes, along with alarms at higher levels at various core positions. These alarms indicated temperatures of $1,350 \mathrm{~K}$ existed either within the core, or in the lower plenum if the leadwires were damaged. 


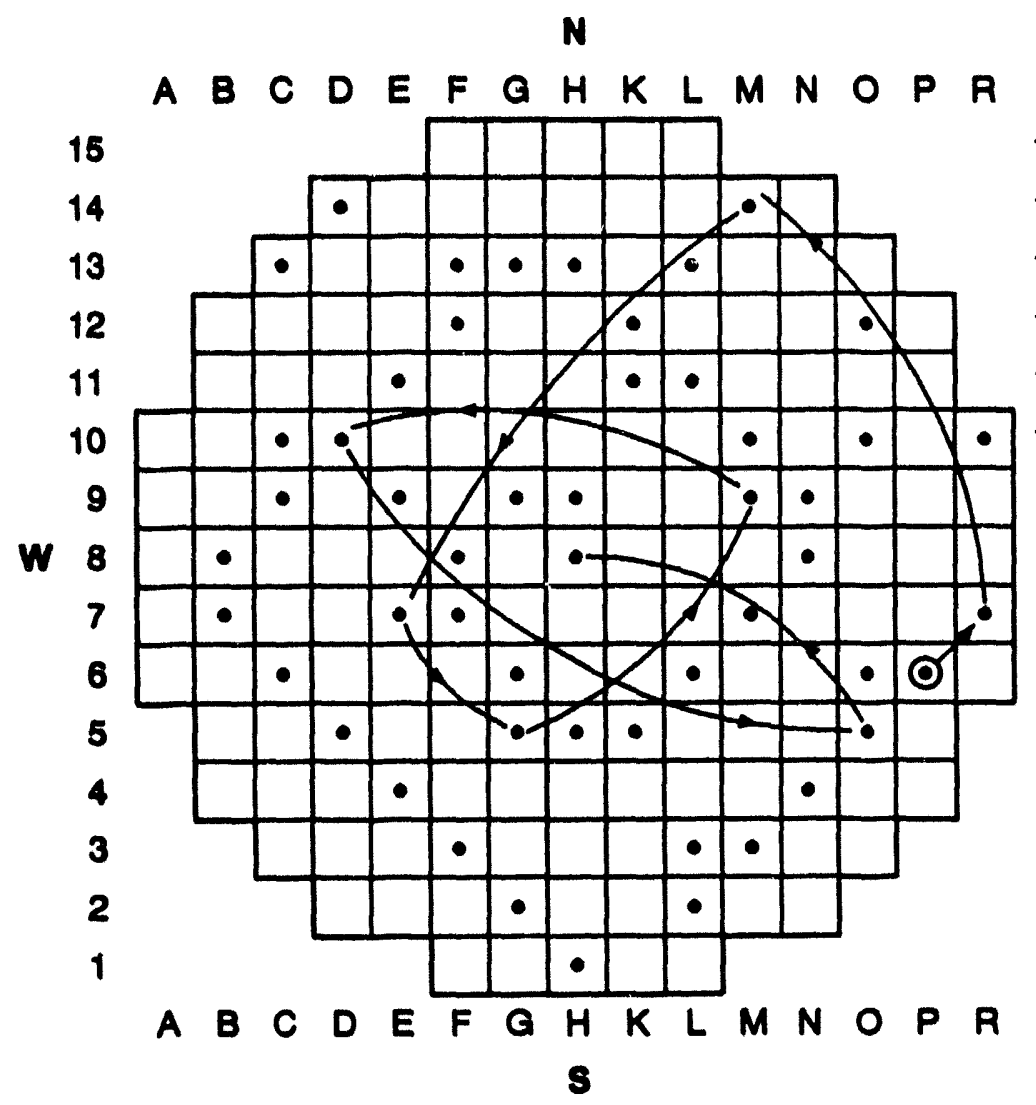

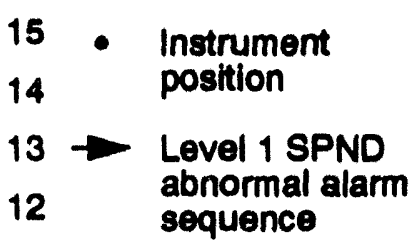

F First alarm

Figure 2-7. SPND level 1 alarm timing.

\subsubsection{Core Configuration}

The end-state core configuration has been estimated based on the results of core boring operations along with visual inspection of the vessel. ${ }^{1}$ Figure 2-8 shows the postulated end-state configuration of the reactor vessel and the core. The end-state configuration was represented by four distinct regions. A void cavity, representing approximately $26 \%$ of the original core volume, existed in the upper core region and extended to the core periphery. A loose core debris bed below the void cavity rested on top of a solid crust located at midcore. The upper debris bed was composed of fuel pieces, cladding fragments, and previously molten ceramic and metallic material. The crust encased a region of previously molten core material, part of which surrounded partially intact fuel rods, in the lower half of the core. The fourth region consisted of fuel rod stubs in the bottom of the core, which extended upwards to the previously molten region.

\subsubsection{Lower Head Debris}

Video inspection and wire probing of the lower head allowed contour maps to be constructed of the debris resting on the lower head. ${ }^{4}$ The material on the lower head consisted of a hard layer covered by a bed of loose debris. The distribution of the material on the lower head 


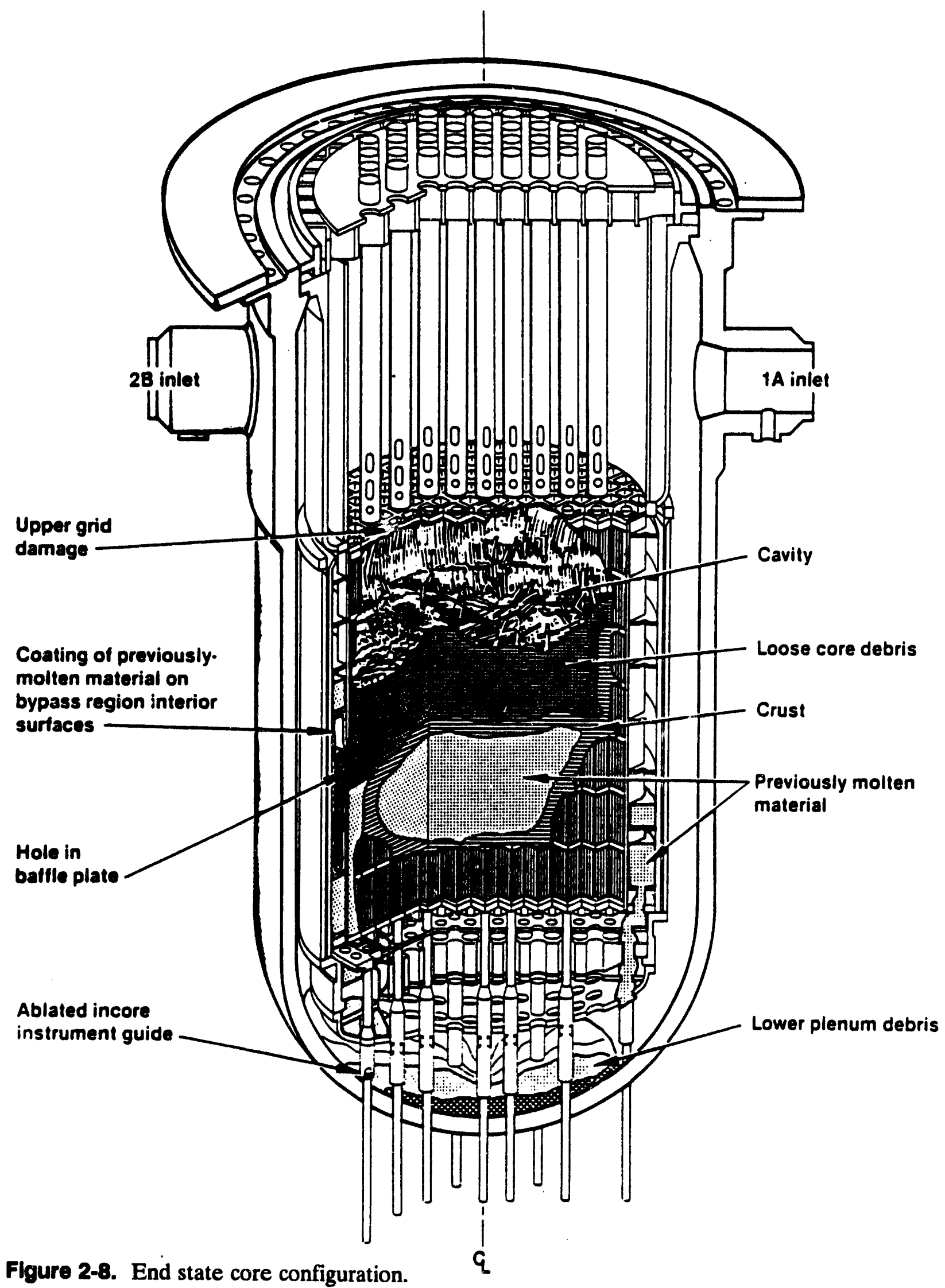


was neither uniform nor symmetric. The particles composing the loose debris bed varied in size from granules to large rocks. The larger pieces were concentrated toward the periphery, especially in the northeast and southwest quadrants. The granular particles were located towards the center of the core. Results from wire probing examinations were used to obtain the topographical map of the hard layer of debris shown in Figure 2-9. Note that the contour lines shown in Figure 2-9 represent the depth of the hard debris, i.e., the difference between the "hard stop" for the probe tests and the bowl-shaped lower head, rather than the surface contour of the hard layer. As shown in Figure 2-9, the height of the hard layer varied between 0.0 to $0.45 \mathrm{~m}$, and was highest at core locations $\mathrm{H} 8, \mathrm{H} 9, \mathrm{~K} 8$, and $\mathrm{K9} .^{4}$

Results from probing 17 of the 52 incore instrumentation tubes indicated that all but one of the tubes were plugged to the extent that a wire would not penetrate into the vessel from the incore seal table. This indicates either the collapse of the probe channel in the instrument string from the pressure gradient, or the presence of melt in the probe channel. Molten debris in the probe channel of the instrument string, see Figure A-43, would not pose a serious safety threat, since it would have to melt through both the instrument string and the instrument tube wall. Penetration into the vessel was achieved at core location L11, and the vessel was gamma-scanned. Results showed increased levels of activity as the probe was retracted from the vessel, suggesting that a layer of fuel-depleted material existed next to the vessel surface. Probes at core locations $\mathrm{M} 7$ and $\mathrm{G} 2$ came within $0.3 \mathrm{~m}$ of penetrating the vessel wall.

Reformed thermocouple junctions embedded in the debris on the lower head indicate that temperatures exceeding $1,000 \mathrm{~K}$ existed within the debris bed for three days following the accident. 5 Thermocouple lead wires located in the instrument string of the instrumentation nozzles were melted by the high temperatures of the molten debris, and later reformed new junctions.

\subsubsection{TMI-2 Lower Head Video Inspection}

Videotaping of the lower head during defueling efforts presented an opportunity to view the damage to the lower head internals, and assisted in postulating relocation scenarios and theories of debris cooling. Ablated nozzles, guide tubes, and the flow distributor plate were videoed. Hard as well as loose debris, ranging from fine silt to large chunks, could be seen. Several surface cracks and crevices were shown, as well as gaps between the nozzles and the debris surrounding the nozzles. With the debris cleared from the lower head, the cladding tear near the nozzle could be seen, as well as the indentations made by the crust impact tool that fractured the layer of hard debris in order to remove it from the vessel.

\subsection{TMI-2 VIP Data}

\subsubsection{Lower Head Temperatures}

Hardness and metallurgical examinations were performed on 15 triangular-shaped steel samples, referred to as boat samples, removed from the lower head of the TMI-2 pressure vessel. ${ }^{6}$ These examinations identified a hot spot on the lower head of the pressure vessel. Hardness measurements indicate that the material exceeded the ferrite-to-austenite transformation temperature but didn't provide conclusive peak temperature estimates. Eleven of the TMI-2 
N

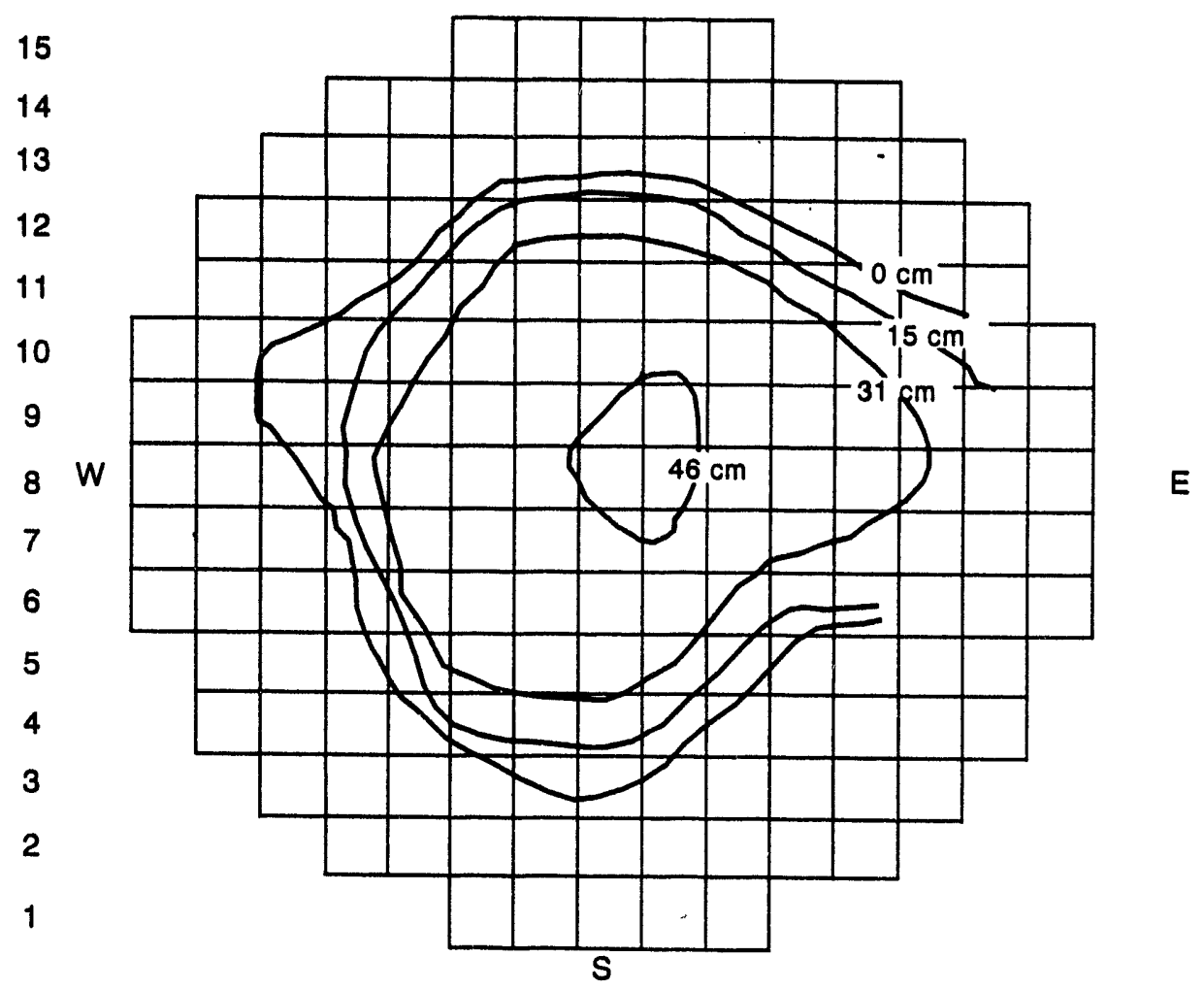

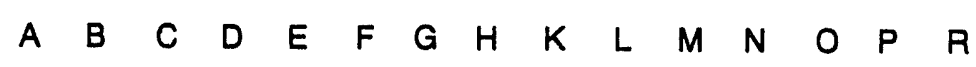

M919 j1r.0793-13

Figure 2-9. Depth of hard layer of solidified debris. (Contour lines designate distance between a "hard stop" from probe tests and the bowl-shaped lower head.)

samples did not exceed $1,000 \mathrm{~K}$ during the accident. These samples were removed from core locations D10, E11, F5, H4, H5, H8, K7, K13, L9, M9, and M11. Hardness measurements indicate samples from locations E6, E8, F10, and G8 were exposed to higher temperatures. Bounds on the thermal loading of the four samples were determined through metallurgical comparison with heat-treated archived samples from a similar reactor vessel. Samples from core locations F10 and G8 experienced temperatures in the range of 1,313 to 1,333 $\mathrm{K}$ for 30 minutes. Samples at locations E6 and E8 experienced temperatures ranging from 1,348 to 1,373 $\mathrm{K}$ for 30 minutes. The temperatures $50 \mathrm{~mm}$ inside the vessel surface were estimated to be $100 \pm 50 \mathrm{~K}$ lower than estimated peak temperatures. Examinations indicate that the vessel material cooled through the transition temperature at rates of $10-100 \mathrm{~K} / \mathrm{min}$ at times between 15 and 50 minutes after peak hot spot temperatures occurred. Stainless steel cladding showed no signs of melt, even inside the hot spot. Figure 2-10 illustrates the relative position and temperature distribution of the hot spot on the lower head. 


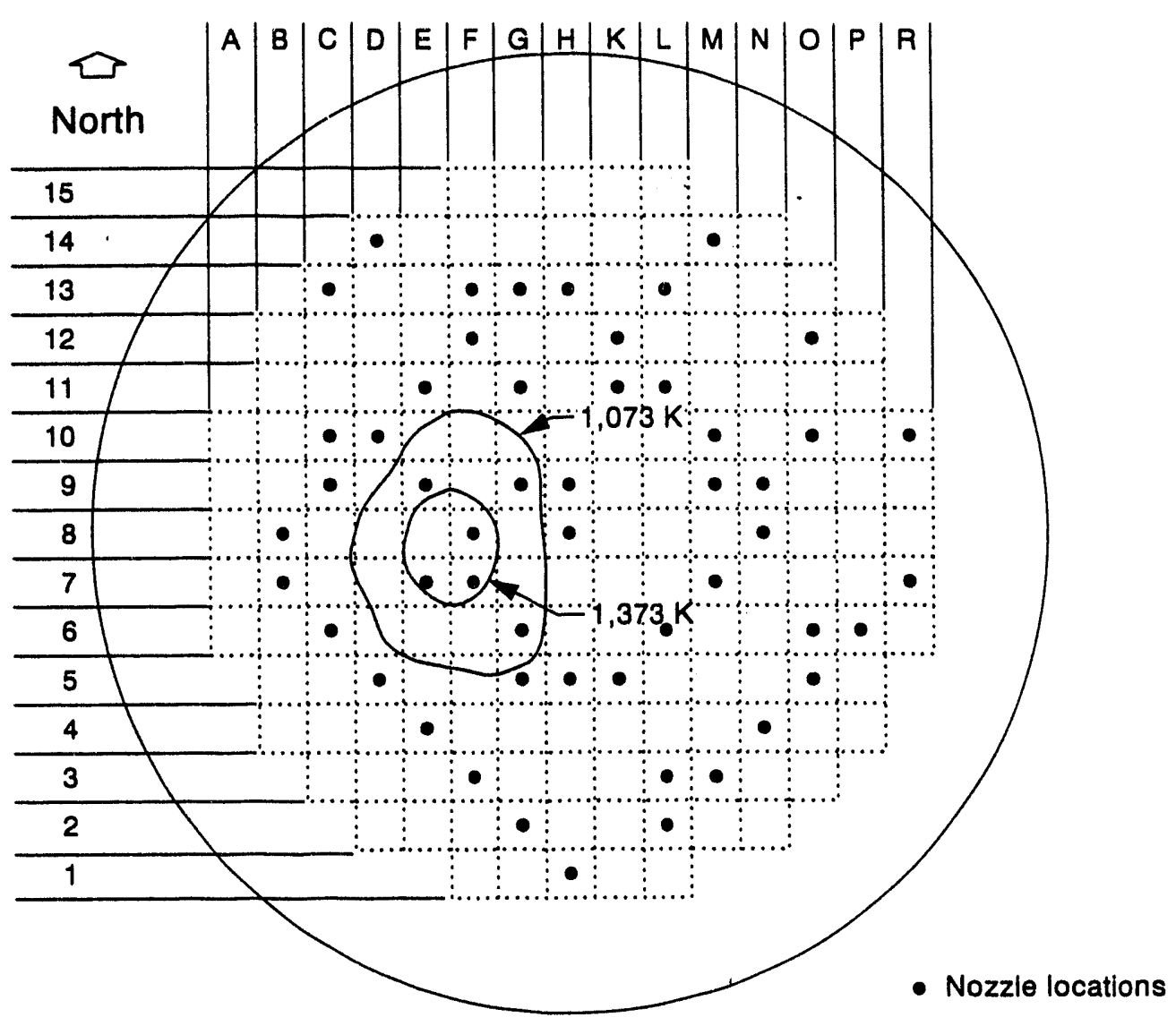

Me12 lag-0393.03

Figure 2-10. Hot spot location on lower head.

\subsubsection{Lower Head Debris Properties}

The debris on the lower head consisted of a hard layer, from which companion samples were cut, covered by a bed of loose debris. Samples of the solidified melt from the hard layer in contact with the lower head, termed companion samples, were extracted from the vessel in order to assess the properties of the melt. ${ }^{7}$ Densities of nine companion samples ranged from 7.45 to $9.40 \mathrm{~g} / \mathrm{cm}^{3}$. Samples with the highest density were extracted from the southeast quadrant of the pressure vessel. Previous examinations ${ }^{8}$ indicated that the loose debris varied in density from 6.57 to $8.25 \mathrm{~g} / \mathrm{cm}^{3}$. Differences in density were attributed to variations in the porosity of the melt. Porosities of 16 companion samples ranged from 5 to $41 \%$, averaging $18 \pm 11 \%$.

The loose debris and companion samples from the hard layer differed slightly in composition. Loose debris had an average uranium content of $65 \mathrm{wt} \%$, while companion samples contained about $70 \mathrm{wt} \%$ uranium. Both had similar amounts of zirconium. The loose debris had slightly higher concentrations of structural materials than the companion samples. The relative composition of the companion samples was determined to be $78 \mathrm{wt} \% \mathrm{UO}_{2}$ and $17 \mathrm{wt} \% \mathrm{ZrO}_{2}$. The remaining 3\% represents stainless steel and Inconel constituents that were probably melted during relocation. Metallic melt was found only in samples from the southwest quadrant of the 
vessel. Peak temperatures of material within the companion samples, which would have occurred prior to when the molten debris flowed from the core to the lower head, were estimated to have ranged from 2,873 to $3,123 \mathrm{~K}$.

Evidence supports the assumption that metallic material may have existed on the lower head prior to the relocation of the molten $(\mathrm{U}, \mathrm{Zr}) \mathrm{O}_{2}$. Control assembly material has been found on the surface of nozzle $\mathbf{H 8}$ for heights up to 12.0 to $17.0 \mathrm{~cm}$, measured from the base of the nozzle.

\subsubsection{Melt Decay Heat}

Decay heat calculations were performed to determine the amount of available heat within the bed of molten fuel in the lower head at 224 minutes and at 600 minutes after reactor scram. ${ }^{7}$ The decay heat at 224 minutes after scram was found to be $0.18 \mathrm{~W} / \mathrm{g}$ of uranium and $0.14 \mathrm{~W} / \mathrm{g}$ of uranium at $\mathbf{6 0 0}$ minutes. Converting the data using the calculated average melt composition of the hard layer ( $70 \mathrm{wt} \% \mathrm{U}, 13.75 \mathrm{wt} \% \mathrm{Zr}$, and $13 \mathrm{wt} \% \mathrm{O}$ ), the decay heat at 224 minutes was $0.13 \mathrm{~W} / \mathrm{g}$ of melt and at 600 minutes was $0.096 \mathrm{~W} / \mathrm{g}$ of melt. The accuracy of the reported decay heat values is estimated at $\pm 20 \%$. Companion sample examinations ${ }^{7}$ also indicated the presence of secondary phases of $(\mathrm{Zr}, \mathrm{U}) \mathrm{O}_{2}$ with $\mathrm{Fe}$ and $\mathrm{Cr}$ around pores and in the matrix material. The formation of these phases requires a long cooldown period (between 3 and 72 hours), rather than a rapid quench. ${ }^{7}$

\subsubsection{Nozzle Ablation}

Fourteen nozzles were cut from the lower head of the pressure vessel for examination. ${ }^{10}$ These nozzles were 'at core locations D10, E7, E11, G5, H5, H8, H9, K11, K12, L6, L11, M9, M10, and R7. The initial length of all nozzles was $30.5 \mathrm{~cm}$. Those nozzles removed from the vessel that were not ablated during the accident included E11, H9, K11, K12, L6, L11, and R7. Several of the nozzles, which were within the hot spot, were severely ablated. These nozzles include E9, F7, F8, G6, and G9. The stubs remaining in the vessel at these locations were estimated to be 1.3 to $2.5 \mathrm{~cm}$ tall. . $^{\text {The }}$ The ablated heights of the other nozzles removed from the vessel were: $H 5-14.6 \mathrm{~cm}, \mathrm{D} 10-29.2 \mathrm{~cm}, \mathrm{H8}-12.1 \mathrm{~cm}, \mathrm{M} 10-10.2$ to $12.7 \mathrm{~cm}, \mathrm{M} 9-27.9 \mathrm{~cm}$, E7-5.1 cm, and G5-10.2 cm. The height of nozzles that were not cut were not measured. Figure 2-11 shows the relative heights of the nozzles and their positioning within the lower head.

\subsubsection{Composition of Melt Attached to Nozzles}

Solidified debris in contact with the inside and outside of nozzles D10, E11, H5, H8, L6, and M9 was examined using scanning electron microscopy (SEM) techniques. ${ }^{9}$ The results are shown in Table 2-1. The elevations are referenced from the base of each nozzle. Table 2-2 presents results of SEM examinations on debris shards attached to the outside of nozzles E7, G5, M10, and R7. ${ }^{b}$ The exact elevations of the measurements are unknown. However, most of the debris shards were removed from the top of each nozzle. No element's percentages were computed.

\footnotetext{
a. Personal communication with Noman Cole, MPR Associates, Inc., Washington, D.C., October 1992.

b. Unpublished research results of Brian $\mathrm{K}$. Schuetz, Idaho National Engineering Laboratory, EG\&G Idaho, Inc., Idaho Falls, Idaho.
} 

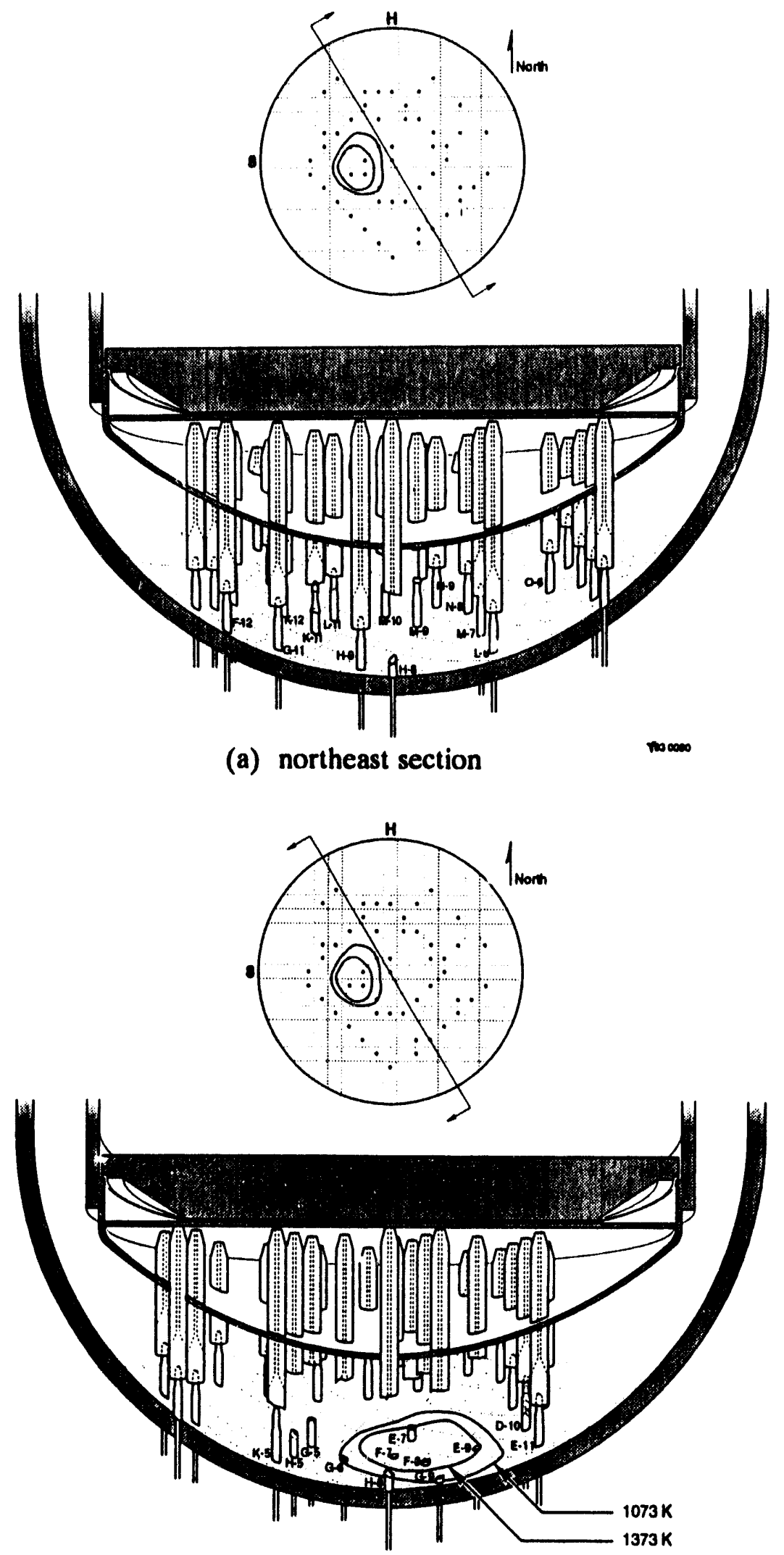

(b) southwest section

Figure 2-11. Three-dimensional figure of nozzle end state in the lower head. 
Table 2-1. Composition of debris in contact with nozzles."

\begin{tabular}{|c|c|c|c|c|c|c|c|c|}
\hline \multirow[b]{2}{*}{ Noznle/Location ${ }^{c}$} & \multirow[b]{2}{*}{$\mathbf{U}$} & \multirow[b]{2}{*}{$\mathrm{Zr}_{\mathbf{r}}$} & \multicolumn{3}{|c|}{ Composition, wt $\%^{b}$} & \multirow[b]{2}{*}{ Ag } & \multirow[b]{2}{*}{$\mathrm{Cd}$} & \multirow[b]{2}{*}{$\mathrm{Al}$} \\
\hline & & & $\mathrm{Fe}$ & $\mathrm{Ni}$ & $\mathrm{Cr}$ & & & \\
\hline \multicolumn{9}{|c|}{ M9@279 mm inside } \\
\hline matrix & 29 & 8 & 6 & 5 & 43 & - & - & 7 \\
\hline matrix & 55 & 12 & 5 & 2 & 15 & - & - & 9 \\
\hline particle & 58 & 19 & 8 & 11 & 3 & - & - & - \\
\hline fuel mass & 88 & 9 & 1 & 1 & 1 & - & - & - \\
\hline fuel mass & 83 & 15 & 1 & - & 1 & - & - & - \\
\hline fuel mass & 55 & 12 & 5 & 15 & 2 & - & - & 9 \\
\hline
\end{tabular}

L6@ 283 mm inside

shard

solidified mass

grain boundary

solidified mass

solidified mass
100

83-87

41

17

74
11-13

19

54

27

H5@ 140 mm inside

$\begin{array}{llllll}\text { ceramic area } & 25-30 & 13-15 & 1-3 & 1 & 51-57 \\ \text { ceramic area }^{d} & 82 & 12 & 1 & 3 & 1 \\ \text { ceramic area }^{d} & (35-40) & (12-16) & - & (40-55) & - \\ \text { ceramic area } & 13-30 & 8-12 & 7-22 & 2-10 & 40-77 \\ \text { ceramic area } & 28 & 15 & 33 & 11 & 13\end{array}$

H8@120 mm inside

particulate area

60

30

4

3

1

D10@280 mm inside

$\begin{array}{llllll}\text { particle } & 65 & 23 & 4 & 3 & 5 \\ \text { particle } & 63 & 12 & 5 & 15 & 6\end{array}$

D10@ 158 mm imbedded in nozzle

$\begin{array}{llllll}\text { particle } & 68 & 23 & 4 & 2 & 2 \\ \text { particle } & 77 & 20 & 1 & 1 & 1 \\ \text { particle } & 91 & 8 & - & 1 & -\end{array}$


Table 2-1. (continued).

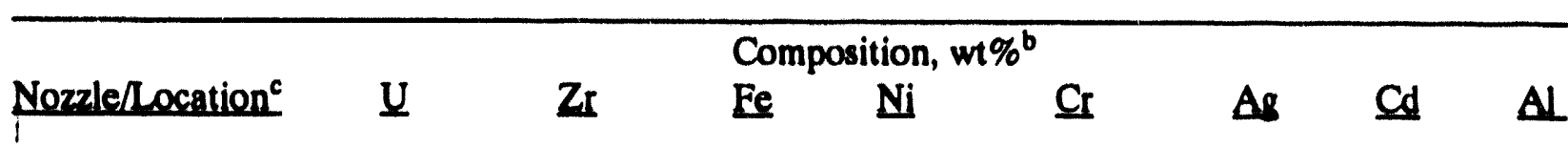

D10@82 mm outside

$\begin{array}{llllll}\text { particle } & 14 & 62 & 8 & 6 & 2 \\ \text { particle } & 81 & 16 & 2 & 1 & \\ \text { particle } & 75 & 16 & 6 & 2 & \\ \text { particle } & 10 & 77 & 6 & 5 & \\ \text { particle } & 22 & 78 & - & - & \end{array}$

D10@69 mm outside

$\begin{array}{llllll}\text { imbedded particle } & 82 & 12 & 1 & 3 & 1\end{array}$

E11 @ 280 mm inside

$\begin{array}{lllllllll}\text { large shard } & 83 & 14 & 1 & - & 1 & - & - & - \\ \text { small shard } & 83 & 14 & 2 & - & 1 & - & - & - \\ \text { matrix } & 34 & 53 & 8 & 3 & 3 & - & - & - \\ \text { matrix } & 47 & 44 & 6 & 2 & 1 & - & - & - \\ \text { matrix } & 66 & 27 & 4 & 2 & 1 & - & - & - \\ \text { matrix } & 87 & 10 & 1 & - & 1 & - & - & - \\ \text { surface fold outside } & 74 & 10 & 2 & 6 & 2 & - & - & 6\end{array}$

E11@ 274 mm inside

$\begin{array}{lllll}\text { inside nozzle } & \sim 9 & \sim 85 & 4 & 2 \\ \text { inside nozzle } & 27 & 71 & 1 & 1 \\ \text { agglomerates } & 62 & 16 & 19 & 3\end{array}$

E11@ @90 mm outside

$\begin{array}{llllll}\text { outer scale } & 20 & 20 & 57 & 2 & 1\end{array}$
a. Normalized to $\sim 100 \%$ metal: oxygen not considered.
b. Estimated accuracy is $\pm 5 \%$.
c. Location from the base of each nozzle.
d. Parentheses identify estimated values for portion of analyzed area. 
Table 2-2. Melt constituents on nozzle surfaces.

E7

Zr-U.Ag-Cd-Fe-Cr-Mn

$\mathrm{Zr}-\mathrm{Ni}-\mathrm{Al}-\mathrm{Cr}-\mathrm{Nb}-\mathrm{Co}-\mathrm{Ag}-\mathrm{In}-\mathrm{Fe}-\mathrm{Cr}-\mathrm{Mn}$

$\mathrm{Zr}-\mathrm{Fe}-\mathrm{Cr}-\mathrm{Mn}-\mathrm{Ni}$

Zr-Nb-Ni-Cr-Fe-Mn-Mg-Al-Ag-Cd

G5

Ni-Al-Si-Co

$\mathrm{Zr}-\mathrm{U}-\mathrm{Cr}-\mathrm{Ag}_{\mathbf{g}}$

M10

Fe-Cr-Mn-U-Zr-Nb-Al-Ag-Co-Mg

Ar-Ni-Fe-Cr-Ag-In

Zr-Fe-Cr-Mn-Ni-Al

R7

U-Cr-Ni-Al-Nb-In-Te-Sb-Mg-Sn-Zr-Ce-Sr

U-Zr-Fe-Cr-Mn-Ni-Al-In-Cd

\subsubsection{Melt Flow Through Nozzles}

The distance molten debris penetrated the nozzles which were removed from the vessel was determined from observation, gamma scanning, and wire probe testing., ${ }^{9, c}$ Several nozzles had been severely melted to within 1.3 to $2.5 \mathrm{~cm}$ of the vessel. ${ }^{\text {The }}$ These nozzes included E9, F7, F8, G6, and G9. It is not known if melt was present in the stubs of these nozzles. After cutting the nozzle at core location K11, what appeared to be resolidified fuel was discovered filling the annulus at the top of the stub remaining in the vessel.

The debris penetration elevations from gamma scans for nozzles D10, E11, H5, H8, L6, and M9 are presented in Table 2-3. The penetration elevation was measured froin the base of each nozzle. Gamma scans were also performed on nozzles E7, G5, H9, K11, K12, L11, M10, and R7. However, penetration elevations were not estimated for these nozzles because SEM examinations, which would verify the results of the gamma scans, could not be performed due to shutdown of the radiation containment facilities at the Idaho National Engineering Laboratory where the work was to be performed.

Wire probe tests were conducted on eight of the nozzle sections removed from the pressure vessel. ${ }^{c}$ The results are presented in Table 2-4. This method identified nozzles with completely blocked coolant passages. Results that indicate no blockage do not imply the absence of melt. Rather, these results indicate that a wire probe was able to penetrate the annulus the length of the nozzle, even though melt may have been present inside the nozzle, and partially blocked the coolant passage.

c. Personal communication with Brian K. Schuetz, Idaho Nationai Engineering Laboratory, EG\&G Idaho, Inc., Idaho Falls, Idaho, June 29, 1992.

d. Personal communication with Noman Cole, MPA Associates, Inc., Washington, D.C., October 1992. 
Table 2-3. Melt penetration elevation" (cm).

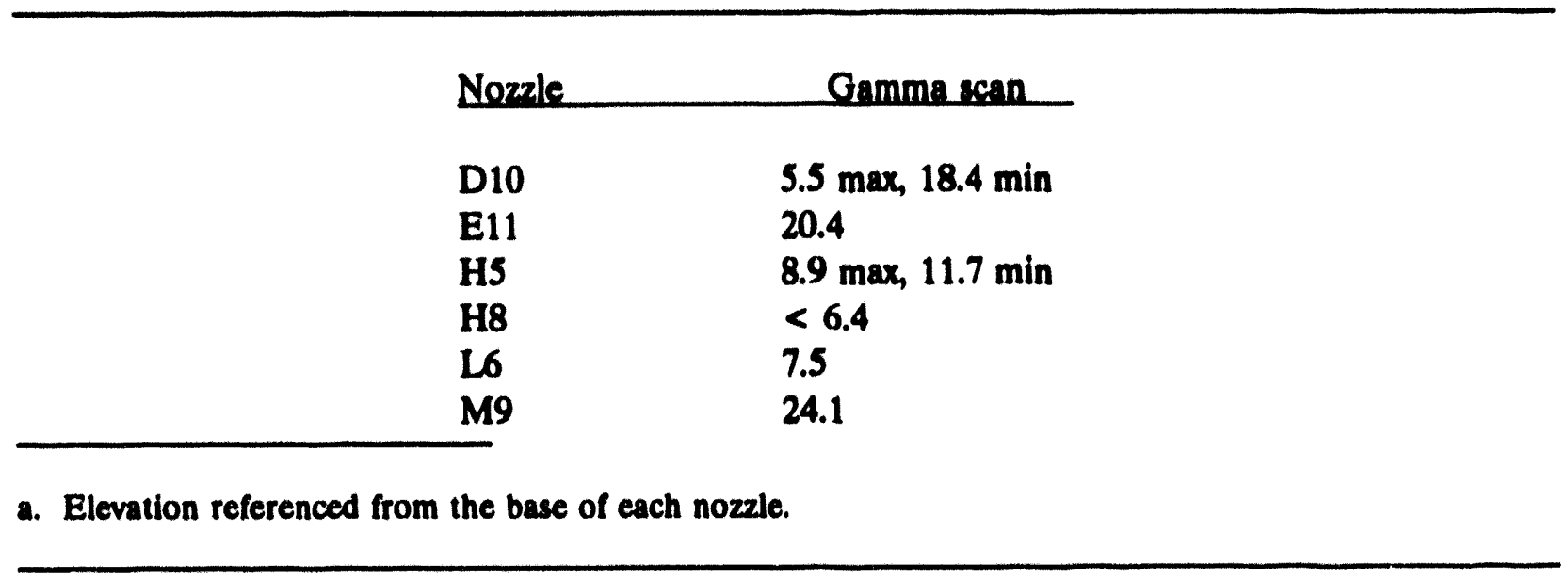

Table 2-4. Wire probe test results.

Nozzle

Probe Results

E7 No blockage

G5 Nozzle completely filled with melt.

H9 No blockage

K11 Complete blockage not encountered, narrowing of the interior noted

K12 No blockages

L11 No blockages

M10 Complete blockage at $5.7 \mathrm{~cm}$ from the cut end. (The shape and depth appeared to vary at this location.)

R7 No blockages 


\subsubsection{Nozzle Tomporatures}

Microhardness measurements have been completed on selected nozzles.9 These results, which are only qualitative, indicate temperatures less than 1,223 K existed near the vessel, with the exception of nozzle H8. Table 2.5 presents the results. Low hardness values that were not associated with chromium-depleted areas indicated high temperatures. Analysis of the results show that average temperatures at the base of nozzle D10 remained below 1,223 $\mathrm{K}$. A solidified 304 stainless steel droplet on nozzle D10 indicated a possible t mperature of $1,673 \mathrm{~K} 13.3 \mathrm{~cm}$ above the bottom of the vessel. Similar hardness values at the top and bottom of nozzle sample E11 indicated that no significant axial temperature gradients existed in the nozzle. The temperature of nozzle $\mathrm{L} 6$ remained below $1,273 \mathrm{~K} 19.1 \mathrm{~cm}$ from the vessel bottom. The surface temperature of nozzle $\mathrm{H} 5$ at a position $10.2 \mathrm{~cm}$ from the vessel bottom ranged from 1,223 to $1,673 \mathrm{~K}$. Hardness values for nozzle $\mathrm{H} 8$ suggested that the average temperature of the nozzle was $1,223 \mathrm{~K}$.

\subsection{Relocation Scenarlo}

This section provides a reference for assumptions and initial conditions used in margin-to-failure calculations that require information related to the manner in which material relocated from the core to the lower head. As noted within this section, data were not sufficient to conclusively determine how material relocated to the lower plenum. Hence, several scenarios are postulated. As margin-to-failure calculations were completed, results indicated that certain assumptions made in some of these scenarios were incorrect. In fact, as indicated by results documented in this report, analyses suggest that only Scenarios 2 and 4 (explained below) were not contradicted by margin-to-failure calculation results.

As discussed in Section 2.2, small amounts of control material may have relocated prior to 224 minutes. However, most ceramic material relocated from the core to the lower head 224 to 226 minutes after reactor scram. The relocation was completed in approximately 100 seconds. The relocation was substantiated by a sharp increase in pressure and by the increase in SRM count rate (see Figures 2-1 and 2-5).

The relocation path of molten debris through control support assemblies and peripheral fuel assemblies took place primarily within the southeast quadrant of the vessel. A large quantity of material existed between the grid forging and the flow distributor plate, as well as above the plate, to the north, east, and south of core location N12. ${ }^{11}$ Figure 2-12 illustrates the location of these core support structures. Resolidified material that flowed through the distributor plate was observed to the northwest, north, northeast, and east of location N12. Material was also visible between the grid forging and the instrument support plate at the periphery of the core. This did not appear to be a major pathway for relocation, because no debris was observed below the instrument support plate. Debris filled approximately $60-80 \%$ of the space between the grid forging and the instrument support plate on the core periphery at core location 07.11 This was the only location where significant quantities of debris existed between the plates and may have been a major relocation pathway. This fact cannot be verified because no inspection holes exist at this location in the lower head and because no other inspection activities covered the region below the flow distributor plate. 
Table 2-3. Microhardness measurements.

\begin{tabular}{|c|c|c|c|c|c|c|}
\hline $\begin{array}{l}\text { Elevation from } \\
\text { Veasel }(\mathrm{cm})\end{array}$ & D10 & E11 & $\begin{array}{l}\text { Nozzle } \\
\text { H5 }\end{array}$ & H8 & 16 & M9 \\
\hline 29.0 & - & $208 \pm 29$ & . & - & - & - \\
\hline 28.3 & - & - & - & - & $167 \pm 7$ & - \\
\hline 28.0 & $140 \pm 4$ & $\cdot$ & - & - & - & - \\
\hline 27.4 & $\cdot$ & $137 \pm 4$ & $\cdot$ & - & $\cdot$ & - \\
\hline 26.6 & $136 \pm 3$ & - & - & - & - & - \\
\hline 26.0 & - & . & - & - & . & $124 \pm 5^{2}$ \\
\hline 15.8 & $124 \pm 2$ & - & - & - & - & - \\
\hline 13.0 & - & - & - & $105 \pm 2^{4}$ & - & - \\
\hline 9.0 & - & $190 \pm 9$ & - & - & - & - \\
\hline 8.2 & $161 \pm 4$ & - & - & - & - & - \\
\hline 7.7 & - & - & - & - & $169 \pm 13$ & - \\
\hline 6.9 & $168 \pm 10$ & $\cdot$ & $\cdot$ & - & - & - \\
\hline 6.4 & - & - & $133 \pm 4$ & - & - & - \\
\hline 3.8 & - & - & - & - & - & $202 \pm 28$ \\
\hline 2.5 & - & - & - & $198 \pm 8$ & - & - \\
\hline 0.0 & - & - & . & $217 \pm 13^{b}$ & - & - \\
\hline $\begin{array}{l}\text { a. Cr-depleted } \mathrm{n} \\
\text { b. Weldment. }\end{array}$ & & & & & & \\
\hline
\end{tabular}

Since there is a lack of conclusive evidence concerning the relocation of debris to the lower head, four scenarios have been postulated to provide background for margin-to-failure calculations.

\section{Scenario 1}

Molten debris łelocated through lower plenum structures with some amount of jet breakup. As debris flowed through the elliptical flow distributor plate, blockages forced the material toward locations E6, E10, F6, and G10, where the vessel was estimated to have undergone a more severe thermal transient. ${ }^{6}$ Debris relocated primarily as a coherent jet from the core distributor plate to the lower head, followed by dispersed particles and molten droplets which fell at a slower rate. The debris formed an insulating crust upon contact with the vessel lower head and/or any metallic material that may have previously relocated to the lower head. Any metallic material was subsumed within the higher temperature molten debris. The increase in RCS pressure was due to steam generated by the heat transferred from the molten debris to the water, which filled the lower head. 


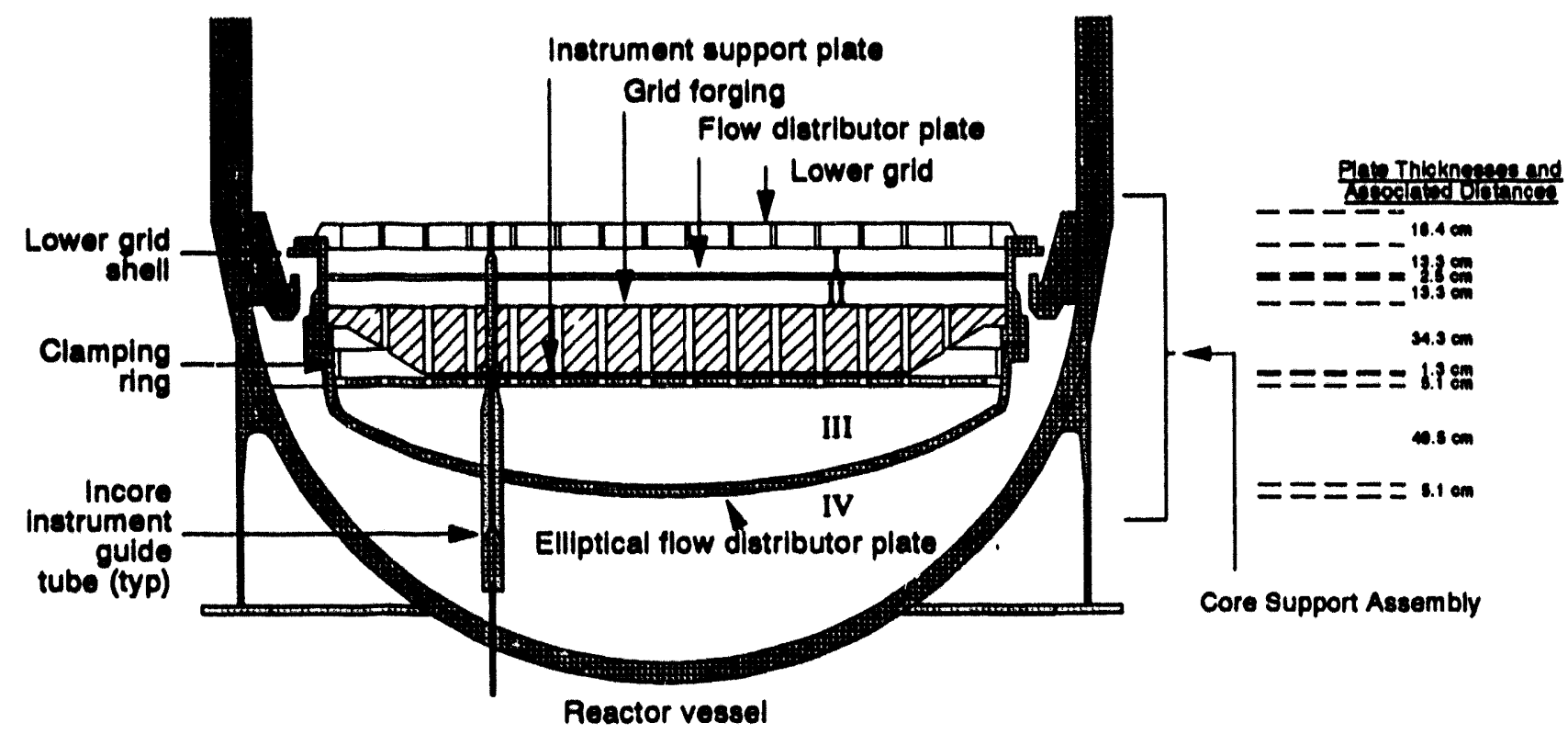

Figure 2-12. Lower head core support assembly.

\section{Scenario 2}

Molten debris relocated downward along the periphery of the vessel with little jet breakup. The material was a two-phase "wet sand" (slurry-like) mixture of liquid and solid debris by the time it reached the lower head. ${ }^{12}$ The two-phase mixture formed a crust upon contact with the lower head and/or any metallic material that may have previously relocated to the lower head. An upper crust of this material was continuously forming and breaking up as material moved across the surface of the lower head. This action produced the loose debris bed on the upper surface of the debris bed. Any metallic material was subsumed within the higher temperature molten debris near the lower head. In this scenario, it is assumed that the large pressure increase beginning at 224 minutes was not due to fuel/coolant interactions between the jet of molten debris and the coolant in the lower/head. Instead, the pressure increase is attributed to fuel/coolant interactions within the core. ${ }^{13}$

\section{Scenario 3}

Multiple jets of debris relocated through lower plenum structures and into the coolant in the lower head. Jet breakup resulted in the formation of a rubble bed on top of metallic debris. Voiding occurred in the central region of the loose debris bed, with remelting of debris in central regions follcwing. This newly molten material subsequently flowed downward and subsumed any metallic material near the lower head.

\section{Scenario 4}

Molten debris relocated at one point at the periphery of the core and outside through the core barrel and baffle plate. Some jet breakup, steam generation, and melt droplet freezing occurred as the debris relocated through the coolant in the lower head. Crusts were formed by top cooling from RCS coolant and bottom cooling from heat removal by the vessel and any metallic debris on the lower head. 


\subsection{References}

1. J. M. Broughton, P. Kaun, D. A. Petti, E. L. Tolman, "A Scenario of the Three Mile Island Unit 2 Accident," Nuclear Technology, 87, August 1989, p. 34.

2. Nuclear Safety Analysis Center, Interpretation of TMI-2 Instrument Data, NSAC/28, Electric Power Research Institute, Palo Alto, CA, May 1982.

3. D. J. N. Taylor, "TMI SPND Interpretation," Proceedings of the First International Information Meeting on the TMI-2 Accident, Germantown, Maryland, October 1985, CONF. 8510166, October 1985, pp. 65-74.

4. A. P. Kelsey, Lower Head Debris Topography, TMI-2 Technical Bulletin TB-89-02, Rev. 0, GPU Nuclear Corporation, Project Planning and Analysis Department, Middletown, PA, February 27, 1989.

5. T. L. Van Witbeck et al., Three Mile Island Unit 2 Annotated Sequence of Events, March 28, 1979, GPU-TDR-044, GPU' Nuclear, Inc., February 6, 1981.

6. G. E. Korth, Metallographic and Hardness Examinations of TMI-2 Lower Pressure Vessel Head Samples, OECD-NEA-TMI-2 VIP TMI V(92)EG01, January 1992.

7. D. W. Akers, S. M. Jensen, B. K. Schuetz, Companion Sample Examinations, OECD-NEATMI-2 VIP TMI V(92)EG10, July 1992.

8 C. S. Olsen, D. W. Akers, R. K. McCardell, Examination of Debris from the Lower Head of the TMI-2 Reactor, GEND-INF-084, January 1988.

9. L. A Neimark, T. L. Shearer, A. Purohit, and A. G. Hins, TMI-2 Instrument Nozzle Examinations at Angonne National Laboratory, OECD-TMI-2 VIP TMI V(93)AL01, February 1993.

10. MPR Associates, Inc., Removal of Test Specimens from the TMI-2 Reactor Vessel Bottom Head, MPR-1195, October 1, 1990.

11. G. Worku, Core Stratification Sampling Program, TMI-2 Technical Bulletin TB-86-35, Rev. 3, GPU Nuclear Corporation, Project Planning and Analysis Department, Middletown, PA, August 18, 1986.

12. R. V. Strain, L. A. Neimark, and J. E. Sanecki, "Fuel Relocation Mechanisms Based on Microstructures of Debris," Nuclear Technology, 87, No. 1, August 1989, p. 214.

13. M. Epstein, and H. K. Fauske, "The Three Mile Island Unit 2 Core Relocation - Heat Transfer and Mechanism," Nuclear Technology, 87, No. 4, December 1989, p. 1021. 


\section{SCOPING CALCULATIONS FOR MELT RELOCATION AND THERMAL RESPONSE}

As discussed in Section 1, several calculations provided input to the margin-to-failure analyses. This section describes calculations performed to determine the distance melt penetrated through the instrumentation nozzles of the TMI-2 pressure vessel, the potential for a jet of molten debris to fragment as it travels through coolant, and the thermal response of the vessel during and after the relocation of molten debris to the lower head.

Figure 1-1 illustrates how results from calculations in this section are used in subsequent failure analyses. For example, if results from melt penetration calculations indicate that molten fuel will not relocate through a tube to locations below the lower head, the reactor coolant system temperatures would be applied in subsequent tube rupture analyses without performing an exvessel tube temperature analysis. If melt penetration calculations indicate molten fuel relocated below the lower head, the ex-vessel tube temperature analysis would be performed, and results from that study would be used as input for the tube rupture analyses. Time-dependent temperature distributions from the vessel thermal analysis were used to evaluate the integrity of the weld holding the lower head penetration tubes to the vessel and the potential for global and localized failures to occur in the vessel.

\subsection{Study of Melt Penetration through TMI-2 Instrumentation Nozzles}

The objective of this study was to determine the degree of melt ingress into the instrumentation nozzles of the TMI-2 vessel lower head, specifically to determine if melt contacted ex-vessel tube sections. This section provides a description of the instrumentation nozzles extracted from the TMI-2 pressure vessel lower head based on examinations performed at Argonne National Laboratory (ANL) and the Idaho National Engineering Laboratory (INEL), outlines the two analytical models considered for calculating the melt penetration distance, examines the calculational parameters for input to the models, and presents the results of comparisons between model predictions and observed melt depths in the nozzles.

\subsubsection{TMI-2 Instrumentation Nozzles}

Fourteen in-core instrumentation nozzles were cut from inside the TMI-2 lower head pressure vessel over a period of 4 days in February 1990. ${ }^{1}$ The nozzles were designated based on their position in the lower head. The nozzles extracted were D10, E7, E11, G5, H5, H8, H9, K11, K12, L6, L11, M9, M10, and R7. Of the 14 nozzles cut, six of these were shipped to ANL for examination, and the remaining eight were to be examined at the INEL. Figure 3-1 illustrates the position of the nozzles in the lower head.

The eight nozzles received at the INEL were E7, G5, H9, K11, K12, L11, M10, and R7.

Each nozzle was visually examined. Radioactivity scans for cobalt-60 and cesium-137 were performed on nozzles $\mathrm{H} 9, \mathrm{~K} 11, \mathrm{~K} 12, \mathrm{~L} 11, \mathrm{M} 10$, and R7. ${ }^{2}$ Nozzles G5 and E7 were too short to be scanned. Cutting locations for sectioning each nozzle were identified from the activity profiles. Microphotography was used to view the microstructure and composition of melt attached to the nozzles. However, very few photographs of transverse cuts that might indicate the presence and 


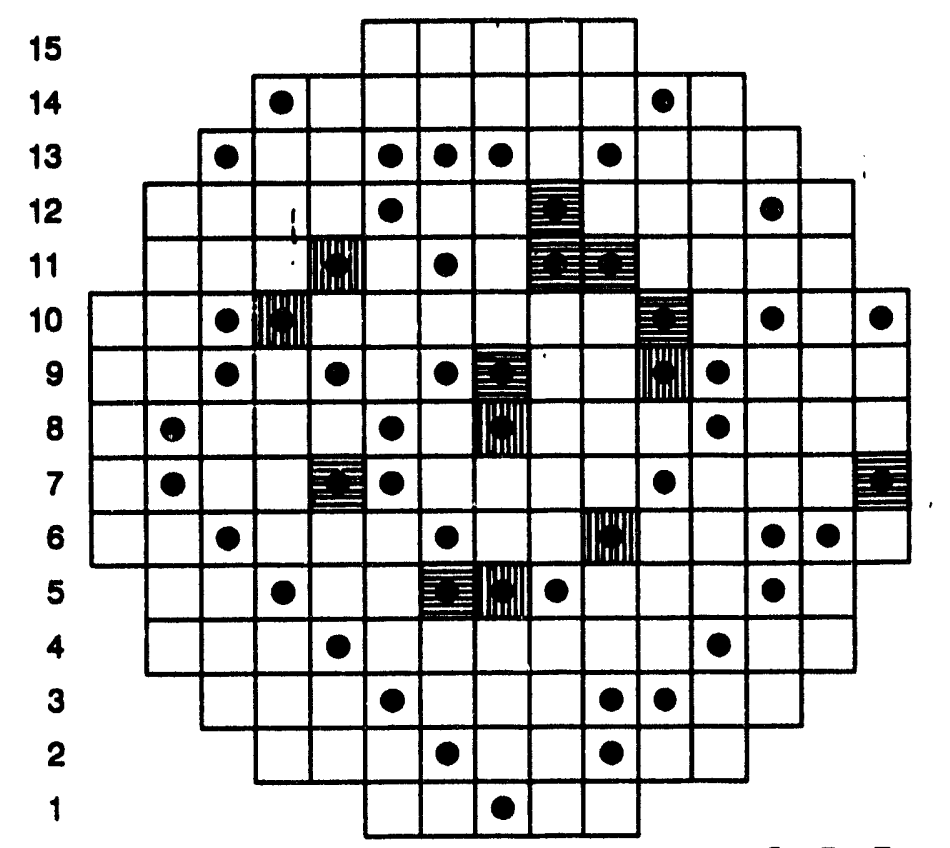

\section{Labs Examining Nozzles}

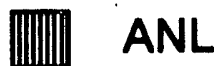

A B C D E F G H K L M N O P

M733-WMT-1002-05

Flgure 3-1. TMI-2 instrumentation nozzle map.

cross-sectional area of melt in the nozzle annuli were taken. Wire probe tests were performed on the eight nozzles to determine the extent of blockage by debris within the nozzles (Table 2-4). ${ }^{a}$ Further work was discontinued due to a shutdown of the hot cells where the work was to be performed.

The remaining nozzles, D10, E11, H5, H8, L6, and M9, were examined at ANL. ${ }^{3}$ The six nozzles underwent visual examinations and activity scans for cobalt-60 and cesium- 137 . Information derived from the activity scans determined locations for sectioning the nozzles for SEM analysis. Microhardness measurements were also taken at various positions along the length of each nozzle. Microphotography of the six nozzles included transverse cuts along the nozzles, showing the size and position of melt in the annulus between the instrumentation string and nozzle wall. This enabled the melt cross-sectional area along each nozzle to be estimated. Figure 3-2 shows curves of the relative annular area covered by melt as a function of the distance from the base of each nozzle. The area of melt estimates given in Figure 3-2 may include debris such as ablated instrument strings, control assembly material, and ablated nozzle material.

Photographs of transverse cuts through the six nozzles show solidified molten material formed either a kidney shape within the nozzle annulus or a ring around the inside of the nozzle wall. Figure 3-3 illustrates the approximate shapes of the two types of formations found in the nozzles. As shown, the sides of the kidney-shaped melt contact coolant, the other sides contact

a. Personal communication from Brian K. Schuetz, Idaho National Engineering Laboratory, EG\&G Idaho, Inc., Idaho Falls, Idaho, June 29, 1992. 


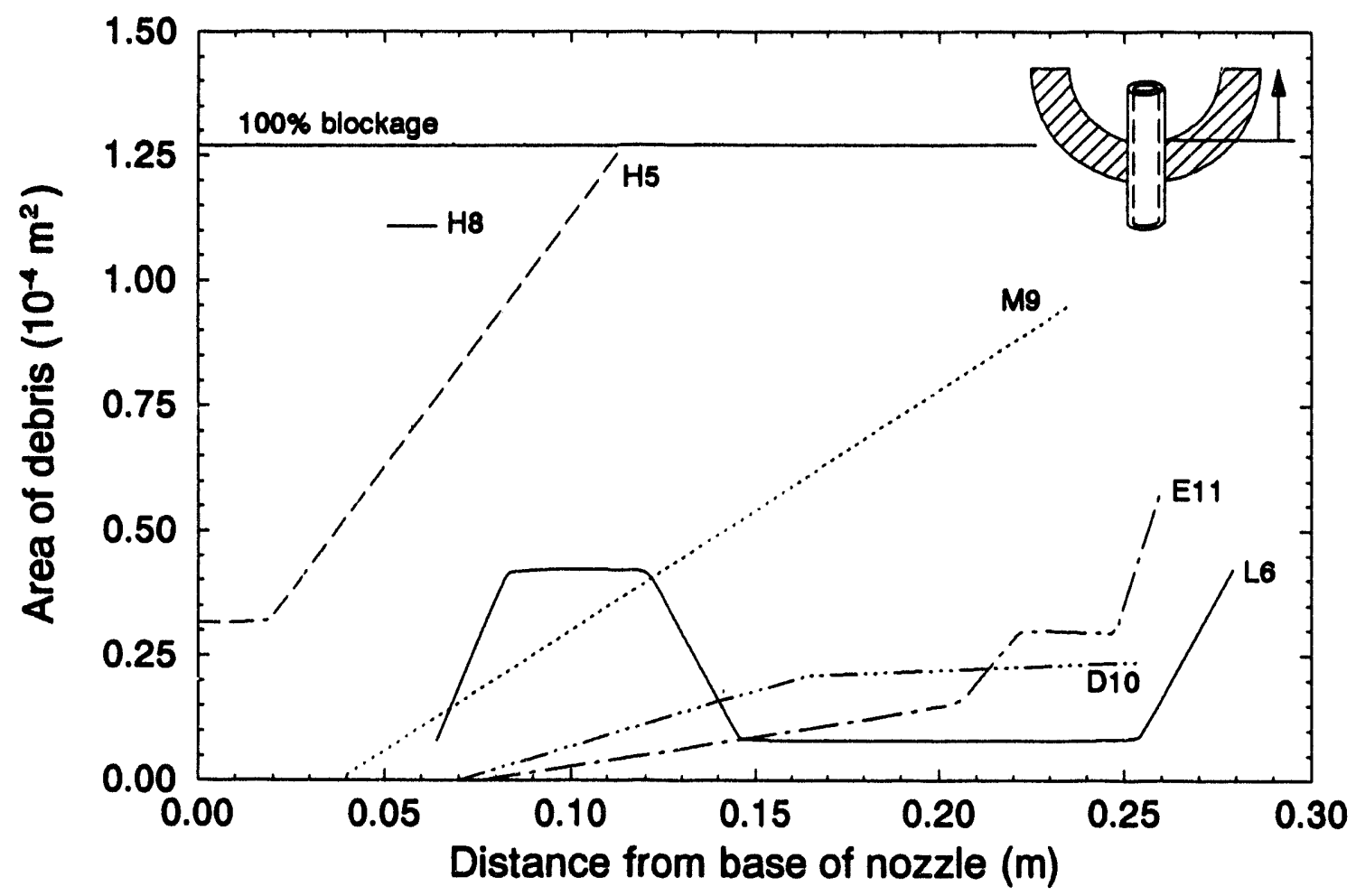

Figure 3-2. Area of debris versus distance from nozzle base for nozzles D10, E11, H5, H8, L6, and M9.

the nozzle wall and/or the instrument string. The circumference of melt in the ring type of formation contacts the nozzle wall on one side and coolant on the other. Five of the six nozzles examined by ANL were determined to hold kidney-shaped melt, and one contained ring-shaped melt.

Nozzle lengths and comments describing each of the 14 nozzles cut from the lower head of the pressure vessel were compiled from various sources ${ }^{1-4}$ and are presented in Appendix B. Additional data from nozzle examinations have also been reported previously in Tables 2-1 through 2-5.

\subsubsection{Model Selection}

Several models have been developed to predict the penetration distance of molten debris through vessel instrumentation nozzles. Reference 5 summarizes previous analytical and experimental studies that have been performed to consider melt transport through failed tubes. Although no validated model is available for predicting melt flow through light water reactor instrument tubes, melt penetration has been experimentally determined to be bounded by distances predicted by the bulk-freezing model first advanced by Ostensen and Jackson ${ }^{6,7}$ and a conduction model proposed by Epstein. ${ }^{8}$ The selection of the most appropriate model for calculating the distance that the melt flowed through the TMI-2 nozzles is discussed below. 

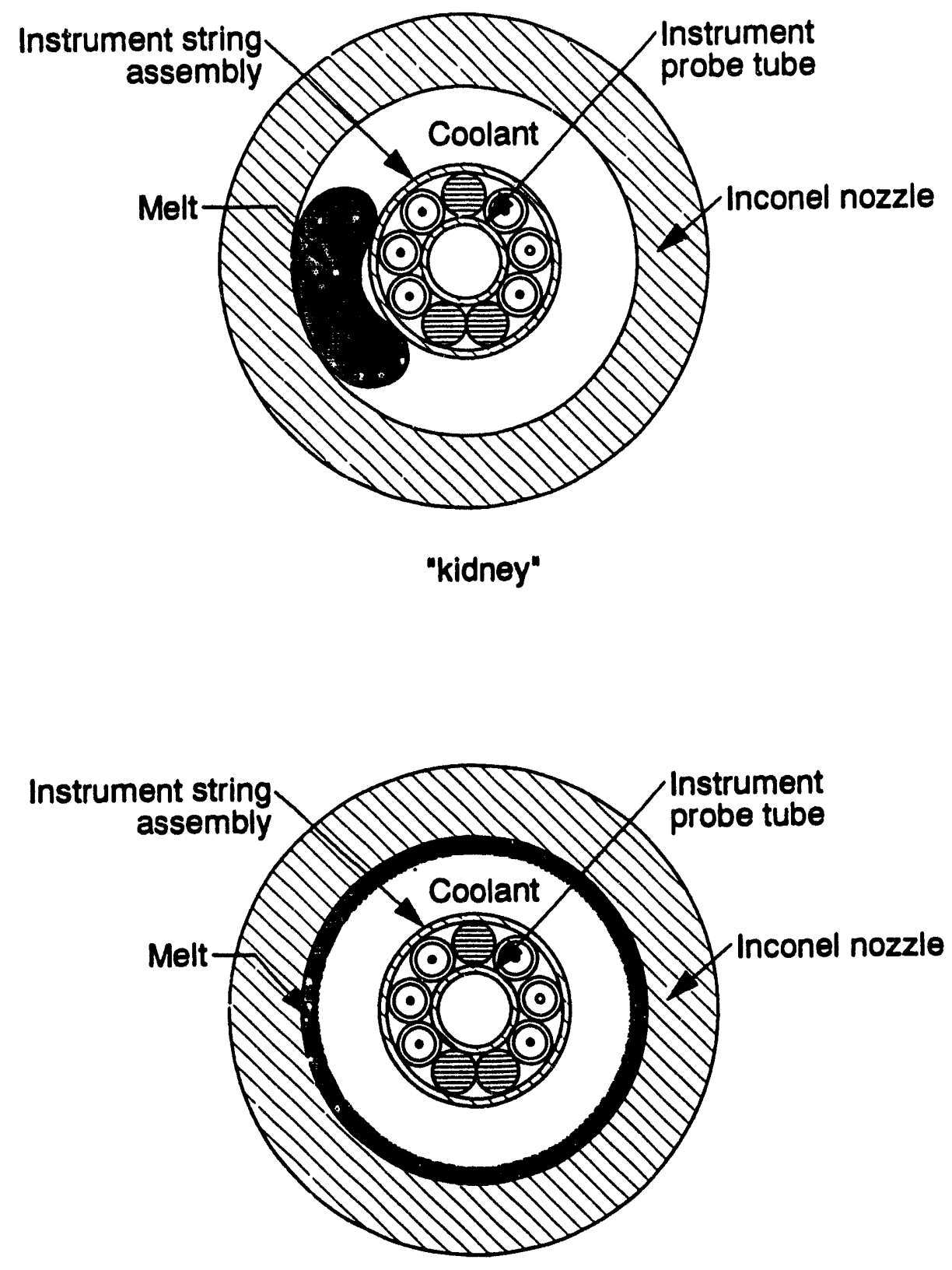

"ring"

M812.WHT-293-08

Figure 3-3. Geometry of melt formations. 
The conduction layer model assumes that transient freezing is governed by crust buildup at the nozzle wall, where conduction heat transfer governs heat loss from the melt to the nozzle wall. Once the frozen layer closes at the center, flow ceases, and the remaining melt inside the nozzle freezes [see Figure 3-4(a)]. The model ignores heat transfer from the leading edge of the flow and considers only radial heat transfer. The model does not account for the presence of any coolant within the nozzle. The model also assumes a constant melt velocity into a thick-walled channel. Since the molten material is assumed to be at or near its melting point, no convective heat exchange occurs at the melt-crust interface. Crust solidification is assumed to be independent of melt flow dynamics. For all times, $t$, the crust thickness is zero at the leading edge and maximum at the inlet.

The conduction model predicts a square root dependence for the crust thickness, $\sigma_{c}$, as a function of time, $t$, in a semi-infinite wall channel ${ }^{8}$

$\sigma_{c}(t)=2 \lambda_{c}\left(\alpha_{t a t}\right)^{0.5}$

where

$\lambda_{c}=$ solidification constant for the melt in contact with an Inconel or stainless steel nozzle

$\alpha_{\text {rd }}=$ melt thermal diffusivity.

The solidification constant is found from various approximations of boundary conditions and the number of regions that may experience phase change. The solidification constant for molten ceramic material in contact with either Inconel-600 or stainless steel nozzles is estimated to have a value of $\sim 0.75 .^{9}$ Likewise, the solidification constant for molten metallic material in contact with either Inconel-600 or stainless steel nozzles is estimated to have a value of $\sim 0.2 .9$

Substituting the criteria for melt freezing $\left(\sigma_{c}=d_{e} / 2\right)$ and the relationship between time and penetration distance, $t=x_{p} / v_{d}$, into Equation (3-1), the following relationship was obtained for predicting melt penetration distance:

$x_{p}=\frac{d_{e} P e}{16 \lambda_{c}^{2}}$

where

$d_{e}=$ effective melt diameter

$P e=$ Peclet number based on the velocity $v_{d}$.

The effect of coolant within the nozzles on the melt penetration distance was modeled by assuming a reduction in melt flow area, thus reducing the effective melt diameter as would occur if coolant were present in the nozzle. 


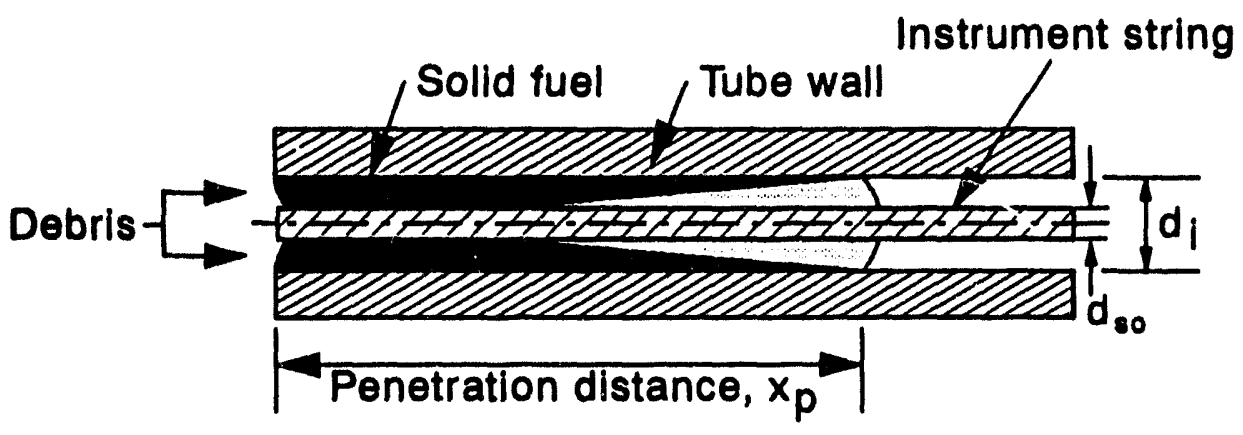

M757-WHT-1192-20

(a) Conduction layer model

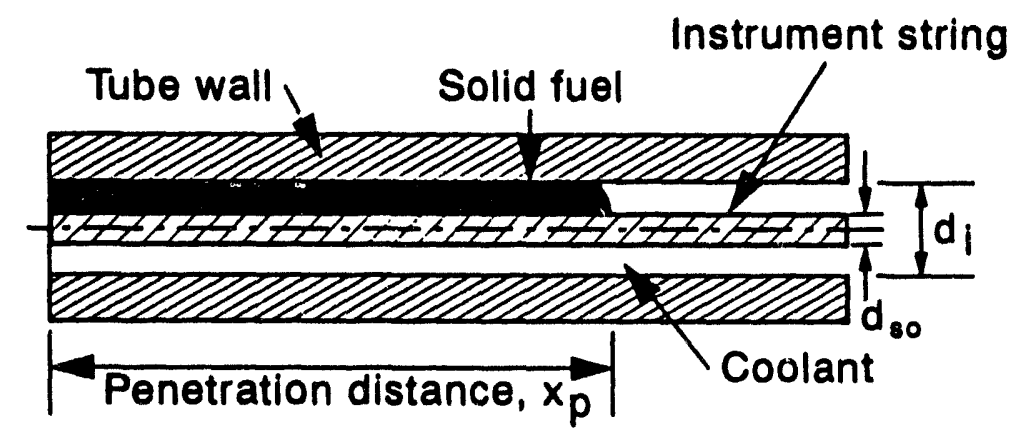

(b) Modified bulk-freezing model showing kidney shaped melt

Figure 3-4. Melt penetration model geometrics. 
Application of the conduction model for a range of melt areas between $1.6 \times 10^{-5}$ to $12.7 \times 10^{-5} \mathrm{~m}^{2}$ predicted penetration distances between 30 and $49,000 \mathrm{~cm}$. The melt area range was based on amounts of melt observed in six of the nozzles removed from the vessel (see Figure 3-2). The distances in the predicted penetration range were much greater than the penetration distances of molten fuel observed in the TMI-2 instrumentation nozzles. Although an attempt to consider the effects of coolant was made by using a reduced effective melt diameter, the penetration distances predicted show that this conduction model is not suitable for modeling the flow of molten fuel through coolant-filled nozzles, as is the case for the TMI-2 instrumentation nozzles.

The bulk-freezing model of Ostensen and Jackson has been modified to account for the presence of coolant in the instrumentation nozzles. The development of the equations for the modified bulk-freezing model are outlined in Appendix B. Figure 3-4(b) illustrates the flow mechanics and assumptions of the modified bulk-freezing model. Preliminary calculations with the modified bulk-freezing model predicted much more reasonable results than the conduction model; therefore, only the penetration distance results of the modified bulk-freezing model are used in comparisons with measured melt penetration distances.

The modified bulk-freezing model assumes that turbulence in the flowing melt prevents a stable crust from forming at the nozzle wall. The melt was modeled as flowing through an annulus with an effective diameter

$$
d_{e}=\sqrt{d_{i}^{2}-d_{s o}^{2}}
$$

where

$$
\begin{aligned}
& d_{i}=\text { inner diameter of the nozzle } \\
& d_{s o}=\text { outer diameter of the instrument string. }
\end{aligned}
$$

Any melt that might be in the instr'ment string was not considered. Molten debris inside the probe channel of the instrument string would first have to melt through the instrument string into the coolant-filled annulus of the nozzle to be considered as a safety threat. The penetration distance was conservatively estimated by assuming the melt stops when the entire amount of molten fuel in the nozzle has solidified. The model uses a heat balance around the molten material to equate the amount of heat given up to solidify the melt, with the convective heat transfer between the melt and the nozzle wall and between the melt and the coolant.

In the derivation of the modified bulk-freezing equation, coolant was allowed to escape from the top of the nozzle. Heat exchange can occur between the melt and the coolant, as well as between the melt and the nozzle wall. Heat transfer from the leading edge of the melt was not considered, along with hydrodynamic effects from melt/coolant interactions. The model does not account for nozzle ablation or for thinning of melt along the nozzle length. However, the model allowed for variations in the melt cross-sectional flow area, which remained constant through the nozzle during the calculation. 
In these calculations, it was desired to use a model with a closed-form solution technique so that calculations could be performed to consider a wide range of input parameter uncertainties. Hence, the models used for these calculations do not allow one to consider phenomena such as the dynamic effects of vapor generation, enhanced cooling of the melt's leading edge, and the reduction in melt viscosity during solidification (although sensitivity calculations considering different melt superheats provide some insight into the effects of melt viscosity). However, any vapor generation or enhanced cooling at the melt's leading edge should reduce the potential for melt to travel below the lower head. Thus, a more complex model that includes all these phenomena should predict shorter melt penetration distances.

\subsubsection{Model Calculations}

Given the uncertainties in several of the input parameters, a matrix of calculational parameters was developed for input to the model to determine the penetration distance. These parameters included the melt composition, the melt flow area, the melt velocity, and coolant conditions. The multiple variations of input parameters resulted in a range of predicted melt penetration distances.

SEM analyses of solidified material in the nozzles examined by ANL indicated compositions ranging from pure uranium to a range of metallics. Compositions varied not only between nozzles and along the length of a nozzle, but also varied for different particles at the same elevation on the nozzles (see Table 2-1). Metallic material within the nozzles resulted primarily from melting of the nozzles. The presence of silver and cadmium in the nozzles indicated that control assembly materials also entered the nozzles, in addition to molten ceramic core material. In order to encompass all possible molten material scenarios, four compositions were examined. These included $100 \% \mathrm{UO}_{2}$, eutectics of $80 \% \mathrm{UO}_{2}-20 \% \mathrm{ZrO}_{2}$, and $20 \% \mathrm{UO}_{2}-80 \%$ SS-304, and a pure, metallic 100\% SS-304 (see Appendix A for properties). These compositions represent bounds for the solidified material found in the nozzles. The $80 \% \mathrm{UO}_{2}-20 \% \mathrm{ZrO}_{2}$ eutectic is based upon the composition of the companion samples. ${ }^{10}$ Although the materials are immiscible, the $20 \% \mathrm{UO}_{2}-80 \%$ SS-304 composition was used to model a metallic material with a high melting temperature.

The melt flow cross-sectional area range used in the model was estimated from the solidified melt pictured in photographs of the nozzles examined by ANL. The photos showed kidneyshaped melt covered between $12.5 \%$ to $100 \%$ of an annulus, producing a melt flow area range of $1.6 \times 10^{-5}$ to $12.7 \times 10^{-5} \mathrm{~m}^{2}$. The kidney shape was approximated in the model by assuming melt completely filled the space between the instrument string and nozzle wall and covered some fraction of the annulus. For this type of formation, the contact area at the coolant-melt interface was independent of the cross-sectional area of melt in the annulus, unless of course the annulus was completely filled with melt. Conservative estimates of the variation in the amount of ringshaped melt ranged from $1.9 \times 10^{-5}$ to $7.1 \times 10^{-5} \mathrm{~m}^{2}$. Figure $3-3$ illustrates the two shapes of melt within the nozzles.

The velocity of the melt was required for calculating melt penetration distances. The velocity was evaluated by applying the energy conservation equation for steady, adiabatic flow to the melt in a nozzle. The melt velocity at the point where melt exits the vessel lower head is given by 


$$
v_{d}=\sqrt{\frac{2 \Delta P / \rho_{d}+2 g l_{t}}{4 f_{f} l_{1} / d_{c}+K+1}}
$$

where

$$
\begin{aligned}
& \Delta P=\text { presdure differential } \\
& f_{f}=\text { Fanning friction factor } \\
& \boldsymbol{K}=\text { entrance loss coefficient } \\
& \boldsymbol{P}_{d}=\text { density of the melt } \\
& d_{c}=\text { effective diameter of the nozzle } \\
& l_{t}=\text { distance the melt travels before exiting the lower head. }
\end{aligned}
$$

This velocity was assumed to approximate the average velocity in the nozzle. Note that $l_{\text {t }}$ includes the vessel thickness and the height of the ablated nozzle, which varies depending upon nozzle location. The solution of Equation (3-3) was plotted as a function of dimensionless penetration distance, as shown in Figure 3-5.

The velocity was primarily gravity driven because the annulus where melt was primarily found within these nozzles was at RCS pressure. However, an upper bound was applied, which corresponded to a $2 \mathrm{MPa}$ pressure differential. This pressure differential is approximately equal to the increase in pressure at the time of core relocation (see Figure 2-1). The bounding pressure differential of 0.0 to $2.0 \mathrm{MPa}$ produced a melt velocity range of 2.5 to $10.0 \mathrm{~m} / \mathrm{s}$ for virtually any value of dimensionless penetration distance, as shown in Figure 3-5.

The coolant conditions in the pressure vessel varied over the accident time frame. The average pressure before core relocation at 224 minutes was $7 \mathrm{MPa}{ }^{11}$ Coolant properties for the analysis of metallic compositions were based on a pressure of $7 \mathrm{MPa}$ because metallic debris was assumed to have entered or existed within the nozzles before the major ceramic core relocation to the lower head. Ceramic melt most likely entered the nozzles soon after core relocation at 224 minutes. For several minutes after relocation, the primary system pressure was $11.5 \mathrm{MPa} .{ }^{11}$ Coolant properties for analysis of ceramic melt penetration were based on this higher pressure. The system pressure increased to normal operating pressure around 350 minutes, ${ }^{12}$ but solidification of melt within the nozzles had probably occurred prior to that time.

As shown in Figure 2-4, temperatures in the cold legs of both the A and B loops during relocation indicate subcooled to saturated coolant temperatures. ${ }^{11}$ Calculations using the modified bulk-freezing model examined melt in contact with either subcooled liquid or saturated liquid. The case of a nozzle void of coolant was also examined to provide a calculational upper bound. In all cases, the nozzle wall temperature was assumed constant and equal to the initial temperature of the coolant. 


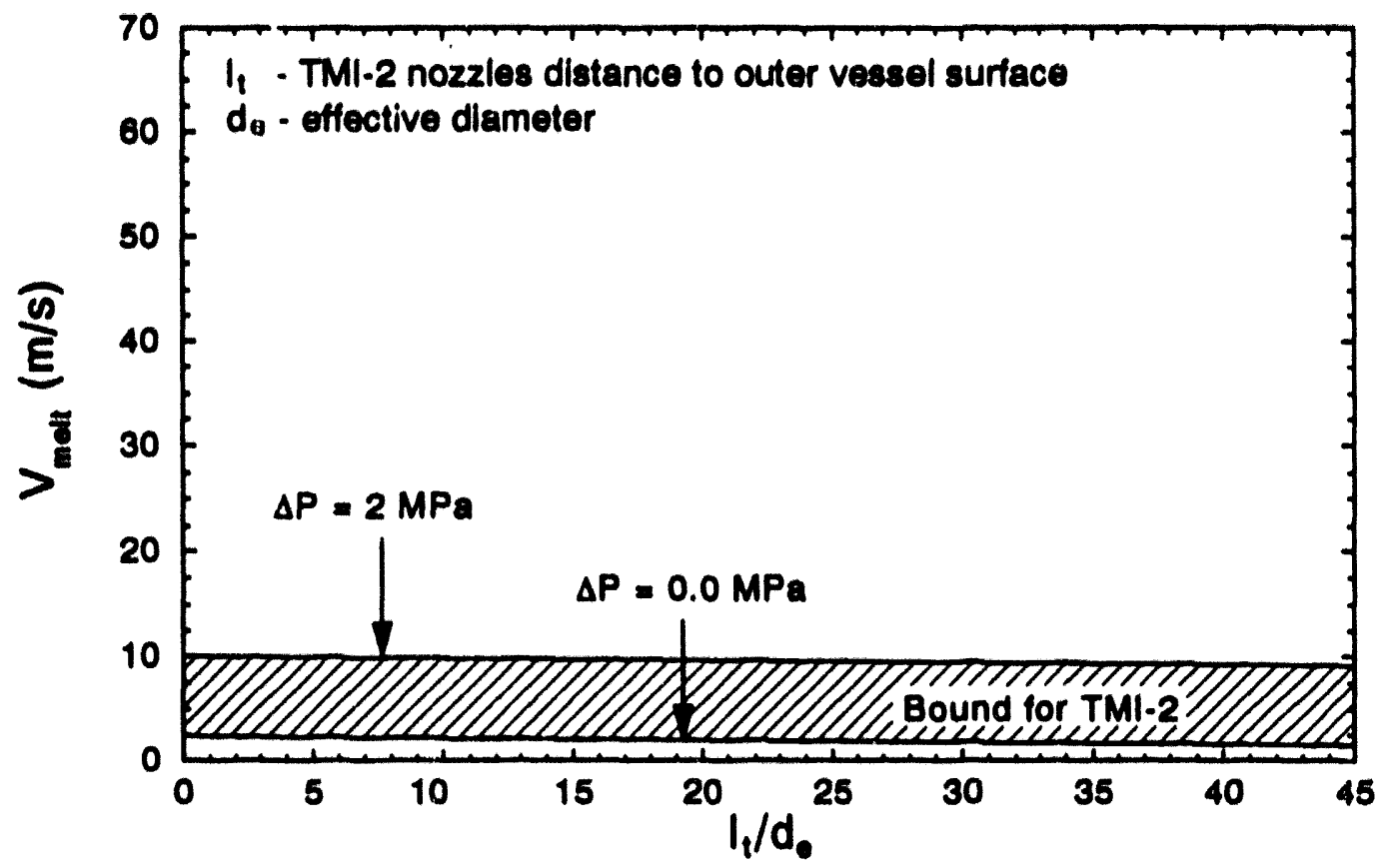

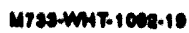

Figure 3-5. Melt velocity plotted as a function of dimensionless penetration distance.

\subsubsection{Reaults}

A criterion for the shortest distance that melt must travel to penetrate the lower head was established. The most conservative penetration distance was determined to be $15.0 \mathrm{~cm}$. This distance corresponds to a minimum nozzle stub length of $1.3 \mathrm{~cm}$ plus the lower head thickness $(13.7 \mathrm{~cm})$. The criterion was developed based on nozzles which had been severely ablated when molten core material relocated to the lower head.

The four representative melt compositions discussed in Section 3.1.3 were initially modeled at their respective solidification temperatures. For each composition, if the distance predicted for melt flow in the absence of coolant at the liquidus temperature was less than the $15.0 \mathrm{~cm}$ criterion, superheat temperatures were then modeled.

The melt penetration distances predicted by the modified bulk-freezing model ranged from 0.2 to $26.0 \mathrm{~cm}$ for kidney-shaped melt and 0.4 to $21.7 \mathrm{~cm}$ for ring-shaped melt. The lower bounds for each melt shape were calculated assuming the smallest melt flow area of gravity-driven ceramic melt, in contact with saturated coolant. The upper bounds were calculated assuming the largest area of $100 \%$ SS-304 flowing at $10 \mathrm{~m} / \mathrm{s}$. Subranges based on melt composition may be extracted from each of the melt shape ranges given above. The range for ceramic kidney-shaped melt was 0.2 to $14.8 \mathrm{~cm}$, and the range was 0.4 to $11.9 \mathrm{~cm}$ for ceramic ring-shaped melt. A range of 3.4 to $26.0 \mathrm{~cm}$ was calculated with metallic kidney-shaped melt, and a range of 1.5 to $21.7 \mathrm{~cm}$ was calculated for metallic ring-shaped melt.

The calculated penetration distances for both melt formations with a 100\% SS-304 composition exceeded the distance criterion of $15.0 \mathrm{~cm}$ at the solidification temperature; 
therefore, superheat temperatures were not investigated for this composition. Calculated penetration distances were less than the criterion when each of the other three compositions were modeled at their respective solidification temperatures for both kidney and ring shapes. Superheat temperatures of the ceramic compositions were examined, which were slightly higher than the peak temperatures reported in the companion samples. ${ }^{10}$ A superheat temperature was also assumed for the eutectic metallic composition. The temperatures existing within the vessel when metallic debris may have entered the nozzles would have been much lower than the core relocation temperature, and the large amounts of melt predicted to cause penetration of the lower head were not seen in the nozzle examinations. ${ }^{3}$ Therefore, distances predicted by the model for the SS-304 composition should be considered highly conservative.

The depth of melt penetration within the six nozzles examined at ANL has been measured and reported. ${ }^{3}$ Table 3-1 lists the results of the measurements based on gamma scans. Maximum and minimum distances are given for nozzles D10 and H5 because it could not be concluded if the cesium-137 activity was inside or on the surface of the nozzles. ${ }^{3}$ The six nozzles are listed in the first column. The shape of solidified material in each nozzle, as seen from photographs, is given in the second column. The third column reports the distances melt traveled through the nozzles, as measured by ANL. Only fuel debris penetrations are reported. The measured depth of fuel in nozzle $L 6$ was attributed to a piece of metallic aluminum which was wated with fuel particles. This debris apparently dropped into the nozzle through the guide tube above and was not from the flow of fuel across the lower head. ${ }^{3}$ This type of debris relocation is not predicted with the models used here. Because the debris particle quenches during this type of relocation, it will not impact ex-vessel tube temperatures. To compare with the observed debris penetration distance, the model ranges for the appropriate shape of ceramic melt are listed in the last column. The distances were measured from the top of each sample down into the nozzle [see Figure 34(b), distance $\left.x_{p}\right]$.

The lower bound of the penetration range for the kidney-shaped ceramic melt was generated with an $80 \% \mathrm{UO}_{2}-20 \% \mathrm{ZrO}_{2}$ melt composition at a temperature of $3,200 \mathrm{~K}$ and velocity of $2.5 \mathrm{~m} / \mathrm{s}$, filling one-eighth of the annular cross section and contacting saturated liquid. The kidney-shaped ceramic melt upper bound was based on a nozzle completely filled with $100 \% \mathrm{UO}_{2}$ at a temperature of $3,200 \mathrm{~K}$ and velocity of $10.0 \mathrm{~m} / \mathrm{s}$. A composition of $80 \% \mathrm{UO}_{2}-20 \% \mathrm{ZrO}_{2}$ at $3,200 \mathrm{~K}$ and $2.5 \mathrm{~m} / \mathrm{s}$ in contact with saturated coolant for the minimum melt cross-sectional area examined produced the lower limit of the penetration range for the ceramic ring shape. The ceramic ring-shaped upper bound was set by $100 \% \mathrm{UO}_{2}$ at $3,200 \mathrm{~K}$ and $10.0 \mathrm{~m} / \mathrm{s}$, with the largest amount of melt examined contacting subcooled liquid.

The penetration distance calculated using the modified bulk-freezing model was highly dependent upon the amount of melt flowing through a nozzle. The greater the volume of melt, the farther it would penetrate into a nozzle. The penetration distances were also dependent upon the contact area between the melt and the coolant and between the melt and the nozzle. The penetration distances predicted by the model for the ring-shaped melt were less than those predicted for a kidney formation, given equal volumes of melt in the nozzles, because of the increased surface contact of the ring formation with both the nozzle wall and the coolant. Both surfaces, of course, provide for heat removal from the melt. 
Tablo 2-1. Comparison of measured melt penetration and model predictions.

\begin{tabular}{|c|c|c|c|}
\hline Nozmele & $\begin{array}{l}\text { Melt } \\
\text { shape }\end{array}$ & $\begin{array}{l}\text { Measured depth } \\
\text { (cm) }\end{array}$ & $\begin{array}{c}\text { Model range } \\
\text { ceramic melt }(\mathrm{cm})\end{array}$ \\
\hline D10 & kidney & $10.8 \mathrm{~min} ., 23.7 \mathrm{max}$. & $0.2-14.8$ \\
\hline H5 & kidney & $2.9 \mathrm{~min} ., 5.7 \mathrm{max}$ & $0.2-14.8$ \\
\hline H8 & kidney & 5.7 & $0.2-14.8$ \\
\hline L6 & kidney & 23.0 & $0.2-14.8$ \\
\hline M9 & kidney & 3.8 & $0.2-14.8$ \\
\hline E11 & ring & 9.8 & $0.4-11.9$ \\
\hline
\end{tabular}

Table 3-2 shows the breakdown of maximum penetration distances predicted by the modified bulk-freezing model for each of the four compositions. Data in the fourth column indicate the upper bound on the penetration distance of each melt composition. These upper limits result from modeling a nozzle annulus completely filled with melt. Except for the 100\% SS-304 composition, these distances meet the criterion for melt remaining within the vessel lower head (i.e., less than $15 \mathrm{~cm}$ ). The second column lists the liquidus temperature of each melt composition. Data in column three indicate the degree of superheat above the liquidus temperature on which the calculations were based.

\subsubsection{Conclusions}

The modified bulk-freezing model was determined to be more applicable than the conduction layer model for the prediction of melt penetration distances through the coolant filled annulus within the TMI-2 instrumentation nozzles. The modified bulk-freezing model accounts for the presence and the state of coolant in contact with melt in the nozzles. The model conservatively predicts the melt penctration distance by not accounting for the energy loss due to nozzle ablation or thinning of the melt flow along the nozzle length. Assuming the melt stops when the entire amount within a nozzle has solidified also produces a conservative distance. Four melt compositions were evaluated over a range of melt flow areas and melt velocities. The model predicts distances that encompass the observed melt penetration in the TMI-2 nozzles. Debris on the outer surface of nozzle D10 and a debris particle falling into nozzle L6 through the overlapping guide tube cause the measured fuel depth in these two nozzles to fall outside the range predicted by the bulk-freezing model. These data points should not be considered when comparing the model with the measured depths.

The model predicts that, in the absence of coolant in the nozzles, only debris with a highly metallic composition may penetrate through the nozzle outside the reactor vessel. The primary source of metallic debris witnin the nozzles was due to nozzle ablation. Other sources included control assembly materials that possibly quenched and solidified before entering the nozzles. Examinations of the nozzles removed from the vessel indicated neither of these types of metallic debris penetrated the nozzles to a depth of consequence or existed in very large quantities. 
Table 3-2. Maximum model predictions of melt penetration distance.

\begin{tabular}{lccc}
\hline \multicolumn{1}{c}{ Composition } & $\begin{array}{c}\text { Liquidus temperature } \\
(\mathbf{K})\end{array}$ & $\begin{array}{c}\text { Superheat } \\
(\mathbf{K})\end{array}$ & $\begin{array}{c}\text { Maximum penetration distance } \\
(\mathrm{cm})\end{array}$ \\
\hline $100 \% \mathrm{UO}_{2}$ & 3,113 & 87 & 14.8 \\
$80 \% \mathrm{UO}_{2}-20 \% \mathrm{ZrO}_{2}$ & 2,860 & 340 & 10.9 \\
$20 \% \mathrm{UO}_{2}-80 \%$ SS-304 & 2,400 & 200 & 13.3 \\
$100 \%$ SS-304 & 1,671 & 0 & 26.0 \\
\hline
\end{tabular}

Hence, penetration of the lower head by metallic debris was highly unlikely. Model predictions for the $100 \% \mathrm{UO}_{2}$ and $80 \% \mathrm{UO}_{2}-20 \% \mathrm{ZrO}_{2}$ compositions at $3,200 \mathrm{~K}$ indicate ceramic melt would not flow below the lower head, conservatively assuming melt completely filled the annulus of a 1.3-cm stub. The melt temperature assumed was conservatively higher than the reported molten core temperature range of $2,873 \mathrm{~K}$ to $3,123 \mathrm{~K}$ in a $78 \% \mathrm{UO}_{2}-17 \% \mathrm{ZrO}_{2}$ composition. ${ }^{10}$ These conservative assumptions, along with the likelihood that coolant was present within the nozzles during melt penetration, support the conclusion from results of the melt penetration calculations that molten debris containing fuel did not penetrate beyond the lower head.

As noted in Section 2, wires were inserted into the instrument string probe channel within seventeen instrument tubes (see Figure 3-3). It was found that all but one of the tested tubes were plugged, which indicates that either the probe channel within the string had collapsed or that melt was present within the channel. Hence, wire probes indicating that the instrument string channels are plugged did not conclusively prove that melt was present within these channels below the lower head. In fact, nozzle examination data indicated that the instrument string channels were collapsed at some locations.

The bulk-freezing model predicted ceramic melt flowing through the annulus between the instrument string and the nozzle wall did not breech the lower head. The flow of melt through the instrument string probe channel was not evaluated. Although melt may travel farther through the probe channel because of the pressure difference between the RCS and the probe channel (which is at atmospheric pressure), melt present within the probe channel does not pose a serious safety threat. As discussed in Section 3.1.2, melt present within the probe channel of the instrument string must ablate through the string and the instrument tube wall before an ex-vessel tube rupture can occur.

\subsection{Jet Impingement and Thermal Response Calculations}

Calculations were performed to investigate melt relocation and the subsequent thermal loading to the vessel during the TMI-2 accident. Specifically, calculations were performed to consider the potential of a debris jet impinging upon the TMI-2 lower head to cause the hot spot temperatures observed in TMI-2 boat sample examinations. ${ }^{13}$ Global and , ocalized vessel temperature results were obtained to provide input for subsequent structur al analysis calculations to determine the margin to failure in the TMI-2 vessel. 
Where possible, input parameters were quantified using data from TMI-2 VIP examinations, data from previous TMI-2 examinations, or other TMI-2 data sources. Parametric studies were performed to investigate the sensitivity of calculational results to input parameter uncertainties. Results from these sensitivity studies are presented and compared with TMI-2 VIP boat sample examination data.

Calculations documented in this section only consider the thermal response of the lower head during and after a substantial amount of ceramic material from the core relocated to the lower plenum. However, scoping calculations were performed to evaluate the impact of previously relocated metallic material on the vessel thermal transient. ${ }^{b}$ To maximize the time lag that this layer could have upon vessel heatup, conservative assumptions were applied, such as assuming that metallic material was present on the entire lower head reaching the height observed by Neimark at nozzle $\mathrm{H8}^{3}$ Results indicate that the maximum time lag that this layer could have upon vessel heatup is between 10 and 25 minutes.

Finally, calculations were performed to provide insight related to the manner in which material relocated from the core to the lower plenum. As discussed within this section, results from these calculations indicate that some of the relocation scenarios postulated in Section 2 may be eliminated from further consideration.

\subsubsection{Melt Relocation}

3.2.1.1 Model Description. The potential for a debris jet to quench as it travels through water was analyzed with the TEXAS fuel-coolant interaction model. ${ }^{16-19}$ Several computer codes are available for predicting melt/water interactions. However, there is considerable uncertainty in code results because of limited data for validating these computer codes. Hence, several sensitivity studies were performed with the TEXAS code to consider the impact of code uncertainties. TEXAS is a computer model which predicts the behavior of molten fuel interacting with water coolant during the mixing and propagation phases of a molten fuel-coolant interaction (FCI). The model was developed to examine FCI behavior under the assumption that the leading edge of the fuel jet pouring into the coolant is the dominant mixing process; i.e., the process can be considered in a one-dimensional manner.

The model employs a unique Lagrangian-Eulerian formulation in which the fuel is divided into Lagrangian material volumes that are tracked as they pass through an Eulerian mesh containing the water and steam. Each fluid is modeled with a complete set of conservation equations and an equation-of-state to describe the balance of mass, momentum, and energy used 'for predicting the volume fraction, velocity, and temperature of each fluid, as well as overall pressure.

The unique feature of the TEXAS model is that the Lagrangian fuel particles can dynamically fragment during fuel-coolant mixing and quenching due to relative-velocity-induced fragmentations (Rayleigh-Taylor instabilities). TEXAS follows this process and determines the

b. Letter from J. L. Rempe, INEL, to A. Rubin, NRC, "Scoping Calculations Discussed During Recent TMI-2 VIP Meeting," JLR-79-92, November 15, 1992. 
fuel mass quenched. TEXAS also considers dynamic fragmentation during an explosion propagation, but this is not relevant to this study, because the high pressure in the TMI-2 reactor pressure vessel suppressed any energetic FCI.

TEXAS only considers leading edge breakup and neglects breakup due to instabilities on the side of the jet, since leading edge breakup is considered to be the dominant effect. In previous analyses, ${ }^{18}$ Epstein determined that the rate of jet erosion due to Kelvin-Helmholtz instabilities along the jet column was negligible because of the dampening effects of the vapor film.

A complete description of TEXAS is provided in References 14 through 17 . Reference 15 gives an extensive summary of the model with relevant reactor simulations and results.

3.2.1.2 Input Assumptions. Several TEXAS simulations were used to analyze a range of debris jets during their initial mixing phase and to bound possible relocation masses, time periods for relocation, and modeling uncertainties. Total mass flow rates ranging from 300 to $1,000 \mathrm{~kg} / \mathrm{s}$ were used to model scenarios in which the debris was assumed to relocate through saturated or subcooled water conditions. These values were chosen to maximize the heat transfer rate, although the duration of the jet pour was reduced to keep the total mass that relocated a constant value of $10,000 \mathrm{~kg}$. (Although it is recognized that nearly $19,000 \mathrm{~kg}$ of material relocated to the lower head, there is uncertainty related to the amount of material that may have relocated during the 224 to 226 minute time frame. Furthermore, in Section 3.2.2, thermal analyses indicate that the heat load from less than $10,000 \mathrm{~kg}$ could result in temperatures that exceeded peak values estimated from metallurgical examinations.) Because melt may have drained from more than one of the holes in the elliptical flow distributor plate, analyses considered one and three jet cases. Table 3-3 lists the five cases considered, with input assumptions related to initial jet velocity, total mass flow rate, jet diameter, and reactor coolant system temperature.

The greatest uncertainty in these simulations involves the initial conditions, which specify the rate of fuel entry into the lower plenum; i.e., the velocity and diameter of the jet, the overall discharge time, and the number of jets impinging upon the lower head. In addition, the amount of coolant subcooling in the vessel was unknown at the time of relocation. Assumptions for these simulations have attempted to bound possible input parameter ranges to discern the effect on quenching behavior.

Melt relocation times up to 1 minute were chosen. Preliminary calculations indicated that relocation times of 1 minute or less maximized the amount of quench that could occur. For all of the cases, the reactor vessel pressure is assumed at $10 \mathrm{MPa}$ during relocation. This is the approximate reactor pressure during the time period (224 to 226 minutes after reactor scram), when most debris relocation is postulated to have occurred. The coolant was assumed to be saturated at a temperature of $584 \mathrm{~K}$ for the first four cases. In the final case, a water pool temperature of $100 \mathrm{~K}$ below saturation was considered to examine the effect of subcooling on jet breakup and quenching. This value corresponds to an average of the subcooled water temperatures measured in the RCS cold legs and the RCS saturation temperature at the time of relocation (see Figure 2-4).

Assumptions related to the debris were based upon results from companion sample examinations. ${ }^{10}$ The debris composition is estimated at $78 \% \mathrm{UO}_{2}-17 \% \mathrm{ZrO}_{2}{ }^{10}$ The remaining 
Tablo 3-3. TEXAS calculational results.

\begin{tabular}{ccccccccc}
\hline \multicolumn{2}{c}{$\begin{array}{c}\text { Number } \\
\text { Case }\end{array} \quad \begin{array}{c}\text { Jet jets } \\
\text { diameter }\end{array}$} & $\begin{array}{c}\text { Initial melt } \\
\text { velocity } \\
(\mathrm{m} / \mathrm{s})\end{array}$ & $\begin{array}{c}\text { Initial melt } \\
\text { mass flow rate } \\
(\mathrm{kg} / \mathrm{s})\end{array}$ & $\begin{array}{c}\text { Coolant } \\
\text { pressure } \\
(\mathrm{MPa})\end{array}$ & $\begin{array}{c}\text { Coolant } \\
\text { temperature } \\
(\mathbf{k})\end{array}$ & $\begin{array}{c}\text { Mass } \\
\text { breakup } \\
(\mathrm{kg})\end{array}$ & $\begin{array}{c}\text { Particulate } \\
\text { size } \\
(\mathrm{mm})\end{array}$ \\
\hline 1 & 1 & 0.1524 & 2.4 & 333.3 & 10 & 584 & 14 & $15-19$ \\
2 & 3 & 0.1524 & 2.4 & 1000.0 & 10 & 584 & 43 & $15-19$ \\
3 & 3 & 0.1524 & 0.8 & 333.3 & 10 & 584 & 43 & $19-24$ \\
4 & 3 & 0.0762 & 3.2 & 333.3 & 10 & 584 & 16 & $3-24$ \\
5 & 1 & 0.1524 & 2.4 & 333.3 & 10 & 484 & 20 & $13-18$ \\
\hline
\end{tabular}

constituents are primarily stainless steel and Inconel from core structural components. Material properties for this debris composition are found in Appendix A. From a phase diagram for a $\mathrm{U}-\mathrm{Zr}$-O compound, ${ }^{19}$ a freezing temperature range of $200 \mathrm{~K}$ was assumed, with a liquidus temperature of $2,850 \mathrm{~K}$ and a solidus temperature of $2,650 \mathrm{~K}$. The debris was initially assumed to ihave a low superheat of only $50 \mathrm{~K}$ above the melt liquidus temperature. This temperature was selected based upon companion sample examination results which indicated that the material arrived at the flow distributor plate and the lower head in a molten state. Although a lower superheat would affect the amount of melt predicted to solidify, it is not felt that the order of magnitude of melt predicted to solidify would change.

Calculations were performed assuming a 0.74-m injection height, which is the height of the elliptical flow distributor plate above the lower head in the center of the pressure vessel lower plenum. The jet flow area was primarily varied by considering single and multiple jet flows through the flow distributor plate. In most cases, jet diameters were assumed to correspond to the diameter of holes in the flow distributor plate. Case 4 was performed to investigate the sensitivity of results to jet diameter, using a jet diameter one-half the size of holes in the flow distributor plate. This smaller jet corresponds to cases where melt had frozen and partially blocked holes of the elliptical flow distributor plate.

3.2.1.3 Results and Discussion. Results from all of the simulations indicate that insignificant amounts of breakup occurred considering the total mass of debris that was assumed to be injected into the lower plenum. Maximum breakup was predicted for cases in which three jets were considered. For the two cases assuming three jets with diameters equal to the diameter of holes in the distributor plate, the total breakup mass was approximately $43 \mathrm{~kg}$. Breakup mass and particle size results are summarized in Table 3-3. Results for the first three cases have a jet length-to-jet diameter ratio (L/D ratio) of less than 5. TEXAS results indicate that only the initial leading edge of the jet (i.e., the first of the Lagrangian material volume parcels) broke up. In Case 4, where there was an L/D ratio of nearly 10, TEXAS predicted that the first three Lagrangian particles of each jet broke up. Based on the model, such a limited L/D is not sufficient for significant breakup of the incoming fuel mass in a saturated water pool. 
In summary, the breakup predicted by TEXAS for molten jets of debris draining from the elliptical flow distributor plate is relatively insignificant. Hence, calculation results indicate that the assumption that major amounts of jet breakup occurred during relocation (assumed in Scenario 3 of Section 2) is incorrect. Therefore, subsequent jet impingement and vessel thermal response calculations continued under the assumption that most debris reached the lower plenum in a molten state without significant breakup or quenching. Because calculation results indicate that the "hard" layer by itself could impose a thermal load resulting in temperatures that exceeded peak values estimated from metallurgical examinations (see Section 3.2.2), and because there is uncertainty about when the additional rubble on top of the "hard" layer relocated, no further ascessment of the impact of the rubble on vessel thermal response was performed.

\subsubsection{Jet Impingement and Vessel Thermal Response}

3.2.2.1 Model Description. A simple phenomenological model, TMI, was developed to estimate the heat transfer that occurs during jet impingement and model natural convection from the molten pool of debris to the wall at the bottom of the vessel. The TMI model is essentially a lumped parameter model. However, continuity of heat fluxes at the inner and outer surfaces of the vessel was then applied so that temperature distributions through the vessel wall could be obtained for subsequent vessel structural response calculations. A summary description of phenomena modeled in these calculations is provided below. Governing equations used in the TMI model are found in Appendix C.

The TMI model assumes that there is one jet that impinges at the center of the pressure vessel. Although the location of jet impingement may have been different during the actual TMI-2 scenario, the precise location of the jet is not important in this model because the important heat transfer effects of the jet will still be observed.

The TMI model calculates the temperature history that occurs in the lower head of the pressure vessel during jet impingement and natural convection that occurs in the pool after relocation. The model predicts that a debris crust will form on the pressure vessel when relocated material contacts the vessel wall. This result is based on preliminary calculations, which indicate that the interface temperature is below the melt solidus temperature upon contact. Heat is then transferred through the crust to the vessel. When the molten jet stops draining and surface agitation is reduced, a crust forms on the upper surface of the pool; this upper crust is initially considered to be of uniform thickness as it continues to cool (see Figure 3-6). The model includes the effects of crust porosity on thermal properties using the relationship suggested by Olander. ${ }^{20}$ The model also considers the effect of melt solidification upon the viscosity of the molten pool. As discussed in Appendix C, when the temperature of the melt pool drops below the debris liquidus temperature, the solid fraction in the molten pool becomes a factor in the analysis using the relationship proposed by Epstein and Fauske. ${ }^{21}$ If the entire pool solidifies, the model is no longer valid and the analysis is terminated.

The pressure vessel is divided into sections, which are best described as a center disk with concentric rings around it. A cross sectional view of this geometry is shown in Figure 3-7. The heat flux from the molten pool travels through the crust and heats up the section of the pressure vessel in contact with the crust. There is no communication between sections in the pressure vessel. Thus, the only portions of the pressure vessel that are directly heated are sections that are 


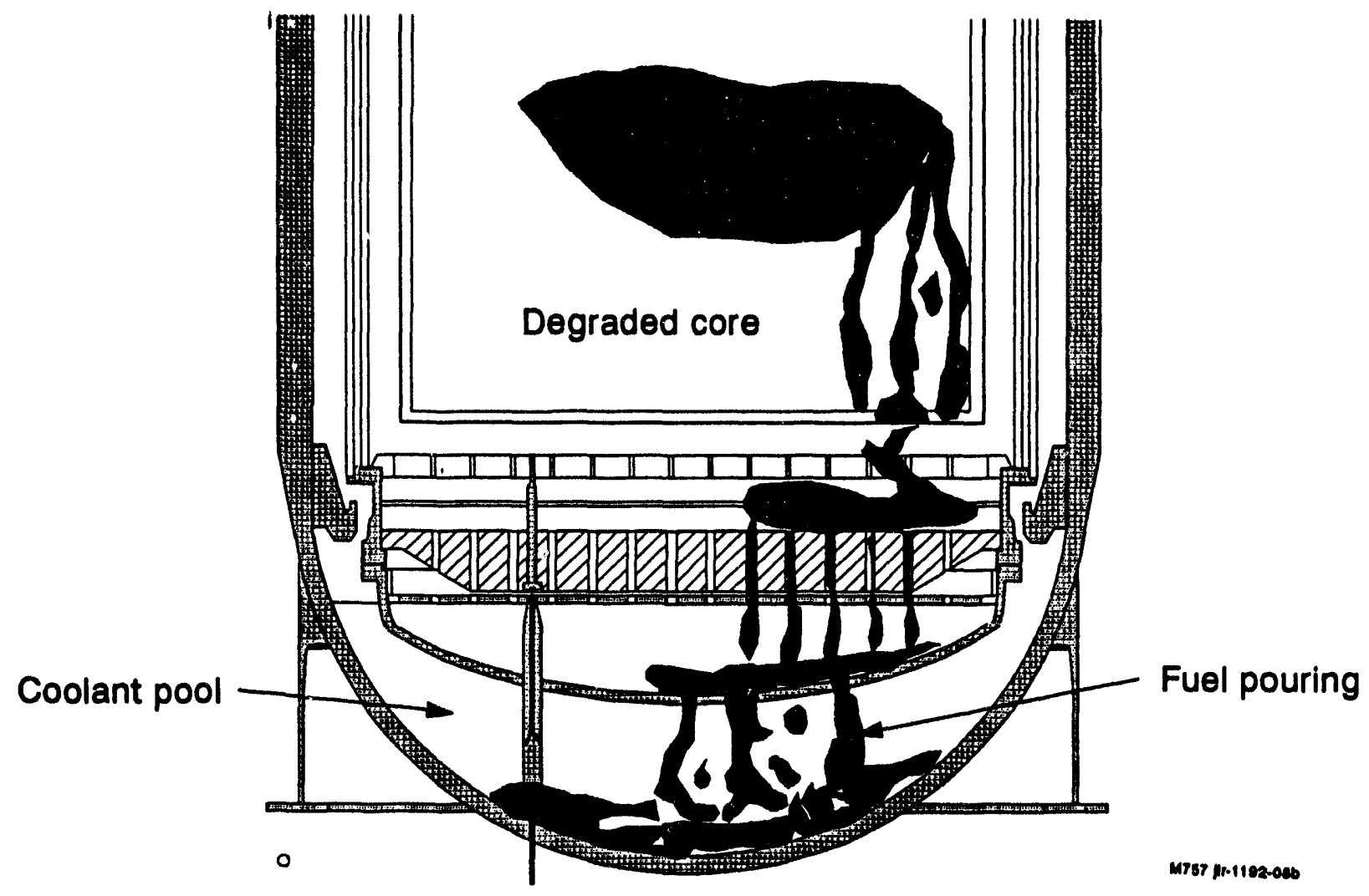

(a) during relocation

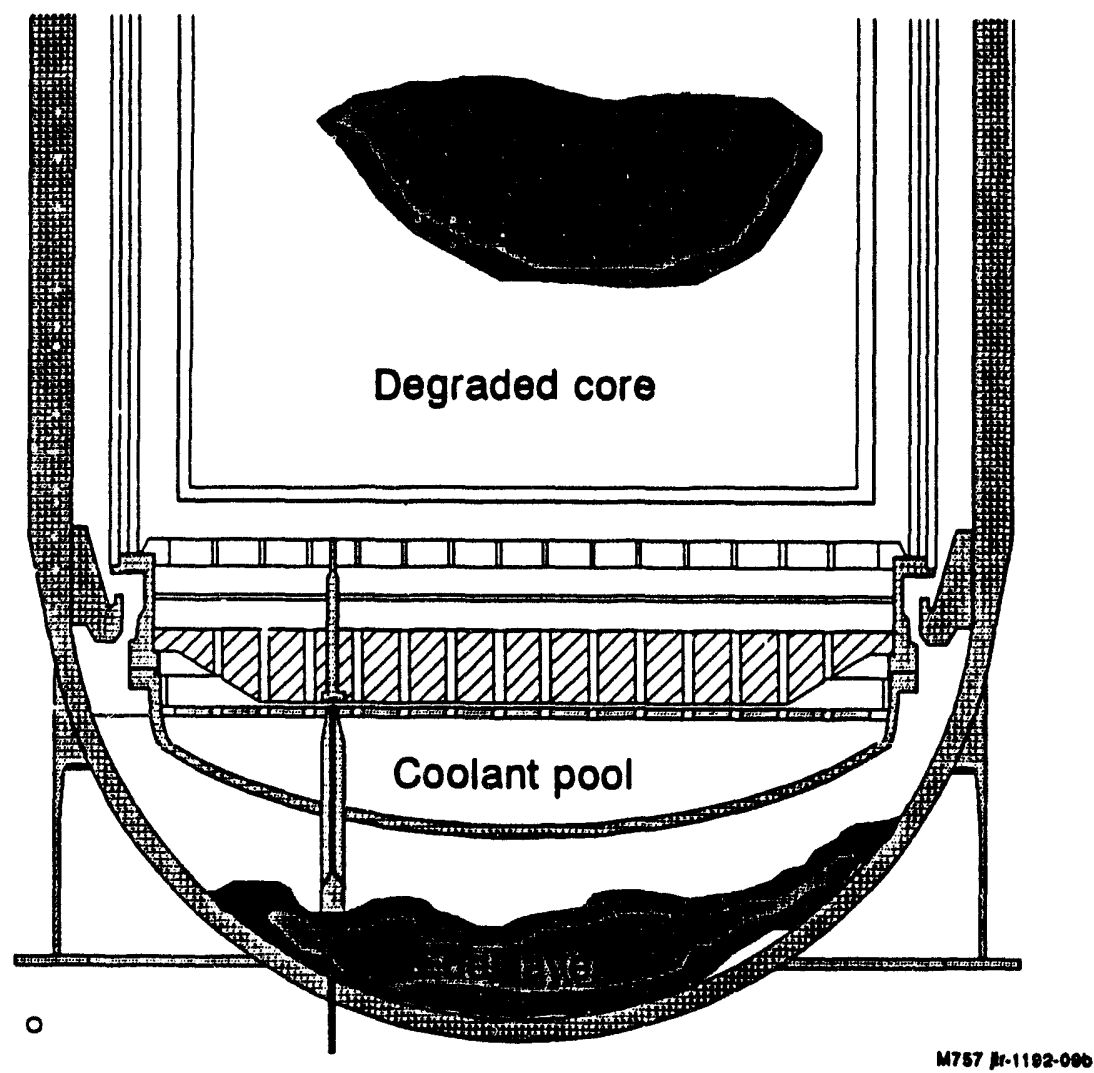

(b) after relocation

Figure 3-6. Thermal loading from jet impingement. 


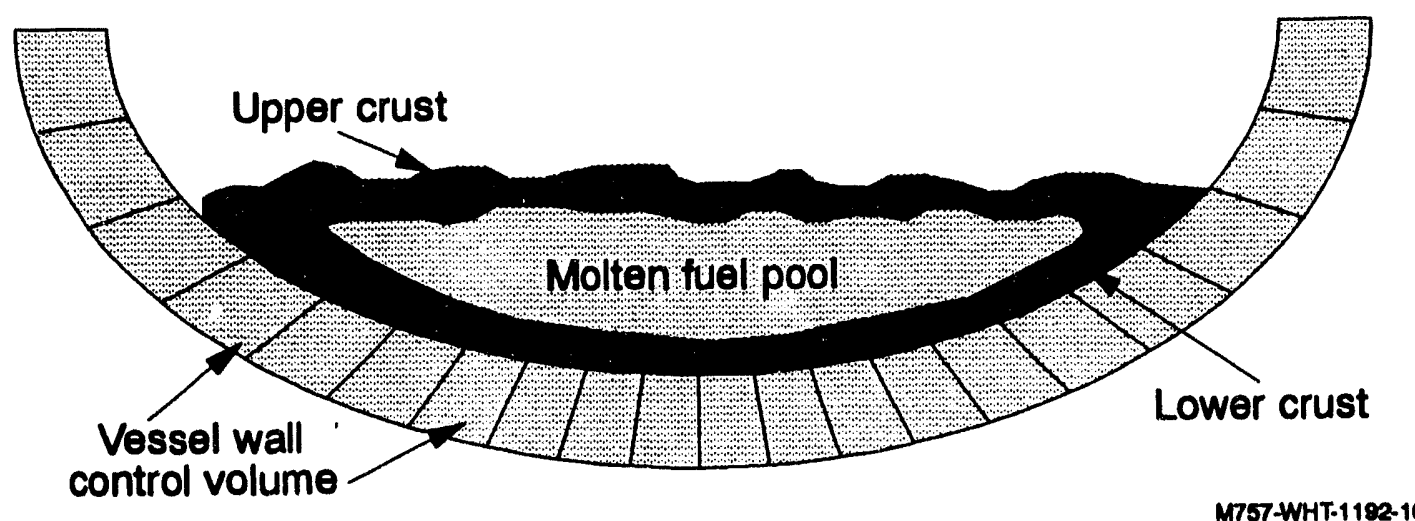

Figure 3-7. Model for TMI-2 thermal analysis.

in direct contact with the crust that has formed on the periphery of the melt pool. The melt pool is considered to be a single control volume at a single temperature, which changes in size due to crust formation. The crusts do not store energy and are considered to be resistances to heat flow that change in size due to the difference between the heat transferred to it (and their decay heat) and the heat transferred through it to the vessel wall.

The transition from jet impingement stagnation heat transfer to the natural convection regime assumes that there is no substantial period over which the debris melt pool would be completely stagnant. 'This assumption is based upon the assumptions that (a) most of the melt, arrives in a molten state and (b) the characteristic time for the onset of natural convection is short compared to the time of interest (several hours). The first assumption is based upon TEXAS calculational results discussed in Section 3.2.1.3. The second assumption is based on results from dimensional analyses, which indicate that the timescale for the onset of natural convection is much less than 1 hour. ${ }^{22}$ As discussed in Section 3.2.2.3, calculation results indicate that the time periods of interest in the vessel thermal response are on the order of several hours. Hence, natural convection behavior within the pool is modeled throughout the transient using correlations dependent upon a Rayleigh number based upon internal heat generation within the pool. Decay heat causes some of the pool to remain molten and can cause significant internal natural convection. Heat transfer to the lower crust from the hemispheric molten zone was modeled based upon the work of Jahn and Reineke. ${ }^{23}$ The experimental and theoretical work by Jahn and Reineke ${ }^{23}$ was also used to predict variations in the heat flux as a function of angle from the bottom of the pool. It should be noted that there is considerable uncertainty in using these data to model large pool behavior during severe accidents. For example, it is estimated that the Rayleigh number for the pools that are formed during a severe accident may be several orders of magnitude higher than the Rayleigh numbers for which the Jahn and Reineke data were obtained. Furthermore, the formation and entrainment of solidified debris in the pool may reduce the heat tranfer predicted by steady-state natural convection correlations.

Heat loss from the melt pool to the coolant in the lower plenum is modeled by initially considering film boiling and radiation heat transfer. This is based upon results from preliminary calculations, which indicate that the fuel/coolant interface temperature is above the critical temperature of water and nucleate boiling could not initially occur. As the upper crust thickens 
and the interface temperature decreases, it is expected that film boiling will cease. The model then considers heat loss via nucleate boiling on the upper crust surface. As the interface temperature continues to decrease, the heat transfer due to natural convection is modeled.

A detailed description of the TMI model is found in Reference 22. Governing equations used in the model are summarized in Appendix C.

3.2.2.2 Input Assumptions. To determine the effects of uncertainties in key parameters, various simulations were performed (see Table 3-4). Sensitivity studies were performed to investigate the effect of assumptions related to debris decay heat, debris properties, the interfacial contact resistance between crust on the pool periphery and the vessel, heat removal from the vessel to the containment, the total debris mass that relocated to the lower head, the effective surface area of the upper pool crust that is exposed to reactor vessel coolant, and RCS coolant subcooling.

The decay heat values listed in Table 3-4 are representative values for the TMI-2 core at the time of core relocation. The upper bound decay heat of $1.27 \mathrm{MW} / \mathrm{m}^{3}$ (Case 1) was obtained from the American Nuclear Society (ANS) Standard 5.1 for the TMI-2 core under the assumption that the noble gases $(\mathrm{Xe}, \mathrm{Kr})$, halogens $(\mathrm{I}, \mathrm{Br})$, and alkali metals $(\mathrm{Cs}, \mathrm{Rb})$ are no longer present in the debris that relocated to the lower head. The nominal value of $1.0 \mathrm{MW} / \mathrm{m}^{3}$ was used based on estimates by Akers ${ }^{10}$ for the ceramic urania/zirconia material examined in the companion samples. A reduced value of $0.95 \mathrm{MW} / \mathrm{m}^{3}$ is also considered to account for the possibility that the lower head contained a melt with 5\% non-fuel material. Decay heat values in Reference 10 are estimated to have an uncertainty of $\pm 20 \%$. Reference 10 also indicates that companion sample debris underwent a long cooldown period (3-72 hours) because the phase separation between the $(\mathrm{U}, \mathrm{Zr}) \mathrm{O}_{2}$ and $(\mathrm{Zr}, \mathrm{U}) \mathrm{O}_{2}$ phases was observed to occur.

As discussed in Section 2.2.2, assumptions related to the debris composition were based upon results from companion sample examinations. ${ }^{10}$ Debris which solidifies on the pool lower and upper boundaries is assumed to have an average porosity of about $20 \% .^{10}$ An interfacial thermal resistance may also be present due to surface roughness between the crust and the vessel. Using the method suggested by Garnier, ${ }^{24}$ values for the gap resistance between the vessel and crust were estimated to range between 150 and $10,000 \mathrm{~W} / \mathrm{m}^{2} \mathrm{~K}$.

Heat losses from the vessel outer surface to the containment were modeled using a heat transfer coefficient that considered losses via natural convection and radiation. As discussed in Reference 5, previous analyses indicate that this heat transfer coefficient may range from 1 to $100 \mathrm{~W} / \mathrm{m}^{2} \mathrm{~K}$. The value for this coefficient is dependent upon parameters such as vessel temperature and containment temperature, which vary during the transient. A combined convective and radiative heat transfer coefficient between the vessel outer surface and the containment for the TMI-2 accident was estimated to range between 30 and $100 \mathrm{~W} / \mathrm{m}^{2} \mathrm{~K}$. The manner in which this coefficient was calculated is documented in Appendix C. However, simulations listed in Table 3-4 were performed by selecting relatively high values (70 to $100 \mathrm{~W} / \mathrm{m}^{2} \mathrm{~K}$ ) to maximize heat losses from the vessel because preliminary results indicated that vessel temperatures were exceeding values observed from boat sample examinations. Hence, analyses with a lower heat transfer coefficient would also indicate that vessel temperatures exceeded values estimated from boat sample examinations. 
Table 3-4. Vessel thermal response calculation results.

\begin{tabular}{|c|c|c|c|c|c|c|c|c|c|}
\hline Case & $\begin{array}{c}\text { Debris } \\
\text { bed mass } \\
(\mathrm{kg})\end{array}$ & $\begin{array}{c}\text { Decay heat } \\
\text { power } \\
\text { density } \\
\left(\mathrm{MW} / \mathrm{m}^{3}\right)\end{array}$ & $\begin{array}{l}\text { Debris-to-vessel } \\
\text { gap heat transfer } \\
\text { coefficient } \\
\left(\mathbf{W} / \mathbf{m}^{2} \mathbf{K}\right)\end{array}$ & $\begin{array}{c}\text { Vessel-to- } \\
\text { containment heat } \\
\text { transfer coefficient } \\
\left(\mathrm{W} / \mathrm{m}^{2} \mathrm{~K}\right)\end{array}$ & $\begin{array}{l}\text { Area } \\
\text { ratio }^{a}\end{array}$ & $\begin{array}{c}\text { Quasi-steady } \\
\text { downward heat } \\
\text { flux at } 6 \text { hours } \\
\left(\mathrm{kW} / \mathrm{m}^{2}\right)\end{array}$ & $\begin{array}{l}\text { Peak vessel } \\
\text { temperature } \\
\text { (K) }\end{array}$ & $\begin{array}{l}\text { Lower crust } \\
\text { thictness at } \\
21,600 \text { seconds } \\
\text { (cm) }\end{array}$ & $\begin{array}{c}\text { Upper crust } \\
\text { thickness at } \\
21,600 \text { seconds } \\
\text { (cm) }\end{array}$ \\
\hline 1 & 10,000 & 1.27 & 10,000 & 100 & 1 & 84 & 1,525 & 7.0 & 5.0 \\
\hline 2 & 10,000 & 1.00 & 10,000 & 100 & 1 & 74 & 1,350 & 9.0 & 7.5 \\
\hline 3 & 10,000 & 1.00 & 10,000 & 70 & 1 & 63 & 1,525 & 8.5 & 5.0 \\
\hline 4 & 10,000 & 1.00 & 10,000 & 70 & 3 & 58 & 1,425 & 9.0 & 20.0 \\
\hline $5^{b}$ & 7,400 & 0.95 & 10,000 & 100 & 1 & 62 & 1,200 & 10.0 & 11.0 \\
\hline 6 & 7,400 & 0.95 & 10,000 & 100 & 3 & 60 & $1,040^{c}$ & $7.0^{c}$ & $19.0^{c}$ \\
\hline $7^{b}$ & 10,000 & 1.00 & 1,000 & 100 & 1 & 63 & 1,220 & 10.0 & 11.0 \\
\hline 8 & 10,000 & 1.00 & 150 & 100 & 1 & 57 & 1,137 & 8.0 & 7.4 \\
\hline 9 & 10,000 & 0.95 & 10,000 & 100 & 1 & 61 & 1,190 & 9.5 & 8.2 \\
\hline 10 & 10,000 & 0.95 & 150 & 100 & 1 & 55 & 1,120 & 8.4 & 8.0 \\
\hline 11 & 10,000 & 1.00 & 10,000 & 70 & 1 & 65 & 1,400 & 9.0 & 8.0 \\
\hline $12^{d}$ & 6,800 & 0.95 & 10,000 & 100 & 1 & 60 & 1,180 & 10.0 & 11.0 \\
\hline 13 & 6,800 & 0.95 & 150 & 100 & 1 & 54 & 1,105 & 8.7 & 10.0 \\
\hline 14 & 6,800 & 0.75 & 10,000 & 100 & 1 & 55 & 1,110 & 11.0 & 13.0 \\
\hline $15^{e}$ & 6,800 & 0.75 & 150 & 100 & 1 & 49 & 1,020 & 10.5 & 13.7 \\
\hline $\begin{array}{l}\text { a. Rati } \\
\text { b. Sam } \\
\text { c. Case } \\
\text { d. Inpu } \\
\text { contain }\end{array}$ & $\begin{array}{l}\text { between th } \\
\text { result was } \\
\text { was trunce } \\
\text { for this cas } \\
\text { ent heat tra }\end{array}$ & $\begin{array}{l}\text { total surface } \\
\text { tained for a c } \\
\text { ed at a time c } \\
\text { was based up } \\
\text { fer coefficien }\end{array}$ & $\begin{array}{l}\text { rea and the projecte } \\
\text { se with a subcooled } \\
3,600 \mathrm{~s} \text { because the } \\
\text { nominal values fo }\end{array}$ & $\begin{array}{l}\text { surface area of the } \\
\text { water pool of } 100 \mathrm{~K} \\
\text { molten pool freezes } \\
\text { input parameters, su }\end{array}$ & $\begin{array}{l}\text { oper sur } \\
\text { this tim } \\
\text { as deb }\end{array}$ & $\begin{array}{l}\text { ce if it was a smo } \\
\text { and the model } \\
\text { decay heat, vess }\end{array}$ & $\begin{array}{l}\text { th surface. } \\
\text { not applicable f } \\
\text {-to-debris heat }\end{array}$ & $\begin{array}{l}\text { later times. } \\
\text { ansfer coefficient }\end{array}$ & nd vessel-to- \\
\hline
\end{tabular}


There is also uncertainty in estimates for the total mass of debris present in the TMI-2 lower head. However, it is estimated that the hard layer of debris in the lower head contained up to $10,000 \mathrm{~kg}$ and that additional loose debris was present on top of this hard layer, so that approximately $19,000 \mathrm{~kg}$ of material had relocated to the lower head. The calculations documented in this section are concerned with the formation of a molten pool that later became the hard layer in the lower head; therefore, total masses of 6,800 to $10,000 \mathrm{~kg}$ were assumed. The value of $6,800 \mathrm{~kg}$ represents the hard layer mass estimated using probe test results; ${ }^{25}$ the value of $10,000 \mathrm{~kg}$ was selected as an upper bound for this mass.

There is the possibility that the surface of the upper crust is not smooth and flat. A rough, cracked, upper crust surface provides more surface area for heat transfer and eventual water ingression and, therefore, better heat transfer to the vessel coolant. The surface area parameter shown in Table 3-4 is a ratio between the total surface and the projected surface area of the upper surface if it were a smooth surface. A maximum value of three was assumed in Cases 4 and 6, based on work by Farmer. ${ }^{26}$ This ratio is used as a factor, which bounds the increase in surface area that is exposed to the coolant. It is recognized that this is a crude estimate, and more work is needed to accurately determine the effect, of surface roughness and water ingression into this hard layer.

The coolant was assumed to be saturated at a temperature of $584 \mathrm{~K}$ for each of the cases listed in Table 3-4. However, to encompass conditions where there may have been subcooling present in the reactor vessel, Cases 5 and 7 were also analyzed assuming a water pool temperature of $100 \mathrm{~K}$ below saturation. This value maximized the subcooling measured in the $\mathrm{RCS}$ cold leg temperature following high pressure injection about 15 minutes prior to the time of melt relocation.

3.2.2.3 Results and Discussion. The results for Case 2 are shown and discussed as a base case example. Case 2 was chosen as a convenient example and is not the best estimate for the TMI-2 relocation. Results for the remaining cases are summarized in Table 3-4, and additional details related to calculational results are found in Reference 22 . None of these cases are a precise representation of the TMI-2 relocation. The important observation for all these cases is that the qualitative trends are quite similar. The initial and boundary conditions primarily impact quantitative values for parameters, such as peak temperature predictions which are given in Table 3-4.

Initial stages of the thermal transient were found to be characterized by high inner vessel surface temperatures over short time periods on the order of 1 minute. The inner surface vessel temperature at 0 and 30 degrees from the vertical for Case 2 are shown in Figures 3-8 and 3-9. For the short-term behavior depicted in Figure 3-8, it is seen that the temperature of the vessel 'surface at the jet impingement point (i.e., 0 degrees) peaks at about $1,500 \mathrm{~K}$ for times when the debris melt jet is still pouring into the plenum and before significant crust formation occurs. Vessel temperatures are then observed to ramp down before they begin to increase over longer times. This characteristic peak temperature was observed in all of the simulations during the time of jet impingement. Although lower pour rates were observed to decrease the magnitude of the peak temperature, the duration of this initial peak was found to increase for lower pour rates. 


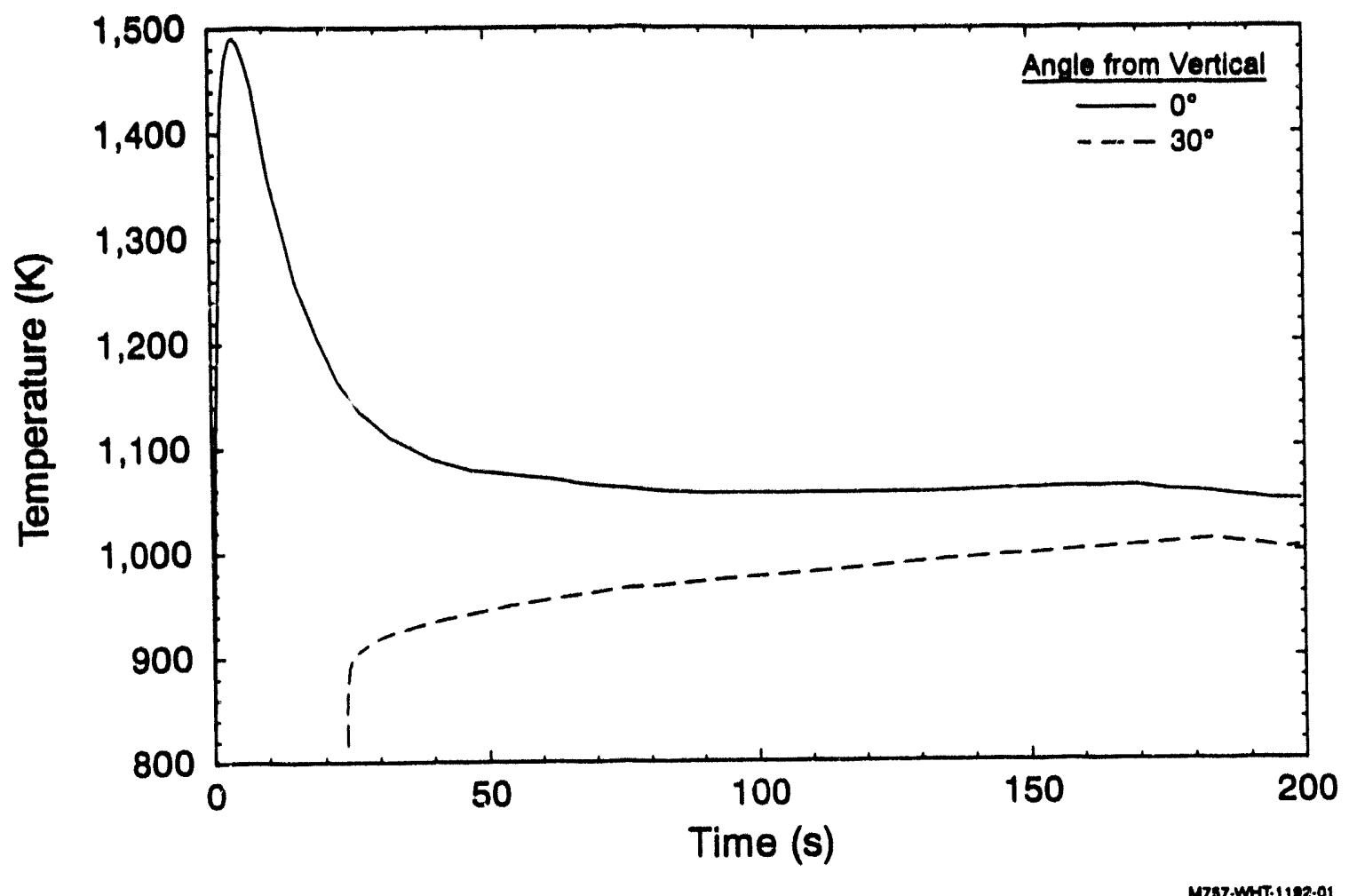

Figure 3-8. Case 2 vessel inner surface temperatures (0 to 200 seconds).

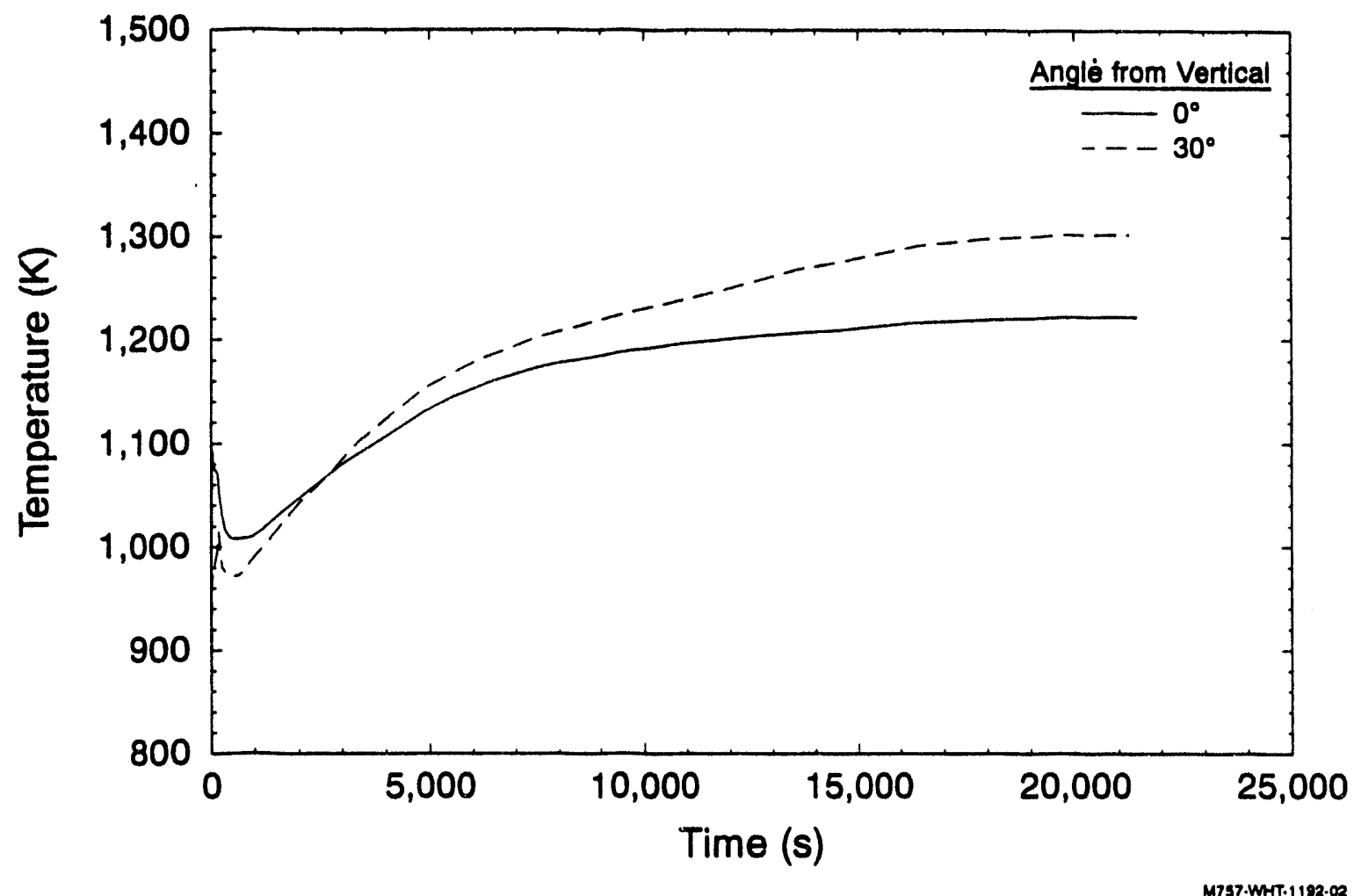

Figure 3-9. Case 2 vesscl inner surface temperatures ( 0 to 21,600 seconds). 
The next stage of the thermal transient may be observed in Figure 3-9. As jet impingement ends and the melt pool accumulates, the vessel inner surface temperature decreases and goes through a minimum (in this case, about $1,000 \mathrm{~K}$ ) and then begins to rise. This occurs because the heat transferred from the melt to the vessel is being transferred to the rest of the vessel wall and diffuses by conduction heat transfer to the outer vessel surface. An additional reason for this phenomena is that additional crust formation occurs in the pool, which reduces the heat transferred to the vessel. Once the conduction thermal wave has reached the outer vessel wall (1,000 to 2,000 seconds), the path for conduction heat transfer has become quasi-steady, and thus the inner surface temperature begins to rise.

The final stage of the thermal transient occurs on the time scale of hours as the inner surface temperature reaches a maximum and then levels off. This phenomenon occurs because the heat loss to the vessel (and then to the containment atmosphere) is now at steady state. Furthermore, the melt pool is cooling and slowly solidifying. Therefore, the driving potential for heating the vessel decreases in this timeframe as a balance is reached between heat gain and heat loss.

These three stages of the transient only occur at locations where jet impingement occurs. At 30 degrees from the bottom, the temperature rise is delayed until the melt pool reaches this elevation and heating begins. The change in slope of the temperature increase at about 6,000 seconds occurs due to a solid-to-solid phase change in the steel. This phase change occurs at $\sim 1,030 \mathrm{~K}$, and the properties of the steel change according to the temperature of the vessel at its centerline. Therefore, the beginning of this effect is not seen when the centerline inner surface temperature reaches $1,030 \mathrm{~K}$, but when the average vessel centerline temperature reaches $1,030 \mathrm{~K}$.

For Case 2, the inner surface temperature reaches a maximum value of $1,300 \mathrm{~K}$ at 30 degrees and 1,215 $\mathbf{K}$ at 0 degrees (see Figure 3-10). The temperature distribution shown in Figure 3-10 illustrates the effect of the angular dependent heat flux due to internal heat generation. A peak inner surface temperature of $1,340 \mathrm{~K}$ is observed to occur at 35 degrees from the vertical. At larger angles from the vertical, the inner surface temperature decreases rapidly, due to upper crust formation over the molten pool. Although this temperature behavior is consistent with deep-pool behavior predicted by the Jahn and Reineke model, ${ }^{23}$ it is enhanced because of the one-dimensional model for heat conduction within the pressure vessel and the lack of heat loss through the vessel wall upward into the coolant above the melt; i.e., fin effects are not included. However, when angular heat fluxes predicted with the TMI model are input to a two-dimensional model, heat losses up the vessel wall were typically found to overshadow enhanced convection effects in deeper pools. For example, Case 2 peak vessel surface temperatures shift toward the bottom and center of the lower head. Note that several parameters play a role in the initial importance of convective currents. In addition to pool depth, which is directly correlated to melt mass, the debris decay heat levels are important. In calculations that were performed to evaluate the vessel thermal response to lower debris masses and debris decay heats, such as Case 15, minor variations were predicted in angular heat fluxes.

As shown in Figure 3-11, the thickness of the upper crust and the lower crust at 0 and 30 degrees increases rapidly for initial stages of the transient. However, prior to 5,000 seconds, the crust growth rate levels; and a more modest growth rate occurs. Note that the lower crust 


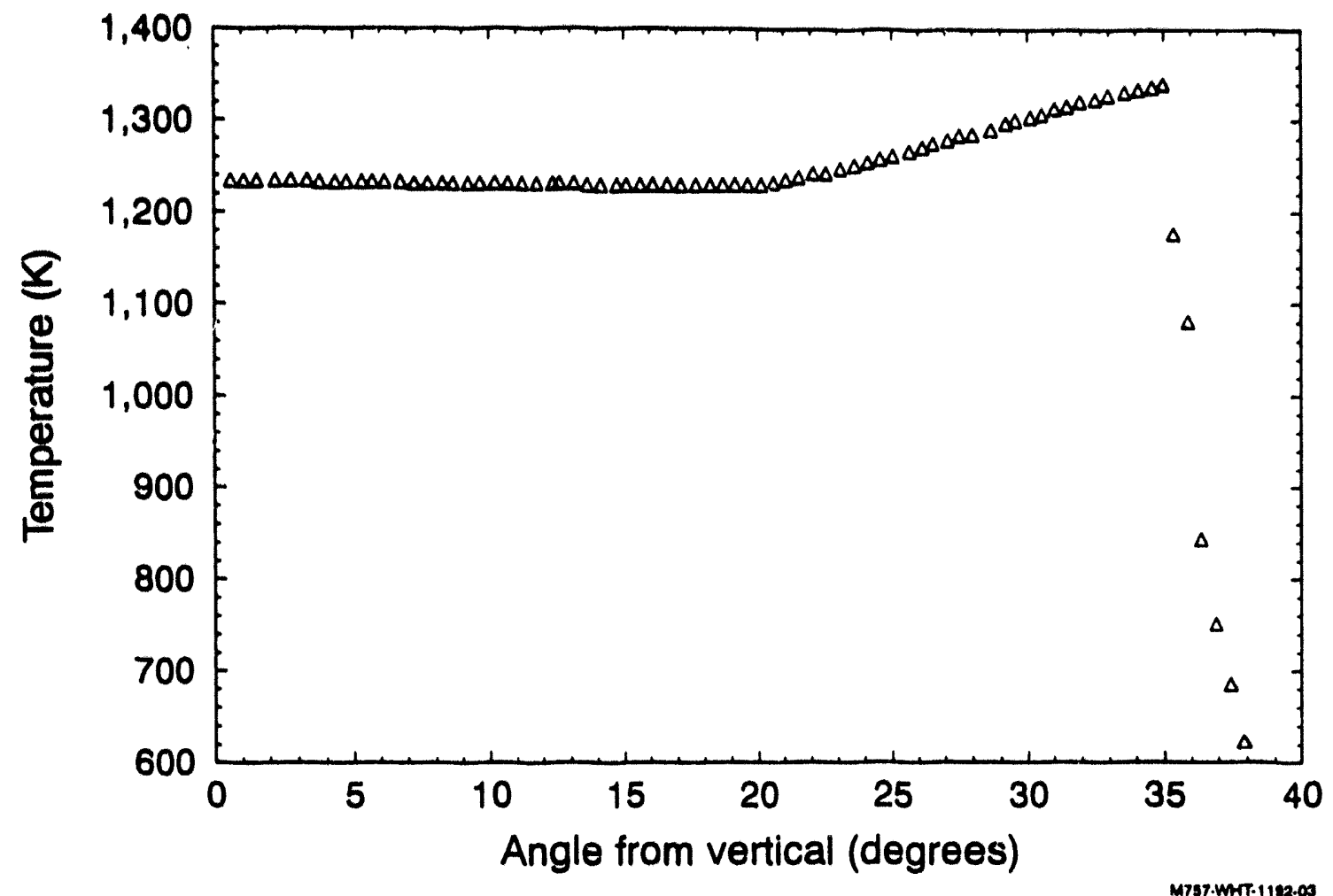

Figure 3-10. Case 2 vessel inner surface temperatures as a function of angle at 21,600 seconds.

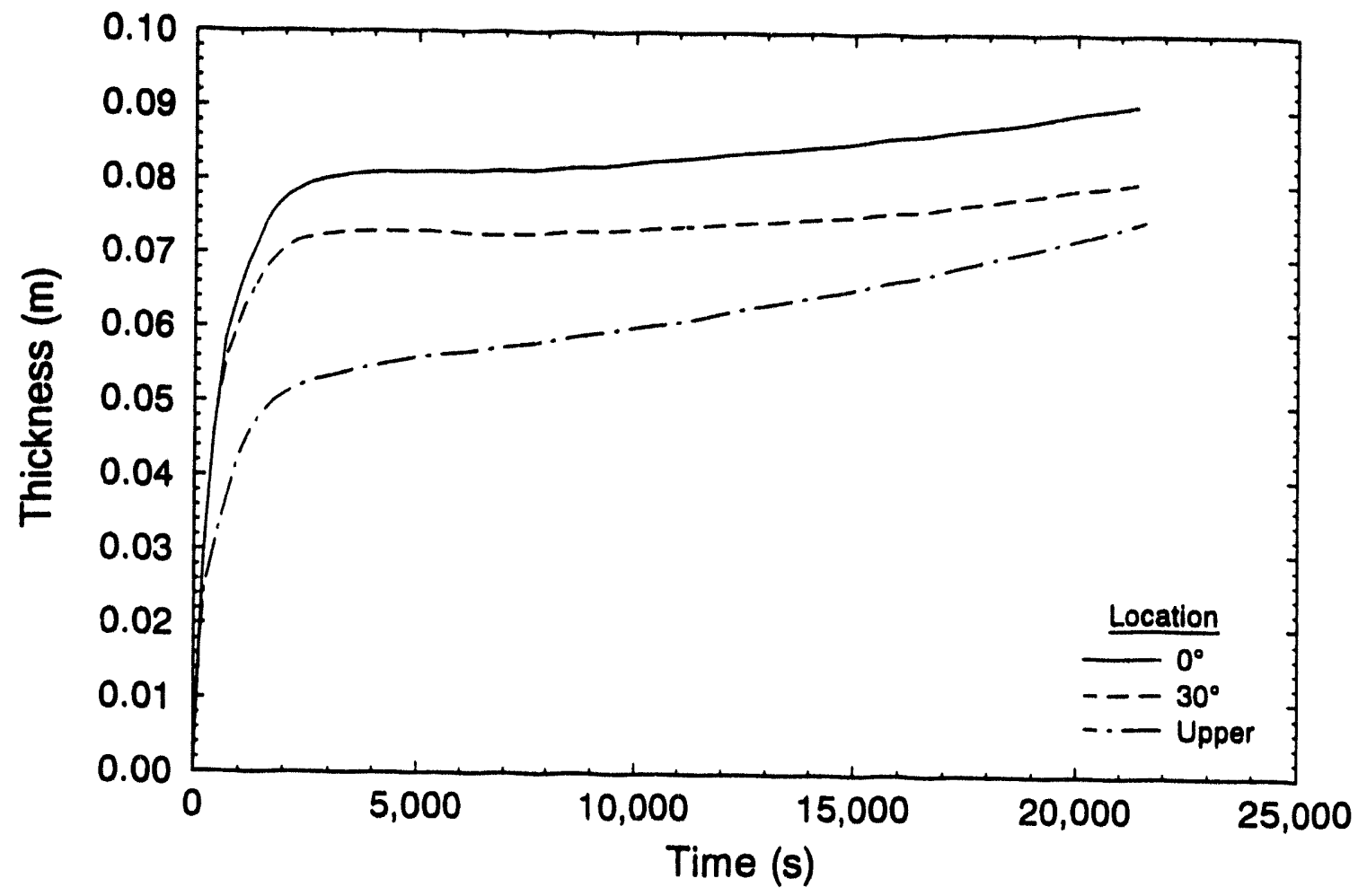

Figure 3-11. Case 2 crust thicknesses. 
thickneas at $\mathbf{0}$ degrees is larger than at $\mathbf{3 0}$ degrees. This is because higher heat transfer rates to the crust are predicted at 30 degrees.

The total heat transferred to the lower head and to the coolant above the debris is plotted in Figure 3-12. The rapid increase in the heat transferred down at the start of the calculation corresponds to the heat transfer that occurs during the jet impingement stage. The heat transfer upward also has a quick rise at the beginning, since the upper crust does not form until the jet pouring has ceased, which occurs one minute into the Case 2 simulation. The abrupt change in heat transfer to the coolant can be seen more easily in Figure 3.13, where the time-dependent heat fluxes up to the coolant and down to the pressure vessel at the centerline are shown. The rapid decay of heat transfer over short times is due to crust formation on the lower head and degraded jet heat transfer due to the formation of the molten pool. If the surface temperature of the crust above the molten pool falls below the minimum film boiling temperature, then the film boiling regime will collapse and nucleate boiling will exist at the surface. In this case, the heat flux would rise as the crust grows to once again balance the heat flow across the interface. This case indicates that the upward heat flux is about $20 \%$ below the downward value. However, this result does change as the initial and boundary conditions are altered.

As noted earlier, results for other cases are summarized in Table 3-4. Results in Table 3-4 are generally for a time of 21,600 seconds, which was a time period past the point where peak temperatures occurred. An exception is Case 6 results, which are for a time of 3,600 seconds. Case 6 results are given at this earlier time because the molten pool freezes at this time and the model is not applicable once the entire pool solidifies. Thus, peak vessel temperatures for Case 6 do not necessarily correspond to the maximum vessel temperature during this transient. This case is only provided to indicate the effects of water ingression and increased upward heat transfer upon the thermal transient. Obviously, the result that the molten debris will solidify within the first hour indicates that increased heat transfer from the debris to the coolant can significantly affect the transient.

The qualitative trends for all the cases are similar; however, the quantitative vessel wall surface peak temperatures differ. The first point to note is that the heating is uniform along the vessel wall, with the only local heating excursion being predicted during the time of jet impingement at the particular location of jet impingement. The model predicts the magnitude of this local hot spot to be on the order of 1,400-1,500 K (see Figure 3-8), and it typically persists for about a minute. This is not in agreement with observations from TMI-2 vessel boat sample material. ${ }^{13}$ Hence, the jet impingement process cannot alone explain the localized hot spot temperatures observed in the boat sample examinations, and Scenario 1 from Section 2 was eliminated from further consideration. A much longer duration and more spatially uniform heating is observed to occur at the vessel wall after several hours ( $-20,000$ seconds). Peak vessel inner surface temperatures for this later heating are predicted to be between $1,020-1,525 \mathrm{~K}$, depending upon the initial and boundary conditions selected.

Boat sample examinations indicate that vessel inner surface temperatures for regions outside the hot spot did not reach temperatures above the ferritic-to-austenitic transition. Hence, temperatures predicted for Case 15 (in which lower bound values for inputs were used) are the only results that are consistent with metallurgic examinations. Recognizing that there is considerable uncertainty in model input parameters and in modeling debris/water interactions, it 


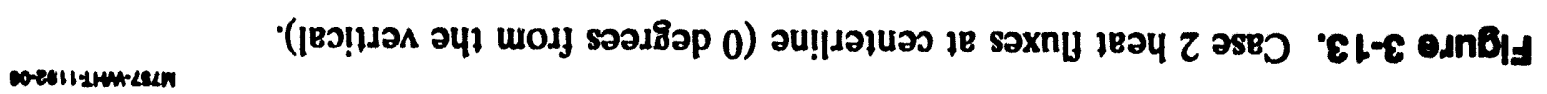

(s) vol!gejo|ed modf ow!I

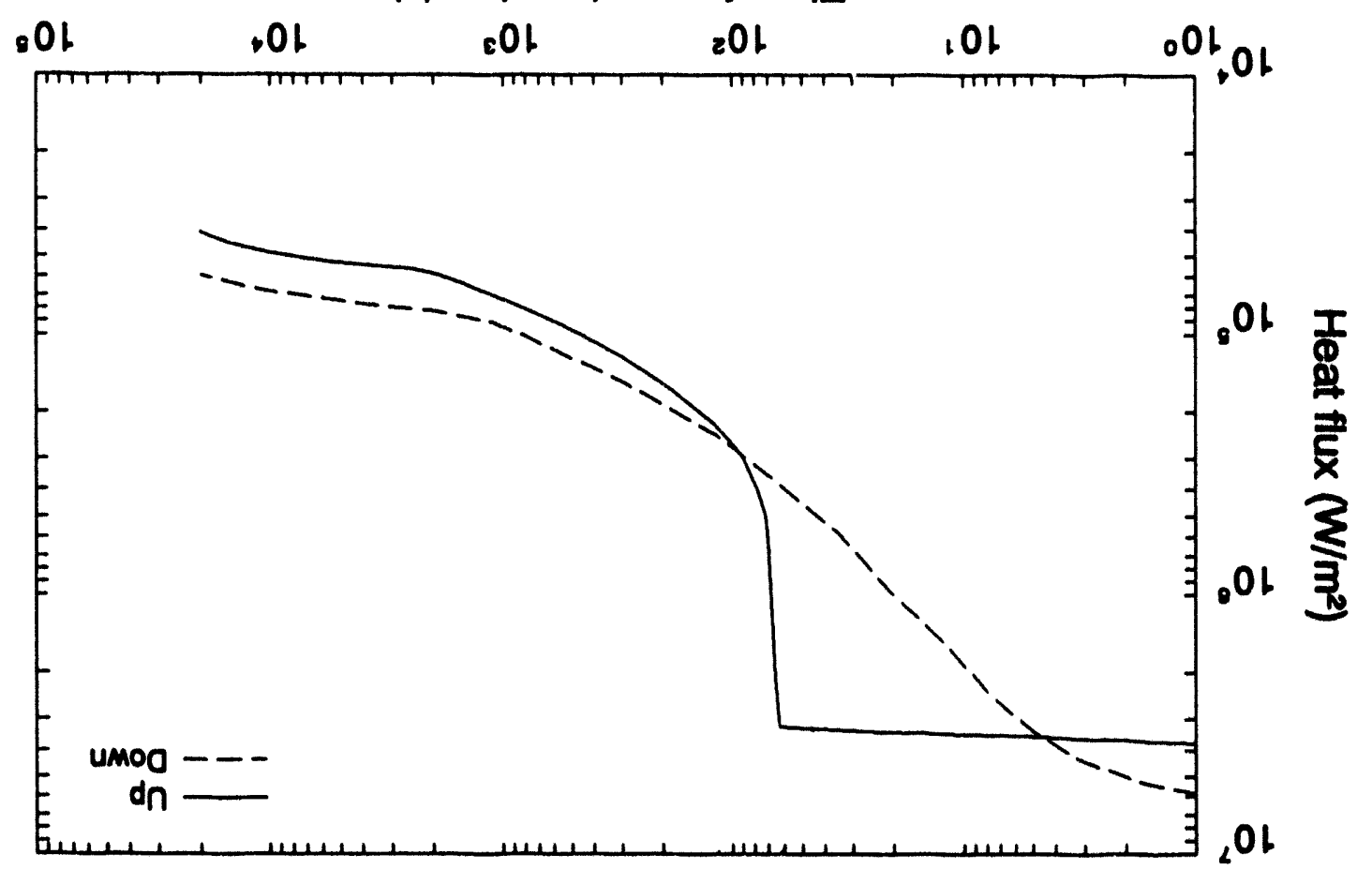

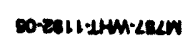

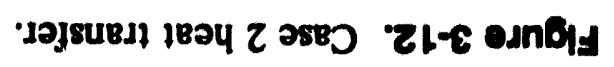

(s) eس! 1

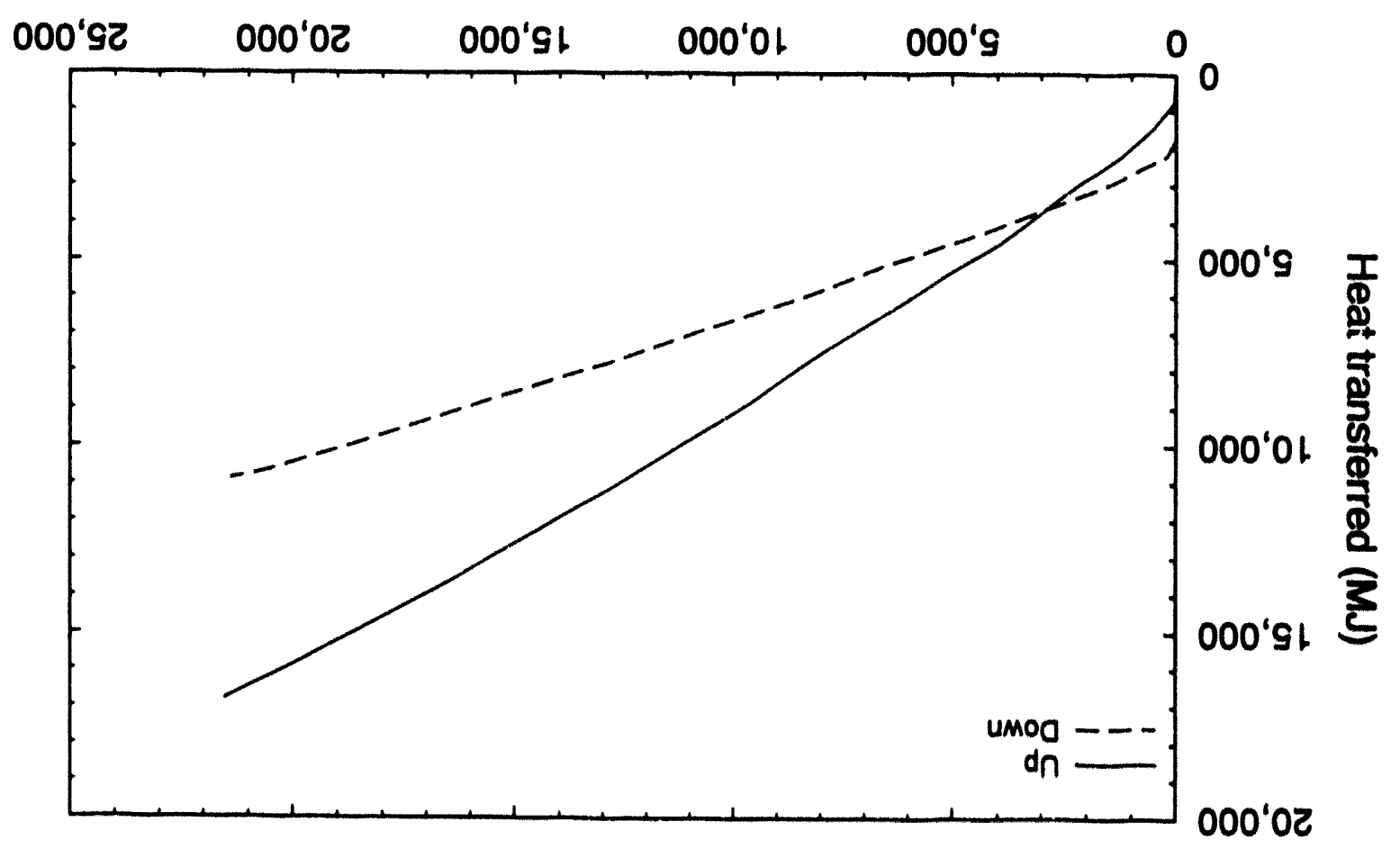


was decided to adopt the following approach for performing calculations to predict global and localized vessel failure:

1. Obtain nominal and lower bound temperature distributions by selecting appropriate values for input parameters.

2. Superimpose a hot spot temperature distribution consistent with results of the vessel steel sample examinations (i.e., a case with heat fluxes close to those used in Case 11, which produces a temperature distribution with peak values between 1,348-1,373 $\mathrm{K}$ for about 30 minutes) on temperature distributions where peak values do not exceed the transition temperature.

Time-dependent temperature distributions for the nominal and lower bound cases, Cases 12 and 15 in Table 3-4, respectively, are plotted in Figures 3-14a and 3-15a. Time-dependent heat fluxes for these cases are plotted in Figures 3-14b and 3-15b. The manner in which these temperature distributions were applied in the global and localized vessel failure calculations is discussed in Sections 4.3.1 and 4.4.1.

\subsubsection{Summary}

Calculations were performed to investigate the potential for the debris jet impinging upon the TMI-2 lower head to cause the hot spot temperatures observed in TMI-2 boat sample examinations. Time-dependent temperature distributions were obtained that can be input to global and localized vessel margin-to-failure calculations.

Calculations provided several useful insights into the TMI-2 accident, which are summarized below.

- Although the quantitative vessel wall surface peak temperature differed, results from several sensitivity studies were qualitatively similar. Namely, the thermal response can be divided into three time periods.

- An initial localized temperature spike for the time and location of jet impingement (typically, on the order of 1 minute)

- A transient vessel heatup (typically, on the order of 1 hour)

- A quasi-steady vessel temperature distribution (typically, lasting for several hours)

Calculations indicate that the vessel temperature gradient is relatively shallow $(150-200 \mathrm{~K})$

- Rapid crust buildup $(5-20 \mathrm{~cm})$ causes the reactor coolant to remove heat from the lower head debris via nucleate boiling. Hence, results were relatively insensitive to coolant subcooling. 


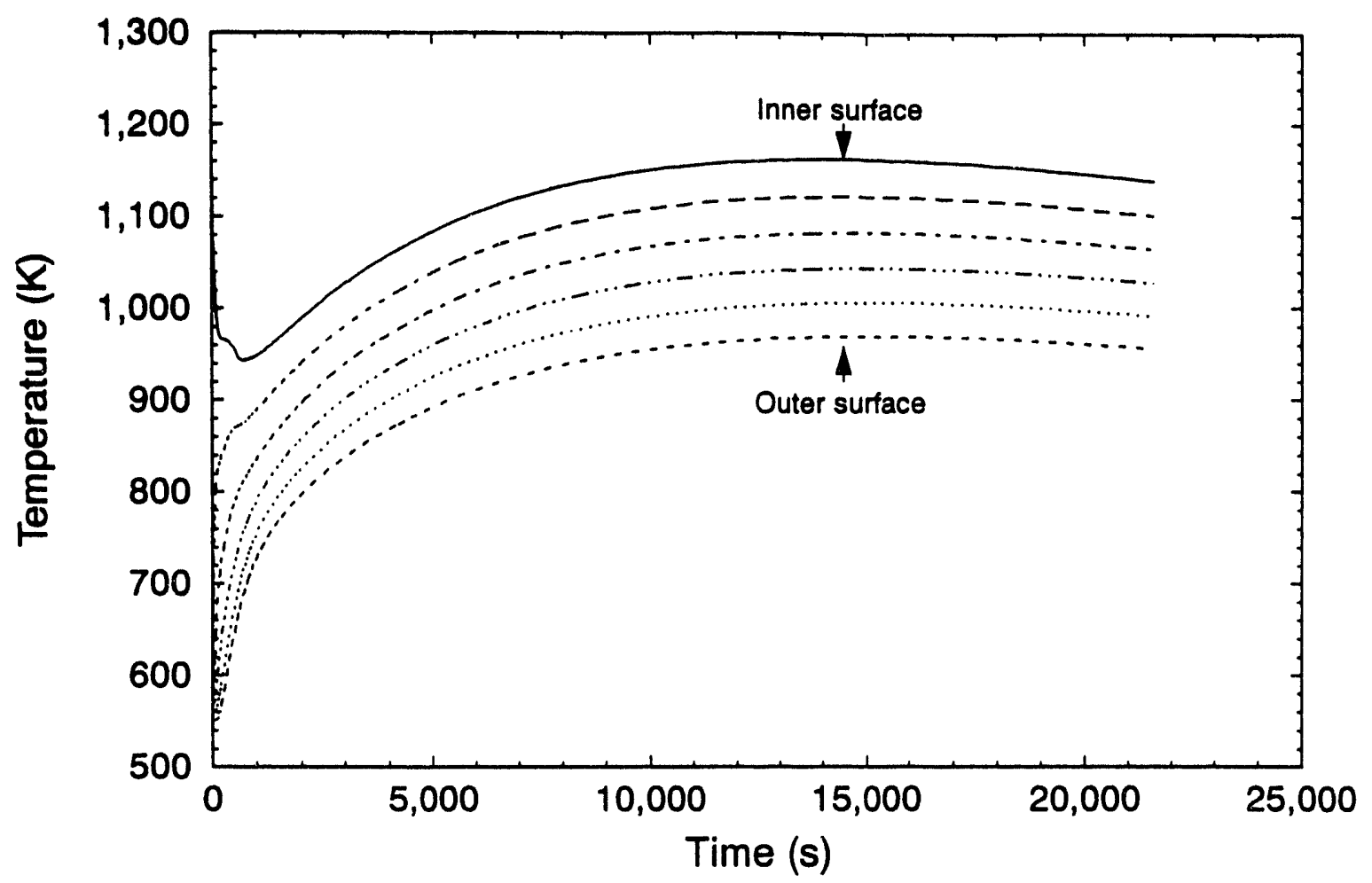

(a) Temperature distribution

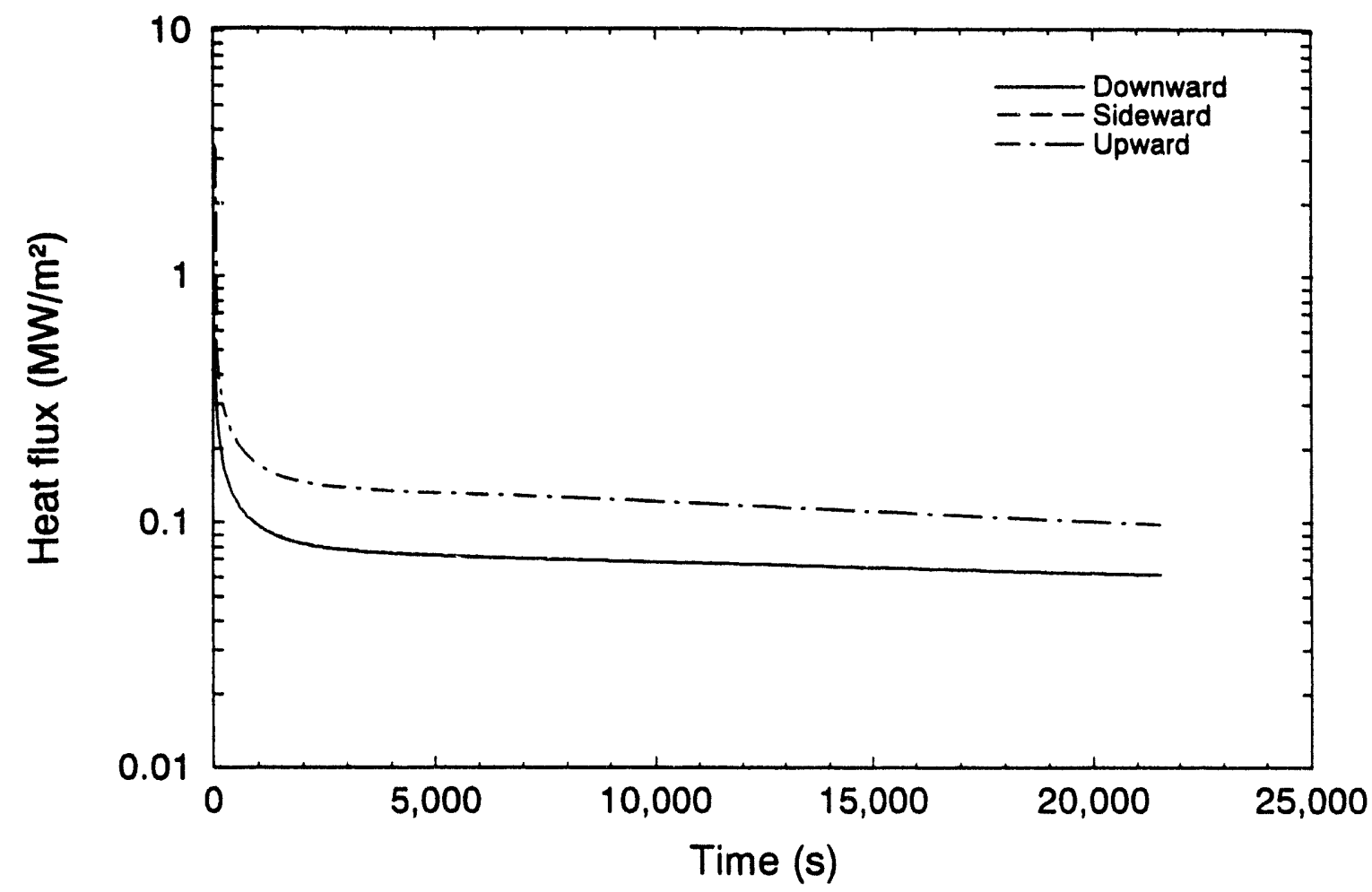

(b) Heat flux distribution

Figure 3-14. Nominal case results. 


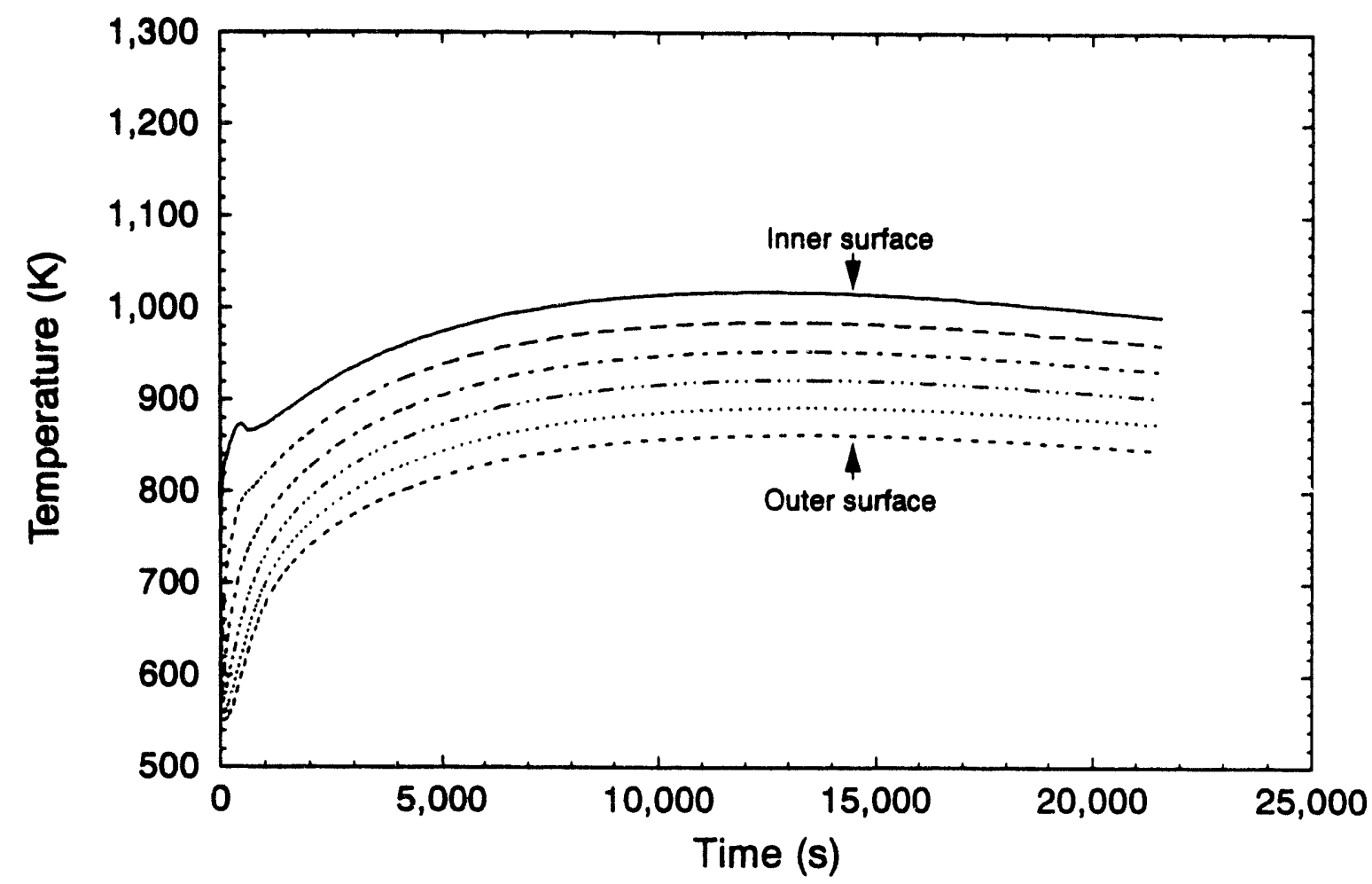

(a) Temperature distribution

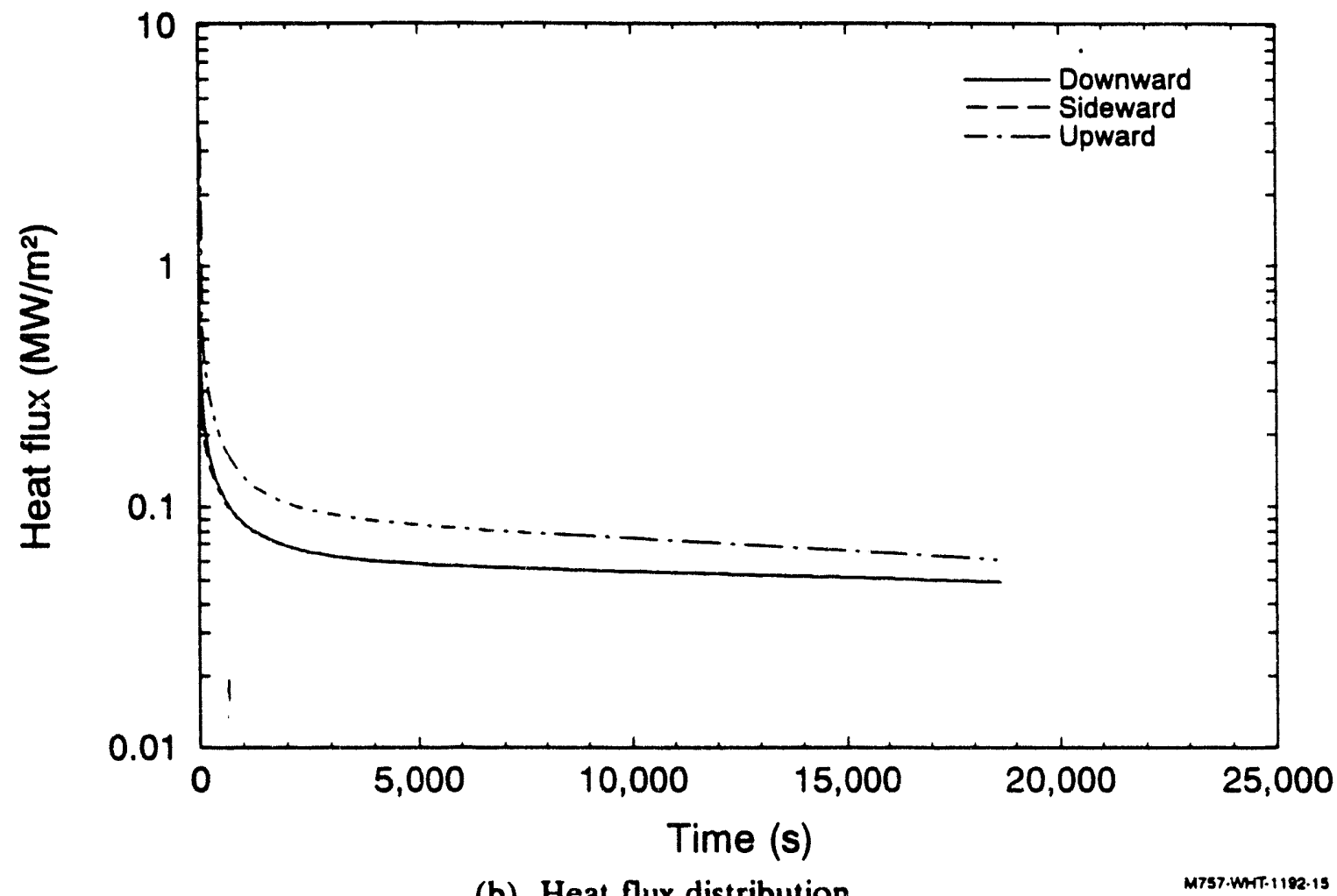

(b) Heat flux distribution

Figure 3-15. Lower bound case results. 
- Only a case with lower bound input assumptions was found to result in global peak temperature predictions that do not exceed the ferritic-to-austenitic steel transition temperature range.

- The magnitude and duration of hot spot temperatures estimated in TMI-2 vessel examinations could not have been caused by an impinging jet. Rather, hot spot temperatures must have occurred later in the scenario from a sustained heat load due to molten debris upon the lower head. Hence, calculation results indicate that the assumption that hot spot temperatures were caused by a coherent jet impinging upon the vessel (assumed in Scenario 1 of Section 2.3) is incorrect.

- The limited area estimated in TMI-2 vessel examinations to have experienced hot spot temperatures suggests that this region was subjected to a localized heat source, such as might occur with a non-homogeneous debris bed or a localized region with enhanced debris-to-vessel contact.

\subsection{Summary for Melt Relocation and Thermal Response Calculations}

Prior to performing failure analyses, scoping calculations were performed to provide boundary conditions for the subsequent tube and vessel failure analyses. Calculations included in this section consider the potential for molten debris to travel through instrumentation nozzles of the TMI-2 pressure vessel, the potential for a jet of molten detris to fragment as it travels through coolant, and the thermal response of the vessel during and after relocation of molten debris. Input to these calculations was based upon data from companion sample debris examinations, nozzle examinations, and other available sources of TMI-2 data, such as plant instrumentation data. Where possible, data from vessel "boat sample" metallurgical examinations, such as peak vessel temperatures, were used as a check on thermal analysis results.

Major insights from these calculations are summarized below:

- Ceramic melt is not predicted to travel through TMI-2 instrument nozzles to locations below th- vessel. Hence, ex-vessel tube temperatures are not predicted to experience higher temperatures than the reactor coolant system temperatures, and tube failure calculations should be performed using RCS temperatures.

- The amount of breakup occurring as melt relocated to the lower plenum is insignificant. Hence, calculation results indicate that the assumption that significant jet breakup occurred during relocation (assumed in Scenario 3 of Section 2.3) is incorrect.

- The magnitude and duration of hot spot temperatures estimated in TMI-2 vessel examinations were not caused by an impinging jet. Rather, hot spot temperatures must have occurred later in the scenario from a sustained heat load from molten debris upon the lower head. The limited area estimated to have experienced hot spot temperatures suggests that this region was subjected to a localized heat source, such as might occur with a nonhomogeneous debris bed or a localized region with enhanced debris-to-vessel 
contact. Hence, calculation results indicate that the assumption that hot spot temperatures were caused by a coherent jet impinging upon the vessel (assumed in Scenario 1 of Section 2.3) is incorrect.

- Only a case with lower bound input assumptions was found to result in global peak temperature predictions that do not contradict the results from boat sample examination data, namely that global vessel temperatures remain below values where the vessel material undergoes a transition from ferritic-to-austenitic steel. It should be noted that the cooling rates observed in metallurgical examinations of vessel specimens in the hot spot region were not predicted in any of the cases analyzed in this section.

\subsection{References}

1. MPR Associates, Inc., Removal of Test Specimens from the TMI-2 Reactor Vessel Bottom Head, MPR-1195, October 1, 1990.

2. D. W. Akers, "INEL Nozzle and Guide Tube Examinations," Eighth OECD TMI-2 VIP Program Review Meeting, Idaho Falls, Idaho, May 12-13, 1992, Presentation OECD-NEATMI-2 VIP TMI V(92)EG05.

3. L. A. Neimark, T. L. Shearer, A. Purohit, and A. G. Hins, TMI-2 Instrument Nozzle Examinations at Argonne National Laboratory, OECD-NEA-TMI-2 VIP TMI V(93)AL01, February 1993

4. R. K. McCardell et al., TMI-2 Reactor Vessel Lower Head Integrity Program Plan, OECDNEA-TMI-2 VIP TMI V(89)21, June 1989.

5. J. L. Rempe, et. al., Light Water Reactor Lower Head Failure Analysis, NUREG/CR-5642, EGG-2618, October 1993.

6. R. W. Ostensen and J. F. Jackson, Extended Fuel Motion Study, ANL-RDP-18, July 1973, pp. 7.4-7.7.

7. R. W. Ostensen et al., "Fuel Flow and Freezing in the Upper Subassembly Structure Following an LMFBR Disassembly," Transactions of the American Nuclear Society, 18, 1974, p. 214.

8. M. Epstein et al., "Transient Freezing of Flowing Ceramic Fuel in a Steel Channel," Nuclear Science and Engineering, 61, 1976, pp. 310-323.

9. M. Epstein, "Heat Conduction in the $\mathrm{UO}_{2}$-Cladding Composite Body with Simultaneous Solidification and Melting," Nuclear Science and Engineering, 51, 1973, pp. 84-87.

10. D. W. Akers, S. M. Jensen, B. K. Schuetz, Companion Sample Examinations, OECD-NEATMI-2 VIP, TMI V(92)EG10, July 1992. 
11. E. L. Tolman et al., TMI-2 Accident Scenario Update, EGG-TMI-7489, December 1986.

12. P. Kuan and E. L. Tolman, Electromatic Relief Valve Flow and Primary System Hydrogen Storage during the TMI-2 Accident, EGG-TMI-7703, May 1987.

13. G. E. Korth, Metallographic and Hardness Examinations of TMI-2 Lower Pressure Vessel Head Samples, OECD-NEA-TMI-2 VIP TMI V(92)EG01, January 1992.

14. C. C. Chu, M. L. Corradini, "A Transient Model for Fuel-Coolant Interactions," Proceedings of the Thermal Reactor Safety Meeting, San Diego, California, February 2-6, 1986, Vol 1, pp. II.2-1 through II.2-10.

15. C. C. Chu, One-Dimensional Transient Fluid Model for Fuel-Coolant Interaction Analysis, Ph.D dissertation, University of Wisconsin-Madison, Madison, WI, May 1986.

16. C. C. Chu, M. L. Corradini, "One-Dimensional Fuel-Coolant Interaction," Journal of Nuclear Science and Engineering, 101, No. 1, January 1989, p. 48-71.

17. C. C. Chu, M. L. Corradini, J. Murphy, J. Tang, A Code Manual for TEXAS-II: One Dimensional Transient Fluid Model for Fuel-Coolant Interaction Analysis, University of Wisconsin Report, UWRSR-39, July 1992.

18. M. Epstein, et al., "Simultaneous Melting and Freezing in the Impingement Region of a Liquid Jet," AICHE Journal, 26, September 1980, p. 743.

19. Sandia National Laboratory, Core-Meltdown Experimental Review, SAND74-0382, August 1975.

20. D. R. Olander, Fundamental Aspects of Nuclear Reactor Fuel Elements, University of California-Berkeley, TID-26711-P1, published by the Energy Research and Development Administration, November 1977.

21. M. Epstein, H. K. Fauske, "Steam Film Instability and the Mixing of Core Melt Jets and Water," Proceedings of the 1985 ANS/ASME/AIChE National Heat Transfer Conference, Denver, Colorado, August 1985.

22. J. A. Kos, Model of Fuel-Melt Quenching in the Lower Plenum of the RPV, Masters of Science thesis, University of Wisconsin, Madison, WI, August 1992.

23. M. Jahn, H. H. Reineke, "Free Convection Heat Transfer with Internal Heat Sources Calculations and Measurements", Proceedings of the Fifth International Heat Transfer Conference, Tokyo, Japan, 3, 1974, p. 74.

24. J. Garnier, Ex-Reactor Determination of Thermal and Contact Conductance, NUREG/CR-0330, April 1979. 
25. Kelsey, A. P., Lower Head Debris Topography, TMI-2 Technical Bulletin TB-89-02, Rev. 0., GPU Nucleai Corporation, Project Planning and Analysis Department, Middletown, PA, February 27, 1989.

26. M. T. Farme al., "CORQUENCH: A Model for Gas Sparging-Enhanced, Melt-Water, Film Boiling Heat Transfer," Presented at the ANS Winter Meeting, CONF-901101--31, Washington, D.C., November 11-15, 1990. 


\section{SCOPING CALCULATIONS FOR STRUCTURAL RESPONSE AND MARGIN-TO-FAILURE ESTIMATES}

As discussed in Section 1, margin-to-failure calculations were performed to evaluate the potential for the TMI-2 vessel to fail via mechanisms such as tube ejection (which must be preceded by weld failure), tube rupture, global vessel failure, and localized vessel failure.

Figure 1-1 illustrates how calculations within this section are coordinated. Thermal analyses, documented in Section 3, provide input for these calculations. For each failure mechanism considered, estimates are provided for a margin to failure to provide insight into which mechanisms had smaller failure margins during the TMI-2 accident.

\subsection{Margin-to-Fallure Background}

Margin to failure, as defined by exceeding ultimate strength or by creep failure, is evaluated for each failure mechanism. The ultimate-strength margin to failure is straight forward, calculated as a function of the ratio of the maximum effective stress to the ultimate strength. Creep margin to failure is more ambiguous to define. Unlike ultimate strength, creep failure is time dependent. Given enough time at high temperatures with some stress, a creep failure will be predicted even when the ultimate-strength-based margin to failure is significant.

As a basis of comparison between failure mechanisms, a margin to failure for creep failure using a stress-based damage failure criterion was defined by the consensus of the Structural Mechanics Peer Review Group. ${ }^{1}$ The procedure includes converting the multi-dimensional stress state to an effective stress, interpolating the time to failure for constant temperature and stress using the Larson-Miller parameter (LMP), and predicting time to failure for the actual stress and temperature history using a time damage model. The entire procedure has not been verified experimentally for cases such as the TMI-2 vessel, where temperature and pressure are changing and a temperature gradient exists through the thickness. However, the individual steps (calculation of effective stress, interpolation of time to failure with the LMP and use of the time damage model) have been verified experimentally. ${ }^{2-6}$ Additionally, this procedure has been used in previous creep analysis of a case with a geometry very similar to the TMI-2 vessel and penetrations: thick-wall furnace tubes, under internal pressure with a temperature gradient through the thickness. ${ }^{7}$

Currently, there is not a single method or procedure that is universally accepted for defining margin to failure. Using a stress-based criterion, other methods are available for each of the steps outlined above. For example, past discussions have centered on the use of Mises effective or maximum tensile stress. The proper stress depends on whether crack initiation or propagation dominates the creep behavior. ${ }^{8}$ Other parameters can be used to interpolate time to failure for constant stress and temperature. Finally, several damage models have been proposed in lieu of the stress-based time damage model.

Some of the damage models proposed in the published literature include a strain damage model, ${ }^{9}$ combined strain and time damage models, ${ }^{10,11}$ and a combined strain and temperature damage model. ${ }^{12}$ Experimental studies comparing time damage and strain damage models for 
high-alloy steels have shown that in some cases the time damage models are more conservative; in other cases, the strain damage model is more conservative; and in many cases, s combined criterion appears to give the best results. ${ }^{10,11}$ It is difficult to assess the applicability of the time and temperature damage model to SA533B, since it was developed for zircaloy, which is not a ferrous material.

No single creep failure criterion, which likely is material dependent, has been proven to be superior. It is beyond the scope of this project to determine which failure criterion is best for SA533B under accident conditions. Given the limited data for SA533B at very high temperatures and the scatter in creep data, a simple procedure that has been used in prior published analyses was initially recommended by the Structural Mechanics Peer Review Group for the margin-tofailure calculations. However, results from initial calculations using this stress-based damage failure criterion predicted failure at times when strains were quite small (less than $10 \%$ ). Members of the Structural Mechanics Peer Review Group noted that these results suggest that the stress-based damage failure criterion used in initial calculations was too conservative. Hence, a second set of calculations (reported in Section 5.2) were performed in which failure was defined as the point where mechanical instability occurs rather than invoking a stress-based damage failure criterion.

\subsection{Scoping Analysis for TMI Penetration Tube Weld Fallure}

A penetration ejection model was developed in the NRC-sponsored lower head program ${ }^{13}$ to predict penetration ejection, assuming that the penetration weld failed. Prior to using the tube ejection model, it is necessary to establish that weld failure occurs. Metallurgical evidence from the VIP examinations indicates that the Inconel penetration welds did not melt. Stainless steel cladding, which has approximately the same melt temperature as Inconel, showed no signs of melt, even inside the hot spot. ${ }^{14}$ Actual examination of a penetration weld slightly outside the hot spot revealed no melting of the weld (including the buildup above the vessel surface). ${ }^{15}$ From this evidence, it was concluded that penetration welds did not melt.

This analysis examines the mechanical behavior of the weld for penetrations inside the hot spot, subject to the maximum predicted temperatures and maximum recorded pressures during the accident. Its purpose is to evaluate the possibility of weld failure by exceeding ultimate strength or by creep. If weld integrity is assured, further penetration ejection analysis is not needed (weld integrity precludes ejection).

\subsubsection{Model Description}

This analysis used a mechanics of materials approach, comparing weld stresses to ultimate strength data and weld creep rupture strength data. Applied stresses, from system pressure and tube dead weight, were assumed to be carried by the weld in pure shear. A margin to failure, based on ultimate capacity, was calculated. The time to fail by creep, at the accident temperatures and the assumed pressure, was calculated using the LMP. 


\subsubsection{Input Assumptions}

Input assumptions for the best-estimate analysis are described below. Uncertainties in the assumptions are provided in the next section.

\section{Geometry}

It was assumed that the critical region for penetration weld failure was in the hot spot of the vessel, located approximately $0.5 \mathrm{~m}$ from the centerline of the vessel. Schematics of a centerline instrument tube and penetration weld are shown in Figures 4-1 and 4-2. ${ }^{16,17}$ Although Figure 4-1 shows the tube intersecting the vessel at 90 degrees, tubes in the hot spot intersect the vessel obliquely because the hot spot is not located at the bottom of the vessel. This did not affect the analysis, due to conservative assumptions in the weld shear area described below. The length of the instrument tube, $5.47 \mathrm{~m}$, from the vessel to the first unistrut support was used to calculate the dead weight of the tube, as shown in Figures 4-2 and 4-3. The unistrut support is located, as shown, at the horizontal end of the pipe bend. ${ }^{a}$

The weld shear area was taken as the area of intersection between the tube and the weld. As a conservative measure, the weld area associated with the weld buildup above the cladding was ignored.

\section{Material Properties}

An INCO82T weld joins the Inconel-600 tube and the SA533B vessel material. High temperature Inconel-600 tensile and creep properties ${ }^{13}$ were used for this analysis, because high temperature INCO82T properties were not available. In general, this will produce conservative results, since weld materials have higher strength properties than their base material counterparts. Inconel-600 ultimate strength as a function of temperature and the LMP fit for creep data are included in Appendix A.

\section{Loads and Temperatures}

This analysis assumed that the pressure load and instrument tube dead weight were carried in pure shear, solely by the penetration weld, as shown in Figure 4-3. The maximum recorded system pressure for over 10 hours after relocation (see Figure 2-2), $15 \mathrm{MPa}$, was used. The dead weight was calculated from the length of tubing from the lower head to the first unistrut support. The unistrut support was not allowed to bear any of the load. The peak weld temperature was assumed to be $1,361 \mathrm{~K}$ for 0.5 hours. This is the mid-point for the peak temperature range $(1,348-1,373 \mathrm{~K})$ estimated from metallurgical examination. ${ }^{14}$

\subsubsection{Uncertainties}

Primary sources of uncertainty in this analysis were the peak temperature estimates from TMI-2 boat sample examinations ${ }^{14}$ and the creep data fit to the LMP. The range for temperature

a. Personal communication with Babcock and Wilcox personnel, Lynchberg, Virginia, September, 1992. 


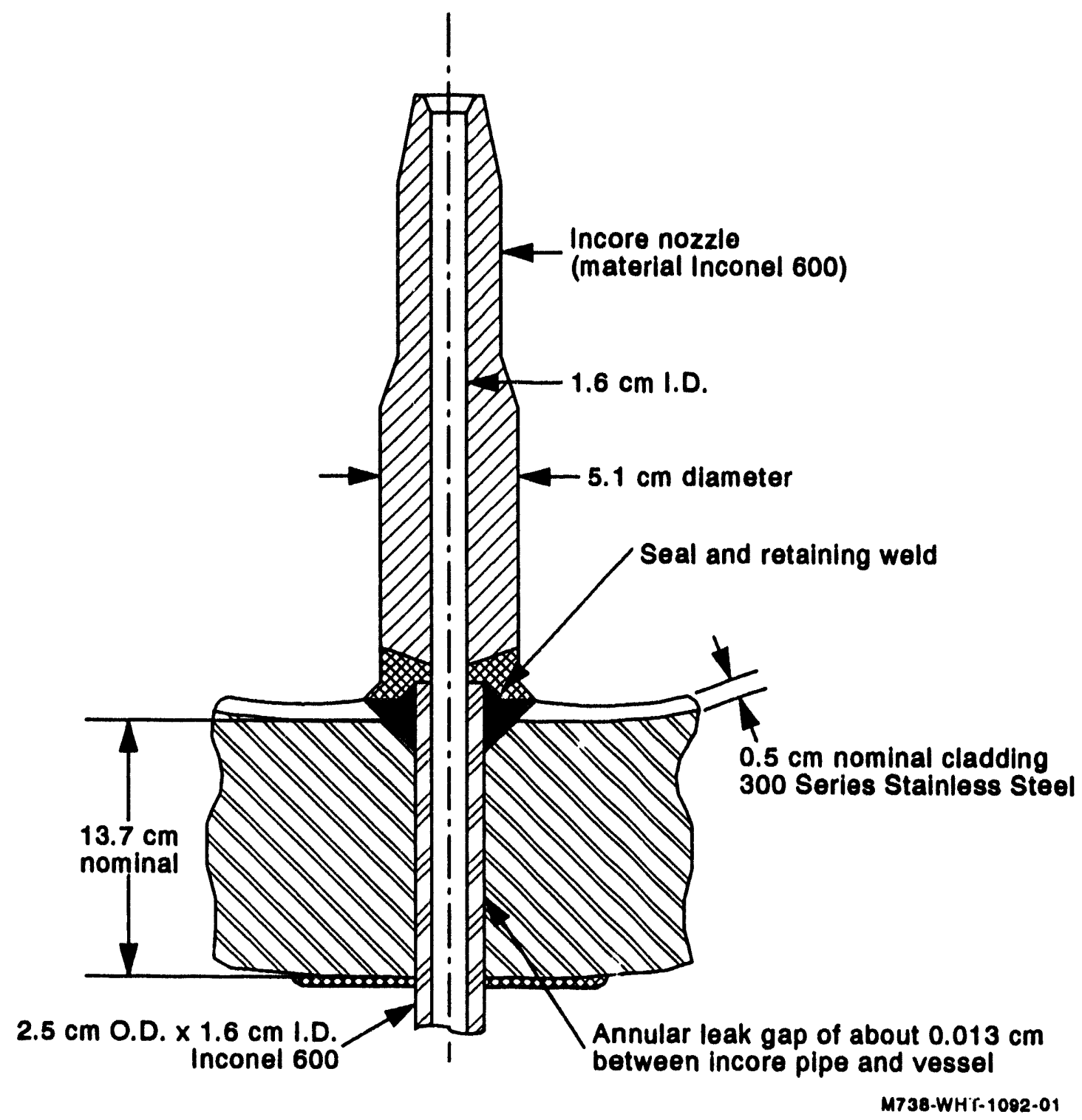

Flgure 4-1. Schematic of instrument tube penetration. 


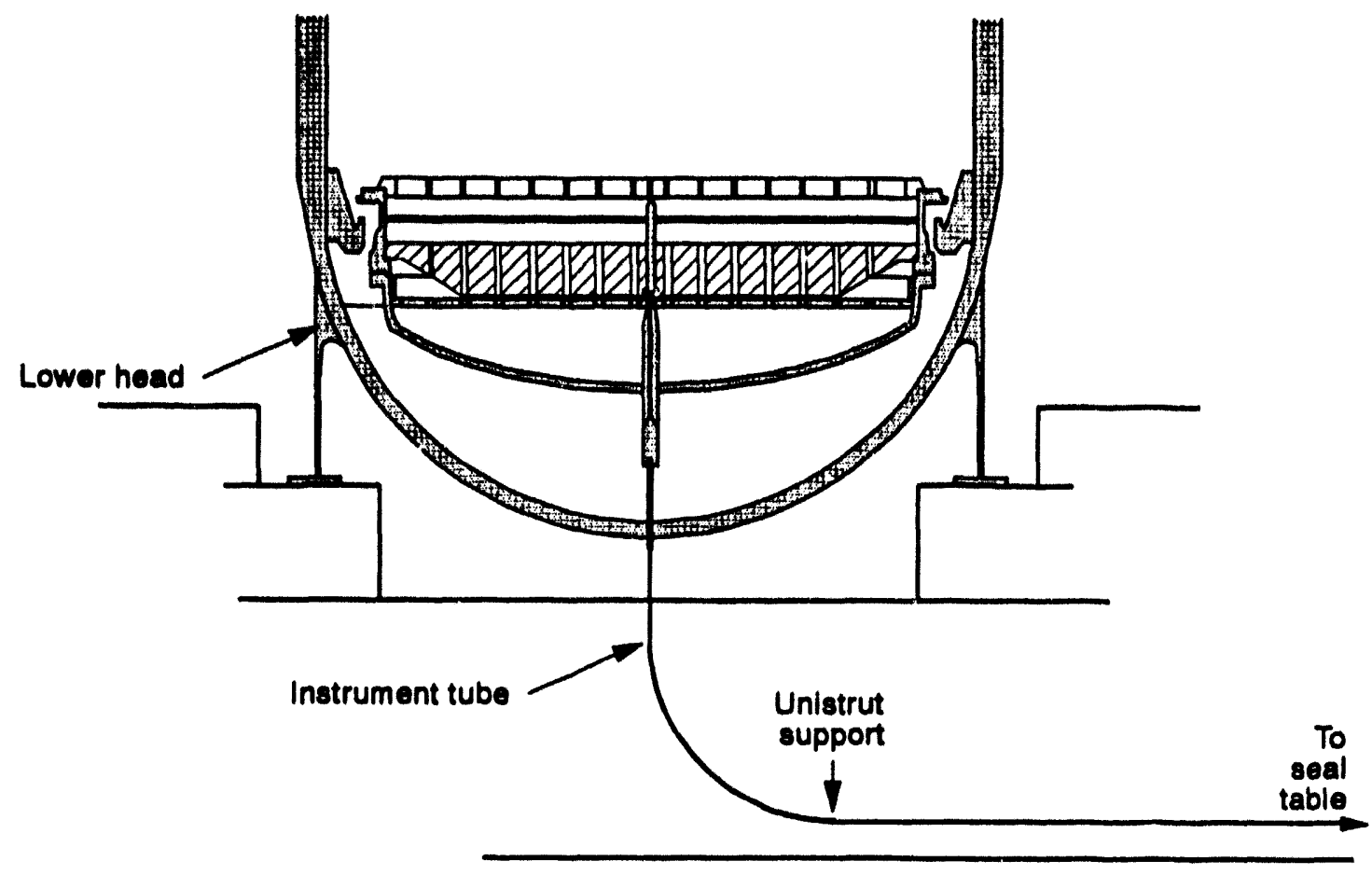

M7sc $000 \cdot 1002 \cdot 946$

Figure 4-2. Schematic of instrument tube and vessel showing location of unistrut support.

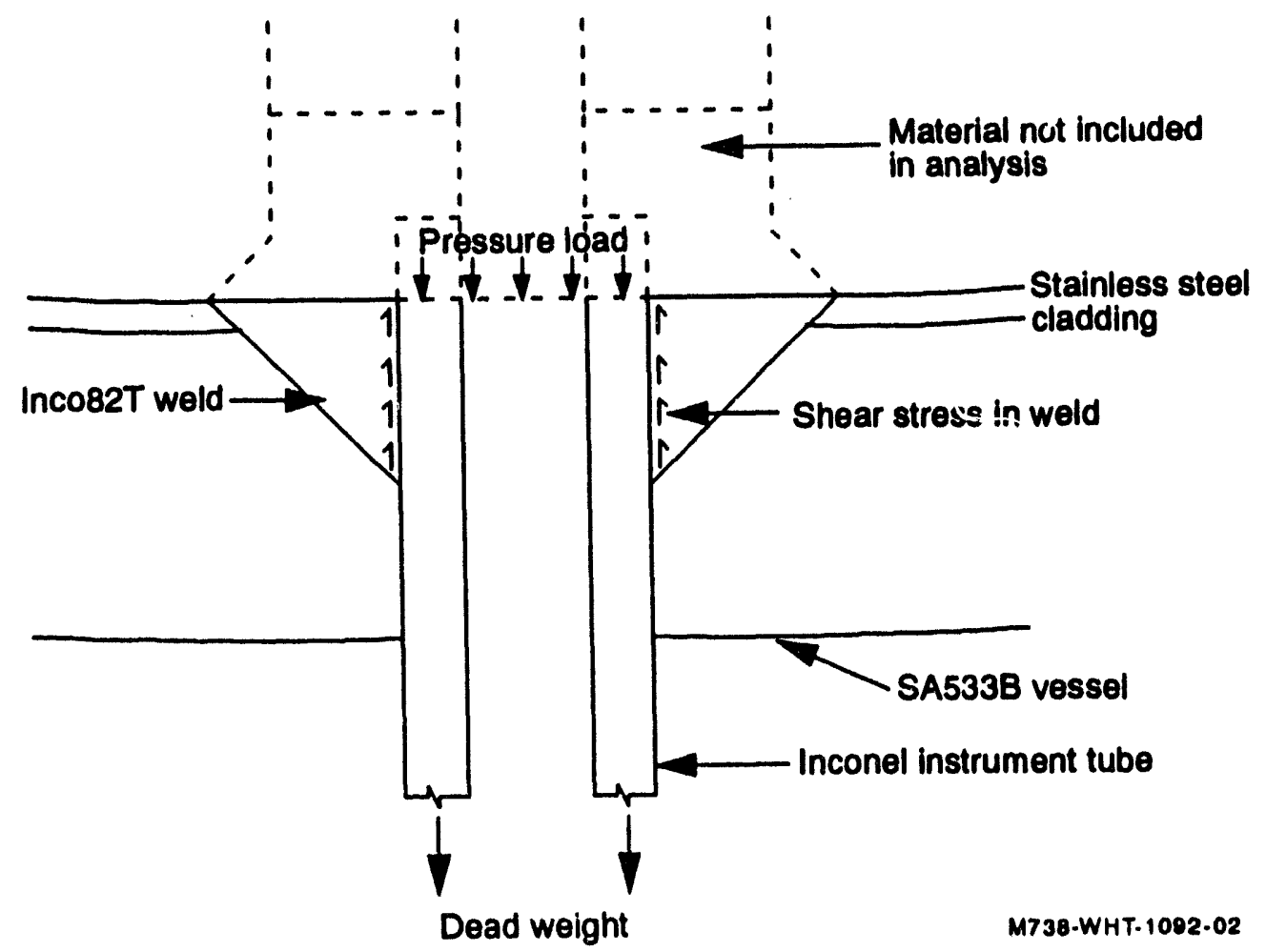

Figure 4-3. Schematic of instrument tube penetration showing applied loads, shear stress and weld buildup material. 
uncertainties $(1,348-1,373 \mathrm{~K})$ was taken from metallurgical studies. ${ }^{14}$ Upper and lower bounds for the LMP data were statistically fit ${ }^{18}$ to $95 \%$ confidence limits, as shown in Appendix A, Figure A-33. The minimum ablation height was also uncertain; therefore, the most reasonable, conservative estimate was used.

The upper limit of the margin to failure and creep failure time were calculated using the lower peak temperature, $1,348 \mathrm{~K}$, and the upper limit of the LMP fit to stress. For the lower limit of margin to failure and creep failure time, the upper peak temperature, $1,373 \mathrm{~K}$, and lower limit of the LMP were used. Upper and lower limit fits for the LMP are listed in Appendix D. Calculations are similar to the best-estimate calculations shown in Appendix D.

\subsubsection{Reoulte}

Results from calculations, detailed in Appendix D, indicate that the dead load is less than $2 \%$ of the total load. The effective stress due to applied loads, $12.32 \mathrm{MPa}$, is low relative to the ultimate strength, $30.78 \mathrm{MPa}$, for Inconel-600 at 1,361 $\mathrm{K}$. The Mises effective stress was used because it was found to be more conservative than the Huddleston effective stress ${ }^{2}$ with a pure shear stress state. Ultimate-strength margin to failure was defined for this analysis as

Margin to Failure $=(1-$ effective stress/ultimate strength $) 100 \%$.

This makes the best-estimate, ultimate-strength margin to failure equal to $60 \%$ (see Table 4-1).

If the peak temperature $(1,361 \mathrm{~K})$ and maximum system pressure $(15 \mathrm{MPa})$ were held constant, the time to rupture is 7.2 hours (see Table 4-2). Estimated time at peak temperature was 0.5 hours. Naturally, the material spent time at some elevated temperature after peaking, but the fact that the weld could carry the most severe conditions for 6.7 hours longer than they were actually imposed assures that the TMI-2 accident would not have caused weld failure.

Table 4-1. Ultimate strength margin to failure for instrument tube weld failure.

\begin{tabular}{lll}
\hline & Upper limit $(1,348 \mathrm{~K})$ & $65 \%$ \\
& Best estimate $(1,361 \mathrm{~K})$ & $60 \%$ \\
& Lower limit $(1,373 \mathrm{~K})$ & $54 \%$ \\
\hline
\end{tabular}

Table 4-2. Time to creep failure for instrument tube weld failure.

Upper limit $(1,348 \mathrm{~K}$, upper LMP)

Best estimate (1,361 K, best LMP)

Lower limit $(1,373 \mathrm{~K}$, lower LMP)
$16.9 \mathrm{~h}$

$7.2 \mathrm{~h}$

$4.2 \mathrm{~h}$ 


\subsubsection{Dbcusalon}

This analysis showed that the ultimate-strength margin to failure for the penetration weld during the TMI-2 accident was at least $54 \%$. If the peak temperature and a $15 \mathrm{MPa}$ system pressure were both maintained constant, the minimum time to creep failure was 4.2 hours. These results, convincing in the large, ultimate-strength margin to failure and the long estimated time to creep failure, are conservative for the following reasons:

- The weld buildup material was ignored, reducing the load bearing weld area (shear area).

- The minimum weld depth into the vessel was used to calculate load bearing weld area (shear area).

- The analysis assumed a pressure of $15 \mathrm{MPa}$. The maximum temperature may have occurred with a lower pressure.

- Calculations for the time to creep failure held the peak temperature constant, when in fact, the peak temperature was estimated for only 0.5 hours.

- The load was carried solely by the weld. None of the load was distributed to the unistrut support.

Ultimate strength failure was not predicted because the applied stress on the weld was very low. Although the assumed temperature for the weld was relativeily high $(1,348-1,373 \mathrm{~K})$, the low applied stress (12.32 $\mathrm{MPa}, 1.786 \mathrm{ksi})$ presented little challenge to the ultimate strength of the weld, as indicated by the $60 \%$ best estimate for margin to failure. Again, because stresses were low, best-estimate creep failure was not predicted before 7.2 hours. Since penetration weld integrity during the TMI-2 accident was assured, penetration ejection was ruled out as a possible failure mode.

\subsection{Ex-Vessel Instrument Tube Fallure}

Another possible failure mode of the primary system containment associated with the instrument tube was that of the tube bursting under accident conditions in a location outside the vessel lower head. This failure would reduce the pressure in the tube, increase the pressure differential across any melt entering the tube from the debris bed above, and allow additional melt penetration through the vessel wall and out of the primary pressure containment. An approach based on force equilibrium, similar to that of the instrument weld inargin to failure was used to evaluate tube failure. Margins to failure based on creep time to failure and ultimate strength were calculated.

\subsubsection{Calculations}

As discussed in Section 3, the melt penetration analysis of the instrument tube indicated that melt would not penetrate beyond the vessel thickness. Hence, the temperature conditions for this analysis were limited to those of the reactor coolant system during the accident (see Figure 1-1). 
An upper bound on the coolant temperature $(600 \mathrm{~K})$ was taken to be the saturation temperature corresponding to the peak system pressure during the first 12 hours after relocation. The lowerbound temperature $(400 \mathrm{~K})$ was based on the minimum value measured in the cold leg during the transient. Since these conditions were expected to result in high margins to failure, a constant upper-bound system pressure of $15 \mathrm{MPa}$ was assumed for the loading. This simplified the analysis and produced a conservative result.

The TMI-2 penetration tube is made of Inconel-600 material. Plots of ultimate strength as a function of temperature and the LMP fit for the creep test data for this material are included in Appendix A, Figures A-28 and A-33.

As Figure 4-4 indicates, the operating system pressure is the primary load on the instrument tube. Because the instrument tube configuration below the lower head (see Figure 4-2) makes a large bend and is subsequently routed horizontally, the ex-vessel pressure load results in an axial stress component, as well as a hoop stress component, in the wall of the tube. Huddleston's criteria $^{2}$ for multi-axial conditions was applied to calculate the effective stress (Appendix A-2.3.1).

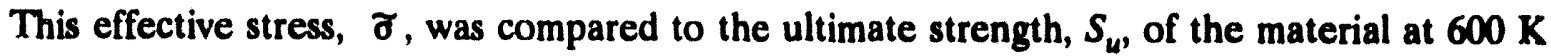
and $400 \mathrm{~K}$ to determine an ulimate-strength margin to failure as shown in

$M F=\left(1-\frac{\tau}{S_{u}}\right) 100 \%$

The creep time to failure was calculated using the applied stress resulting from a constant $15 \mathrm{MPa}$ system pressure, the bounding temperatures, and the Larson-Miller curve for Inconel-600.

\subsubsection{Results}

Results of these calculations indicate that the ultimate strength margin to failure is $96.0 \%$ at a temperature of $400 \mathrm{~K}$ and $95.8 \%$ at $600 \mathrm{~K}$. The small variation in margin to failure is a result of the minor variation in the ultimate strength for Inconel-600 in this temperature range. Times to creep rupture at these temperatures are of the order of $10^{13}$ and $10^{29}$ hours. Hence, both measures of margin to failure calculated here are very high.

\subsection{Global Vessel Rupture}

A calculation of margin to failure for global vessel rupture requires that the lower head be considered for a structural collapse mechanism under the primary loading of the vessel's internal pressure. Thermal stresses complicate the analysis by causing stress redistribution, some plastic resporise, and, at higher temperatures and stresses, creep relaxation, resulting in further stress redistribution. These stresses tend not to cause ultimate collapse of a structure unless the primary load-carrying capacity is affected by the thermal plasticity and creep damage. 


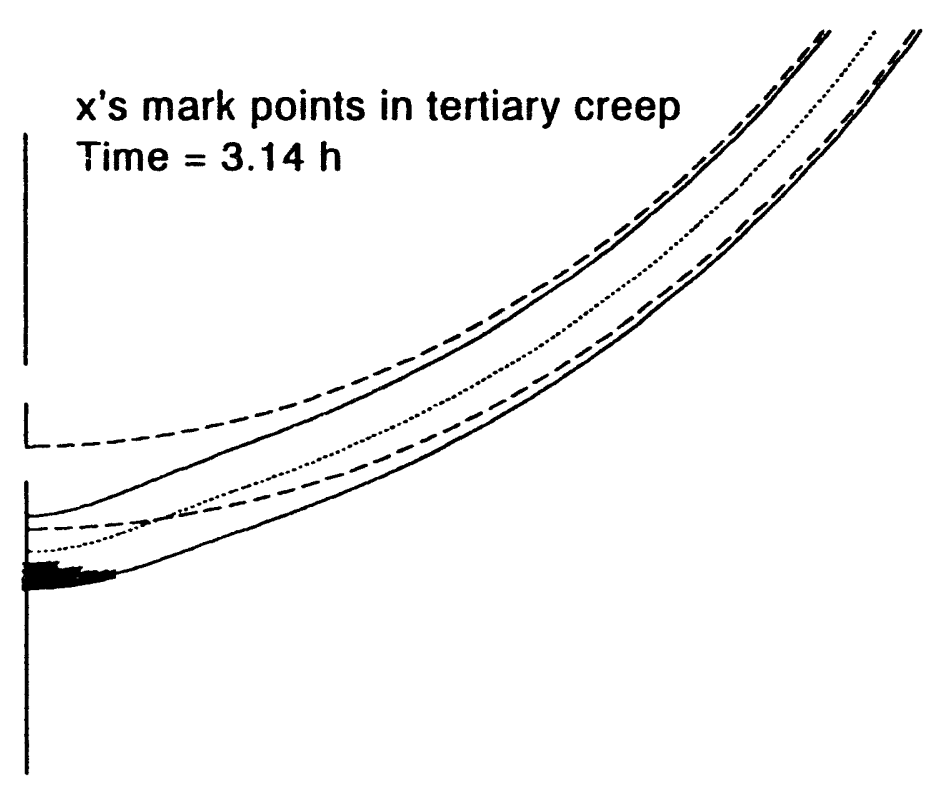

ur

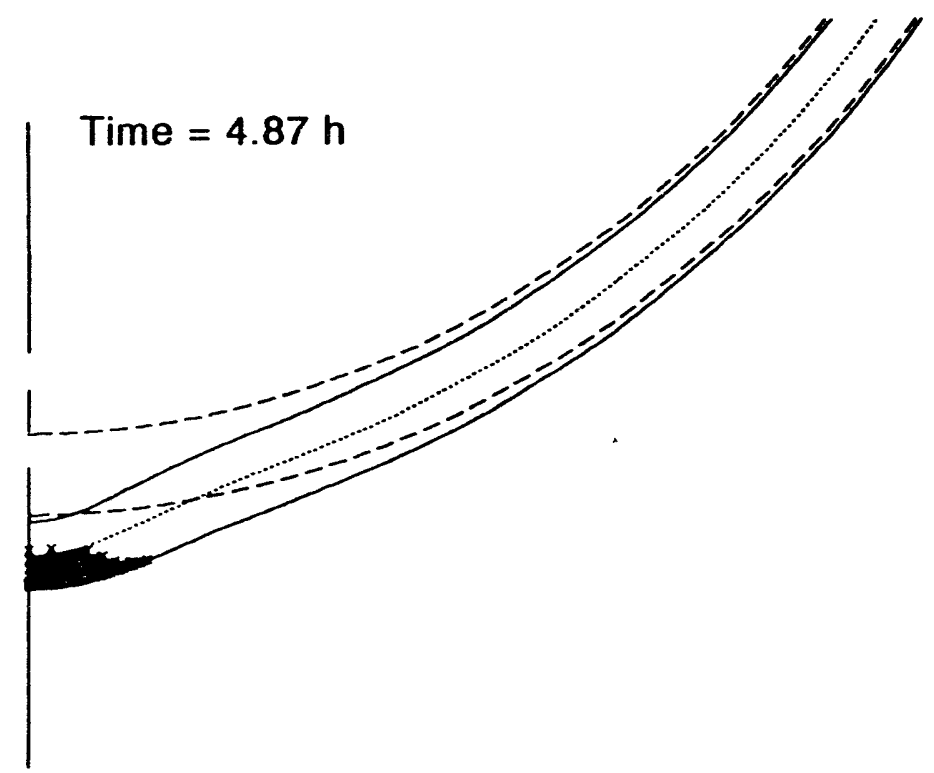

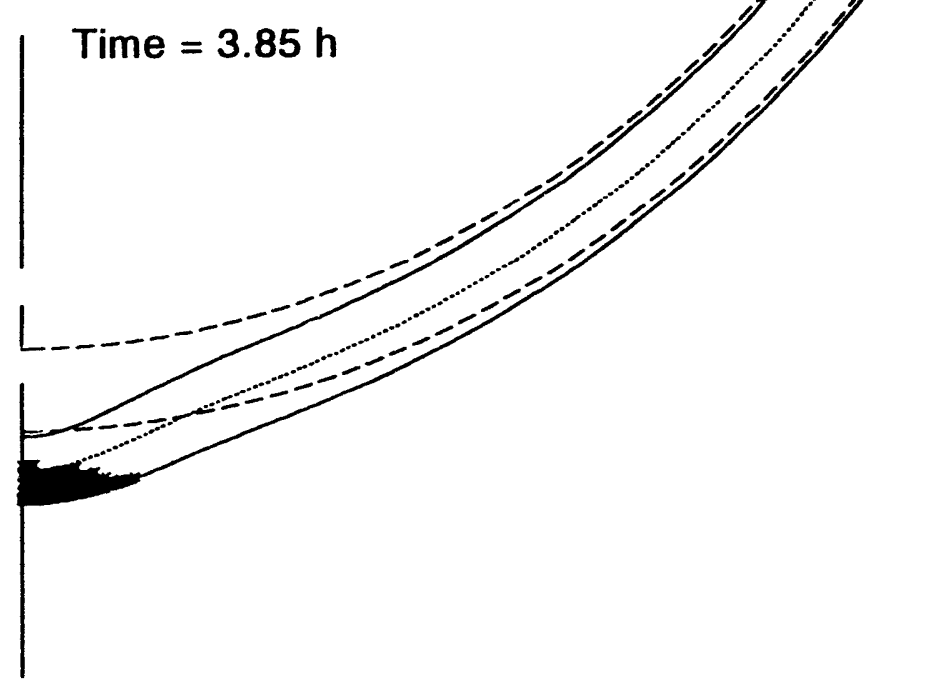

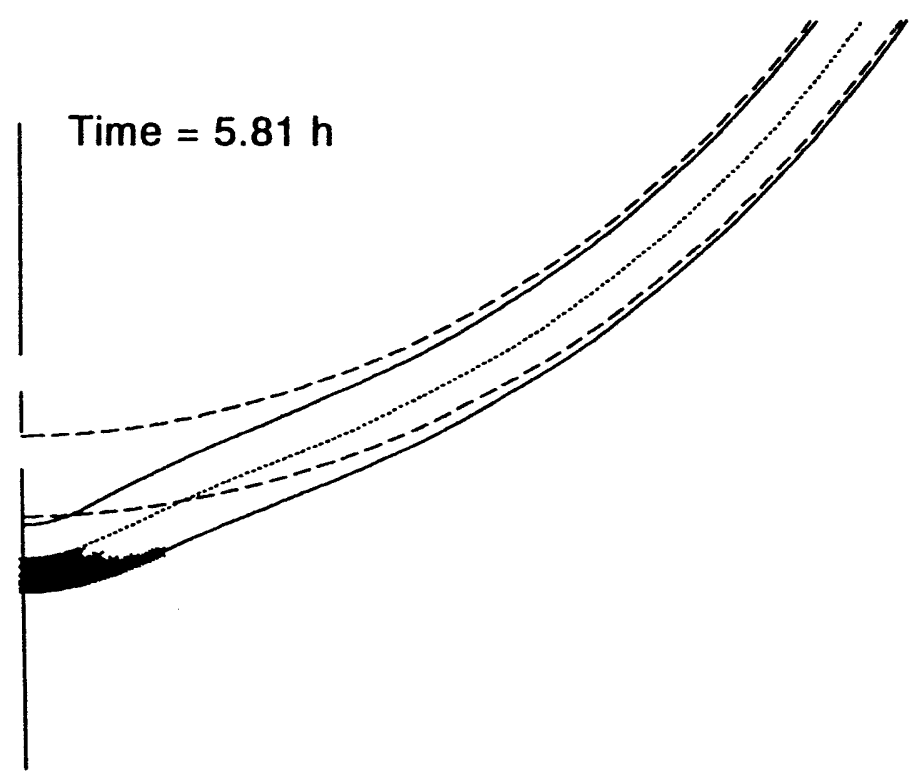

Figure 5-30. Distribution of ligaments experiencing tertiary creep at various times for the $62.5 \%$ nominal case with a hot spot. 

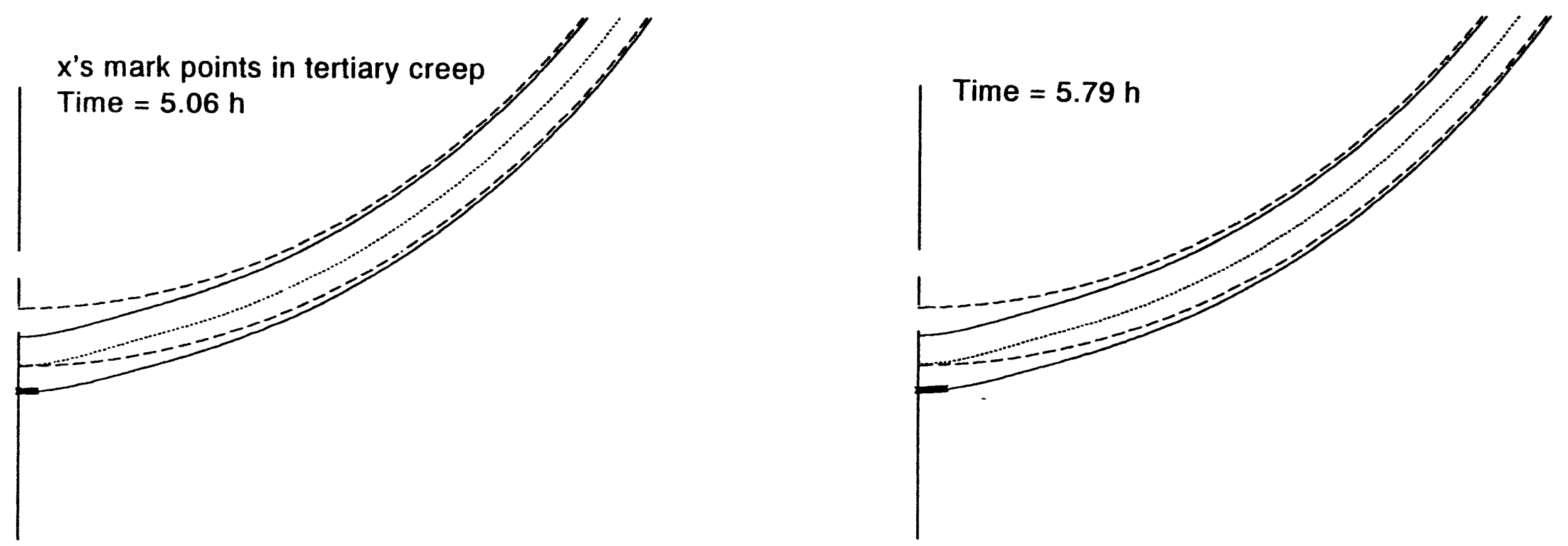

us

in
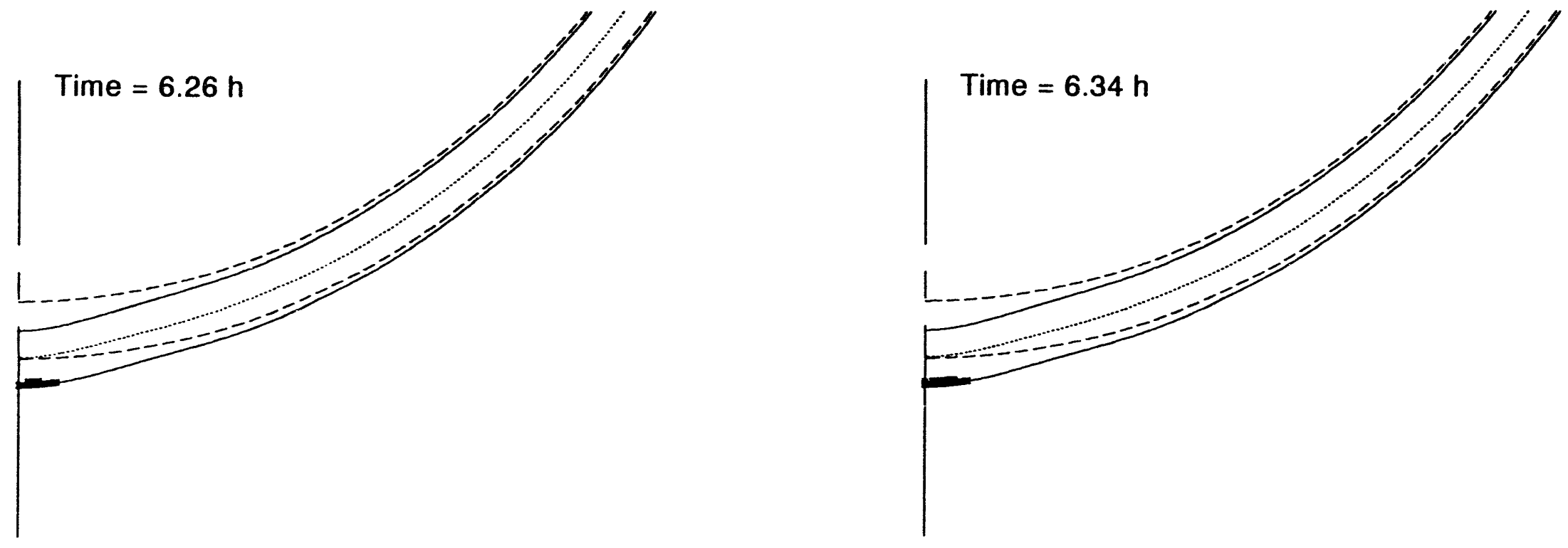

Figure 5-31. Distribution of ligaments experiencing tertiary creep at various times for the 50\% nominal case with a hot spot. 


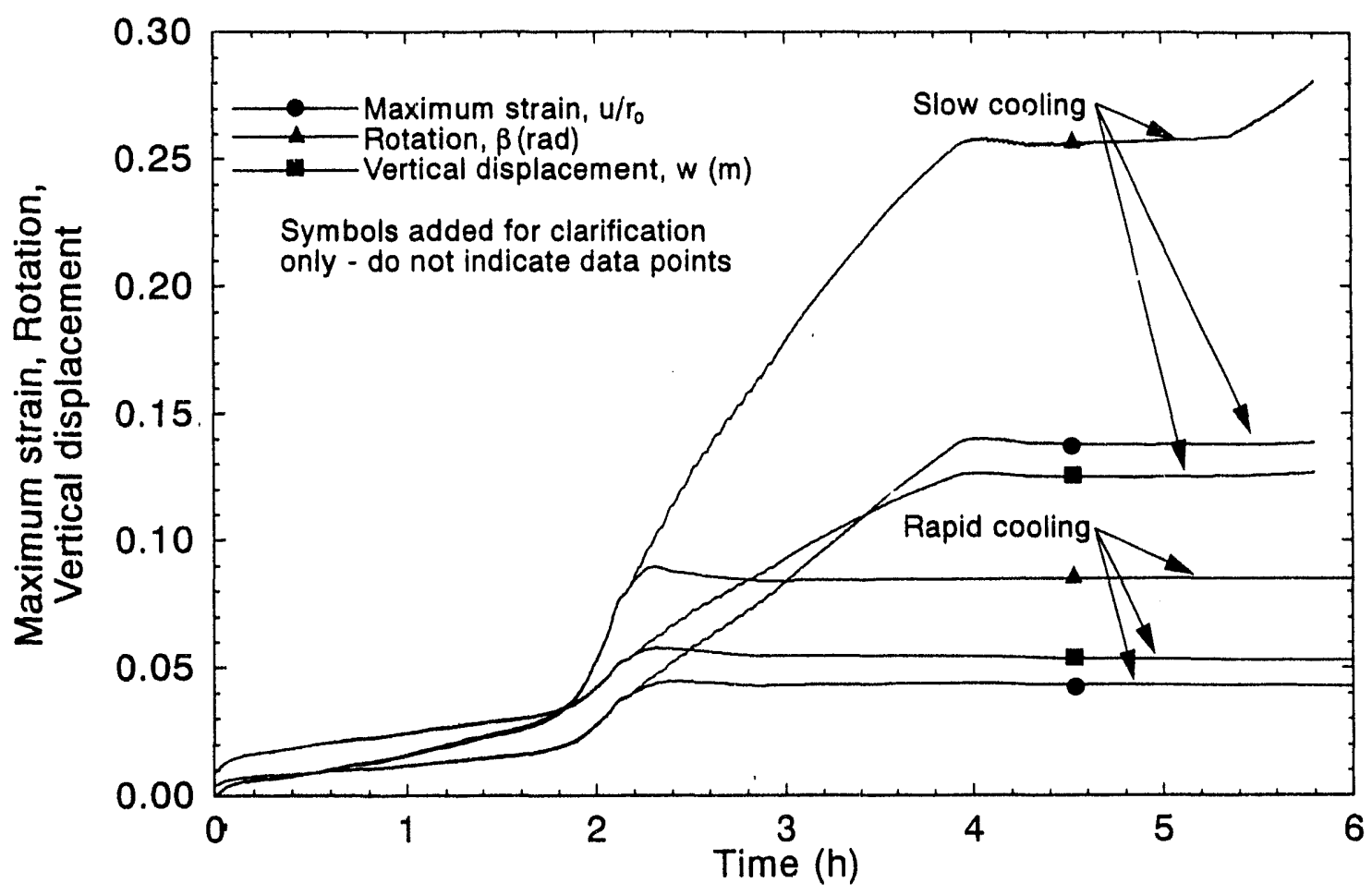

M971 |11-0893-07

Figure 5-32. Comparison of results with and without rapid cooling for a $62.5 \%$ nominal case with a hot spot.

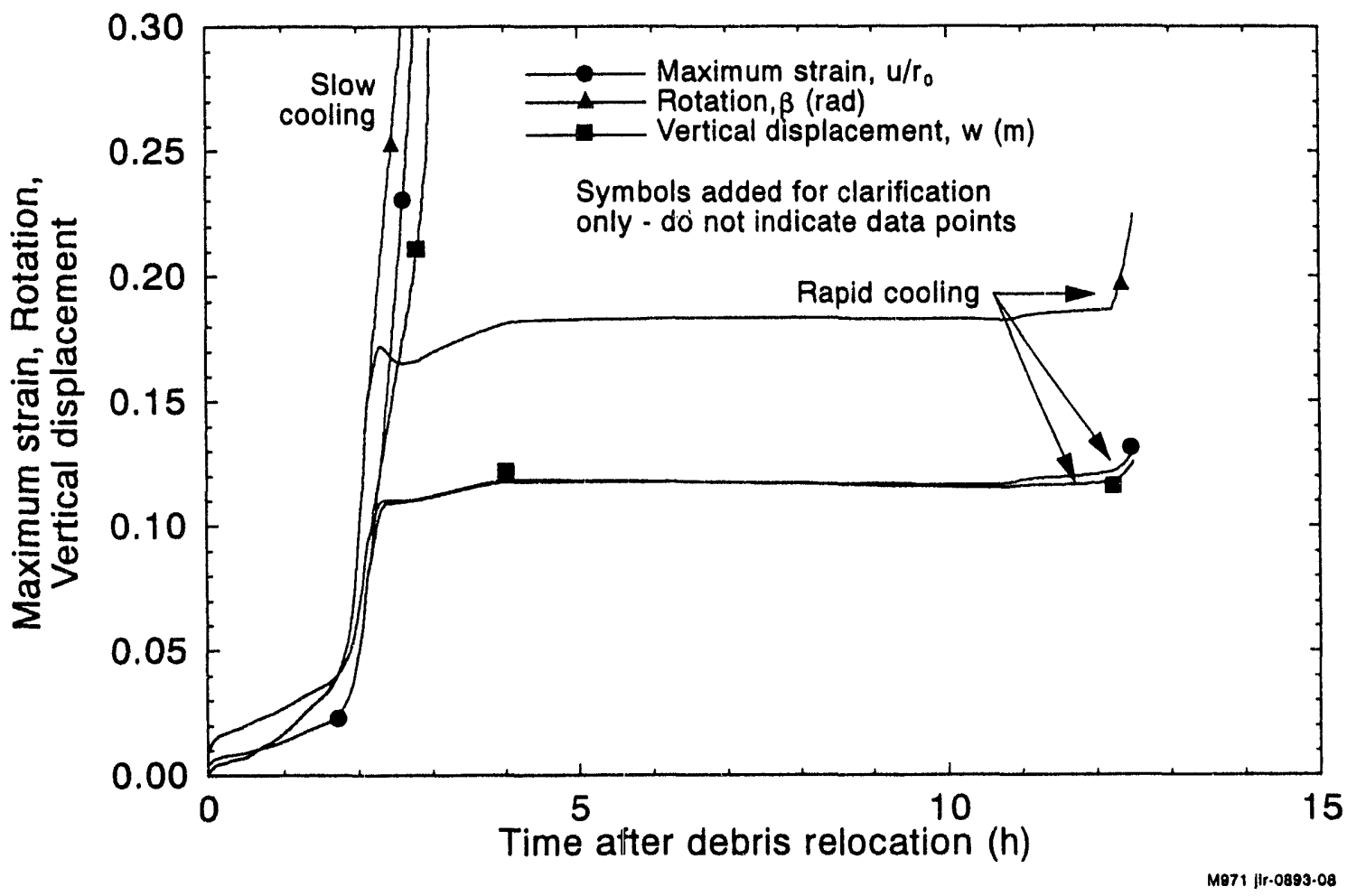

Figure 5-33. Comparison of results with and without rapid cooling for a $75 \%$ nominal case with a hot spot. 


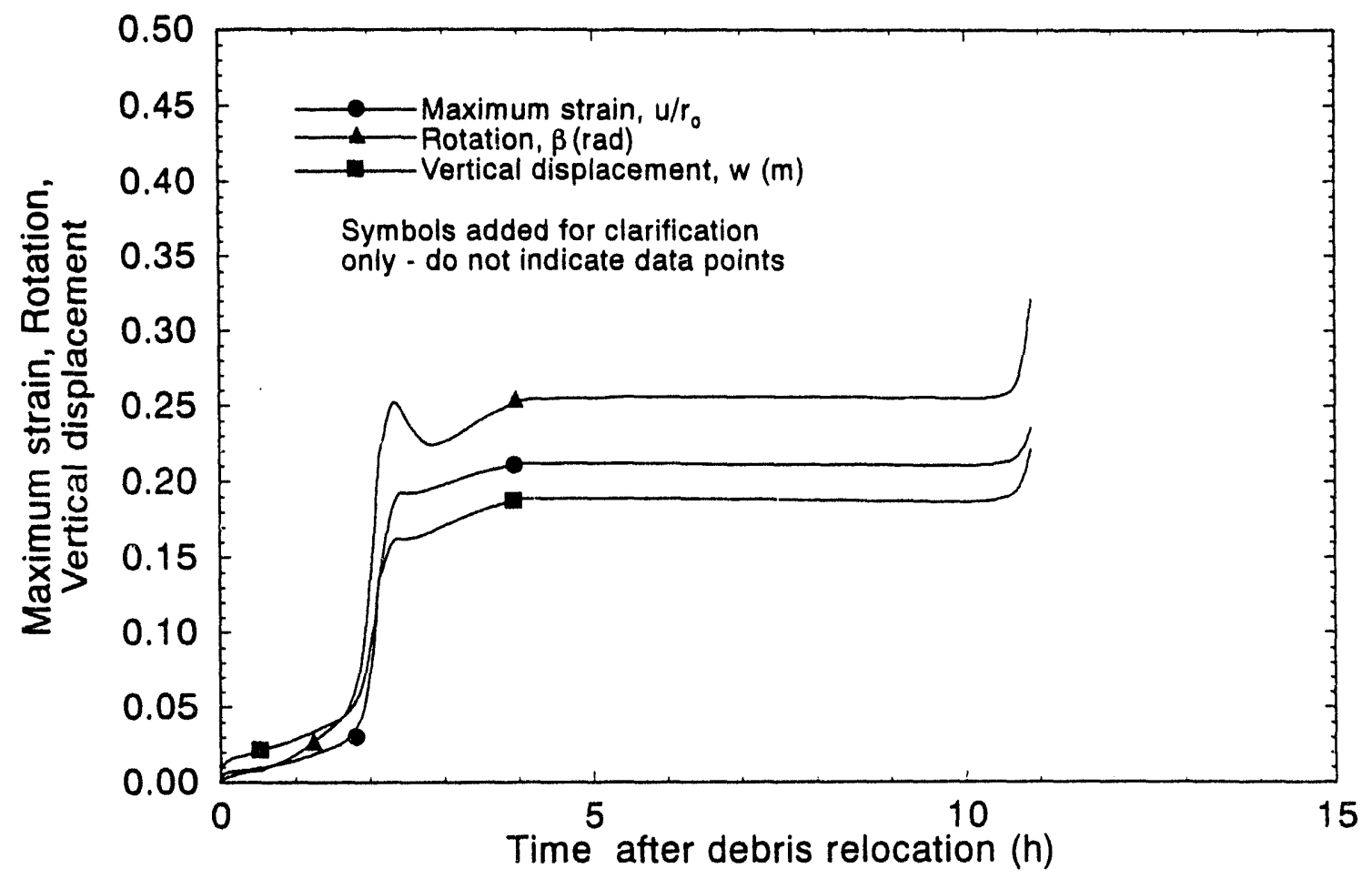

M971 jir.0893.09

Figure 5-34. Results for a $80 \%$ nominal case with a hot spot and rapid cooling.

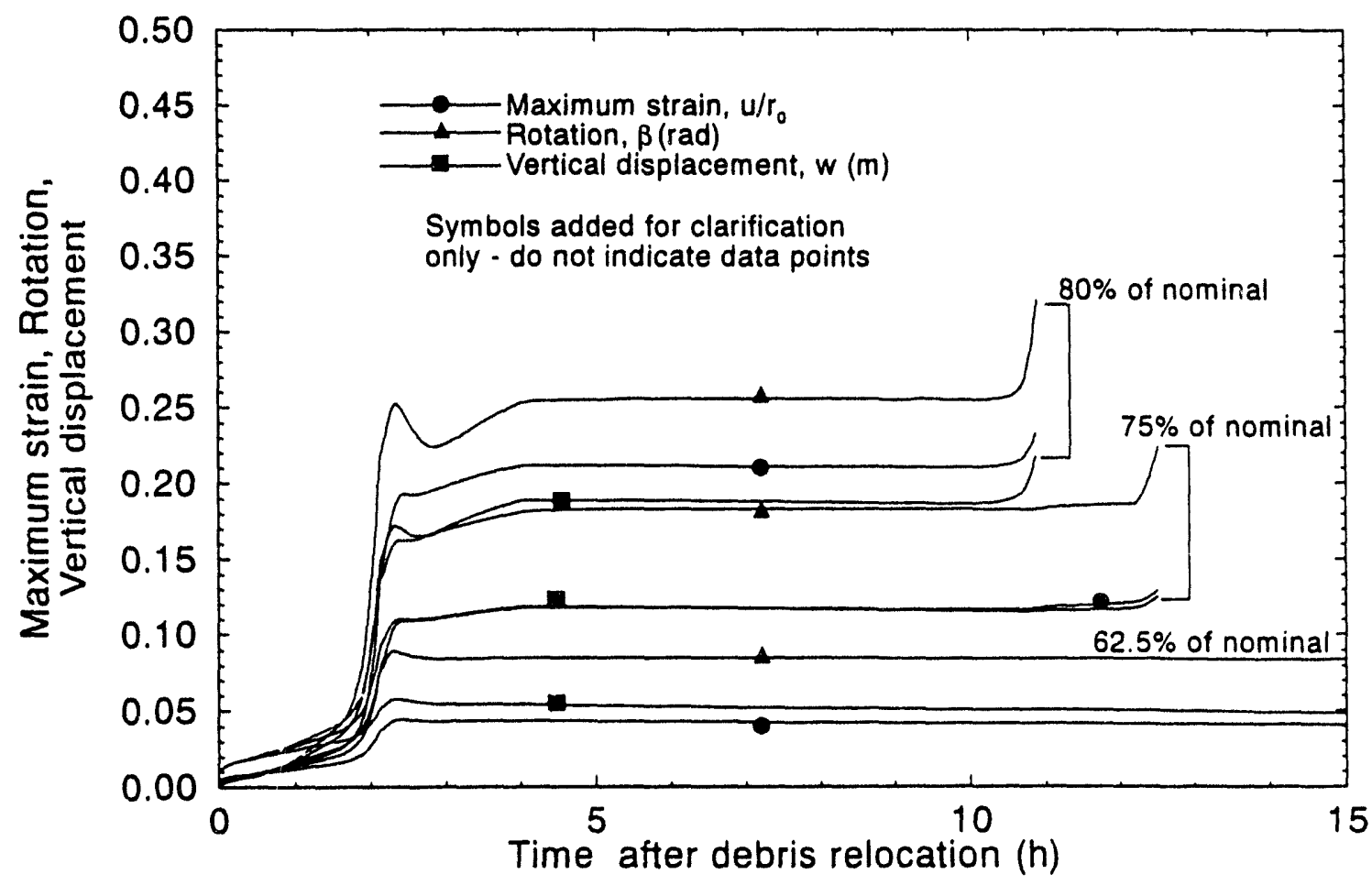

Figure 5-35. Comparison of results for rapid cooling on various nominat heat fluxes with a hot sp97 11:0995.06

Figure 5-35. Comparison of results for rapid cooling on various nominal heat fluxes with a hot spot. 

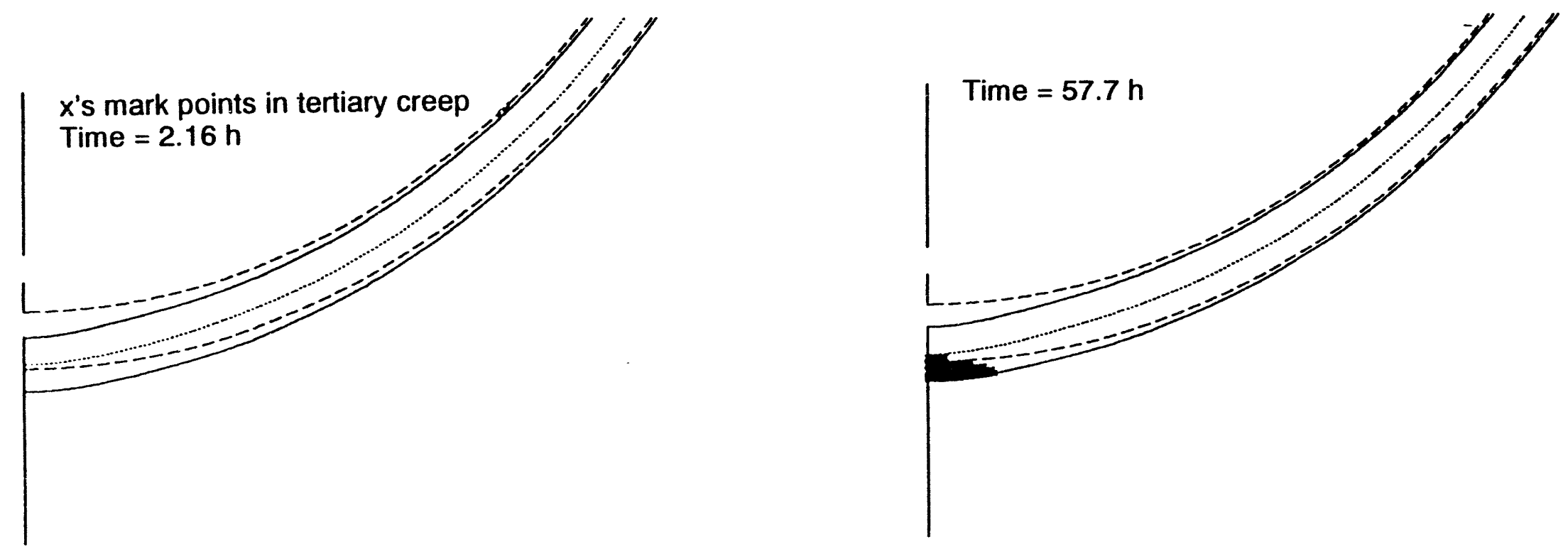

$\ddot{\ddot{~}}$
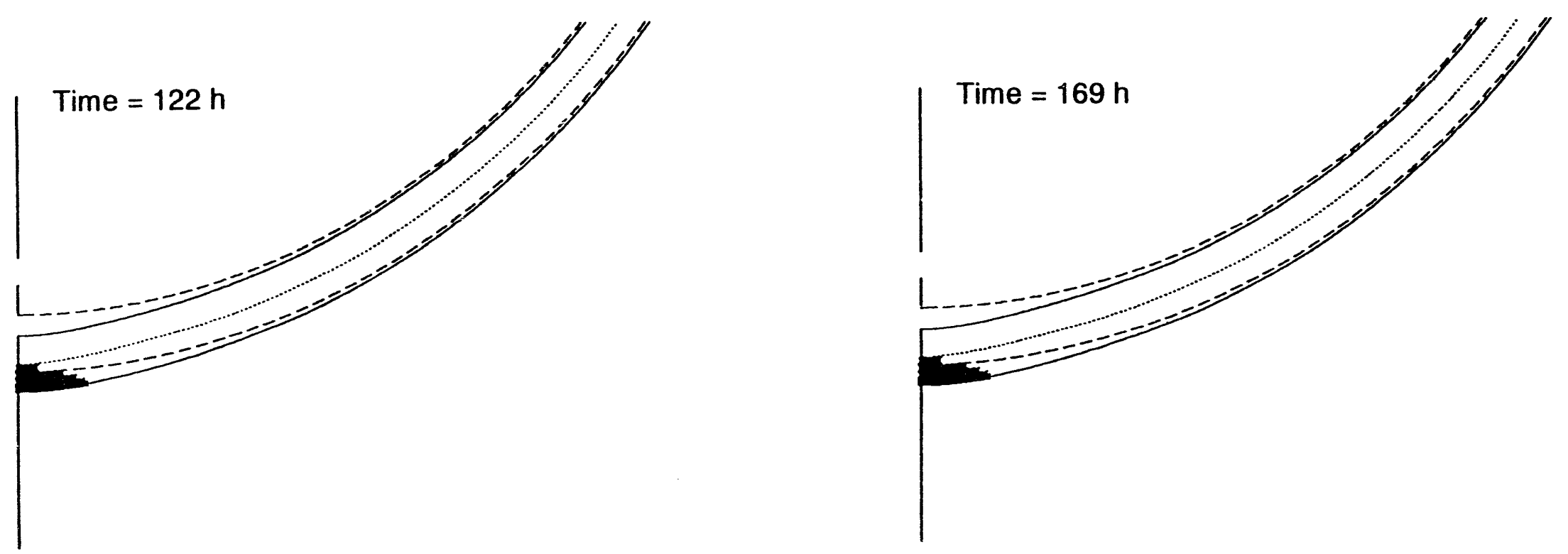

Figure 5-36. Distribution of ligaments experiencing tertiary creep at various times for the $62.5 \%$ nominal case with a hot spot and rapid cooling. 

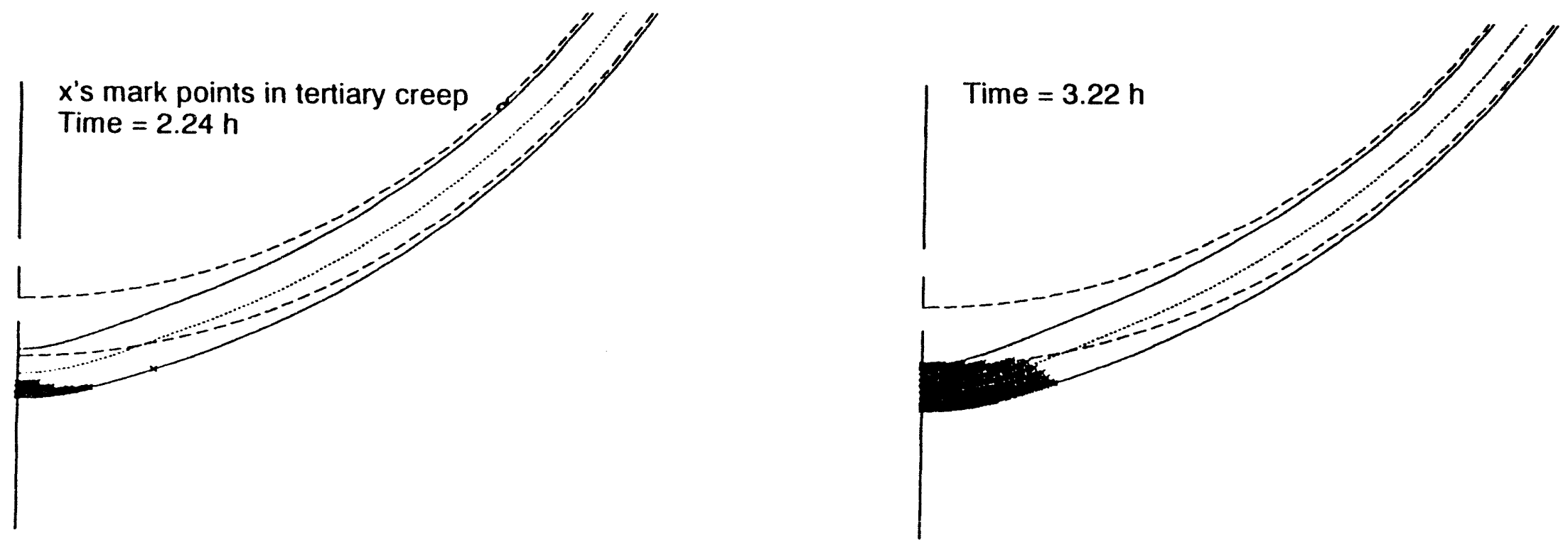

$\ddot{\tilde{u}}$
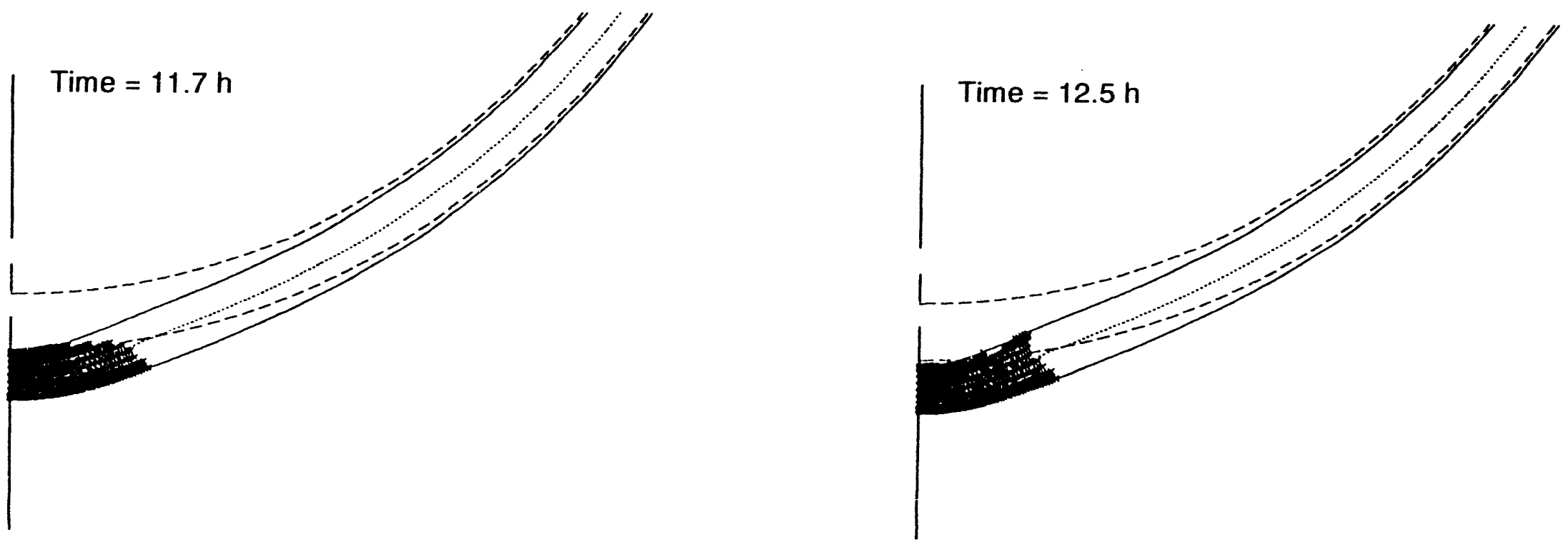

Figure 5-37. Distribution of ligaments experiencing tertiary creep at various times for the $75 \%$ nominal case with a hot spot and rapid cooling. 
nominal, with failures occurring just under two and three hours respectively. A very different response is seen for the case involving the hot spot on $50 \%$ of nominal background. Here the rate of change of deformations appears to become more modest with time after a few hours.

To further define the fraction of nominal heat flux resulting in failure, a case was run corresponding to $62.5 \%$ of nominal. A comparison of this case with the case involving $50 \%$ nominal is shown in Figure 5-27. Note that both the vertical and horizontal scales differ from Figure 5-26. At approximately four hours into the transient, the pressure history contains a substantial depression, resulting in pressures as low as $3 \mathrm{MPa}$ before ascending back to $16 \mathrm{MPa}$ at 11 hours. The rate of change of deformations drops dramatically once this depression is encountered. In the case of a hot spot on $50 \%$ nominal, the hot region is still quite restrained before depressurization, with very small tensile normal stress components in the hot spot region. When the system depressurizes, the vessel unloads elastically, and most of the hot spot experiences compression following depressurization. Only the outer two ligaments experience tension at this time. The structure creeps down for a period of time, so that the hoop strain actually decreases during depressurization. There is less of this effect for the case of $62.5 \%$ of nominal, and, after the depressurization is complete (approximately 5.25 hours), values for these deformation parameters begin to rise again. The increase in meridian rotation at this time is the most obvious of the three. Unfortunately, the combination of depressurization with the partial propagation of tertiary creep through the vessel results in a few severe stress states which slow the simulation down dramatically. Ligaments were allowed to and did return to the secondary regime, but this did not relieve all points from the tertiary regime. As a result, it was not possible to get the simulation to advance past six hours with the actual pressure history. Figure 5-27 illustrates that the case involving $62.5 \%$ of the nominal heat flux advanced to substantially greater deformations than the case involving $50 \%$ nominal heat flux before the depressurization, and the deformations appear to recover and continue to climb after depressurization. Results involving rapid cooling, discussed below, suggest that a vessel experiencing these deflections and subject to repressurization to $16 \mathrm{MPa}$ will again experience rapid rates of increasing deformation. The simulations suggest that the vessel is not able to survive slow cooling of a hot spot on a background heat flux $62.5 \%$ of the nominal level.

Figures 5-28 through 5-31 illustrate the distribution of tertiary ligaments for the cases of hot spots on $100 \%, 75 \%, 62.5 \%$ and $50 \%$ of nominal background heat fluxes under the actual pressure history. It is clear from the figures that the tertiary regime occupies a decreasing fraction of the lower head as the nominal background heat flux is reduced, until, at $62.5 \%$ of nominal, it is unable to propagate all the way through thickness before the depressurization. Also note that once the depressurization occurs, the through thickness propagation recedes in the case of $62.5 \%$ nominal. The results of these slow cooling analyses are that the vessel is capable of surviving a hot spot on a background heat flux between $50 \%$ and $62.5 \%$ of nominal; this is to be compared with the results from the stress-based damage failure criterion results, which suggest that survival is possible on a background between $25 \%$ and $33 \%$ of the nominal case heat flux (see Section 5.1.1).

\subsubsection{Effects of Failure Criterion on Rapid Cooling Case Results}

Rapid cooling simulations were performed for hot spots on background heat fluxes equal to $62.5 \%, 75 \%$ and $80 \%$ of the nominal level. Maximum values of deformation parameters are 
plotted in Figures 5-32 through 5-35, and distributions of tertiary ligaments and vessel deformations are shown in Figures 5-36 through 5-38. Rapid cooling in all cases was initiated at 2.16 hours into the transient, at which time the hot spot had been above $1320 \mathrm{~K}$ for a sufficient period of time to be consistent with observations from TMI-2 metallurgical examinations. At the time rapid cooling is initiated for the case of $62.5 \%$ of the nominal heat flux, the vessel has experienced only modest deflections, and the hot spot is still well restrained. Initiation of rapid cooling results in a small decrease in all freedoms and the vessel asymptotically reaches a benign state. The vessel easily survives the case of rapid cooling for $62.5 \%$ of the nominal heat flux. In the cases of rapid cooling for $75 \%$ and $80 \%$ of the nominal heat flux, the vessel has experienced considerably greater deformation before rapid cooling is initiated. The characteristic response of the freedoms is quite different from the case of $62.5 \%$ of the nominal heat flux. During the cooling period itself, there is little change in either the peak strain or vertical deflection, but the maximum meridian rotation decreases. Once the cooldown is completed, all freedoms continue to increase, but at a slower pace than experienced before the initiation of rapid cooling. At four hours into the transient, the system depressurizes, and virtually no change in any of the freedoms occurs during this period. Once the system begins to repressurize at 11 hours, however, all freedoms begin to rapidly increase again. Although these latter two cases were not run all the way to failure, it appears from the plots that failure occurs in about 13 and 11 hours, respectively, for the cases of rapid cooling of a hot spot from $75 \%$ and $80 \%$ of the nominal backgrcund heat flux. Figure 5-35 shows a comparison of the three cases with rapid cooling.

Plots of vessel deformation and the distribution of tertiary ligaments are shown in Figures 5-36 through 5-38. A word about the secondary to tertiary transition criterion is in order to permit comparisons of Figures 5-28 through 5-31 with Figures 5-36 through 5-38. The transition criterion is based on strain, and the transition strain is a function of both temperature and stress as described in Appendix A. The creep data indicate the transition occurs at relatively low strains (few percent) at low temperatures $(873 \mathrm{~K})$, but that the transition strain increases dramatically (as high as $20 \%$ ) at intermediate temperatures $(1,073 \mathrm{~K}$ ), before falling again to $10-12 \%$ at high temperatures $(1,273 \mathrm{~K})$. In examining the distributions of tertiary ligaments in Figures 5-28 through 5-31, it should be kept in mind that these are slow cooling cases with the hot spot near its peak temperature, and substantial strains are required to reach the tertiary transition through thickness. Once rapid cooling is initiated, the temperatures fall dramatically, and the vessel can experience the tertiary state at more modest strains. In examining Figure 5-36, for instance, corresponding to rapid cooling of a hot spot on $62.5 \%$ of nominal background, it can be seen that at 2.16 hours, just about the time rapid cooling is initiated, there are no tertiary ligaments in the vessel. The vessel is still at elevated temperature, and the lack of tertiary ligaments is consistent with the first frames in Figures 5-28 through 5-31, which show only a few tertiary ligaments at comparable strains. Once rapid cooling is initiated, however, the transition from secondary to tertiary occurs at more modest strains, so that the outer half of the vessel underneath the hot spot enters the tertiary regime. The stress levels in the tertiary regions of Figure 5-36 are nearly zero, with the entire load being taken by the inner portion of the vessel. Figures 5-37 and 5-38 both indicate that the vessel has experienced some propagation of the tertiary regime through thickness prior to rapid cooling, and the onset of cooling is sufficient to push the entire hot spot region into the tertiary regime through thickness. This would be largely responsible for the rapid rates of increase of freedoms following repressurization at 11 hours. 

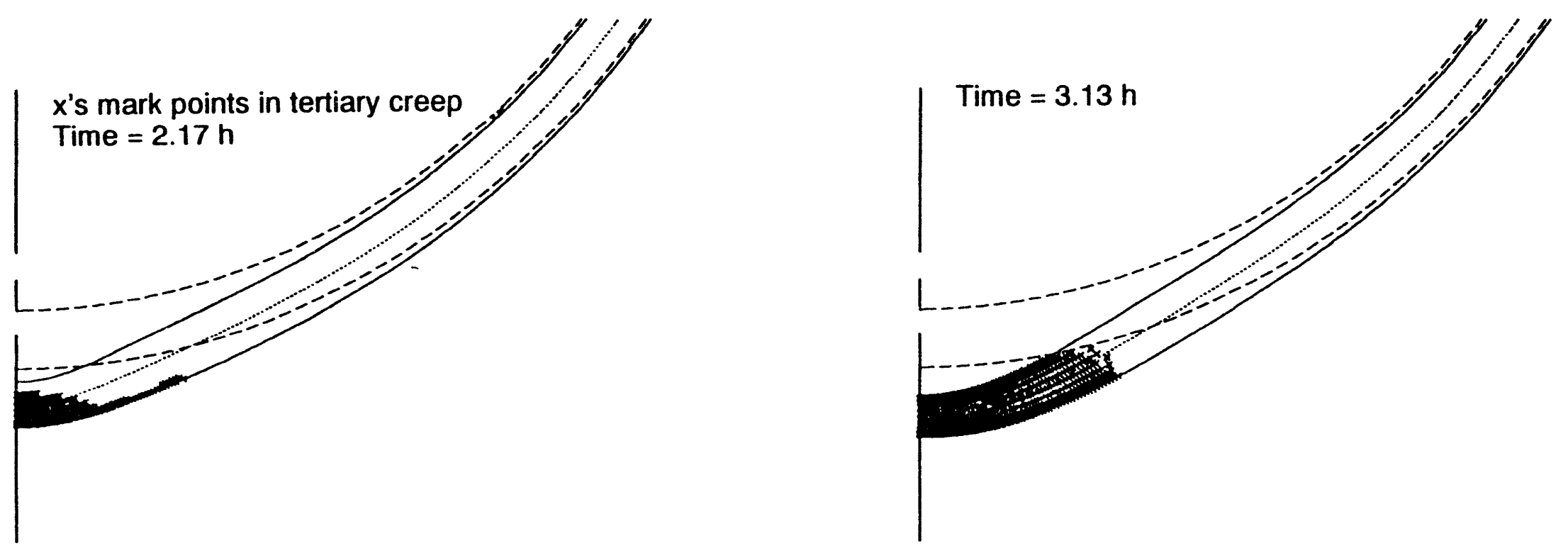

ஜ̂̀
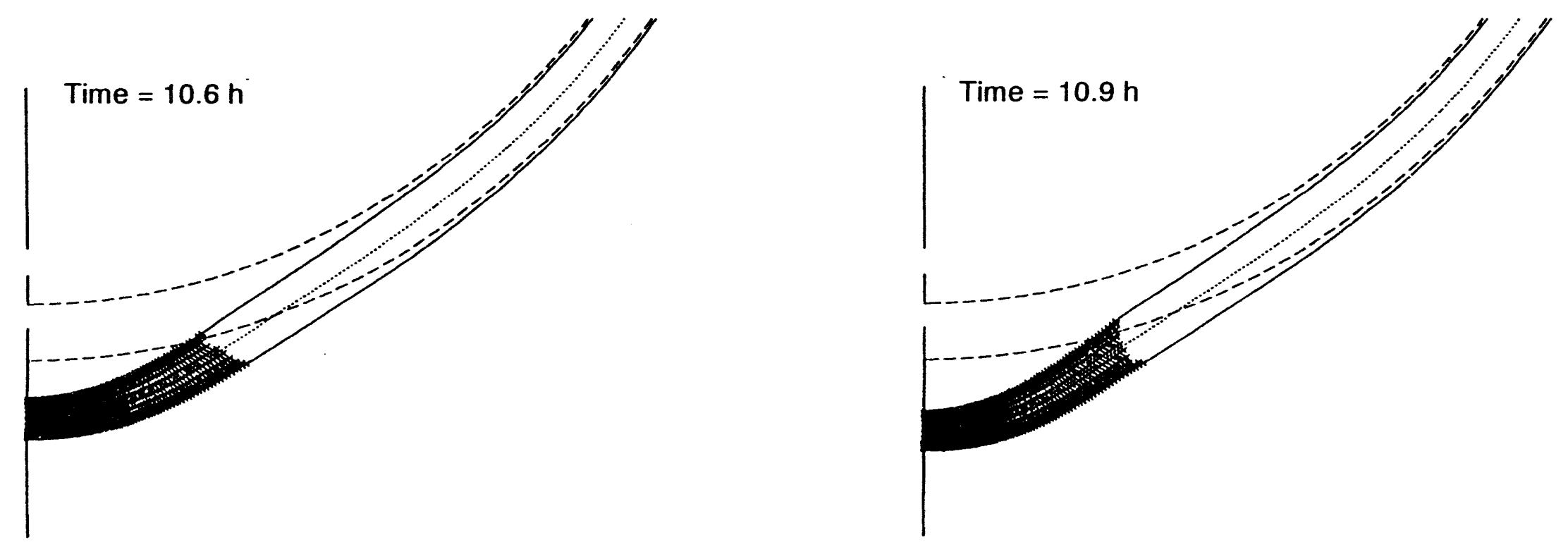

Figure 5-38. Distribution of ligaments experiencing tertiary creep at various times for the $80 \%$ nominal case with a hot spot and rapid cooling. 
It should also be noted that the tertiary data in Appendix $A$ are provided at and above $873 \mathrm{~K}$. Below this temperature, the relationships at $873 \mathrm{~K}$ were used. Twelve hours into the transient following rapid cooling, temperatures in the hot spot region were only $50-100 \mathrm{~K}$ below this value, so the use of these relationships at these temperatures is conservative but not unwarranted. At some point, however, there needs to be a criterion for deciding at what temperature the transition from tertiary back to secondary is permitted. The final states in Figure 5-36, for instance, are at $573 \mathrm{~K}$, where creep is not likely to occur at all, and the notion of some states being in the tertiary regime is meaningless. In this particular simulation, however, the final tertiary states are entirely benign and of no consequence to the vessel's survival.

In summary, it has been found that vessel survival based on a mechanical instability failure criterion is possible for a hot spot on $50 \%$ to $62.5 \%$ of nominal case background heat flux under slow cooling conditions, and between $62.5 \%$ and $75 \%$ of nominal case heat fluxes in the presence of rapid cooling. Levels of survivable heat flux are substantially larger than in the slow cooling case analyzed using the stress-based damage failure criterion, but the distinction between slow and rapid cooling survivability is not nearly as great.

\subsection{Conclusions}

Additional calculations were completed to investigate two areas of uncertainty identified by the initial scoping calculations in Section 4. Specifically, the amount of cooling that occurred within the debris after relocation and the criterion used for predicting vessel failure were investigated with additional sensitivity studies.

Although data are not sufficient to determine the exact mechanism that caused the debris to cool within the first two hours after relocation, two possible forms of cooling were investigated that have the potential to produce this additional cooling:

- A slow cooling mode in which it is assumed that water slowly removes heat as it travels through cracks in the debris

- A rapid cooling mode in which it is assumed that coolant rapidly removes heat as it travels through gaps or channels between the vessel and debris.

Three types of calculations were performed to investigate debris cooling. Using a stressbased damage failure criterion, calculations were first performed to quantify the magnitude of cooling needed to prevent vessel failure and obtain vessel temperature responses consistent with VIP metallurgical examination data. Then, analyses were performed to evaluate the type of debris configuration (i.e., the number and size of cracks and the gap size) needed to obtain the estimated cooling rates. Finally, the hypothesis of debris cooling was evaluated using an energy balance based on parameters measured directly during the accident or inferred from data measured during the accident.

Slow cooling analysis results indicate that the vessel will survive a hot spot in the presence of a background heat flux that is between $25 \%$ and $33 \%$ of the nominal, best estimate, heat flux assumptions in Section 3. Rapid cooling analysis results indicate that negative heat fluxes 
between 25 and $125 \mathrm{~kW} / \mathrm{m}^{2}$ are needed to obtain cooling rates consistent with metallurgical examination data of vessel steel in the hot spot region.

Although higher percentages of the nominal heat flux in the region outside the hot spot may occur if rapid cooling is present, analyses indicate that a combination of both cooling mechanisms must occur in order for results to be consistent with metallurgical examination data. For example, if only a slow cooling mechanism were present, the vessel temperatures would not experience the rapid cooling rates observed in the metallurgical examinations. Furthermore, a rapid cooling analysis for a case in which a 75\% nominal background heat flux is imposed on the vessel indicates that the vessel would fail before the hot spot temperatures could be sustained for the 30 minute time period estimated in metallurgical examinations. Therefore, these cooling analyses not only provided an estimate for the magnitude of cooling that must occur, but also indicated that analyses considering both cooling mechanisms were needed in order to be consistent with results of the TMI-2 VIP examinations.

Scoping thermal analyses were performed to postulate the types of cracks or gaps that are needed in the debris to obtain the estimated cooling 'rates. Conservative heat transfer assumptions were fused in these analyses to obtain lower estimates on the amount of heat that would be removed by coolant traveling through debris cracks or a debris-to-vessel coolant gap. Results indicate that the nominal background heat flux could be reduced by $25 \%$ if less than 220 "through cracks" with a 0.5 -cm effective diameter existed in the hard layer of debris on the lower head. This number of cracks represents an insignificant volume fraction of the hard layer of debris in the lower head. Calculations also indicate that coolant traveling through a $0.1-\mathrm{cm}$ gap between the debris and the vessel could result in the rapid vessel cooling rates estimated by metallurgical examination data. Note that both of these calculations conservatively assumed that the coolant remained liquid as it removed heat from the debris. If the coolant traveling within the debris channels.was assumed to boil, heat transfer would be much more efficient (thus reducing the number and/or size of channels).

An energy balance considering coolant mass flows entering and leaving the vessel indicates that the debris must have cooled after relocation. Calculations were conservatively performed by neglecting heat losses to the vessel and internal structures. Input parameters, such as debris decay heat, coolant injection rates, and relief valve flow rates, were quantified based on data measured during the accident or inferred from data measured during the accident. For all cases evaluated, which included upper-bound and lower-bound estimates on debris decay heat and mass flow rates, the debris was predicted to cool in the time period between debris relocation and vessel repressurization.

Calculations were also performed to assess the influence of failure criterion and the inclusion of tertiary creep on failure predictions. Specifically, analyses were performed including the effects of tertiary creep with failure defined as the point where mechanical instability occurs rather than invoking a stress-based damage failure criterion. Results from these calculations indicate that the vessel would survive if exposed to a hot spot on 50 to $62.5 \%$ of the nominal case heat fluxes under slow cooling and between 62.5 and $75 \%$ of the nominal heat fluxes in the presence of rapid cooling. The percentages of nominal case heat fluxes for which the vessel is predicted to survive for the slow cooling cases are nearly a factor of two larger than percentages predicted using a stress-based damage failure criterion. However, the percentages of nominal case 
heat flux for which the vessel is predicted to survive for the rapid cooling cases is similar to levels predicted with the stress-based damage failure criterion.

In summary, scoping calculations led to the hypothesis that the debris cooled within the first two hours after relocation although there are insufficient data to determine the exact mechanisms that caused the debris to cool. Although the magnitude of cooling required was lower when a mechanical instability failure criterion was used instead of a stress-based damage failure criterion, analyses using either failure criterion indicated that the debris cooled within the first two hours after relocation. This cooling is substantiated by calculations based upon RCS coolant injection and relief rates. Several plausible mechanisms for achieving this cooling were investigated. Calculations indicate that the debris cooling rates needed to prevent vessel failure could be achieved if a minimal volume of cracks were present in the debris. Furthermore, it is predicted that coolant traveling through a minimal size of gap between the debris and the vessel could cool the vessel at rates consistent with the results of metallurgical examinations of the vessel steel. samples.

\subsection{References}

1. D. R. Dierks and L. A. Neimark, Results of Mechanical Tests and Supplementary Metallographic Examinations of the TMI-2 Lower Head Samples, OECD-NEA-TMI-2 VIP TMI (93) AL02, June 1993.

2. G. V. Smith, Evaluations of the Elevated Temperature Tensile and Creep-Rupture Properties of C-Mo, Mn-Mo, and Mn-Mo-Ni Steels, Metal Properties Council, American Society for Testing and Materials, ASTM Data Series Publication DS47, November 1971.

3. National Research Institute for Metals, NRIM Creep Data Sheet 18B, Elevated Temperature Properties of 1.3Mn-0.5Mo-0.5Ni Steel Plates for Boilers and Other Pressure Vessels (SBV 2), Tokyo, Japan, 1987.

4. D. W. Akers et al., Companion Sample Examinations, OECD-NEA-TMI-2 VIP TMI V(92)EG10, July 1992.

5. W. M. Rohsenow, J. P. Hartnett, and E. N. Ganić, Handbook of Heat Transfer Fundamentals, Second Edition, New York: McGraw-Hill Book Company, 1985.

6. W. Elenbass, "The Dissipation of Heat by Free Convection: The Inner Surface of Vertical Tubes of Different Shapes of Cross-Section," Physical, IX, No. 8, 1942, pp. 865-874.

7. J. R. Dyer, "Natural Convective Flow Through a Vertical Duct With Restricted Entry," International Journal of Heat and Mass Transfer, 211, 1978, pp. 1341-1354.

8. N. E. Todreas, and M. S. Kazimi, Nuclear Systems I, Thermal Hydraulic Fundamentals, New York: Hemisphere Publishing Corporation, 1990. 
9. J. G. Collier, Convective Boiling and Condensation, Second Edition, New York: McGraw-Hill International Book Company, 1972.

10. F. W. Dittus, and L. M. K. Boelter, "Heat Transfer in Automobile Radiators of the Tubular Type," University of California Publications in Engineering 2, No. 3, 1930, pp. 443-461.

11. J. R. Welty, C. E. Wicks, and R. E. Wilson, Fundamentals of Momentum, Heat, and Mass Transfer, Second Edition, New York: John Wiley \& Sons, 1976.

12. G. D. Raithby, and K. G. T. Hollands, "A General Method for Obtaining Approximate Solutions to Laminar and Turbulent Free Convection Problems," in Advances in Heat Transfer, 11, edited by T. F. Irvine and J. P. Hartnett, pp. 266-315, New York: Academic, 1975.

13. G. D. Raithby, et al., "Free Convection Heat Transfer from Spheroids," Journal of Heat Transfer, 98, 1976, pp. 452-458.

14. E. R. G. Eckert, and T. W. Jackson, Analytical Investigation of Flow and Heat Transfer in Coolant Passages of Free Convection Liquid Cooled Turbines, NACA RM, E50D25, July 1950.

15. W. H. McAdams, Heat Transmission, Third Edition, New York: McGraw-Hill, 195 \%.

16. R. D. McCormick, TMI-2 Data Summary Report, EGG-TMI-7843, September 1987.

17. Nuclear Safety Analysis Center, Analysis of Three Mile Island-Unit 2 Accident, NSAC-80-1, March 1980.

18. J. L. Anderson, Recommended HPI Rates for the TMI-2 Analysis Exercise (0-300 Minutes), EGG-TMI-7833, September 1987.

19. P. Kuan, and E. L. Tolman, Electromatic Relief Valve Flow and Primary System Hydrogen Storage during the TMI-2 Accident, EGG-TMI-7703, May 1987.

20. Y. Nomura, PORV Discharge Flow during the TMI-2 Accident, EGG-TMI-7825, July 1987.

21. R. E. Henry and H. F. Fauske, "The Two-Phase Critical Flow of One-Component Mixtures in Nozzles, Orifices, and Short Tubes," Journal of Heat Transfer, May 1971, pp. 179-187.

22. K. H. Sun et al., "The Prediction of Two-Phase Mixture Level and HydrodynamicallyControlled Dryout under Low Flow Conditions," International Joumal of Multiphase Flow, 7, No. 5, 1981, pp. 521-543.

23. J. H. Keenan, et al., Steam Tables-Thermodynamic Properties of Water Including Vapor, Liquid, and Solid Phases, New York: John Wiley \& Sons, 1978. 
24. R. R. Hobbins, et al., "Fission Product Release as a Function of Chemistry and Fuel Morphology," Fission Product Transport Processes in Reactor Accidents, New York: Hemisphere, 1990, pp. 215-224.

25. B. G. Schnitzler, Fission Product Decay Heat Modeling for Disnupted Fuel Regions (FDECAY), EGG-PHYS-5698, December 1981.

26. J. R. Larson, System Analysis Handbook, NUREG/CR-4041, EGG-2534, December 1984.

27. J. L. Rempe, et al., Light Water Reactor Lower Head Failure Analysis, NUREG/CR-5642, October 1993.

28. Y. R. Rashid, "Summary of Comments on the Margin-to-Failure Report," Presentation at the 11th Programme Review Meeting of the OECD NEA Vessel Investigation Project, TMI V(93)MAN, May 17, 1993. 


\section{SUMMARY AND CONCLUSIONS}

As part of the TMI-2 VIP, margin-to-failure calculations were performed to increase understanding about events that occurred during the TMI- 2 accident. Because there is considerable uncertainty in input parameters for these calculations, analyses relied upon methods with closedform or simplified numerical solution techniques. With this approach, a large number of cases could be evaluated rapidly and efficiently.

Calculations were performed to consider the four failure mechanisms identified in Figure 6-1:

- Tube rupture

- Tube ejection

- Global vessel failure

- Localized vessel failure.

Unshaded shapes in Figure 6-1 indicate which analyses were performed in this study. Note that several analyses for evaluating certain phenomena-such as jet impingement, melt penetration distance, vessel thermal response, and weld failure-provided input to the failure analyses. As indicated by the shaded boxes, results from some of these preliminary analyses eliminated the need for subsequent analyses. For example, results from melt penetration calculations indicate that molten fuel will not relocate to locations below the lower head. Therefore, reactor coolant system temperatures were applied in subsequent tube rupture analyses, rather than performing an ex-vessel tube heatup analysis with debris in the tube.

As indicated in Figure 6-1, these calculations employed three major sources of VIP examination data:

- Nozzle examination data for characterizing melt composition and penetration distances within nozzles

- Companion sample examination data for characterizing debris properties, such as decay heat and material composition

- Vessel steel boat sample examination data for characterizing peak vessel temperatures, duration of peak temperatures, and vessel cooling rate.

Some of the data were used to quantify input to the calculations and some were used to verify output from the calculations. As illustrated by results within this report, some of the companion sample data-namely that the debris underwent slow cooling-were inconsistent with the vessel steel cooling rate inferred from examinations of the boat samples. When results based upon companion sample data indicated that vessel failure would occur, it was postulated that additional cooling, not indicated by companion sample data, needed to be considered in the analysis. Hence, calculations were performed to quantify the magnitude of this cooling and the hypothesized debris 


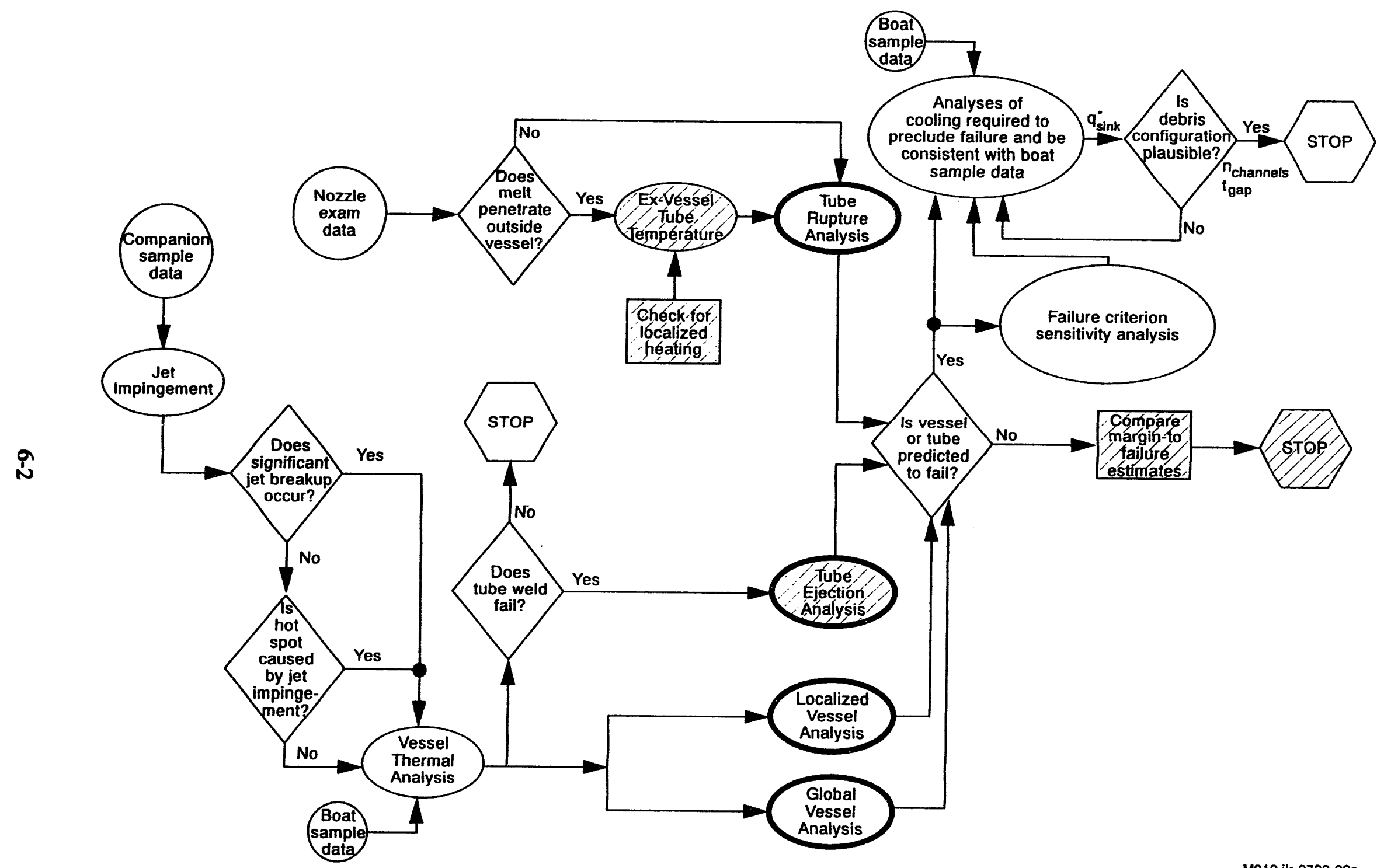

M919 jir-0793-02a

Figure 6-1. Flow diagram illustrating margin-to-failure calculations performed in this study. 
configuration required to support this cooling. An energy balance was also performed to verify the existence of this cooling based upon plant thermal hydraulic parameters.

Results from calculations documented in this report are summarized in this section. These calculations not only provide insights into the potential for vessel failure, they also provided insights into the manner in which debris relocated into the lower plenum and the potential for debris cooling after relocation. Insights gained from these calculations may have implications for severe accident analyses in general.

\subsection{Summary of Results}

Results from scoping calculations are presented in this section according to the order shown in the flow diagram (Figure 6-1). Starting at the upper left hand corner ("nozzle exam data"), melt penetration calculations (reported in Section 3) indicate that molten debris would not penetrate below the vessel head with sufficient heat capacity to raise ex-vessel penetration tube temperatures. Hence, ex-vessel tube rupture calculations were performed assuming tube temperatures consistent with the vessel coolant temperatures. Since such temperatures were expected to result in very high margins to failure, a constant upper system pressure of $15 \mathrm{MPa}$ was also applied in the tube failure calculations. Results indicate that the margin to failure for this mechanism was very high.

Jet impingement calculations (left side of Figure 6-1) indicate that the amount of breakup that occurred as melt relocated to the lower plenum was insignificant. Hence, calculation results indicate that the postulated scenario with major amounts of jet breakup occurring during relocation (Scenario 3 of Section 2.3) is incorrect. Jet impingement calculations also indicate that the magnitude and duration of the hot spot temperatures estimated in TMI-2 vessel examinations could not have been caused by an impinging jet. Rather, hot spot temperatures are predicted to occur later in the scenario due to a sustained heat load from molten debris on the lower head. The limited area estimated to have experienced hot spot temperatures suggests that this region was subjected to a localized heat source, such as might occur with a non-homogeneous debris bed or a localized region with enhanced debris-to-vessel contact. Hence, calculation results indicate that the scenario with hot spot temperatures caused by a coherent jet impinging upon the vessel (assumed in Scenario 1 of Section 2.3) is incorrect.

Although the quantitative value predicted for the vessel wall surface peak temperature differed in each case, results from several sensitivity studies were qualitatively similar. Namely, the thermal response can be divided into the following three time periods:

- An initial localized temperature spike for the time and location of jet impingement (typically lasts for about 1 minute)

- A transient vessel heatup (typically lasts for about 1 hour)

- A quasi-steady vessel temperature distribution (typically lasts for several hours).

Only a case with lower bound input assumptions (discussed in Section 3.2) resulted in global vessel temperature predictions that are consistent with the boat sample examination data; namely 
that vessel temperatures remain below values where the material undergoes a transition from ferritic to austenitic steel.

As noted in Figure 6-1, prior to performing a tube ejection analysis, it must be established that the weld holding the nozzle to the vessel has failed. Since it is not known if the hot spot temperatures occurred at the same time that the RCS was repressurized to $15 \mathrm{MPa}$, weld failure calculations were conservatively performed assuming that peak temperatures and pressures occurred simultaneously. Results indicate that even for these very conservative assumptions, there was considerable margin in the weld's integrity. Therefore, there was no need for a tube ejection analysis.

The potential for the vessel to experience a global failure was evaluated for vessel temperature distributions based upon nominal and lower bound input assumptions (see Section 3.2). Note that both of these temperature distributions were obtained by assuming that the molten debris experienced relatively slow cooling rates, in order to be consistent with companion sample examination data. Global failure was predicted to occur at 1.7 hours after relocation for the nominal case and 2.3 hours after relocation for the lower bound case. In fact, parametric studies indicate that failure is predicted in less than 3 hours for temperatures above 800 to $900 \mathrm{~K}$, if the reactor vessel is maintained at pressures near the operating pressure. Thus, results indicate that enhanced debris cooling occurred within the first 2 hours to prevent global vessel failure.

The potential for the vessel to experience a localized failure was evaluated by imposing hot spot temperatures on two background distributions, the lower bound case temperatures and a benign case with cool background temperatures. These two temperature distributions bounded possible background distributions. Boat sample examinations indicate that temperatures outside the hot spot remained below the ferritic to austenitic transition temperature, and the minimum vessel temperature was the normal operating condition temperature. Results for the lower bound case indicate that the presence of a hot spot reduces failure time predictions by about 0.4 hours. Furthermore, the presence of the hot spot affected predictions of the geometry of the vessel and the damage distribution in the vessel at the time of failure. However, results from the benign case indicate that the vessel is capable of surviving local hot spots in the temperature range and of the duration inferred from the metallurgical examinations if the balance of the shell remains relatively cool.

Results from thermal and structural calculations based upon debris decay heats from companion sample examinations combined with the relatively rapid vessel cooling indicated by metallurgical examinations indicate that some form of debris cooling occurred that was not evident in the TMI-2 companion samples. In addition, analysis results suggest that a stress-based damage failure criterion may be too conservative for predicting failure. Therefore, additional analyses were performed to investigate the effects of debris cooling and failure criterion on calculation results. An energy balance considering coolant mass flows entering and leaving the vessel indicate that the debris cooled in the time period between relocation and vessel repressurization (between 220 and 320 minutes). Although there are insufficient TMI-2 data to determine the exact mechanisms that caused the debris to cool, scoping calculations were performed to investigate two forms of cooling that have the potential to produce additional cooling: 
- A slow ccoling mode in which it is assumed that water slowly removes heat as it travels through channels or "cracks" within the debris

- A rapid cooling mode in which it is assumed that coolant rapidly removes heat as it travels through channels or "gaps" between the vessel and the debris.

Slow cooling analysis resulis indicate that coolant traveling through a relatively insignificant volume of cracks within the debris (i.e. less than $1 \%$ of debris volume) will remove sufficient heat to prevent vessel failure. Rapid cooling analysis results indicate that coolant traveling through a gap of minimal thickness (i.e. as small as $1 \mathrm{~mm}$ ) will remove sufficient heat to allow the vessel to experience cooling rates consistent with the results of metallurgical examinations of the vessel steel samples. In order for either of the above forms of cooling to occur, coolant must be present within the lower head. Hence, the presence of coolant within the lower head during the TMI-2 accident was instrumental in providing these postulated forms of cooling.

Although the magnitude of cooling required was decreased when the stress-based damage failure criterion was replaced with a mechanical instability failure criterion, calculational results indicate that a combination of both cooling mechanisms is needed in order for results to be consistent with metallurgical examination data. For example, if only a slow cooling mechanism was present, the vessel temperatures would not be predicted to experience the rapid cooling rates observed in the metallurgical examinations. Furthermore, analyses indicate that a vessel subjected to peak hot spot temperatures on nominal case background heat fluxes could not survive the 30-minute time period estimated in metallurgical examinations. Thus, analyses indicate that both mechanisms need to be considered in order to obtain results consistent with TMI-2 VIP examinations.

\subsection{Insights from Calculations and Severe Accident Implications}

Major insights from the failure analyses include:

- The large margin-to-failure estimates for tube failure mechanisms essentially preclude the potential for tube failure to occur during the TMI-2 event.

- It is possible for the vessel to withstand the hot spot temperatures and durations determined from the vessel metallurgical examinations if the balance of the vessel outside the hot spot remains relatively cool. Localized and global vessel failure calculations indicate that the background temperature behavior of the vessel (i.e., outside the hot spot), which is highly dependent upon the heat load from relocated debris in the lower head, is key to predicting failure from either of these mechanisms.

- Debris cooling may have occurred within the first two hours after relocation to the lower head. Although companion sample examination data are insufficient to quantify the timing and rate of debris cooling, additional scoping calculations indicate that the debris cooled in the time interval after relocation and before vessel repressurization.

- Debris cooling may have occurred via coolant traveling in channels within the debris and in channels between the debris and the vessel. Although there are insufficient 
TMI-2 data to determine the exact mechanisms that caused the debris to cool, scoping calculations indicate that the presence of a relatively insignificant volume of flow chanuels within the debris or a relatively thin channel between the debris and the vessel would have significantly enhanced debris cooling during this time period.

Several results and insights from these calculations may have considerable impact upon severe accident safety analyses. Some of these implications are the following:

- The background, or global, temperature behavior is key to predicting PWR vessel failure at high pressure conditions. Although vessel failure times may be shortened if a localized region of the vessel is exposed to higher temperatures, cool background temperatures have the potential to prevent such failures.

- If relocating debris solidifies containing channels or with channels between it and the vessel, debris coolability may be enhanced. Hence, TMI-2 analyses may provide additional insight about phenomena not currently modeled in severe accident analyses that could provide additional safety margins for such analyses.

Hence, the importance of these calculations is not only limited to increasing understanding of the TMI-2 accident. Calculation results may also provide another step toward answering broader severe accident questions. 
Appendix A

Modeling Input 


\section{Appendix A}

\section{Modeling Input}

\section{A.1 Thermal Materlal Property Data}

This section summarizes the material data used for the thermal calculations in the TMI-2 margin to failure analyses. Temperature-dependent properties, such as thermal conductivity, density, enthalpy, specific heat, and viscosity of the debris and vessel material are included.

\section{A.1.1 $\mathrm{UO}_{2}$ Data}

This section contains data for properties of $\mathrm{UO}_{2}$. Properties, such as thermal conductivity, theoretical density, enthalpy, specific heat capacity, and viscosity are summarized in Figures A-1 through A-5. As indicated in the figures, these data are based upon information in Reference A-1. Reference A-1 also indicates that the solidus and liquidus temperature for $\mathrm{UO}_{2}$ is $3,113 \mathrm{~K}$. 


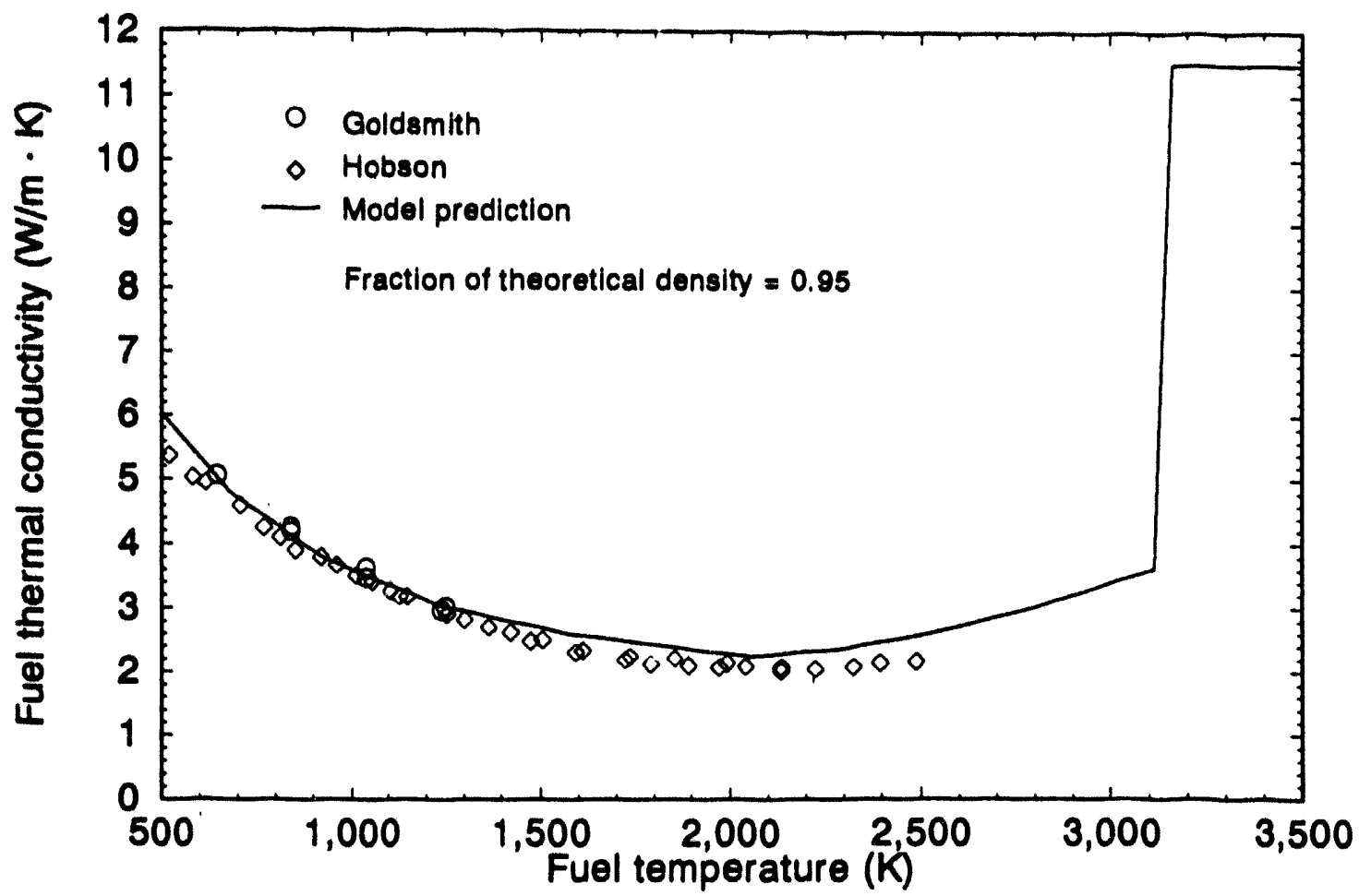

Figure A-1. Model prediction for thermal conduction of $0.95 \mathrm{TD} \mathrm{UO}_{2}$ compared with data from specimens with densities in the range of 0.945 to $0.955 \mathrm{TD} .^{\mathrm{A} \cdot 1}$

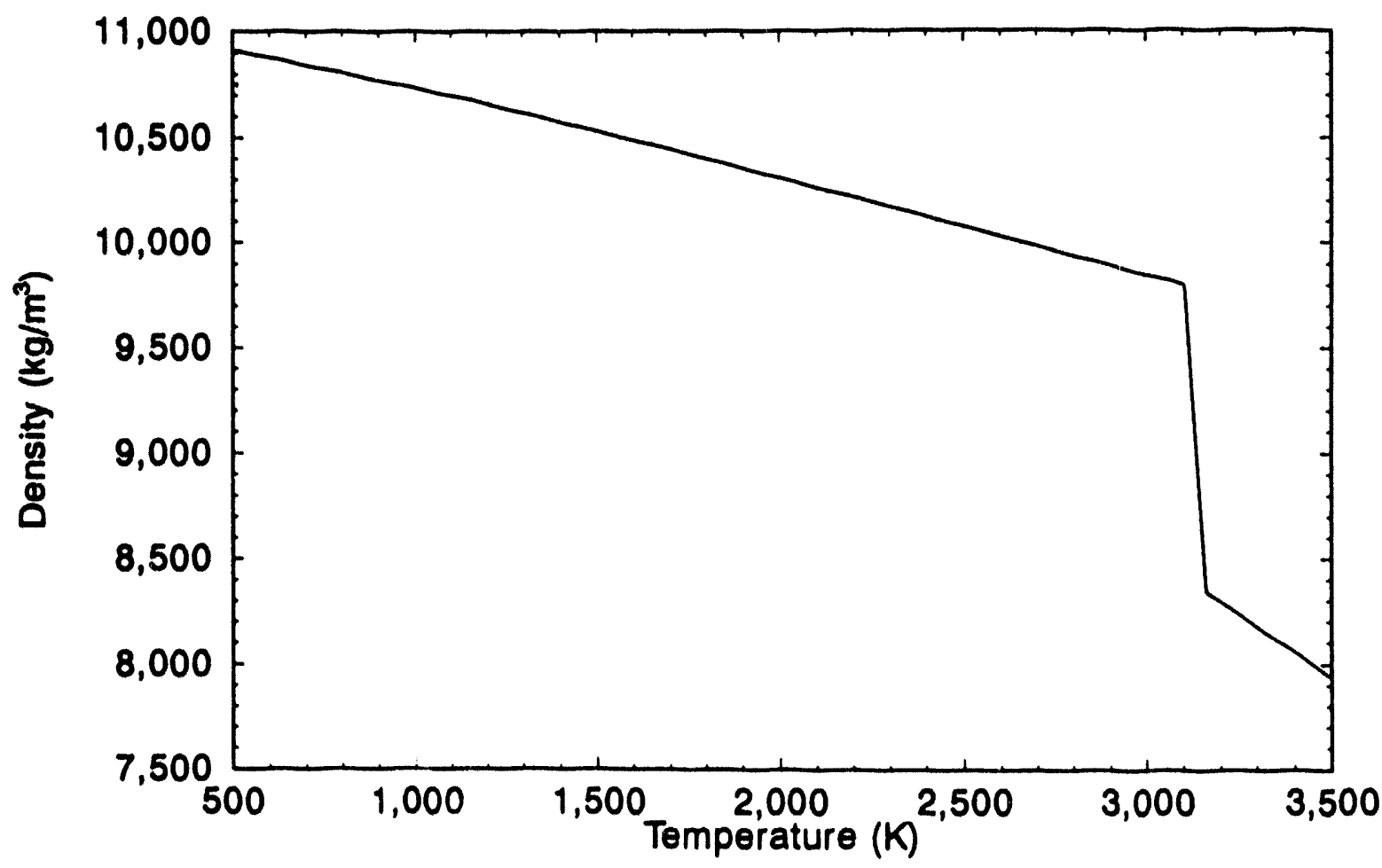

Figure A-2. Theoretical density of $\mathrm{UO}_{2} \cdot{ }^{\mathrm{A}-1}$ 


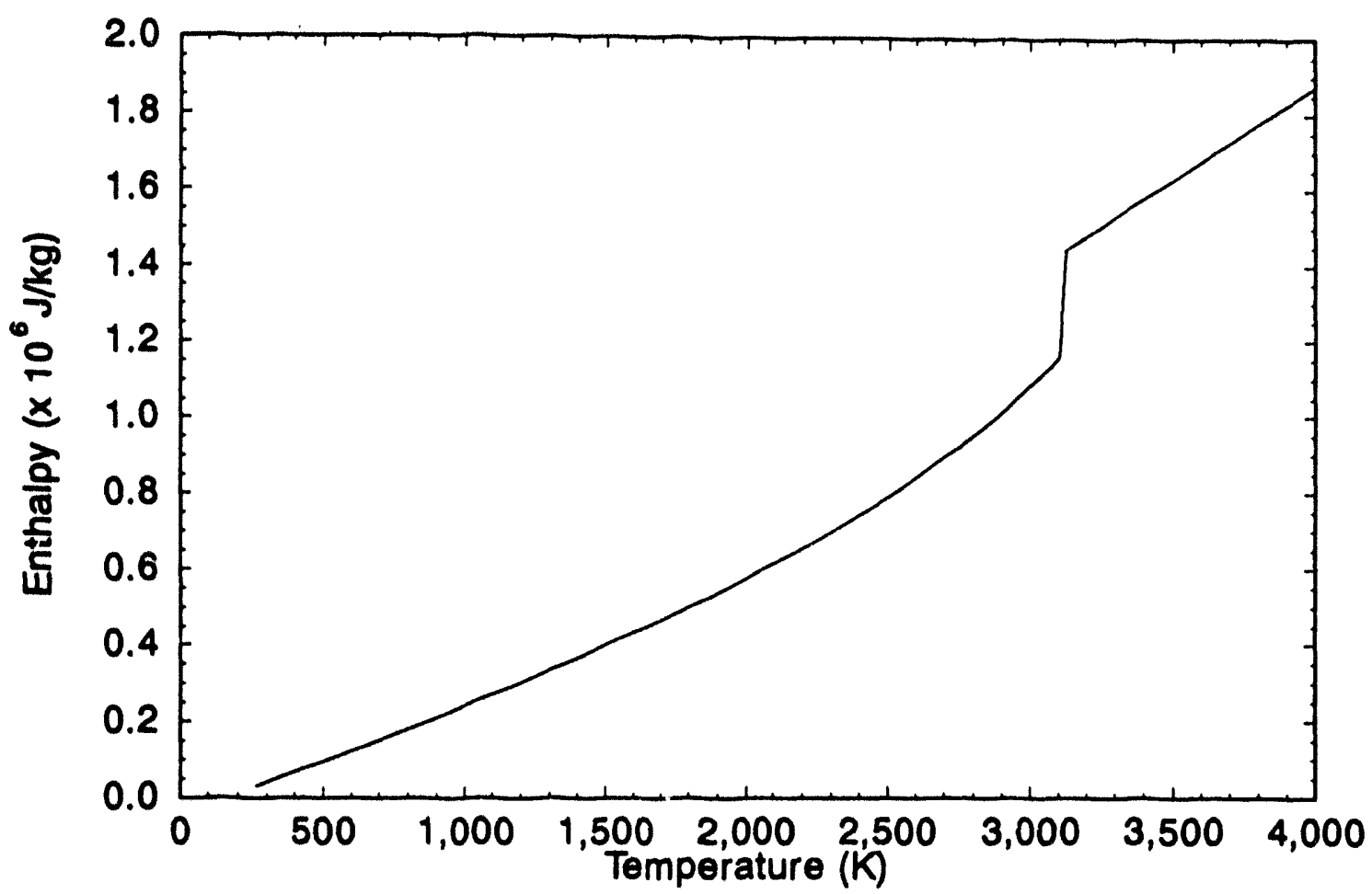

Figure A-3. Enthalpy of $\mathrm{UO}_{2}$ as a function of temperature to $4,000 \mathrm{~K}^{\mathrm{A}-1}$

mis treme-os

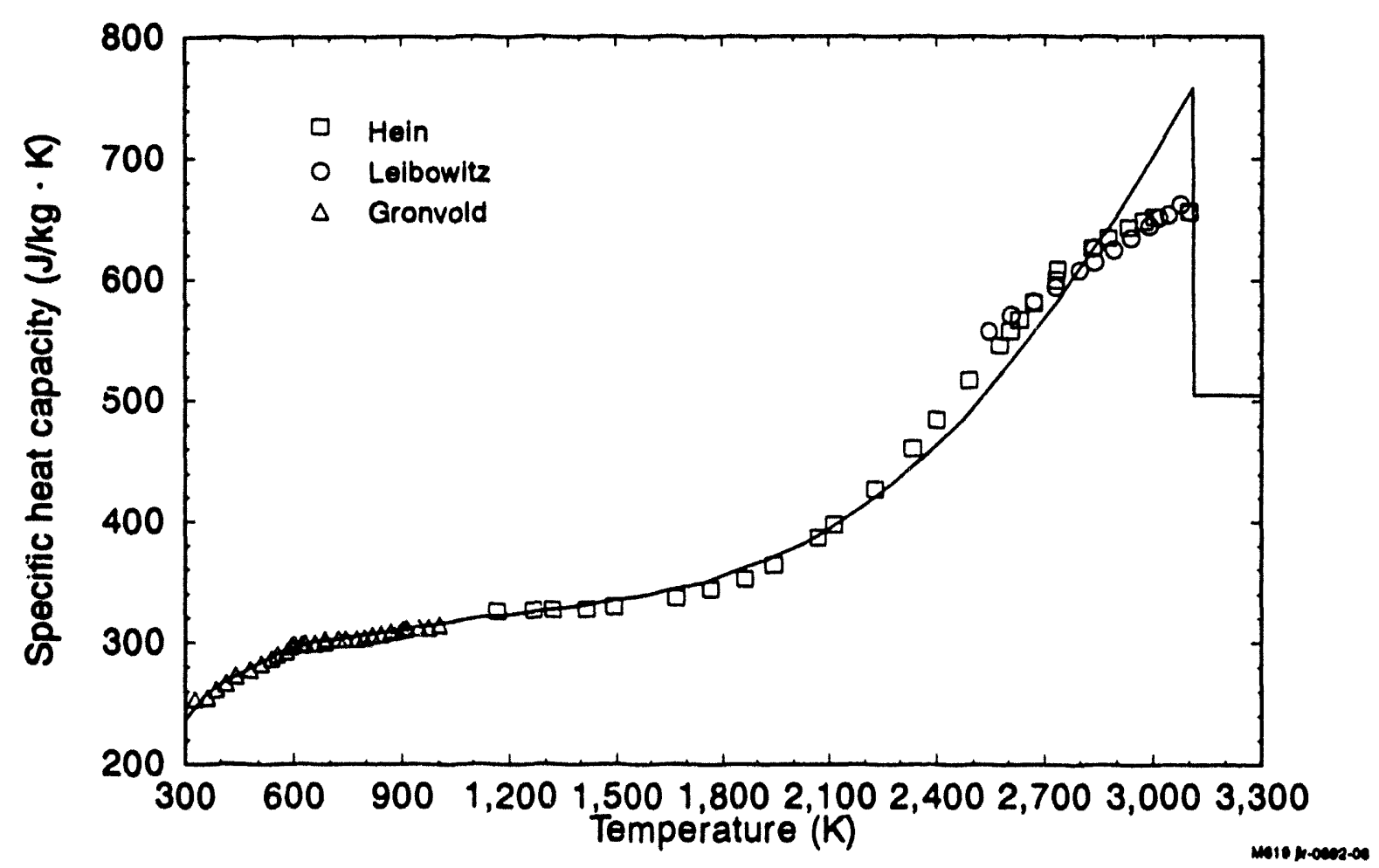

Figure A-4. $\mathrm{UO}_{2}$ specific heat capacily data from threc experimenters compared with $\mathrm{UO}_{2}$ specific heat capacity correlation (solid linc). ${ }^{\wedge \cdot 1}$ 


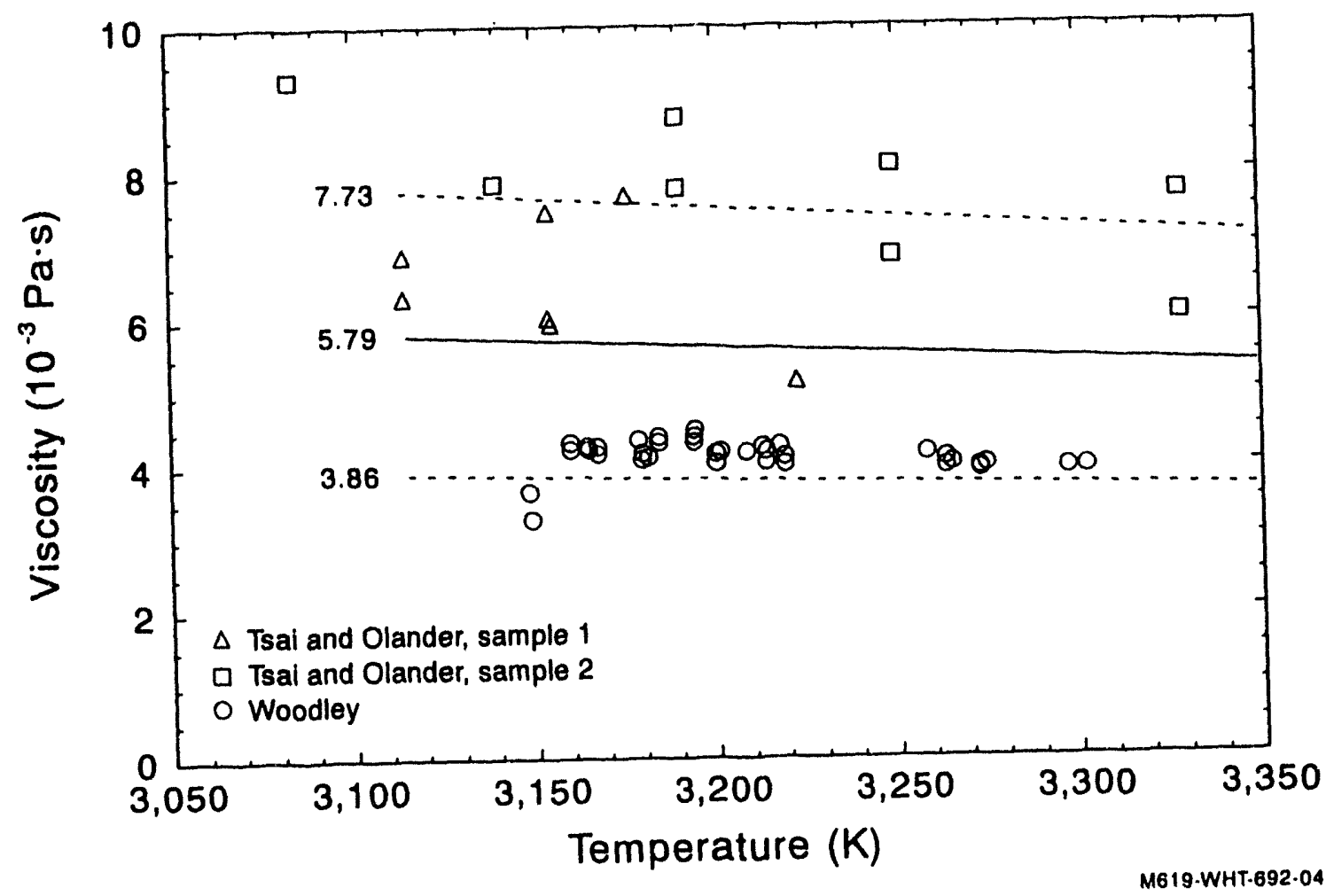

Figure A-5. Estimated $\mathrm{UO}_{2}$ viscosity (solid line) with upper and lower uncertainty estimates (dashed lincs) compared with data. ${ }^{A-1}$ 


\section{A.1.2 $\mathrm{ZrO}_{2}$ Data}

This section contains data for properties of $\mathrm{ZrO}_{2}$. Properties, such as thermal conductivity, theoretical density, enthalpy, and specific heat capacity are summarized in Figures A-6 through A-9. As indicated in the figures, this data is based upon information in Reference A-1. Reference A-1 also states that the solidus and liquidus temperature for $\mathrm{ZrO}_{2}$ is $2,960 \mathrm{~K}$, assuming that the oxygen-to-metal ratio is 2.0 . 


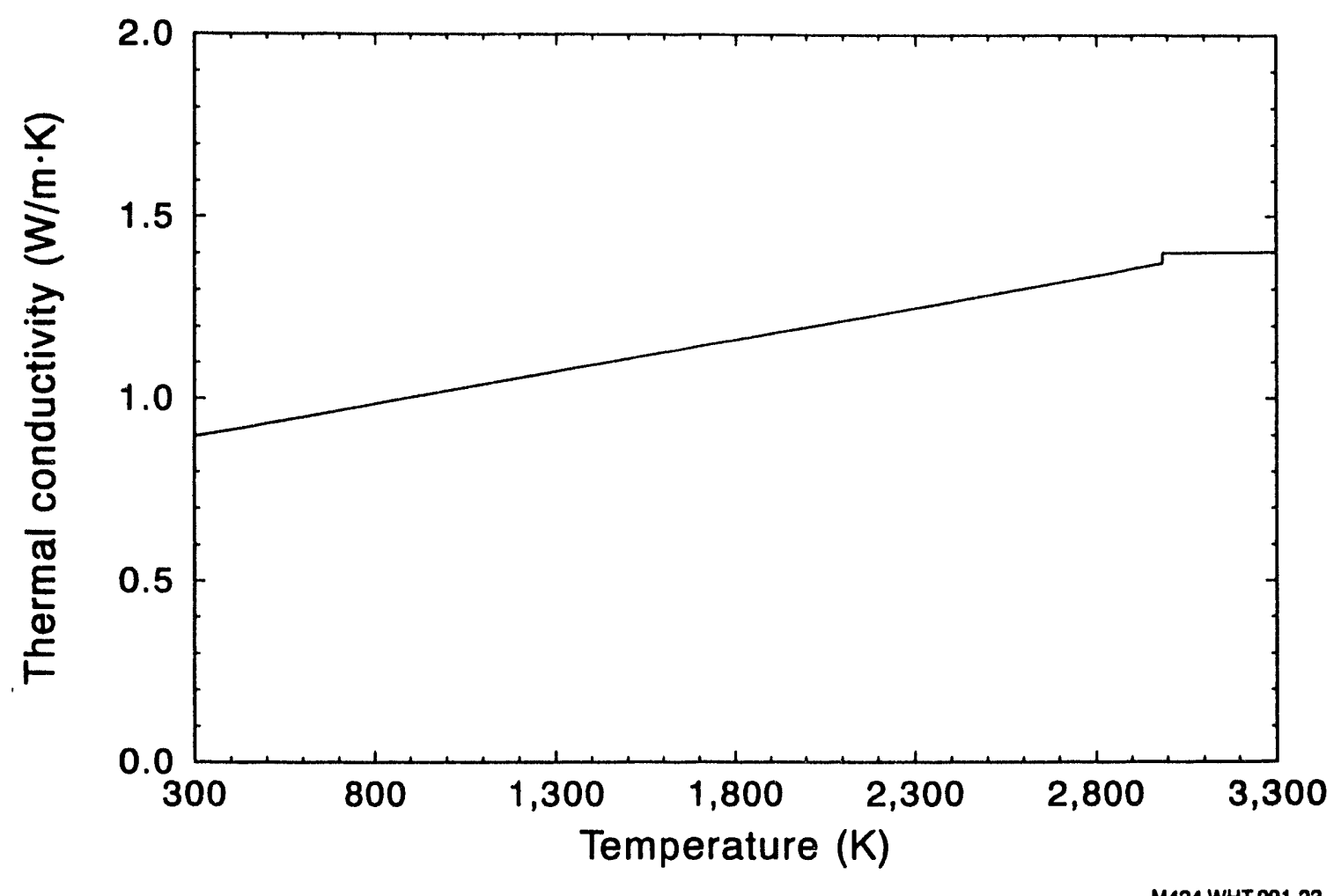

Figure A-6. Zircaloy oxide thermal conductivity as a function of temperature. ${ }^{A-1}$

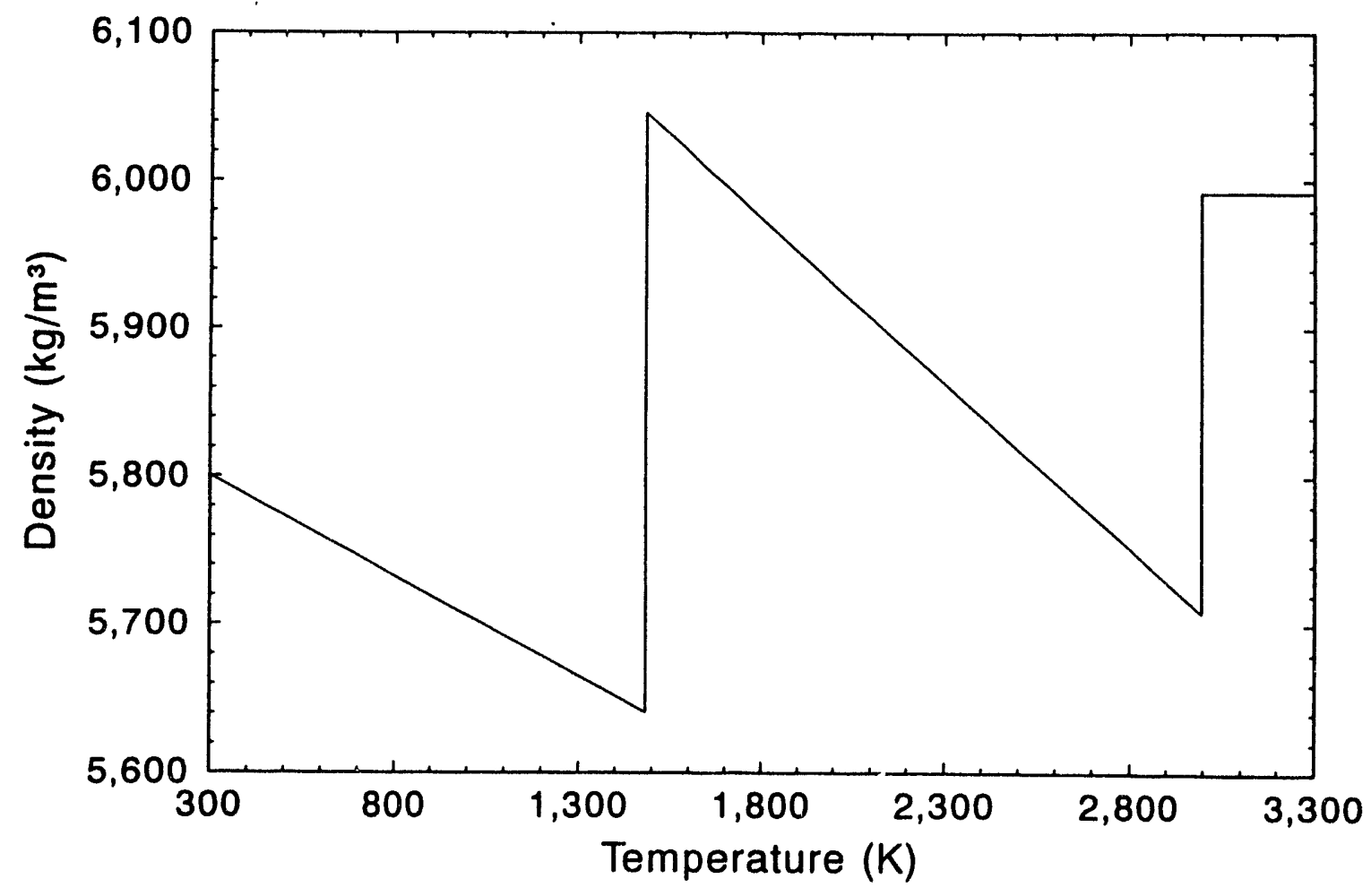

Figure A-7. Zircaloy oxide density as a function of temperature..$^{A-1}$ 


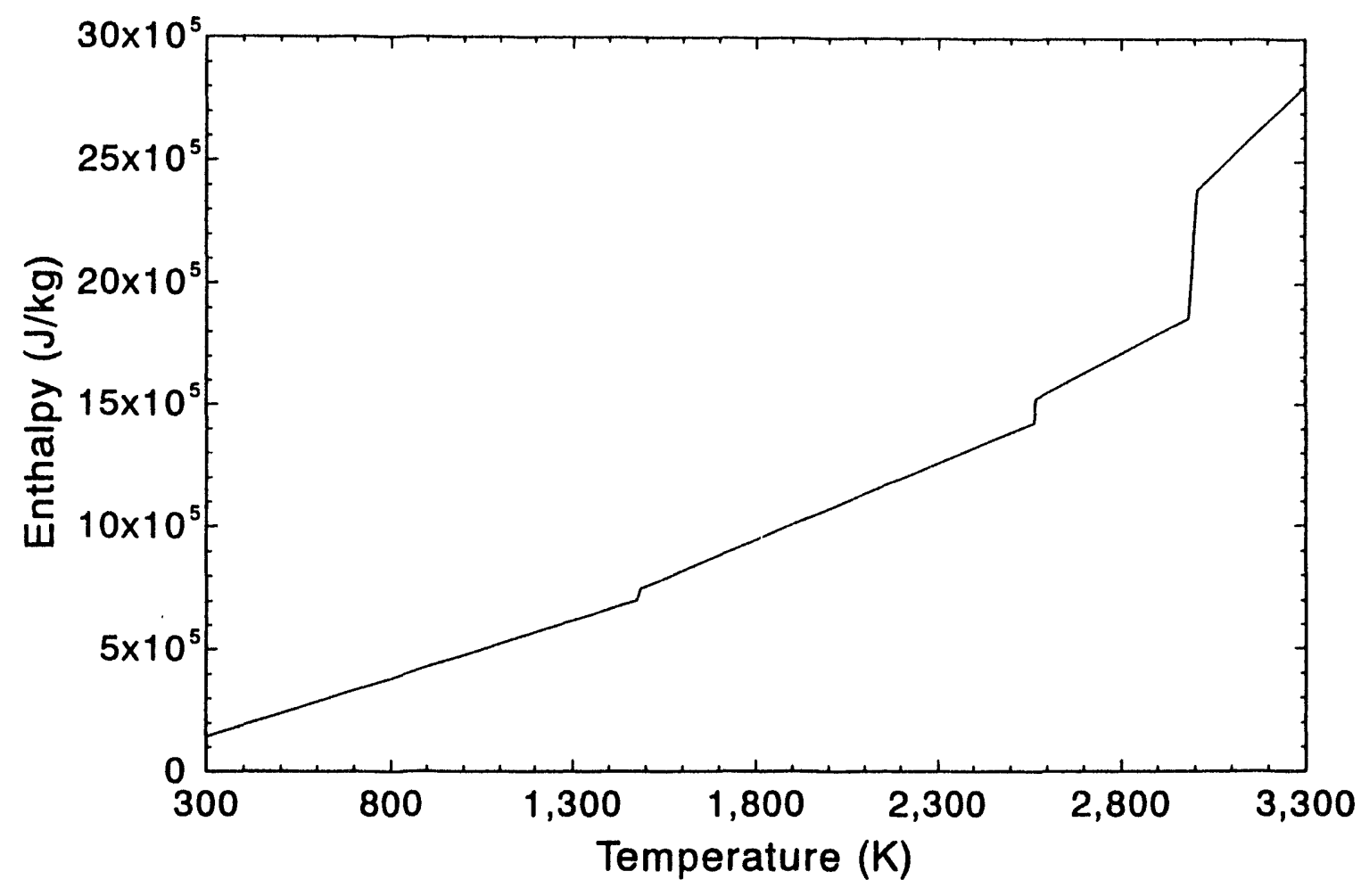

Figure A-8. Zircaloy oxide enthalpy as a function of temperature. ${ }^{A-1}$

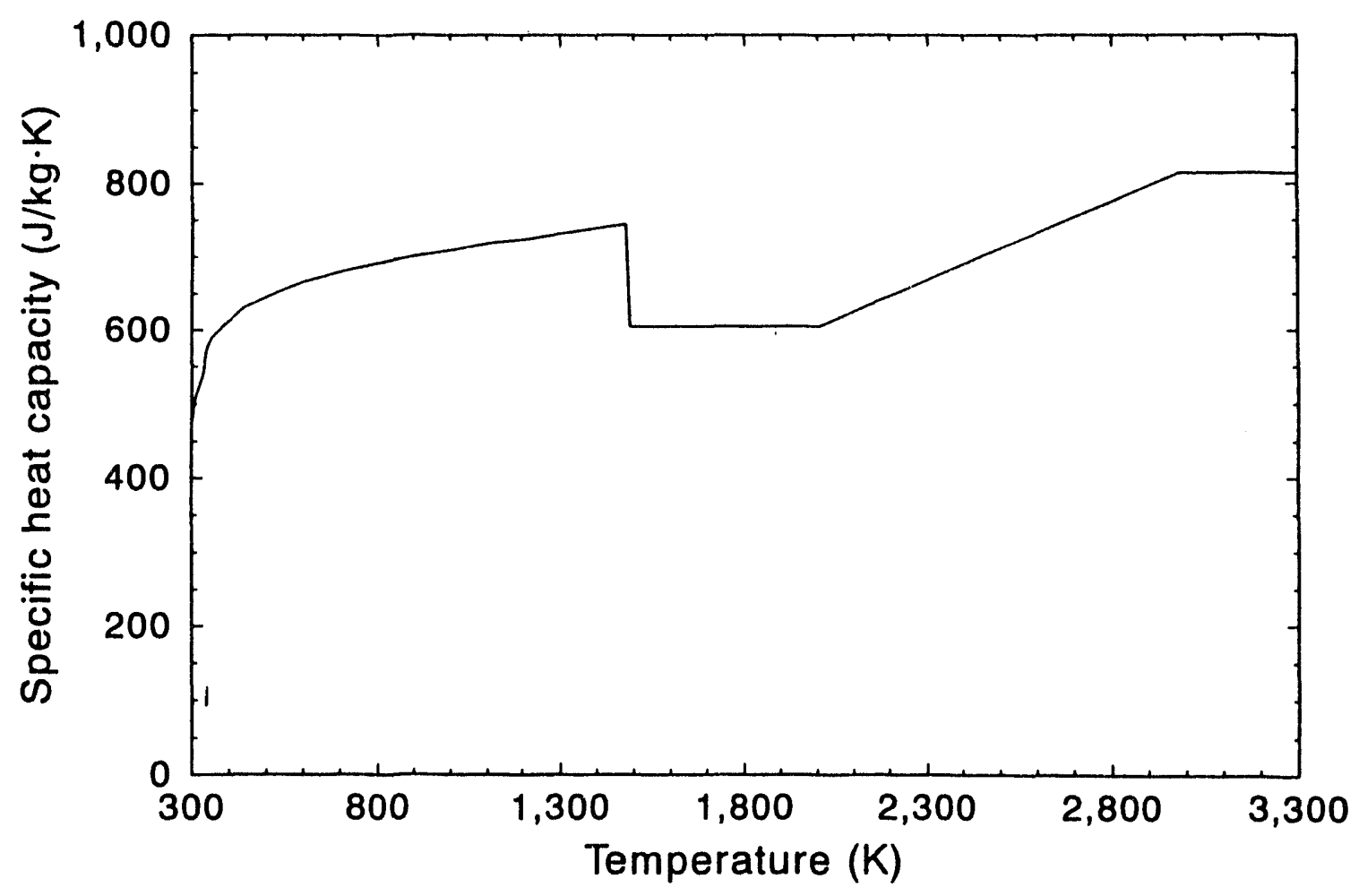

Figure A-9. Zircaloy oxide specific heat capacity as a function of temperaturc. ${ }^{A-1}$ 


\section{A.1.3 (U,Zr) $\mathrm{O}_{2}$ Compound Data}

This section contains data for properties of a $78 \% \mathrm{UO}_{2}-17 \% \mathrm{ZrO}_{2}$ weight fraction compound, which is the composition estimated for debris companion samples. A-2 Properties, such as thermal conductivity, theoretical density, enthalpy, specific heat capacity are summarized in Figures A-10 through A-13. As indicated in the figures, this data was calculated using information in Reference A-1. Based on the phase diagram for U-Zr-O in Reference A-3, it is estimated that the solidus temperature for this compound is $2,650 \mathrm{~K}$ and that the liquidus temperature for this compound is approximately $2,850 \mathrm{~K}$. 


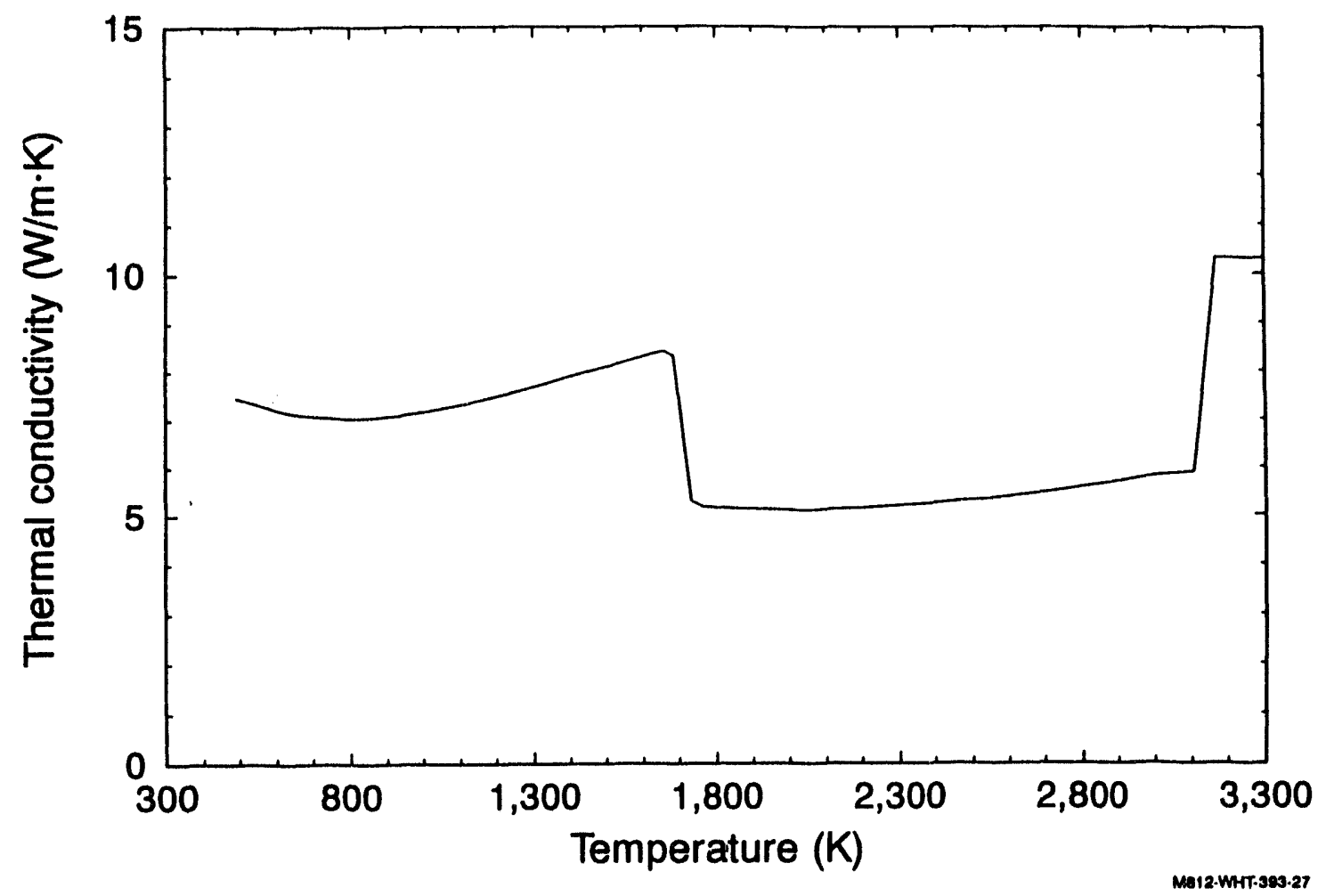

Figure A-10. Thérmal conductivity for a $78 \% \mathrm{UO}_{2}-17 \% \mathrm{ZrO}_{2}$ weight fraction compound. ${ }^{\mathrm{A}-1}$

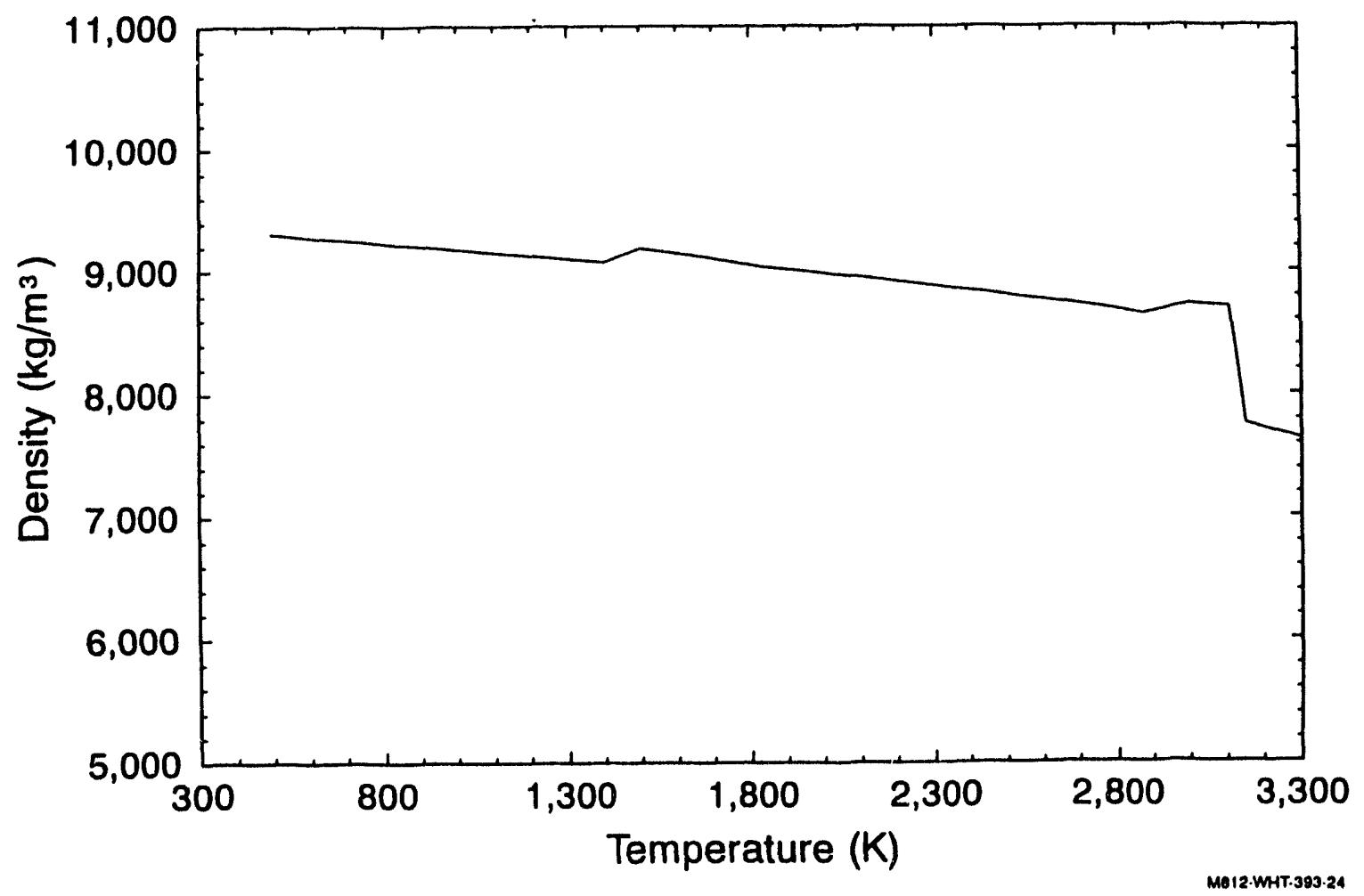

Figure A-11. Density for a $78 \% \mathrm{UO}_{2}-17 \% \mathrm{ZrO}_{2}$ wcight fraction compound. ${ }^{\mathrm{A} \cdot 1}$ 


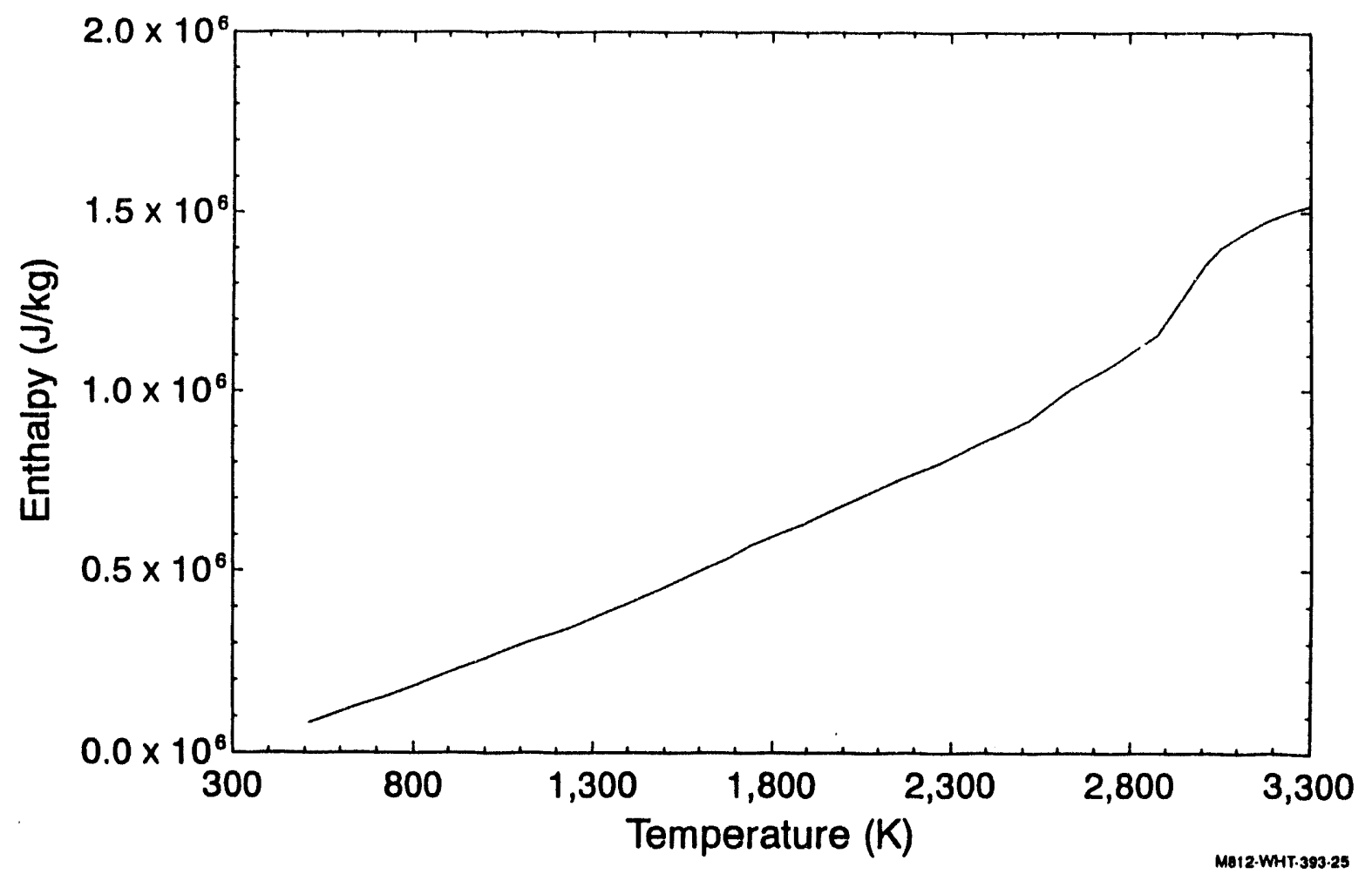

Figure A-12. Enthalpy for a $78 \% \mathrm{UO}_{2}-17 \% \mathrm{ZrO}_{2}$ weight fraction compound. ${ }^{\mathrm{A}-1}$

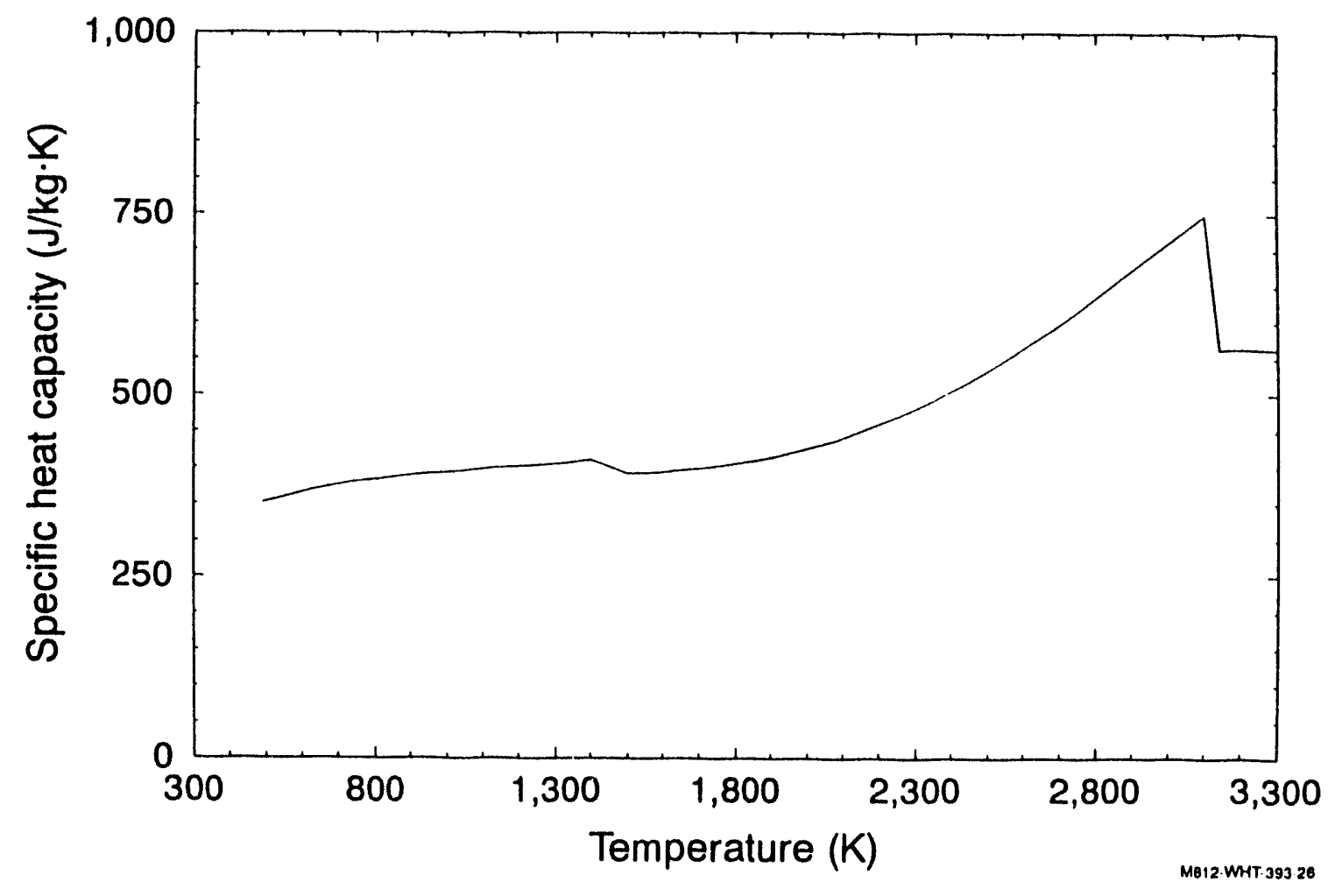

Figure A-13. Specific heat capacity for a $78 \% \mathrm{UO}_{2}-17 \% \mathrm{ZrO}_{2}$ weight fraction compound. ${ }^{\wedge-1}$ 


\section{A.1.4 Inconel-600 Data}

This section contains data for properties of Inconel-600, which is the material used in the TMI-2 instrument tube nozzles. Properties, such as thermal conductivity, theoretical density, and specific heat capacity are summarized in Figures A-14 through A-16. As indicated in these figures, the data are extrapolated for temperatures above $1,100 \mathrm{~K}$. This data is based upon information in References A-4 and A-5. Reference A-4 indicates that the solidus and liquidus temperatures for Inconel-600 are 1,644 and 1,700 K, respectively. 


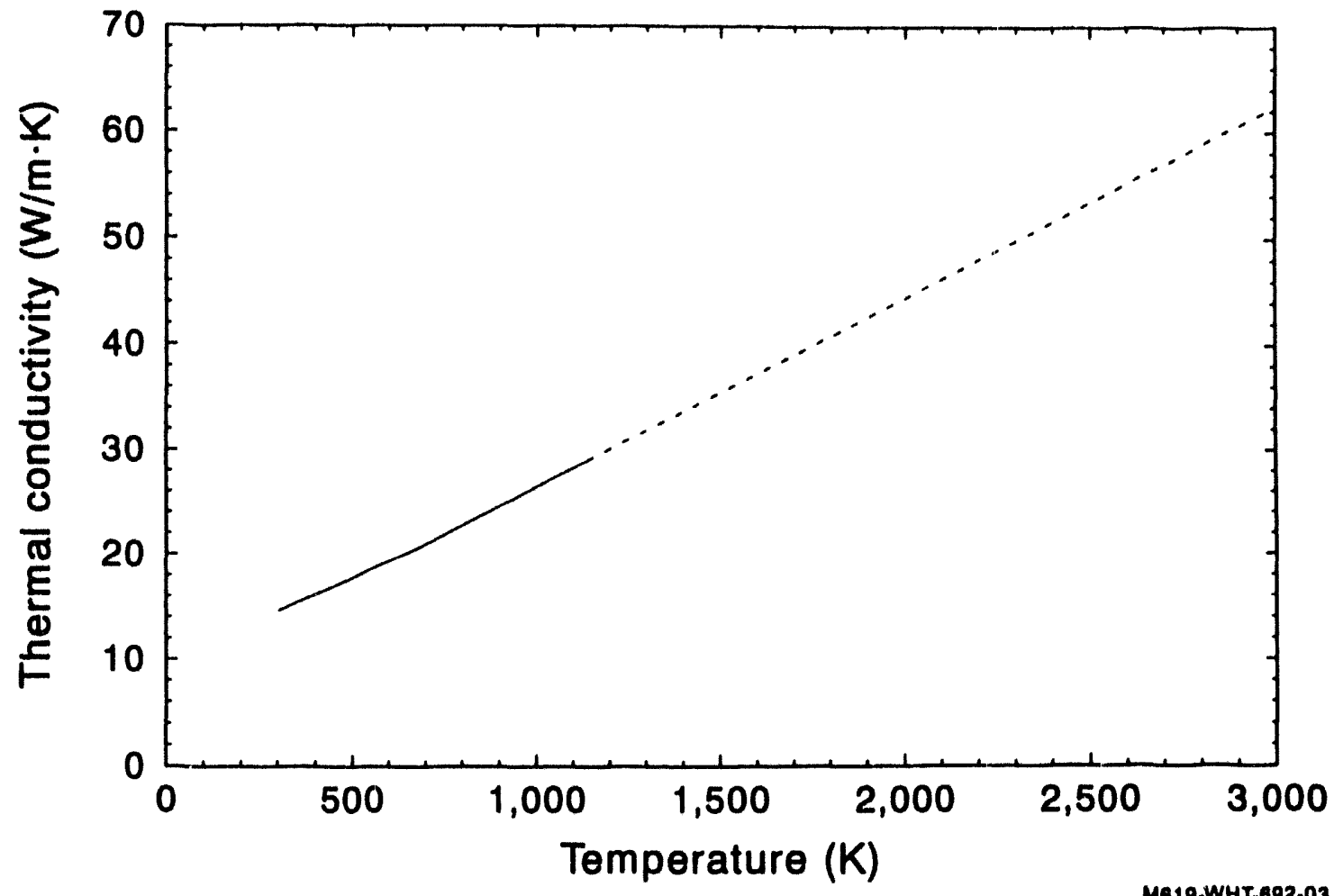

Figure A-14. Inconel-600 thermal conductivity as a function of temperature..$^{A-5}$

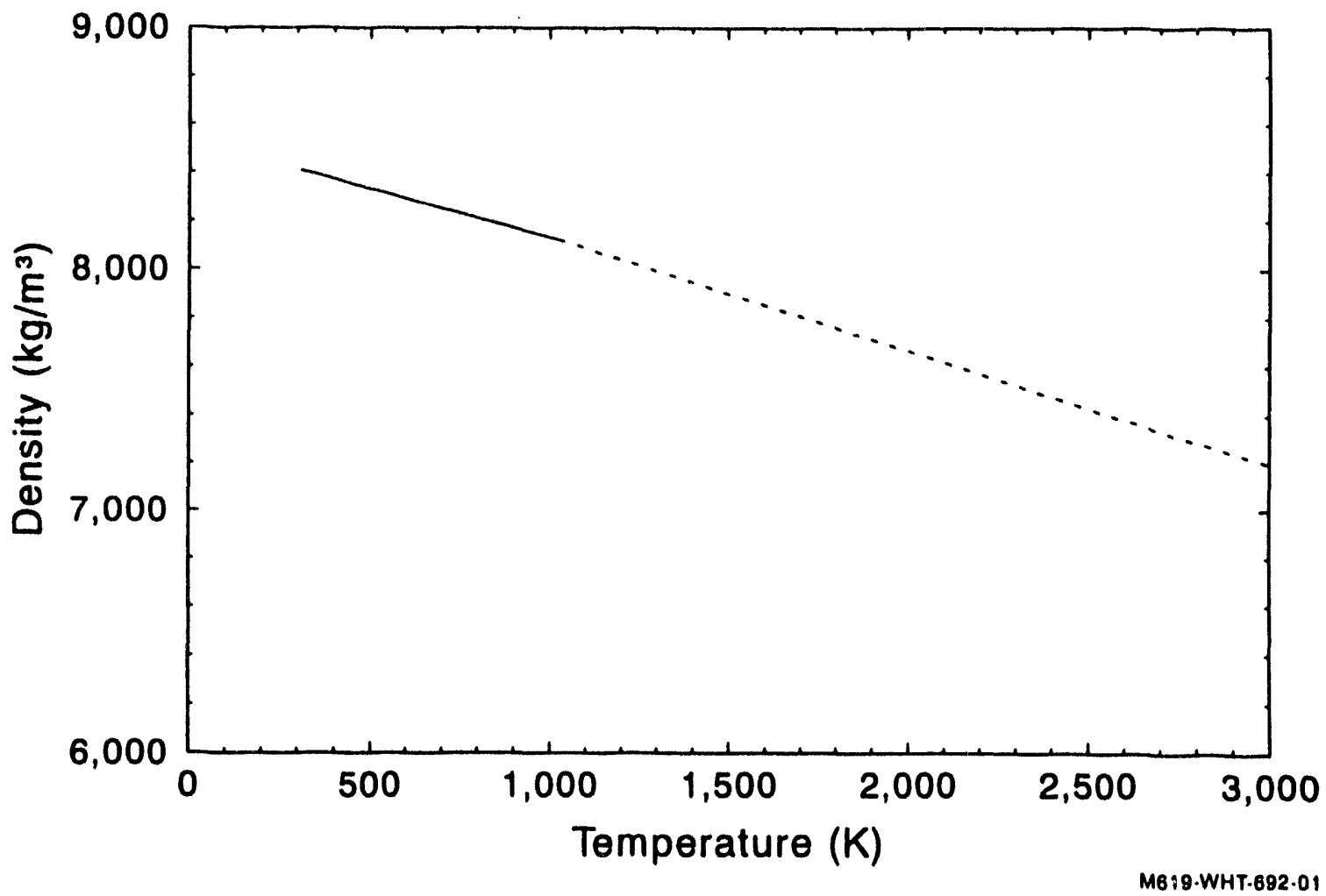

Figure A-15. Incoricl-60M density as a function of temperature. ${ }^{A-4}$ 


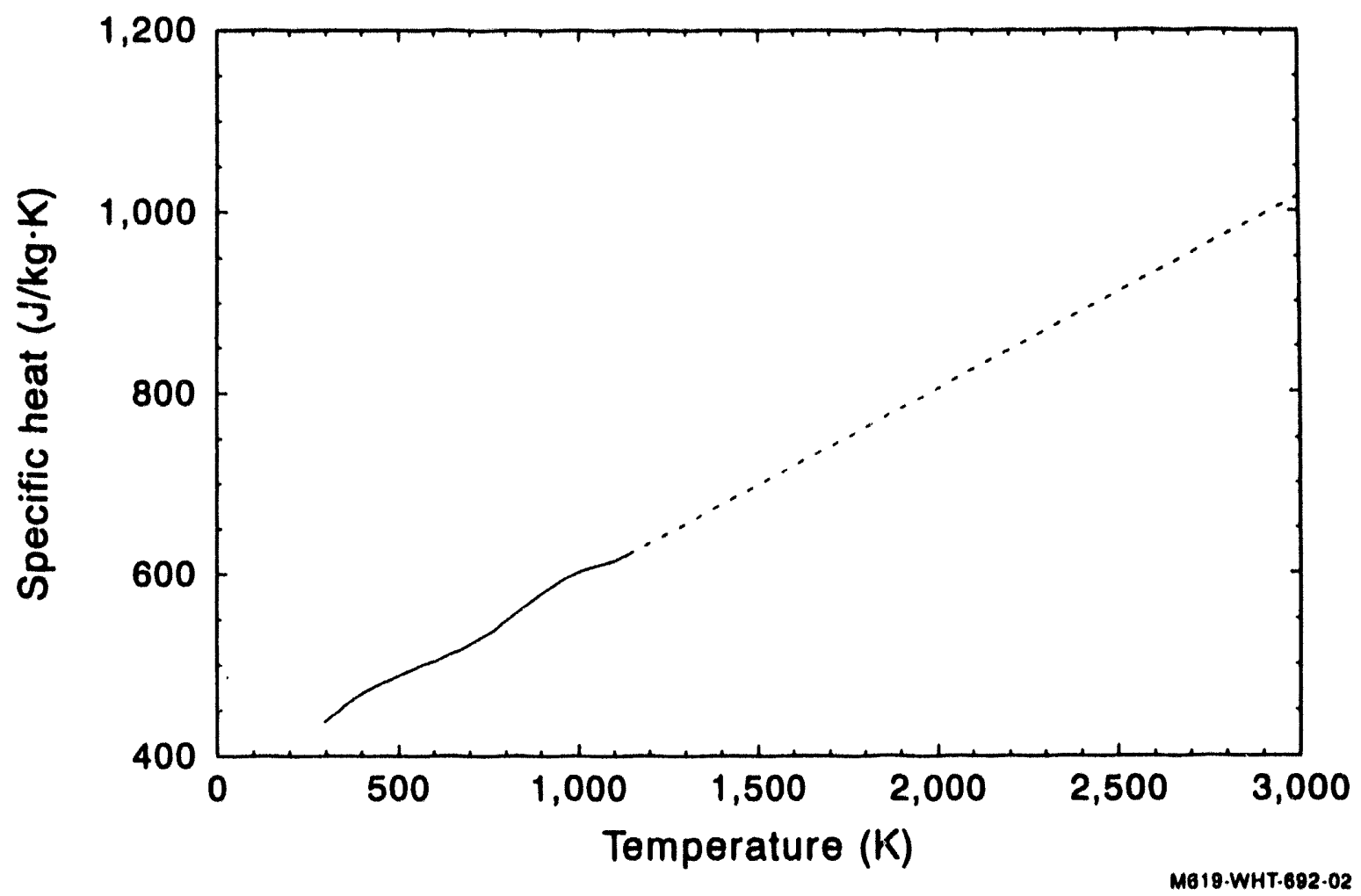

Figure A-16. Inconcl-600 specific heat as a function of temperaturc. ${ }^{A-5}$ 


\section{A.1.5 8A633B1 Carbon 8teol Data}

This section contains data for properties of SAS33 Grade B Class 1 (SA533B1) carbon steel, which is the material used in the TMI-2 vessel. Properties, such as thermal conductivity, density, specific heat capacity, and thermal diffusivity are summarized in Figures A-17 through A-20. References for the data are indicated in each figure. Information in Reference A-6 indicates that the solidus and liquidus temperature for SA533B1 carbon steel is $1,789 \mathrm{~K}$. 


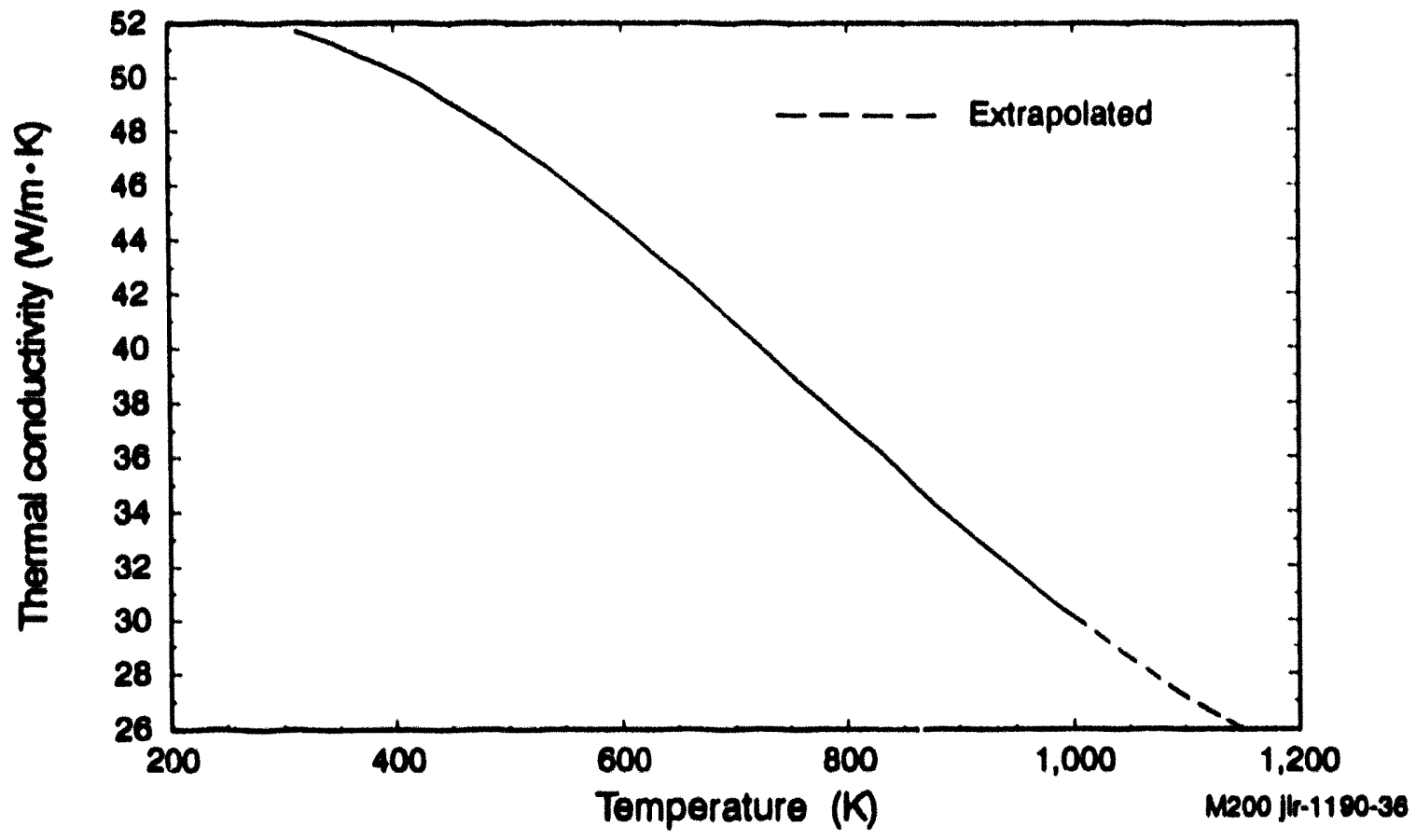

Flgure A-17. Thermal conductivity of carbon stecl (SA533B1).A-7,A-8

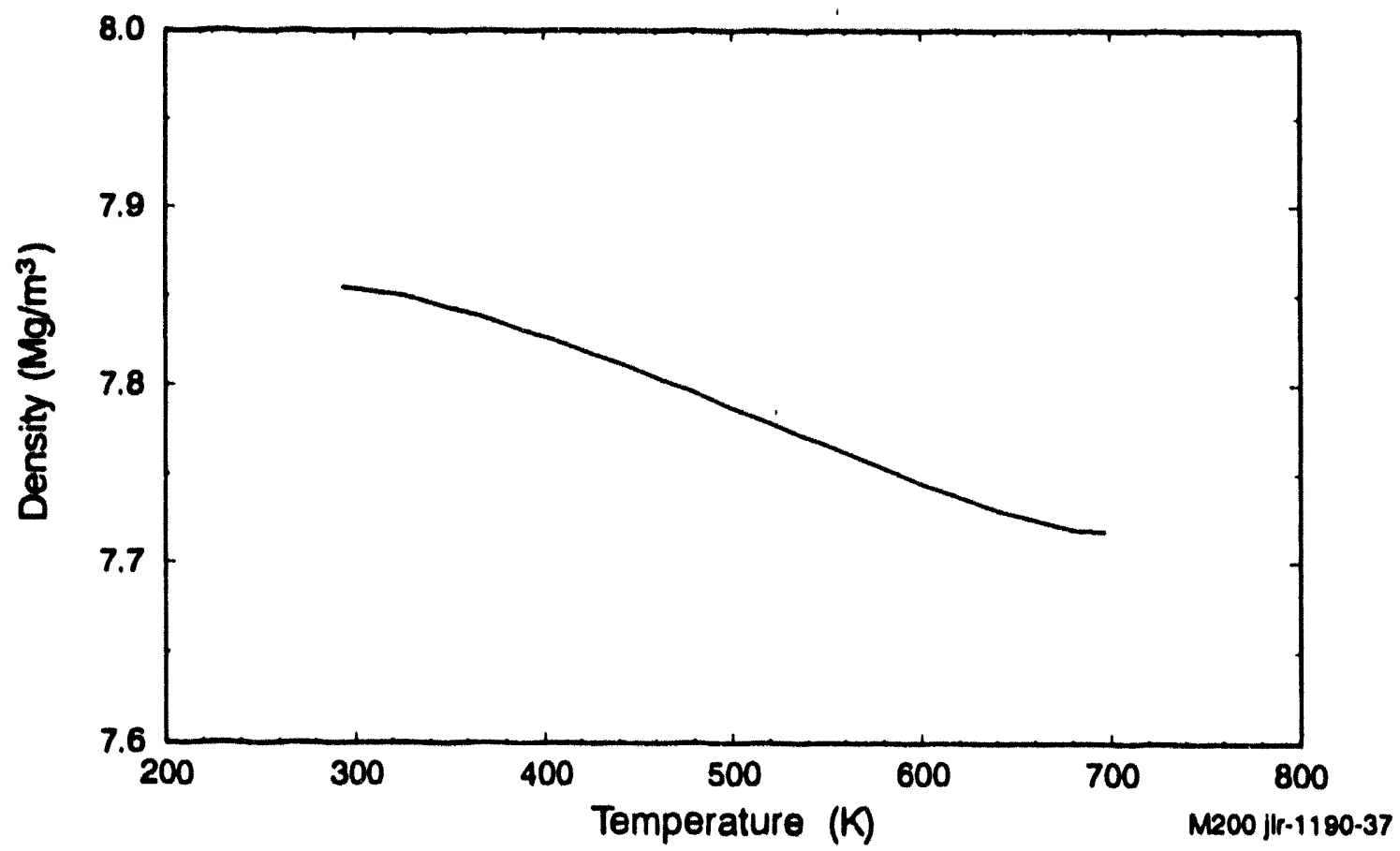

Figure A-18. Density of carhon stecl (SA533B1). ${ }^{\text {A.9 }}$ 


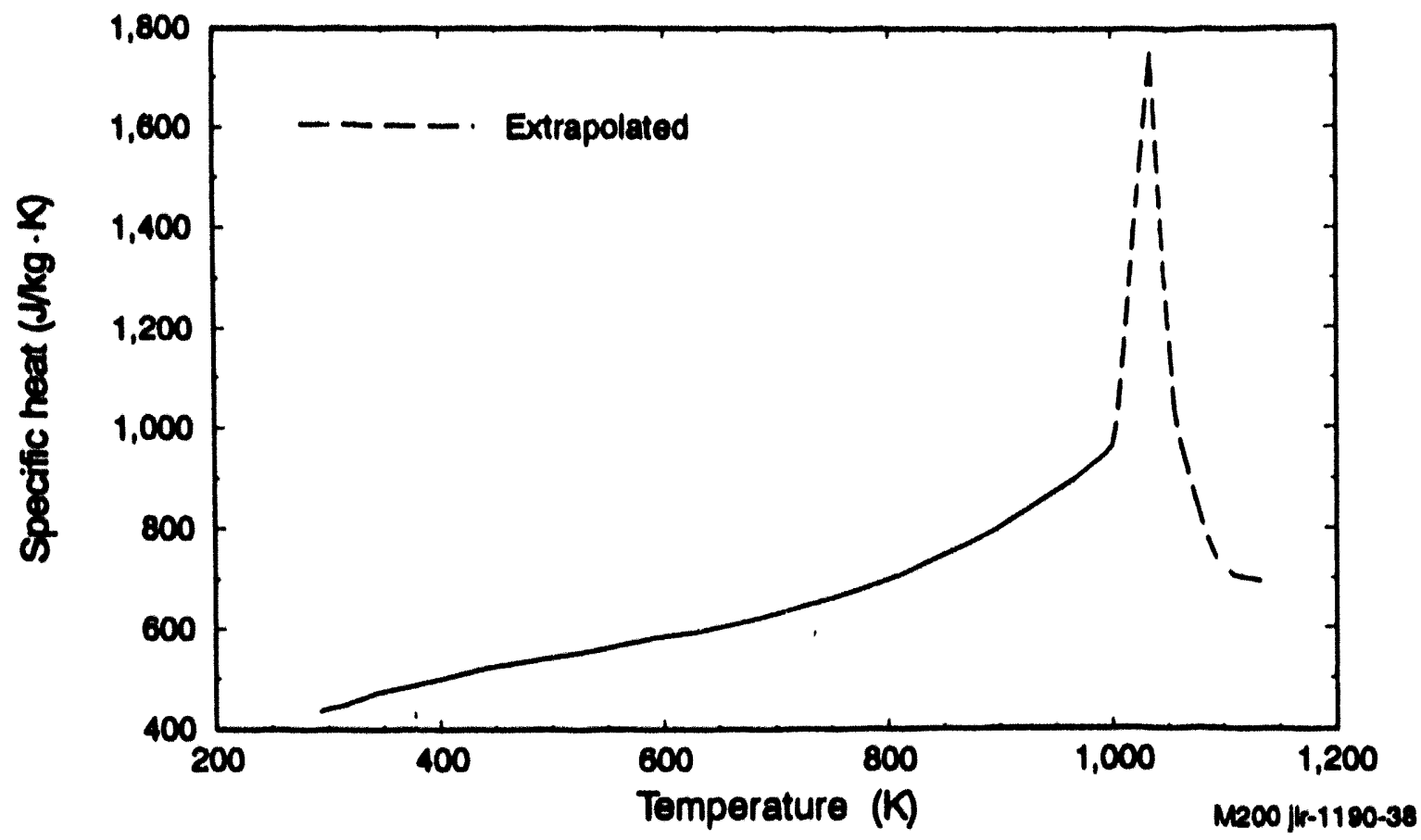

Figure A-19. Specific heat of carbon stccl (SA533BB1). . $10, A \cdot 11, A \cdot 12 . A \cdot 13^{-13}$

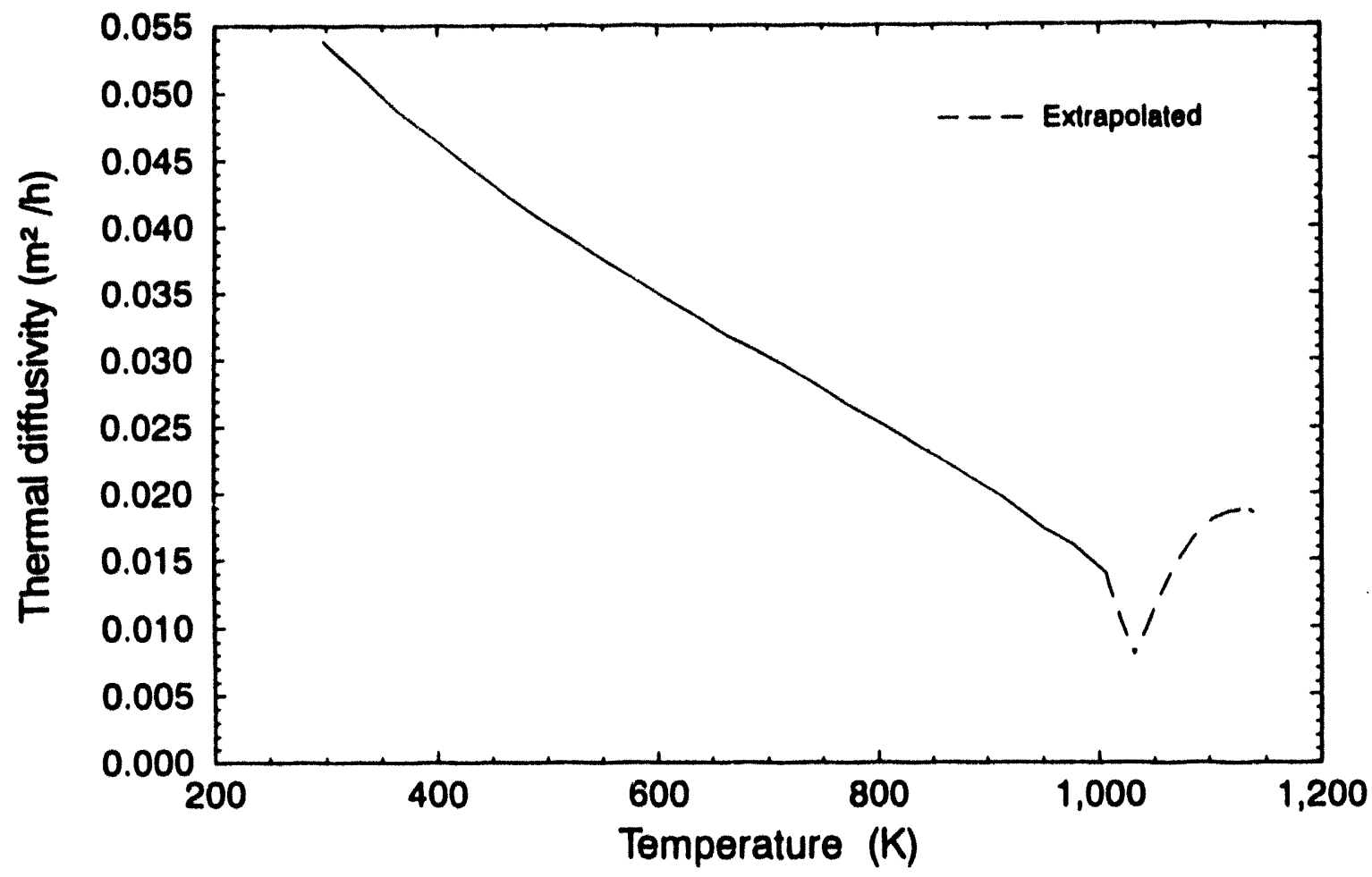

Figure A-20. Thermal diffusivity of carhon stcel (SA.53.3B1). ${ }^{\text {A-9.A.14 }}$ 


\section{A.1.6 Stainloes Steel Data}

This section contains data for the following properties of stainless steel: thermal conductivity, density, enthalpy, and specific heat capacity. These data are summarized in Figures A-21 through A-24. 
$6 L-062 L-1 H M-66 \mathrm{IW}$

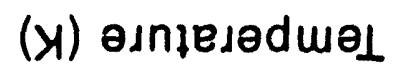

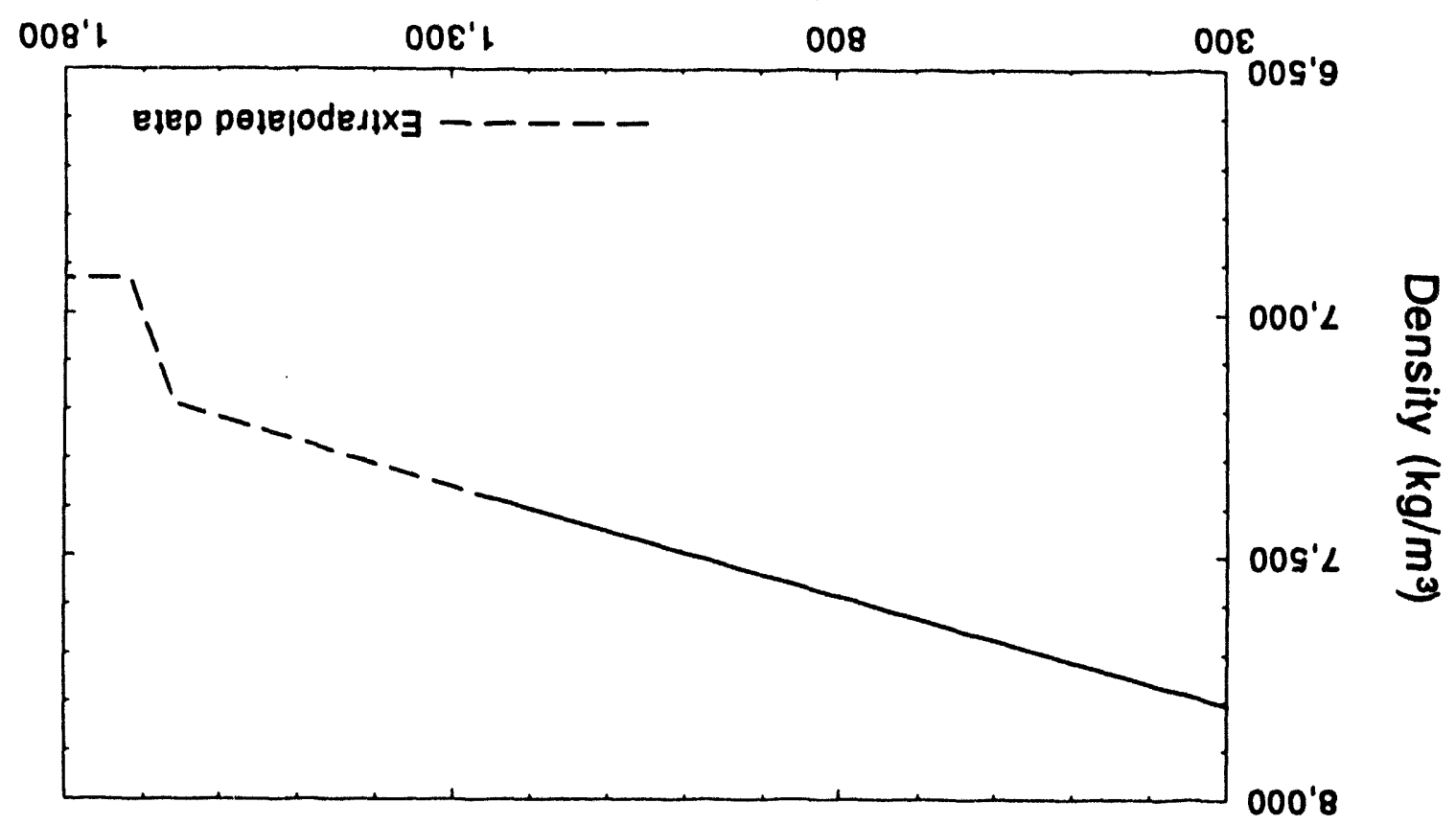

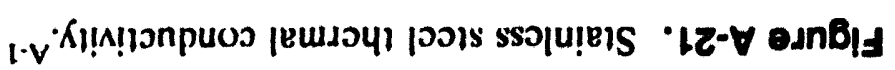
8L-06ZL-LHM-66LW

(x) eınłejedwel

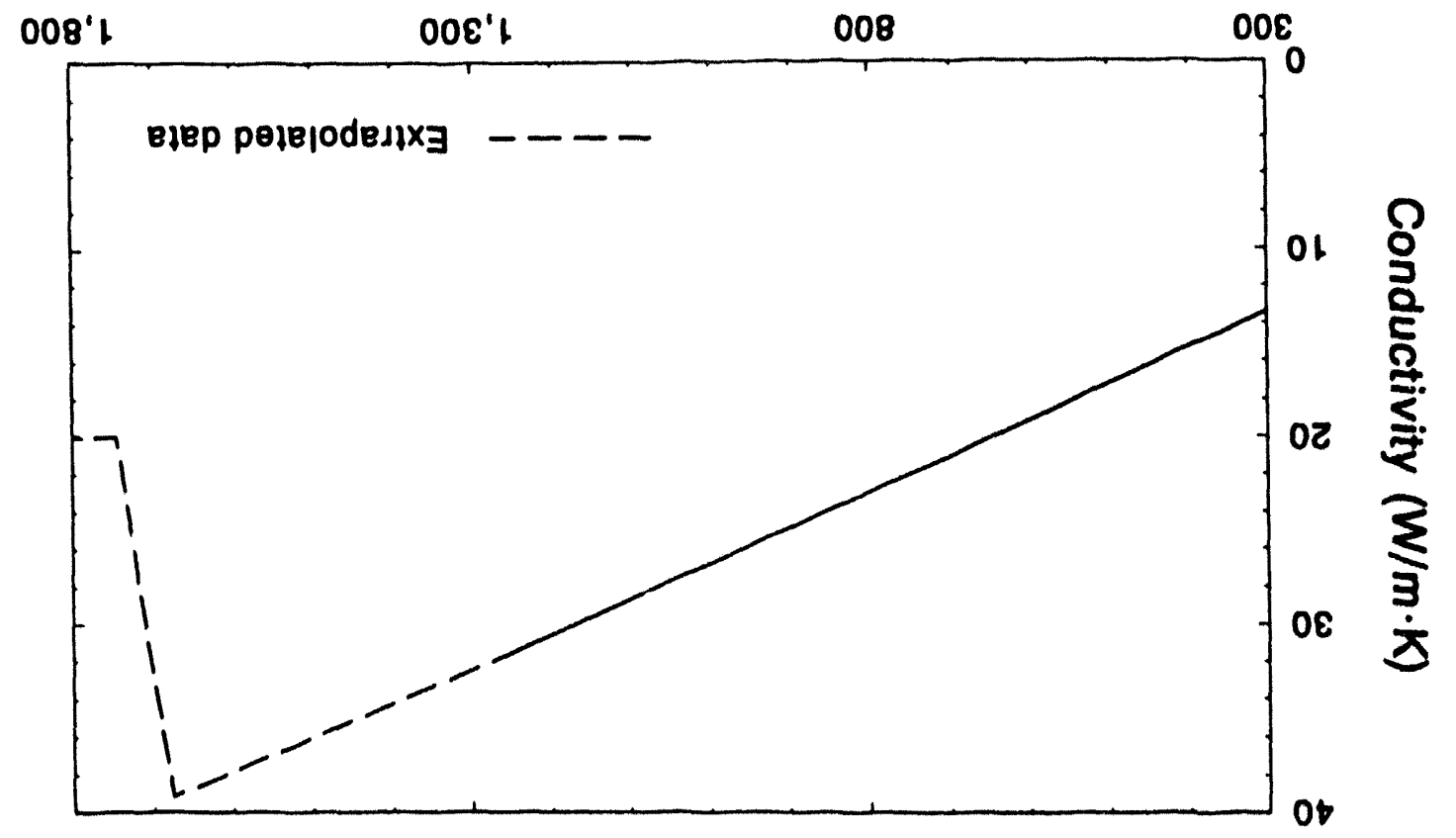




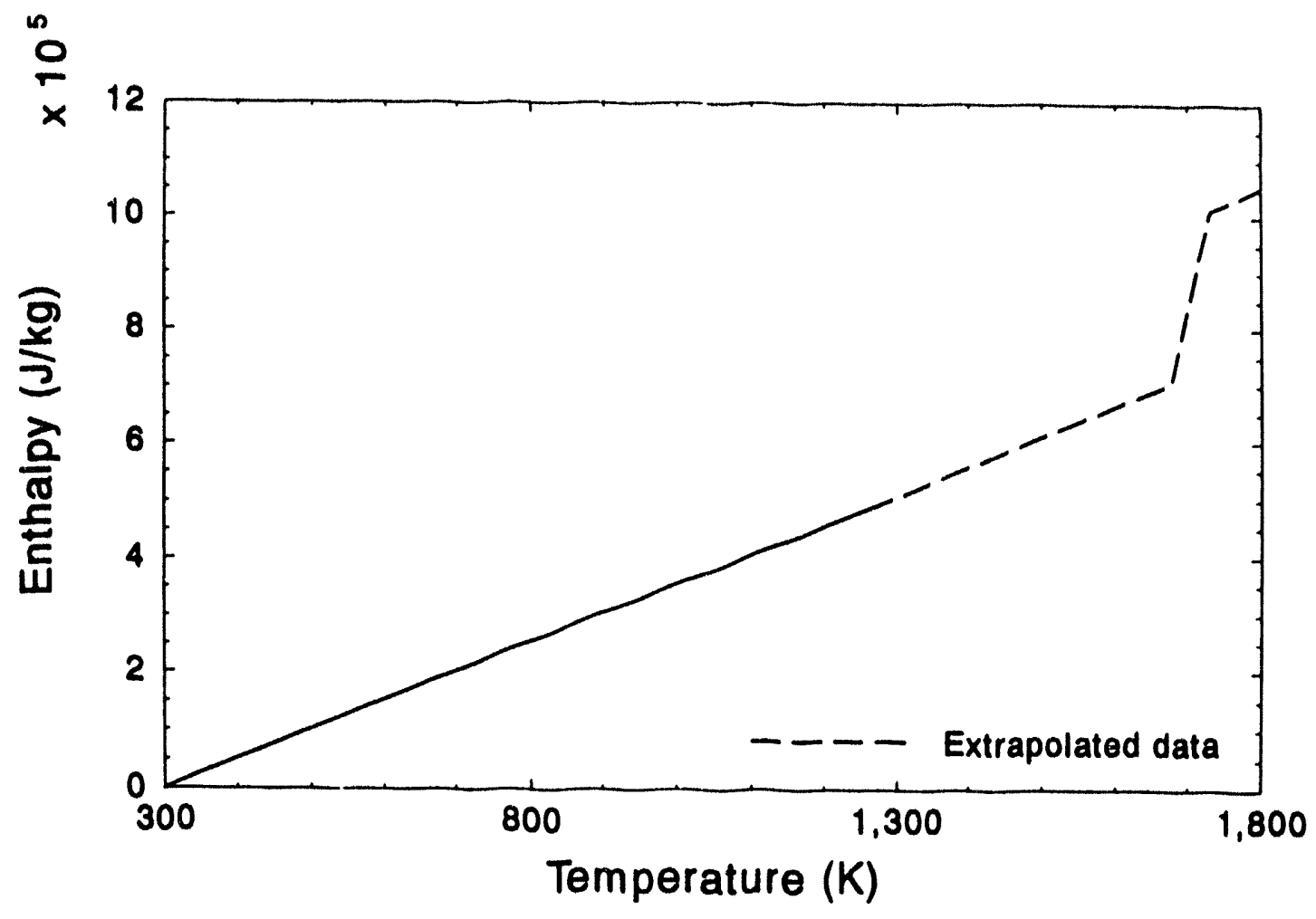

M199-WHT-1290-17

Figure A-23. Stainless stecl enthalpy. ${ }^{A-1}$

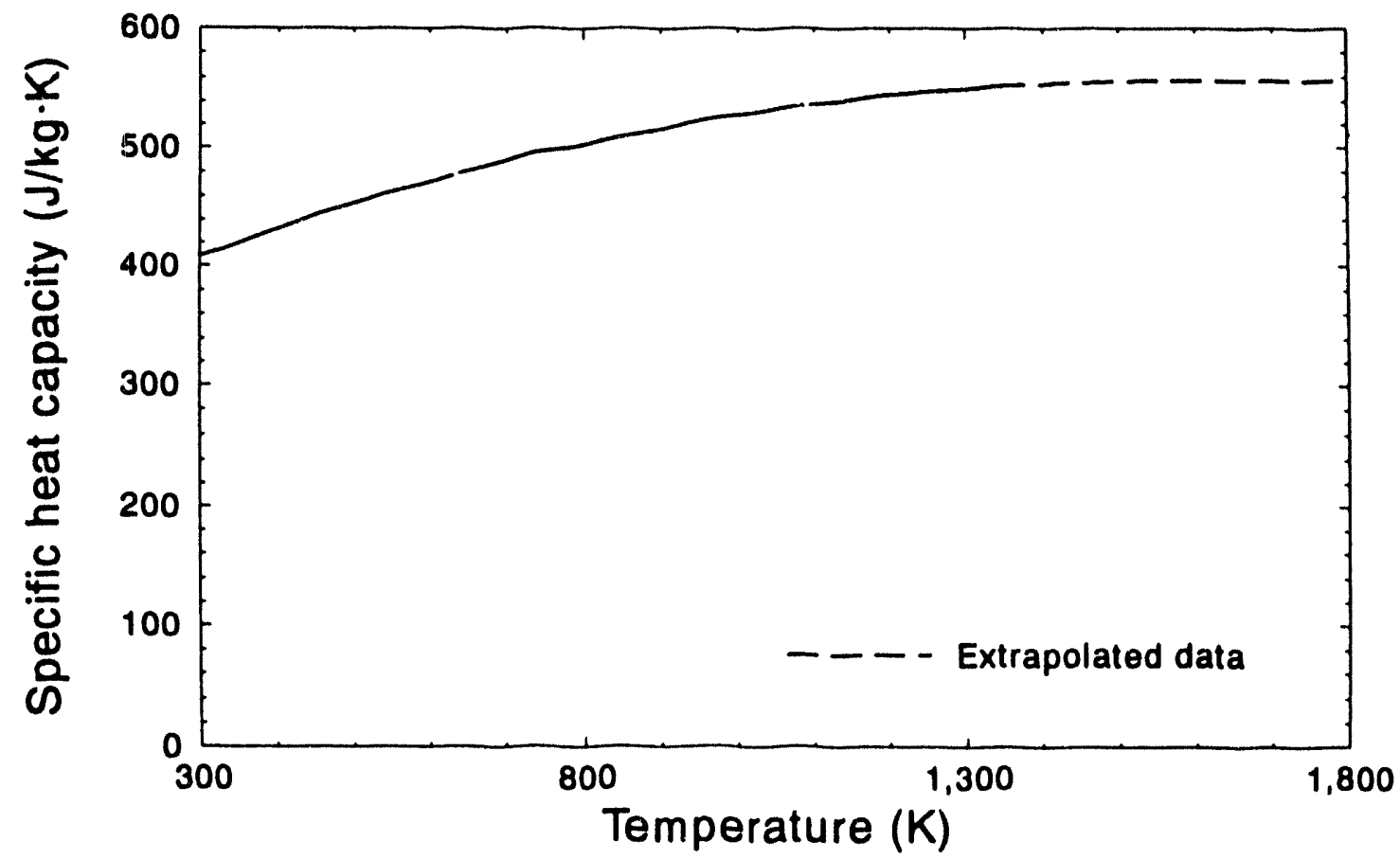

M199-WHT-1290.16

Figure A-24. Stainless stecl heat capacity at constant pressurc. ${ }^{A-1}$ 


\section{A.2 Structural Material Property Data}

Structural calculations for the TMI margin-to-failure analysis used the material data for Inconel-600 and SA533B steel summarized in this appendix. Included are temperature-dependent structural properties such as elastic modulus, Poisson's ratio, yield strength, ultimate strength and thermal coefficient of expansion. The elastic portions of the stress-strain curves were derived from published values of temperature-dependent elastic moduli, plastic portions were taken from test data. Creep failure times are plotted for corresponding stresses at various temperatures and the Larson-Miller parameter is plotted as a function of log(stress).

Some of the data listed in the tables (e.g., \% total elongation) and in the figures (e.g., Inconel-600 Poisson's ratio) were not actually used in the analysis, but are included for completeness. For penetration ejection analysis, weld material was assumed to have the same material properties as its base Inconel-600 material.

\section{A.2.1 Inconel Data}

This section contains data for structural properties of Inconel-600, annealed for 1 hour at $1,143 \mathrm{~K}$ and force air cooled. Temperature-dependent properties include elastic modulus, Poisson's ratio, yield strength, ultimate strength and thermal coefficient of expansion. In Figures A-25 through A-33 stress-strain curves are plotted for various temperatures, creep rupture times are plotted for corresponding stresses at various temperatures, and the Larson-Miller parameter is plotted against $\log$ (stress). Tables A-1 and A-2 contain listings of tensile and creep data. Not all temperature-dependent properties were used in the penetration tube rupture or penetration weld analyses, but are included here for completeness. Much of the high temperature property data was obtained as part of the NRC-sponsored Lower Head Failure Program. A.15 


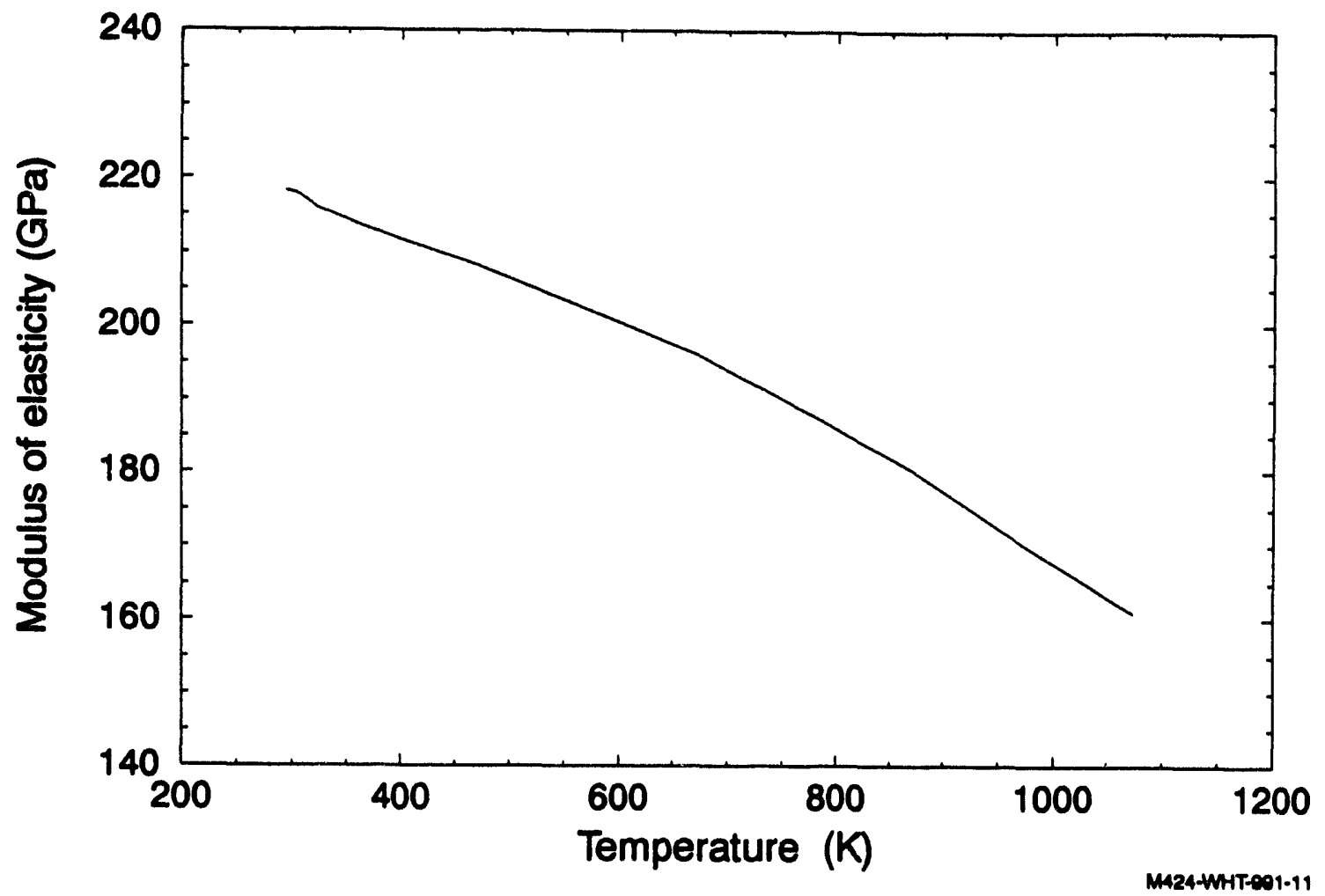

Figure A-25. Inconel-600 elastic modulus as a function of temperature. ${ }^{A-5}$

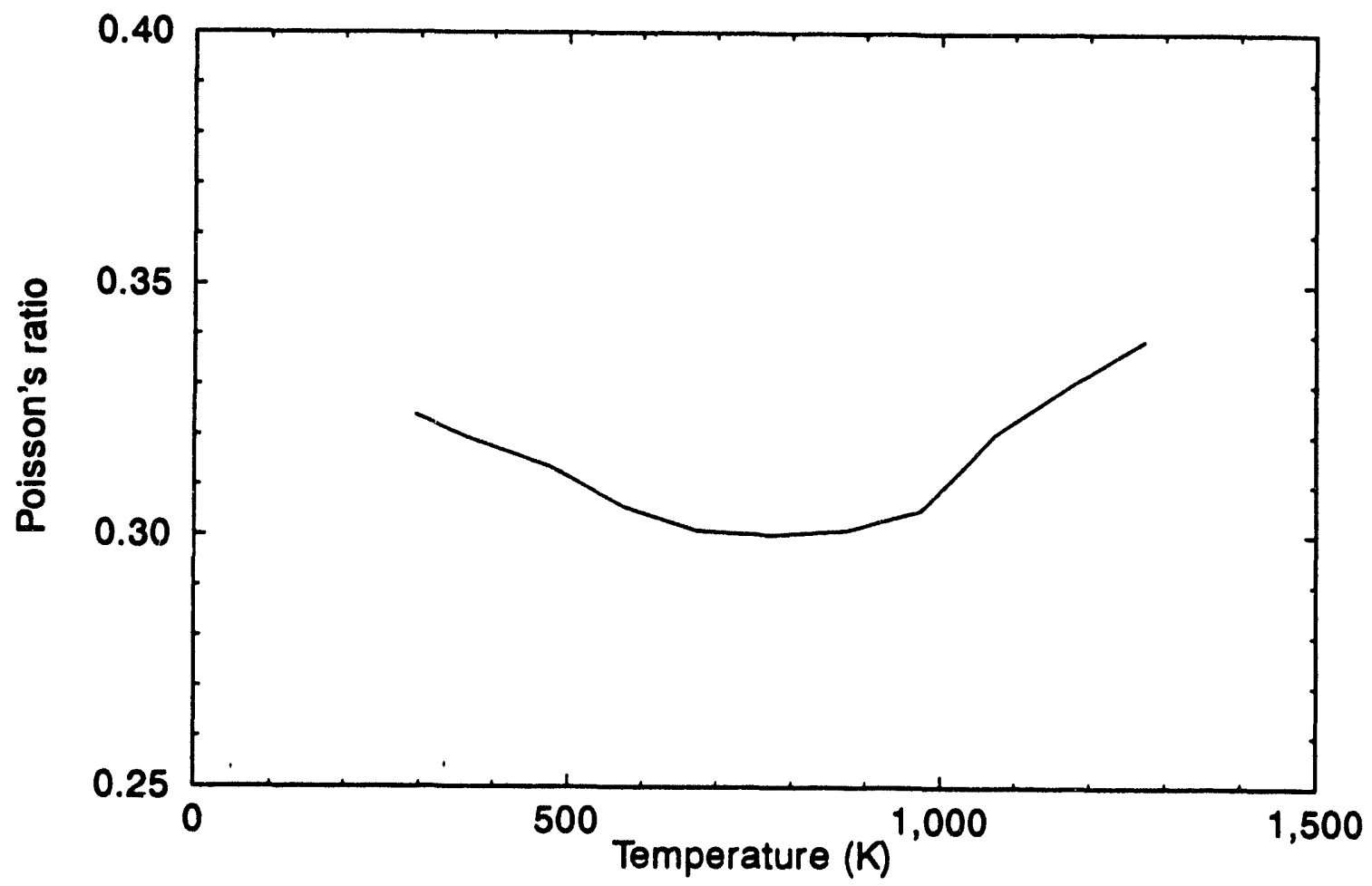

Figure A-26. Inconel-600 Poisson's ratio as a function of temperature. ${ }^{\text {A.5 }}$ 


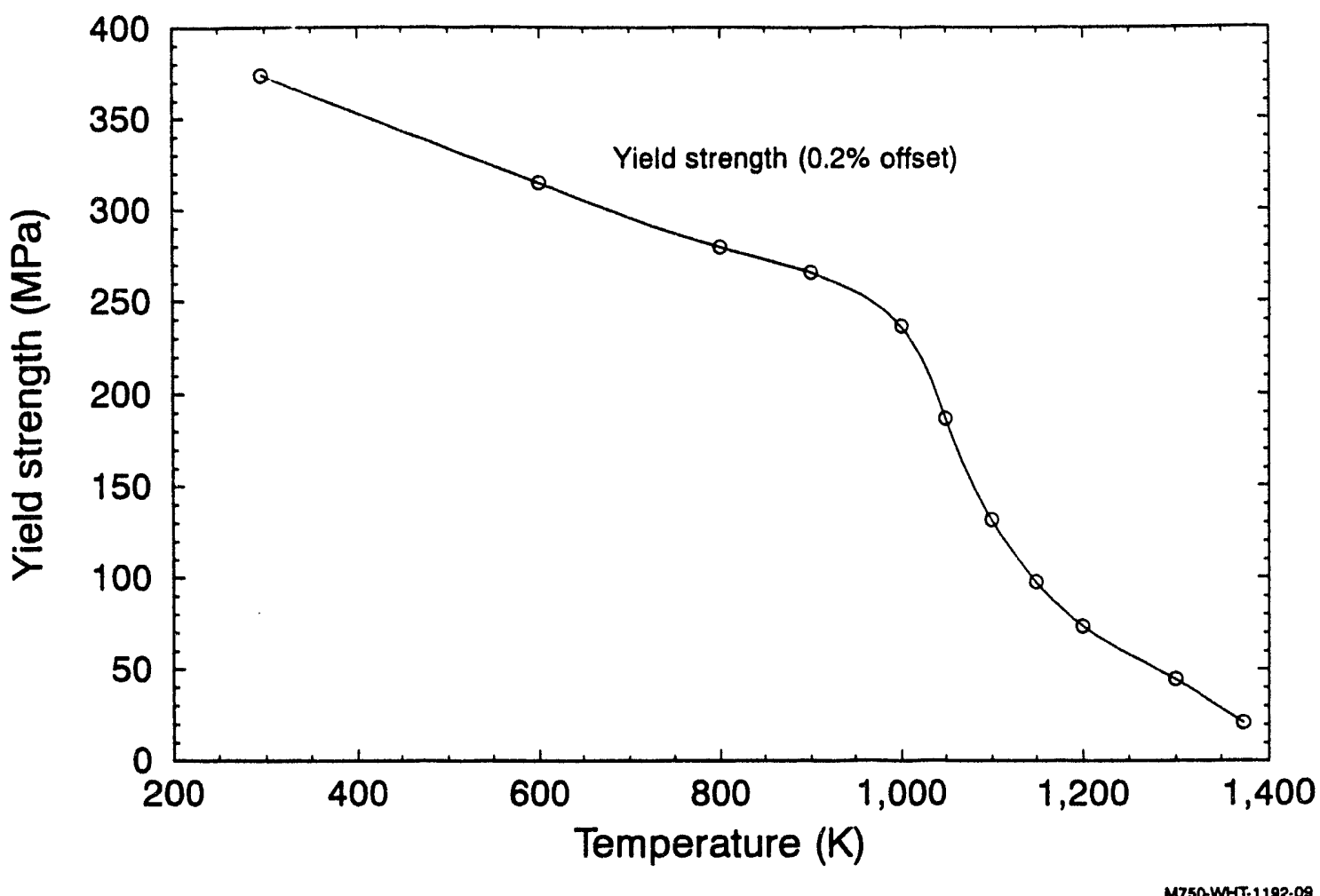

Figure A-27. Inconel-600 yicld strength as a function of temperature. ${ }^{A-15}$

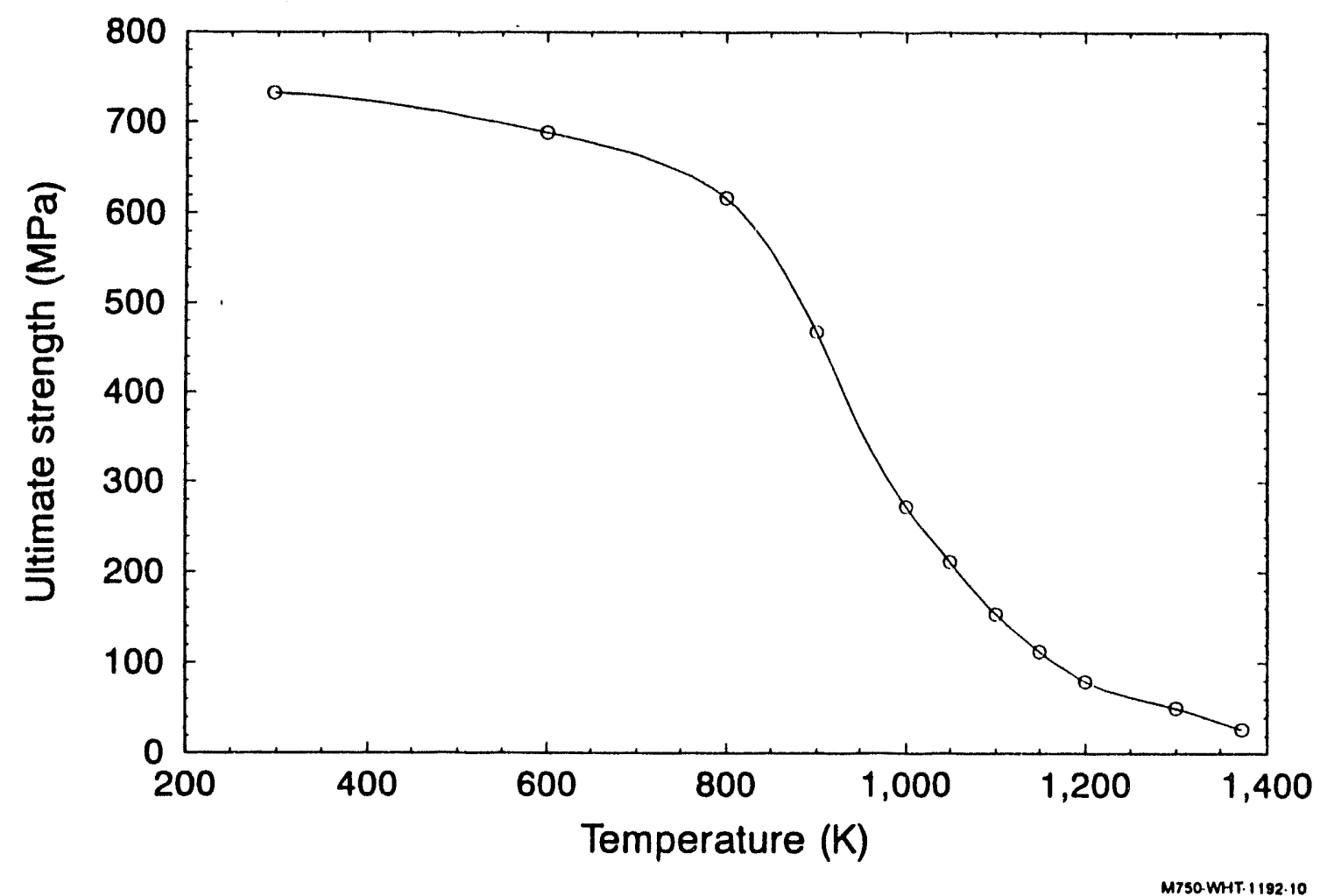

Figure A-28. Inconcl-600 ultimate strength as a function of temperature. ${ }^{A-15}$ 


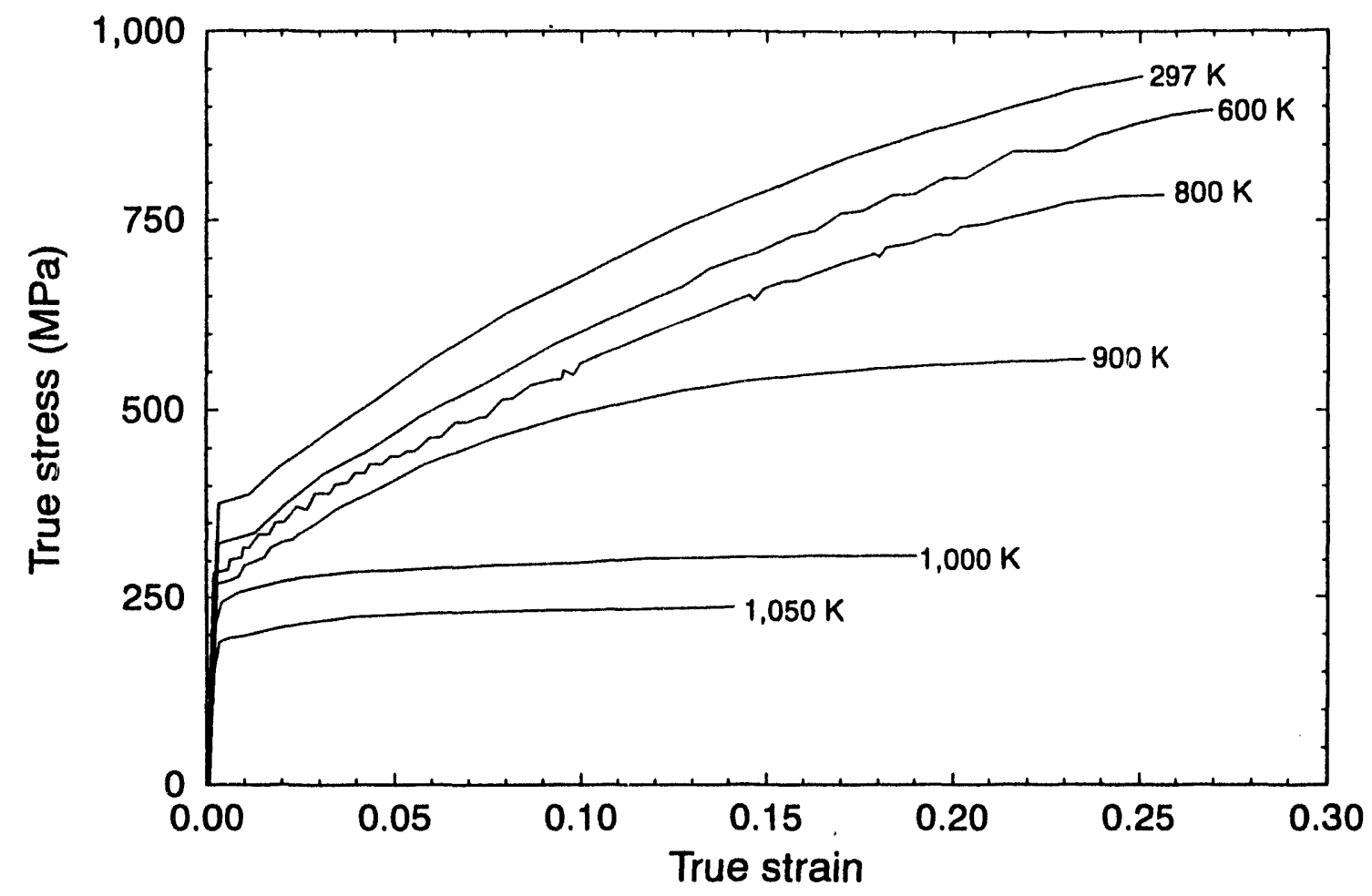

Figure A-29. Inconel-600 stress-strain curves for 297 to $1,050 \mathrm{~K} \cdot{ }^{A-15}$

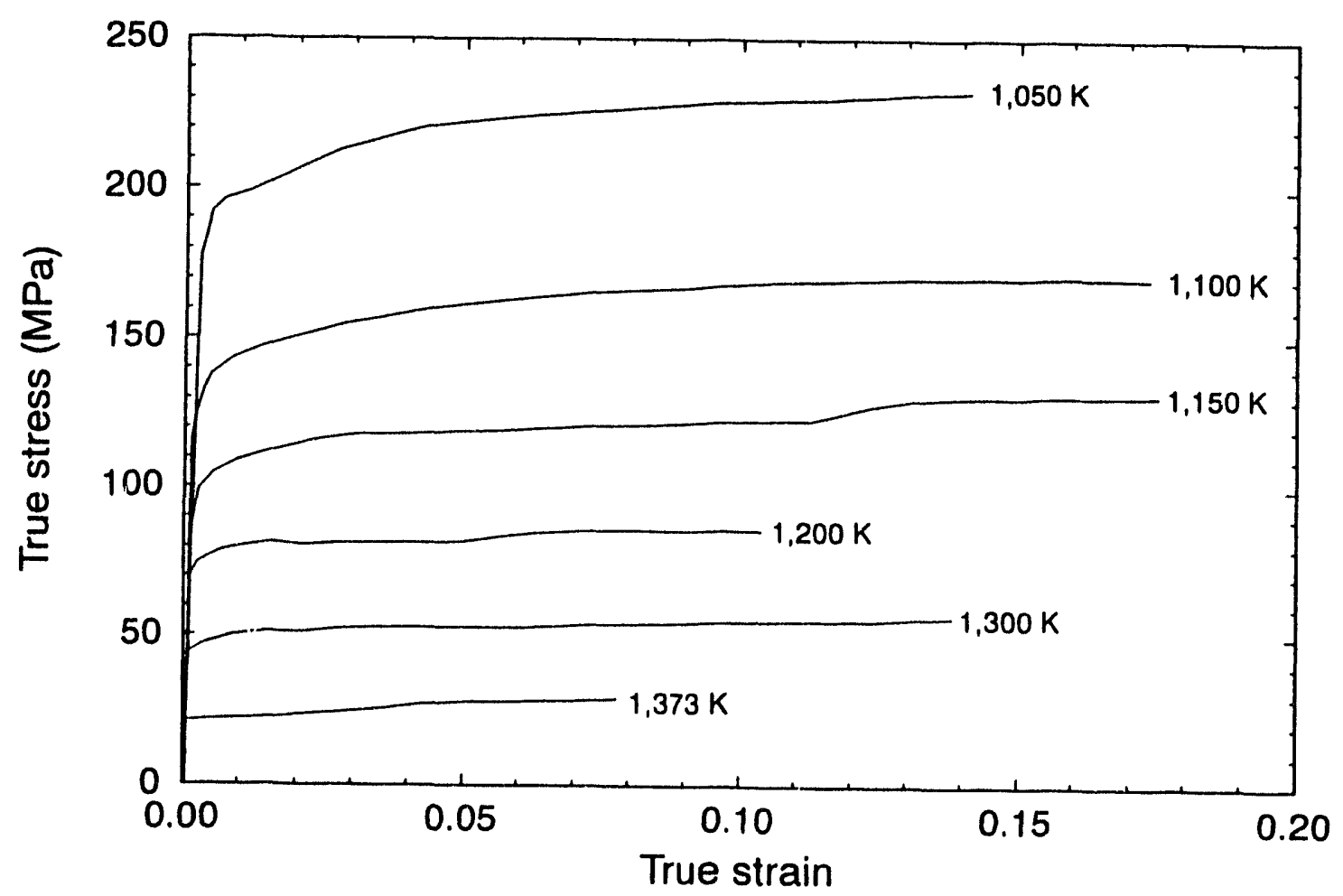

Figure A-30. Inconcl-6mo stress-strain curves for 1.050 to $1.373 \mathrm{~K}^{\wedge-15}$ 


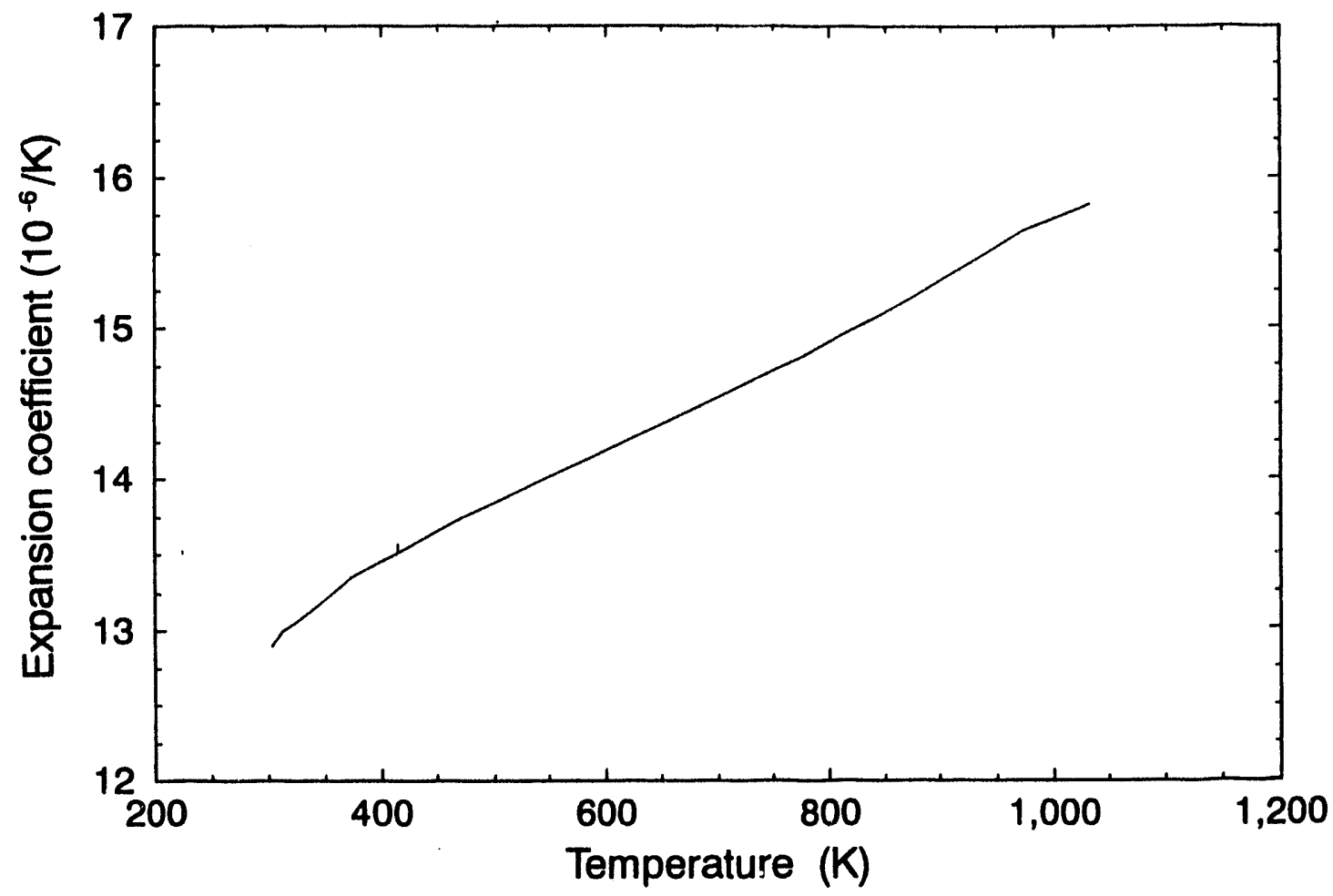

M424-WHT-991-10

Figure A-31. Inconcl-600 mean linear thermal coefficient of expansion as a function of temperature. A-S $^{-5}$

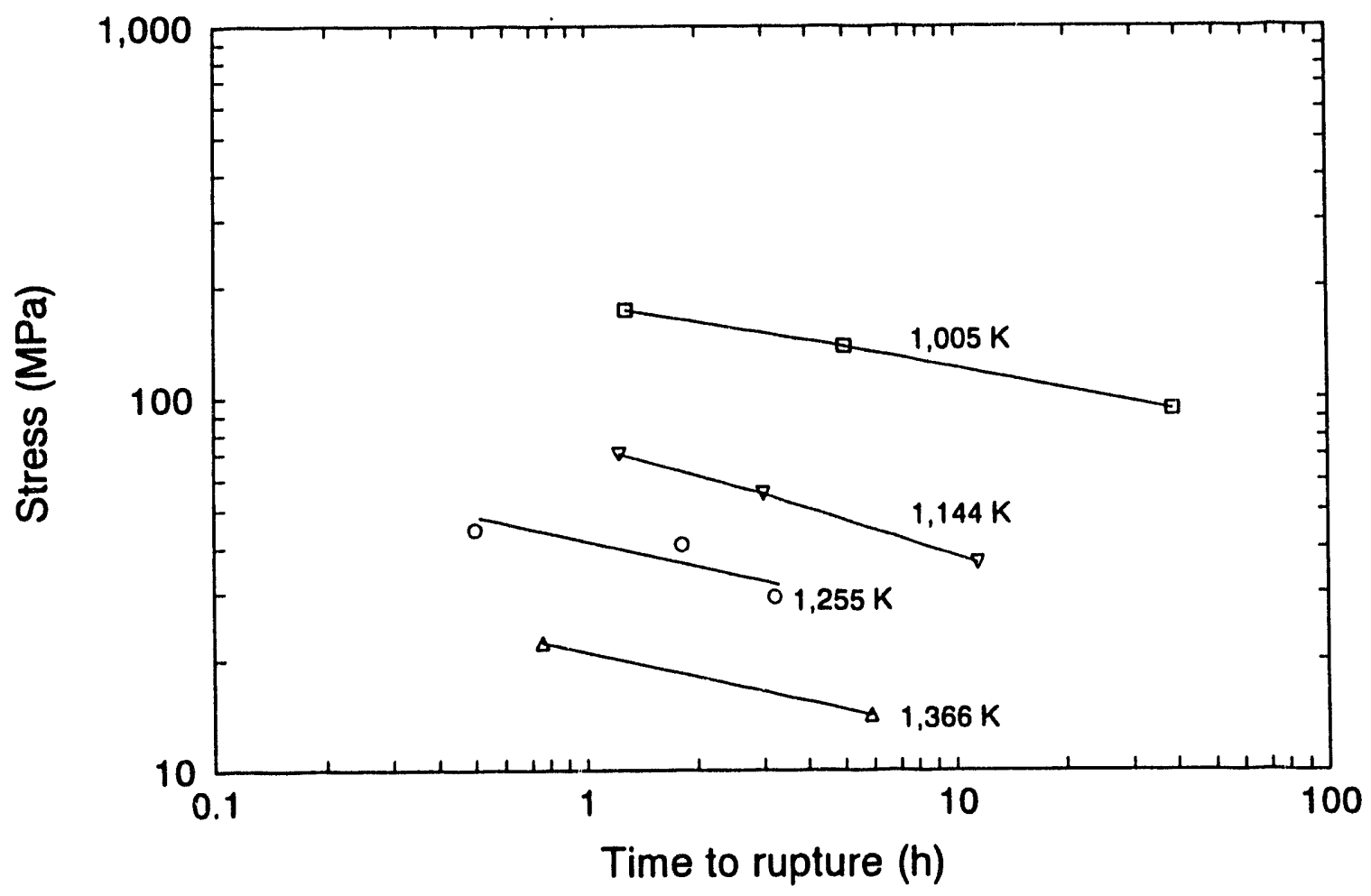

Figure A-32. Inconcl-600 crecp time to rupturc as a function of stress and temperaturc. ${ }^{A-15}$ 


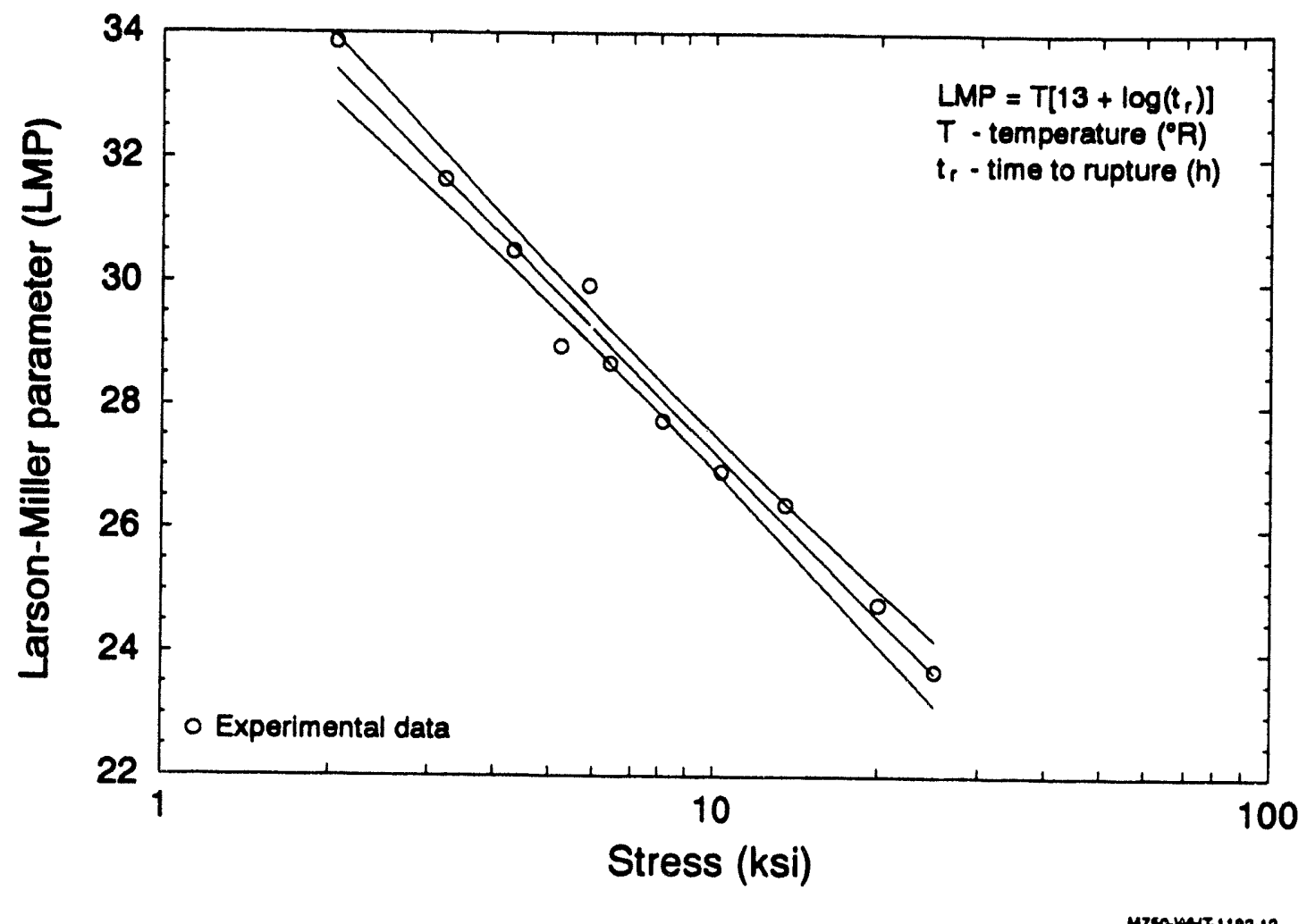

Figure A-33. Inconcl-600 Larson-Miller parameter versus log (stress) with $95 \%$ confidence limits for tests between 873 and $1.473 \mathrm{~K} .^{\mathrm{A} \cdot 15}$ 
Table A-1. Inconel-600 tensile test results.

\begin{tabular}{cccccc}
\hline $\begin{array}{c}\text { Temperature } \\
(\mathrm{K})\end{array}$ & $\begin{array}{c}\text { Yicld } \\
\text { strength } \\
(\mathrm{MPa})\end{array}$ & $\begin{array}{c}\text { Ultimate } \\
\text { strength } \\
(\mathrm{MPa})\end{array}$ & $\begin{array}{c}\text { Uniform } \\
\text { clongation } \\
(\%)\end{array}$ & $\begin{array}{c}\text { Total } \\
\text { clongation } \\
(\%)\end{array}$ & $\begin{array}{c}\text { Reduction } \\
\text { of area } \\
(\%)\end{array}$ \\
\hline 297.0 & 374.00 & 733.00 & 30 & 43 & 68 \\
600.0 & 315.00 & 689.00 & 30 & 39 & 61 \\
800.0 & 280.00 & 617.00 & 26 & 39 & 65 \\
900.0 & 266.00 & 468.00 & 16 & 45 & 73 \\
$1,000.0$ & 237.00 & 273.00 & 4 & 76 & 94 \\
$1,050.0$ & 187.00 & 212.00 & 6 & 76 & 95 \\
$1,100.0$ & 132.00 & 154.00 & 6 & 76 & 93 \\
$1,150.0$ & 98.00 & 113.00 & 5 & 88 & 91 \\
$1,200.0$ & 74.00 & 79.00 & 7 & 62 & 83 \\
$1,300.0$ & 45.00 & 50.00 & 3 & 66 & 91 \\
$1,373.0$ & 21.00 & 27.00 & 7 & 55 & 97 \\
\hline
\end{tabular}

Table A-2. Inconel-600 creep test results.

\begin{tabular}{ccc}
\hline $\begin{array}{c}\text { Temperature } \\
(\mathrm{K})\end{array}$ & $\begin{array}{c}\text { Stress } \\
(\mathrm{MPa})\end{array}$ & $\begin{array}{c}\text { Time to } \\
\text { rupture } \\
(\mathrm{h})\end{array}$ \\
\hline $1,005.0$ & 173.2 & 1.30 \\
$1,005.0$ & 137.8 & 5.00 \\
$1,005.0$ & 93.6 & 38.50 \\
$1,144.0$ & 71.1 & 1.20 \\
$1,144.0$ & 55.6 & 3.00 \\
$1,144.0$ & 36.1 & 11.50 \\
$1,255.0$ & 44.4 & 0.50 \\
$1,255.0$ & 40.6 & 1.80 \\
$1,255.0$ & 29.5 & 3.20 \\
$1,366.0$ & 22.2 & 0.75 \\
$1,366.0$ & 14.1 & 5.90 \\
\hline
\end{tabular}




\section{A.2.2 SA533B Data}

This section contains data for structural properties of SA533B. Temperature-dependent properties include elastic modulus, yield strength, ultimate strength, and thermal coefficient of expansion. A Poisson's ratio of 0.3 was assumed in the localized vessel failure model. Stress-strain curves and creep test results from high temperature, TMI-2 VIP testing of TMI-2 vessel material are shown in Figures A-34 through A-40 and Tables A-3 and A-4. Tensile data includes previously published data, as well as the TMI-2 VIP data. The elastic portions of the stress-strain curves were derived from published values of temperature-dependent elastic moduli. TMI-2 VIP strain measurements were designed for relatively large deformations and were not sensitive enough to accurately measure elastic moduli. For this reason, published values of a chemically similar material (STBA12) were used to develop the elastic portions of the stress-strain curves. The plastic portion of the stress-strain curve at each test temperature was taken from a representative TMI-2 VIP test specimen.

The creep properties include deformation behavior (power law relations for strain versus time curves at given temperatures and pressures) and failure behavior (Larson-Miller parameter). The scoping global vessel analyses in Section 4.4 only required the failure behavior, whereas the localized vessel analyses required both failure and deformation behavior.

The Larson-Miller parameter is used in creep problems to predict failure (time to rupture), given a stress and temperature. Results from TMI-2 VIP test data are shown in Figure A-40. The creep data for tests conducted at temperatures below the transition temperature $(1,000 \mathrm{~K})$ only include specimens which did not reach $1,000 \mathrm{~K}$ during the accident. Specimens subjected to accident temperatures above $1,000 \mathrm{~K}$ during the accident were considered atypical because they exhibited unusually high yield and ultimate strength when tested at temperatures below $1,000 \mathrm{~K}$. Because the lowest TMI-2 VIP test temperature was $873 \mathrm{~K}$, data from other published sources ${ }^{\mathrm{A}-16, A-17}$ were used to predict creep failures for lower temperatures, rather than extrapolating the TMI- 2 data beyond its range (Figure A-41).

Data for strain versus time data used in the localized vessel analyses were taken from several different sources. At low temperatures, creep strain rates were evaluated on the basis of an algorithm suggested be Reddy and Ayres ${ }^{A-18}$, based on their experimental lower temperature $(<922 \mathrm{~K})$ data. Creep strain rates are evaluated from the relation

$\widetilde{E}_{c r}=(1+\mu)^{1 / 1+\mu}\left(\frac{\sigma}{\sigma_{m}}\right)^{m / 1+\mu}\left(\frac{t}{\tau}\right)^{1 / 1+\mu}$

where $\tau$ is a characteristic time ( $10^{7}$ hours), $t$ is time (hours), $1 / 1+\mu$ and $m / 1+\mu$ are temperaturedependent expressions, $\tilde{\sigma}$ is an effective stress (Huddleston's effective stress ${ }^{\mathrm{A}-21}$ is used in the localized effects model; see Section A.2.3.1) and $\sigma_{m}$ is a stress and temperature dependent constant. The only difficulty with this relationship is that some combinations of stress and elevated temperature produce negative values of $\sigma_{m}$, which is evidently intended to be a positive quantity. For this reason, the procedure at temperatures below $922 \mathrm{~K}$ is to use these relations as long as $\tilde{d} \sigma_{m}$ in Equation (A-1) exceeds one. If the ratio falls below unity, alternative relations are used. 


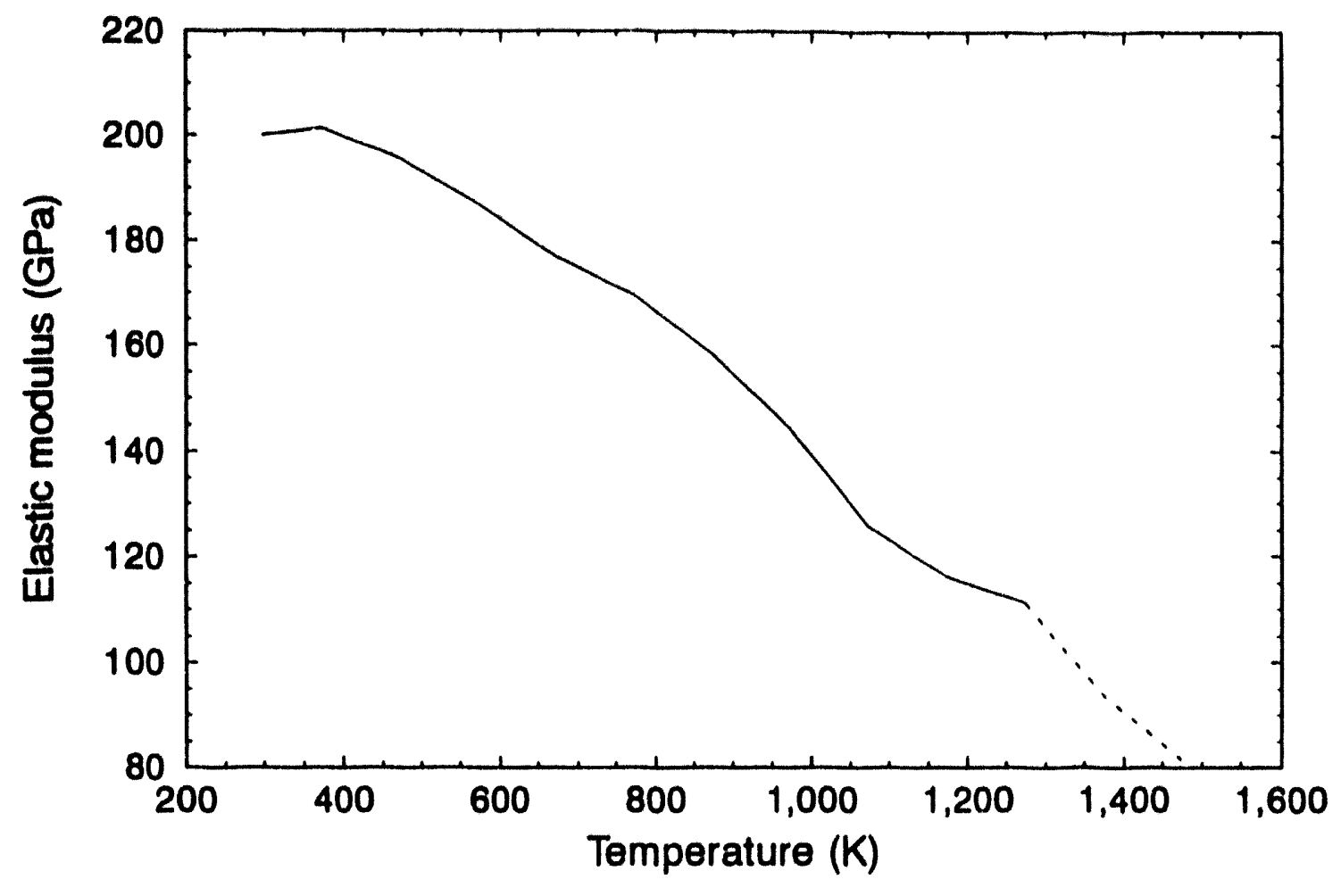

Figure A-34. STBA12 (chemically similar to SA533B) modulus as a function of temperature. ${ }^{A-19}$

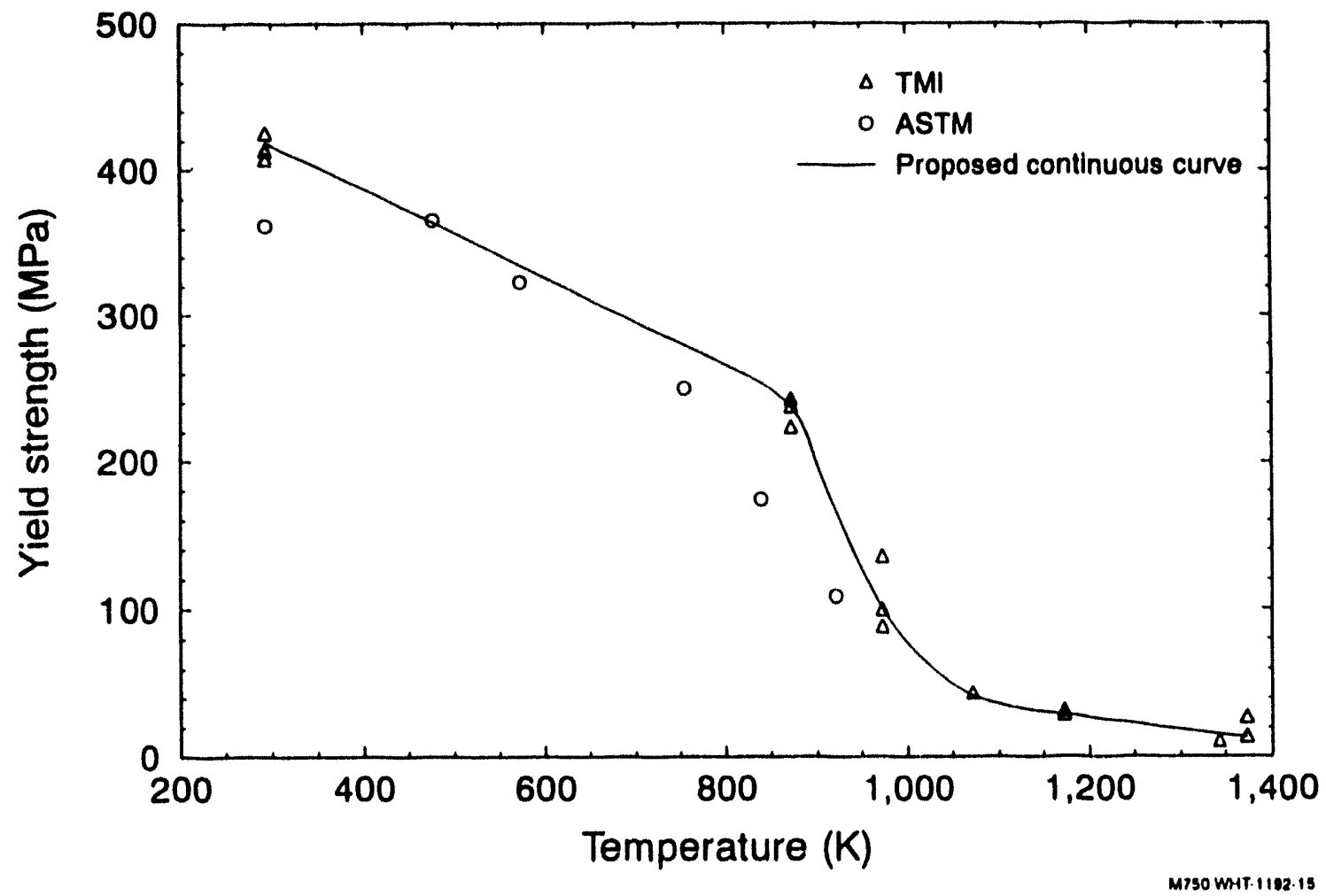

Figure A-35. SA533B $0.2 \%$ offset yield strength as a function of temperature, based on TMI-2 VIP and ASTM data. ${ }^{A \cdot 16}$ 


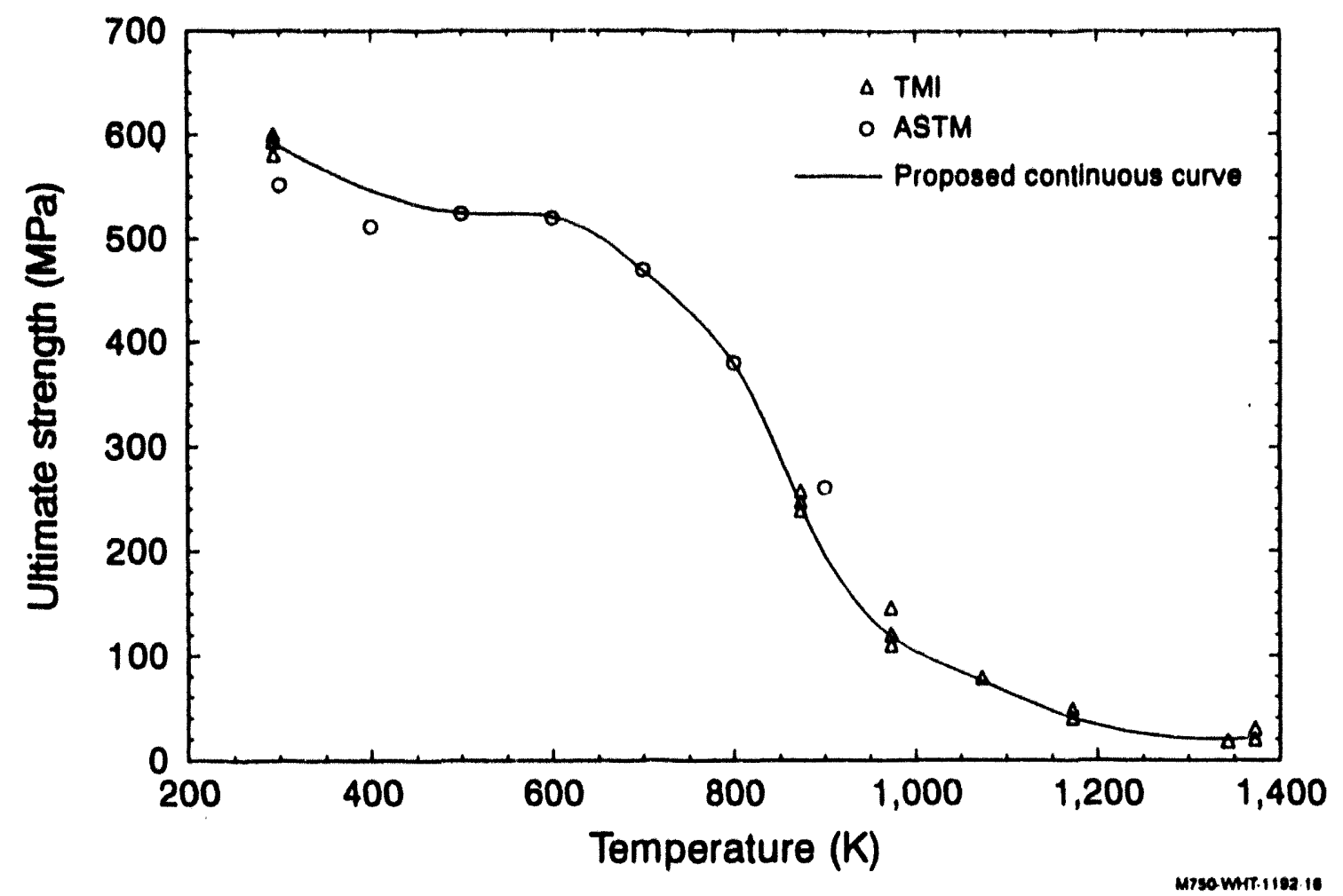

Figure A-36. SA533B ultimate strength as a function of temperature, based on TMI-2 VIP data.

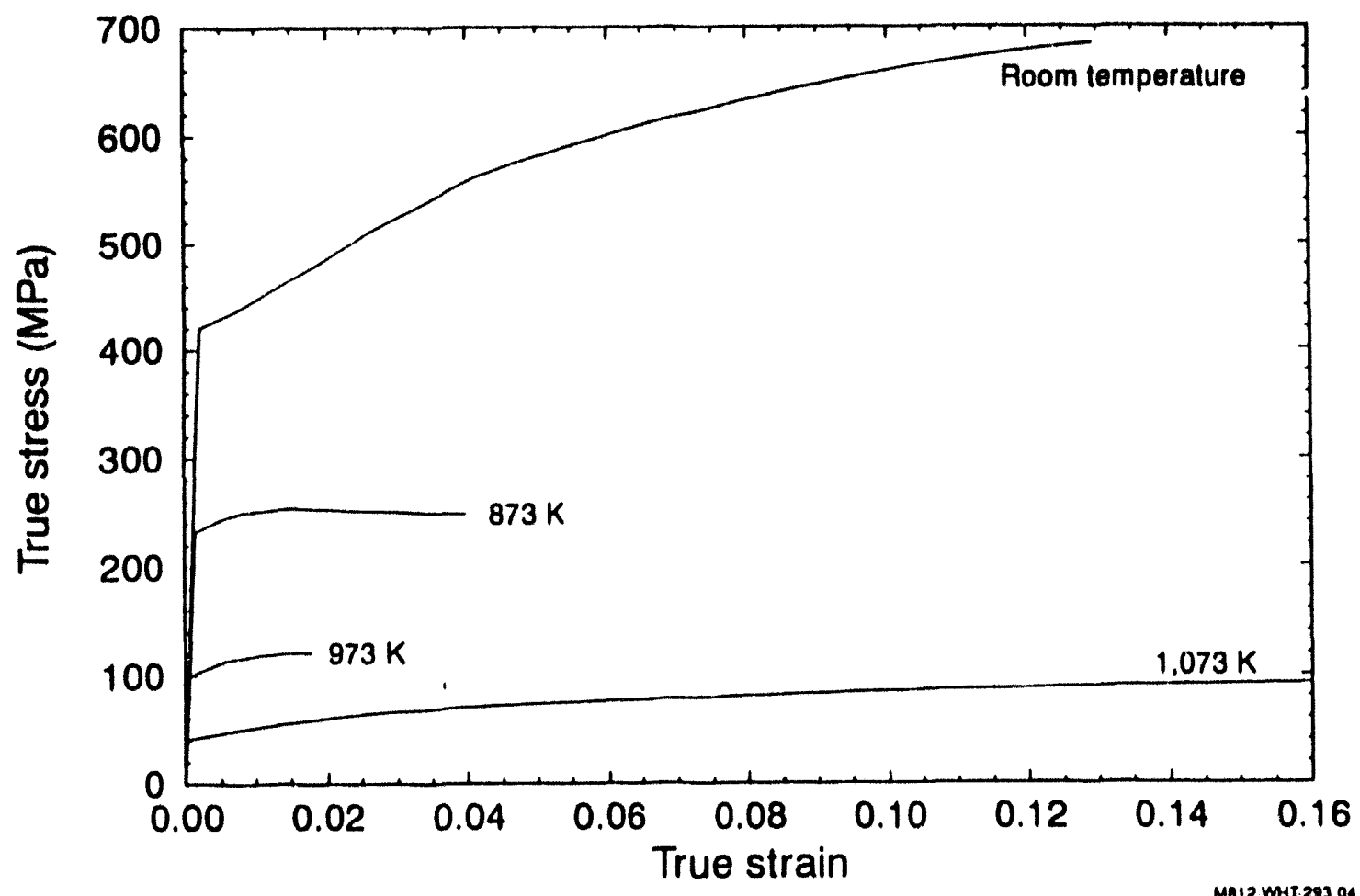

Figure A-37 (a). SAS33B stress-strain curves for $297 \mathrm{~K}$ and 873 to $1,073 \mathrm{~K}$, based on TMI-2 VIP data. 


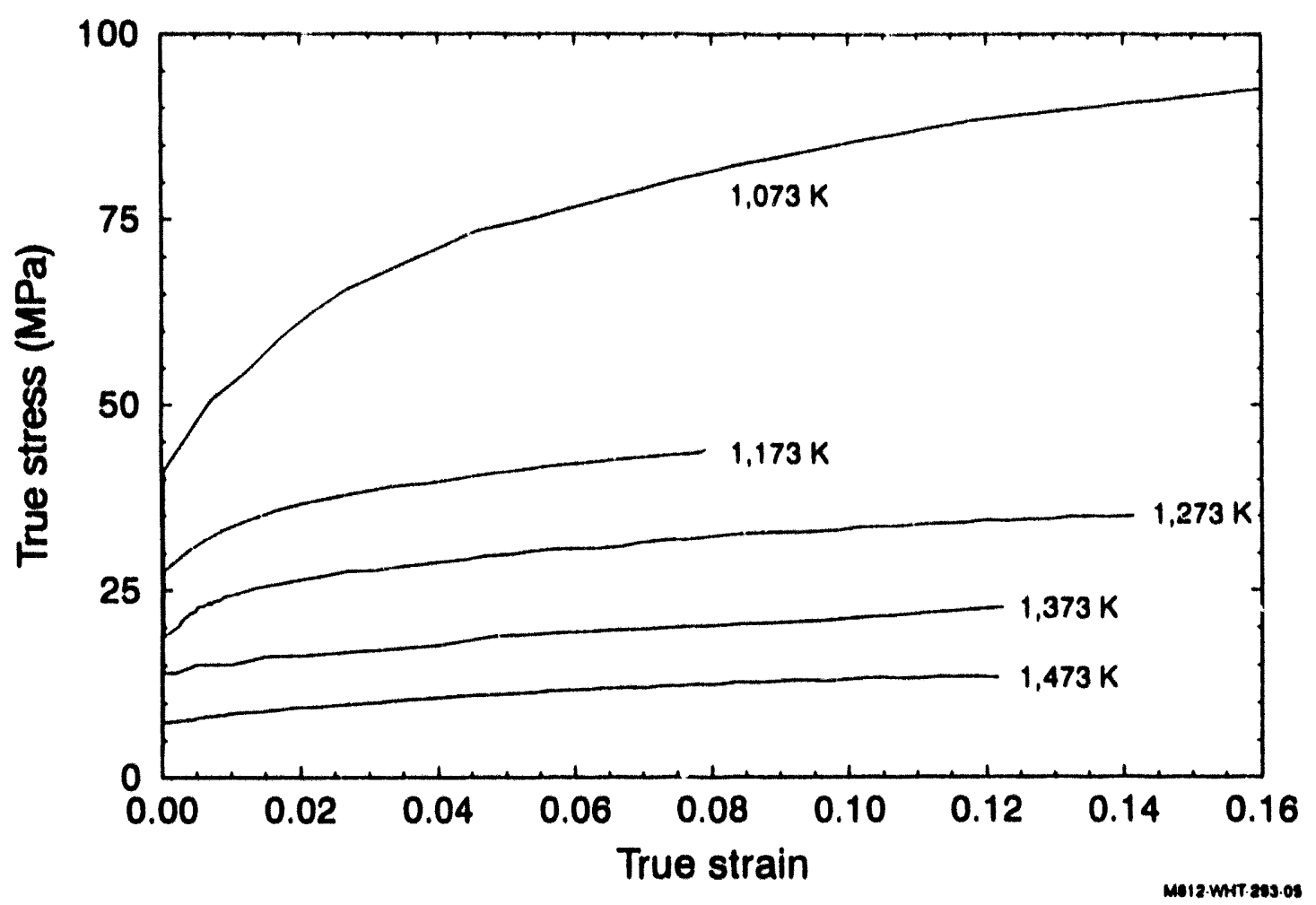

Figure A-37 (b). SA533B stress-strain curves for 1,073 to $1,473 \mathrm{~K}$, based on TMI-2 VIP data.

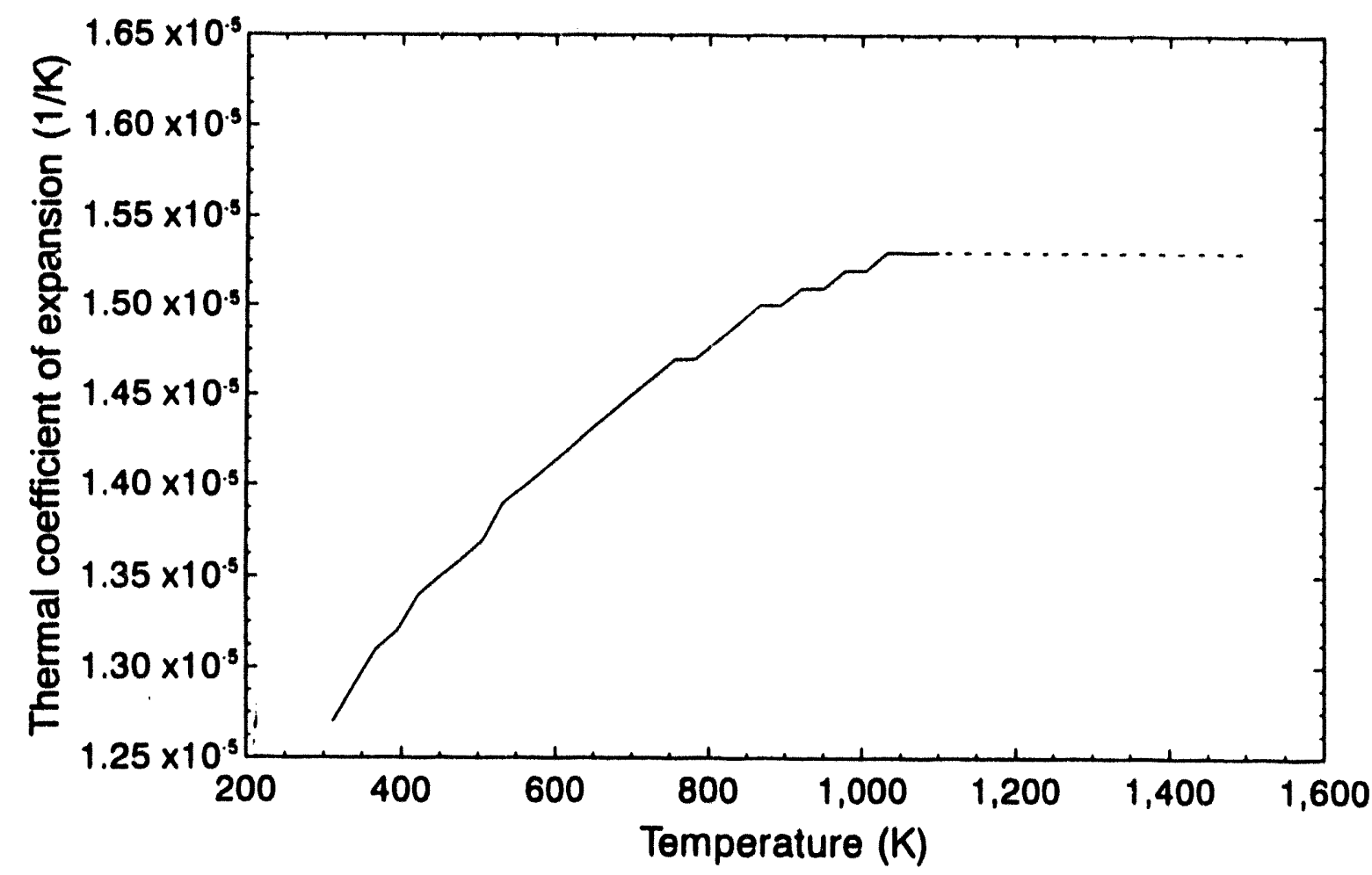

Figure A-38. SA533B mean linear coefficient of thermal expansion as a function of temperature. ${ }^{A-20}$ 


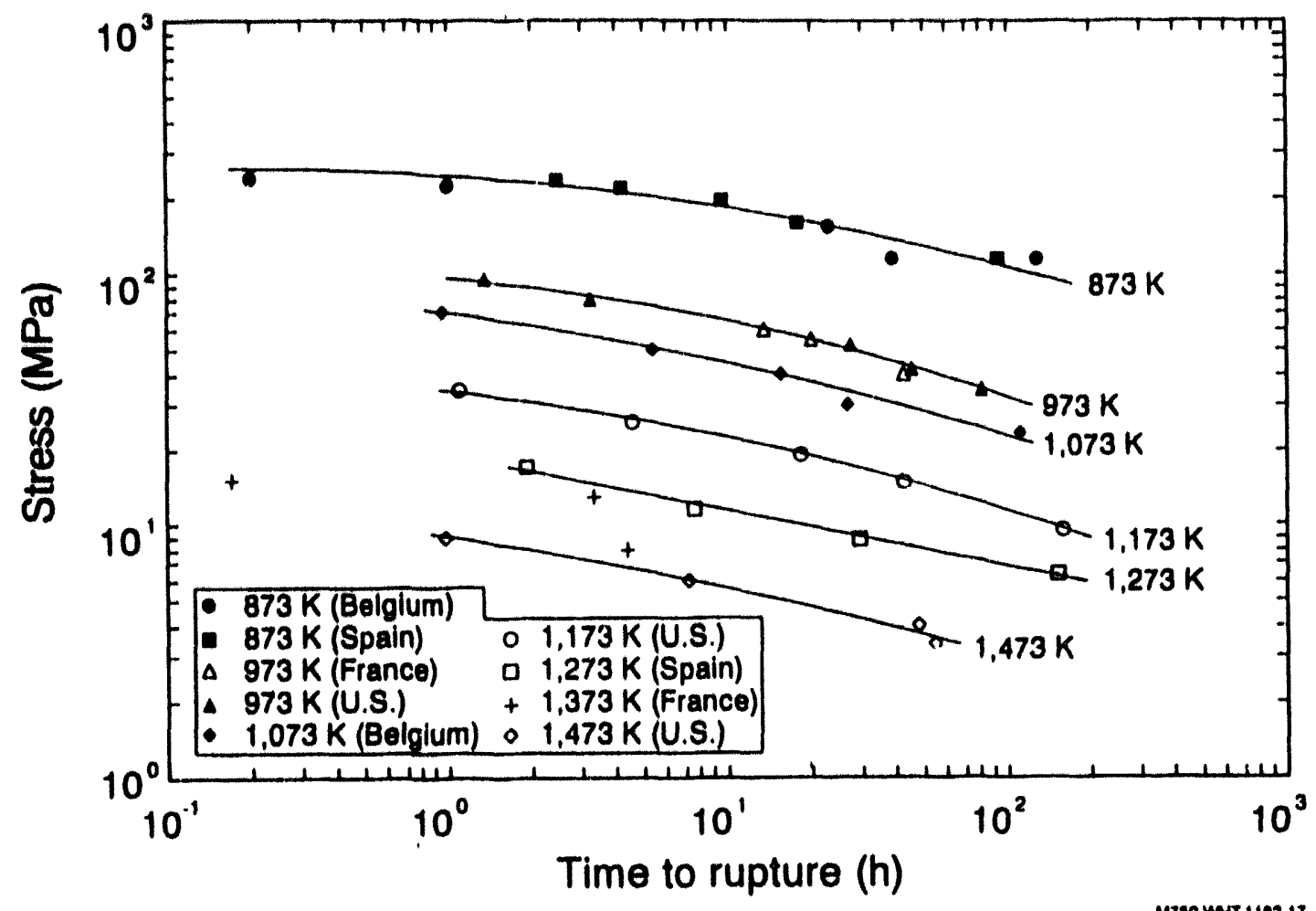

Figure A-39. SA533B creep time to rupture as a function of stress and temperature, based on TMI-2 VIP data.

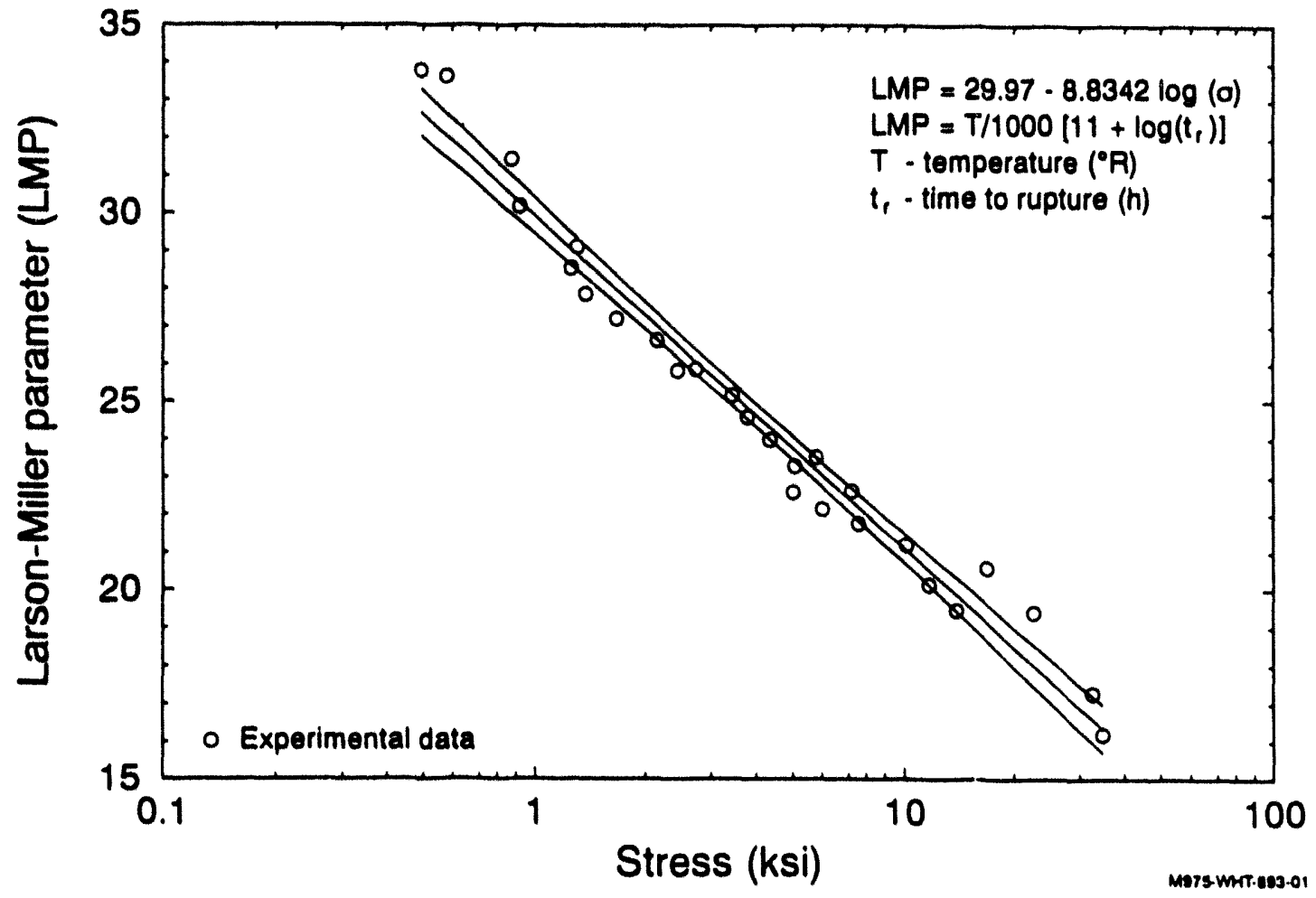

Figure A-40. SA533B Larson-Miller parameter versus log (stress) with $95 \%$ confidence limits for tests between $873 \mathrm{~K}$ and $1.473 \mathrm{~K}$, based on TMI.2 VIP data. 
Table A-3. SA533B TMI-2 VIP tensile test results.

\begin{tabular}{|c|c|c|c|c|c|c|}
\hline $\begin{array}{l}\text { Country/ } \\
\text { specimen }\end{array}$ & $\begin{array}{c}\text { Temperature } \\
\text { (K) }\end{array}$ & $\begin{array}{l}\text { Yield } \\
\text { strength } \\
\text { (MPa) }\end{array}$ & $\begin{array}{l}\text { Ultimate } \\
\text { strength } \\
(\mathrm{MPa})\end{array}$ & $\begin{array}{c}\text { Uniform } \\
\text { elongation } \\
(\%)\end{array}$ & $\begin{array}{c}\text { Total } \\
\text { elongation } \\
(\%)\end{array}$ & $\begin{array}{c}\text { Reduction } \\
\text { of area } \\
(\%)\end{array}$ \\
\hline $\begin{array}{l}\text { Spain/ } \\
\text { K-7 }\end{array}$ & 294.0 & 426.00 & 600.00 & 13.0 & 29 & 63 \\
\hline $\begin{array}{l}\text { France/ } \\
\text { M-11 }\end{array}$ & 294.0 & 408.00 & 581.00 & 11.0 & 22 & 65 \\
\hline $\begin{array}{l}\text { Beigium/ } \\
\mathbf{K} \cdot \mathbf{1 3}\end{array}$ & 294.0 & 414.00 & 594.00 & 11.0 & 24 & 72 \\
\hline $\begin{array}{l}\text { U.S.A./ } \\
\text { L.9 }\end{array}$ & 294.0 & 423.00 & 592.00 & 9.0 & 16 & 62 \\
\hline $\begin{array}{l}\text { Spain/ } \\
\text { K-7 }\end{array}$ & 873.0 & 238.00 & 247.00 & 3.2 & 48 & 81 \\
\hline $\begin{array}{l}\text { France/ } \\
\text { M-11 }\end{array}$ & 873.0 & 224.00 & 239.00 & 1.2 & 33 & 75 \\
\hline $\begin{array}{l}\text { Beigium/ } \\
\mathrm{K}-13\end{array}$ & 873.0 & 243.00 & 257.00 & 0.8 & 25 & 72 \\
\hline $\begin{array}{l}\text { U.S.A./ } \\
\text { L.9 }\end{array}$ & 873.0 & 231.00 & 256.00 & 1.6 & 44 & 91 \\
\hline $\begin{array}{l}\text { Spain/ } \\
\text { K-7 }\end{array}$ & 973.0 & 89.00 & 110.00 & 4.8 & 83 & 87 \\
\hline $\begin{array}{l}\text { France/ } \\
\text { M-11 }\end{array}$ & 973.0 & 136.00 & 146.00 & 1.6 & 42 & 66 \\
\hline $\begin{array}{l}\text { Belgium/ } \\
\mathbf{K}-13\end{array}$ & 973.0 & 100.00 & 120.00 & 1.7 & 77 & 90 \\
\hline $\begin{array}{l}\text { U.S.A./ } \\
\text { H-8 }\end{array}$ & 973.0 & 126.00 & 137.00 & 2.8 & 50 & 86 \\
\hline $\begin{array}{l}\text { 'France/ } \\
\text { L-9 }\end{array}$ & $1,073.0$ & 44.00 & 79.00 & 18.0 & 64 & 43 \\
\hline $\begin{array}{l}\text { U.S.A./ } \\
\text { G-8 }\end{array}$ & $1,073.0$ & 52.00 & 77.00 & 15.0 & 80 & 65 \\
\hline $\begin{array}{l}\text { Spain/ } \\
\text { L-9 }\end{array}$ & $1,173.0$ & 29.00 & 40.00 & 13.0 & 36 & 27 \\
\hline $\begin{array}{l}\text { Belgium/ } \\
\text { F-3 }\end{array}$ & $1,173.0$ & 32.00 & 49.00 & 13.0 & 43 & 31 \\
\hline $\begin{array}{l}\text { U.S.A./ } \\
\text { H-8 }\end{array}$ & $1,273.0$ & 20.00 & 30.00 & 14.0 & 42 & 35 \\
\hline $\begin{array}{l}\text { Spain/ } \\
\text { L-9 }\end{array}$ & $1,343.0$ & 11.00 & 19.00 & 13.0 & (110) & $\begin{array}{l}\text { (Not } \\
\text { received) }\end{array}$ \\
\hline $\begin{array}{l}\text { Belgium/ } \\
\text { F5-T7 }\end{array}$ & $1,373.0$ & 14.00 & 20.00 & 13.0 & 124 & 97 \\
\hline $\begin{array}{l}\text { U.S.A./ } \\
\text { H-8 }\end{array}$ & $1,473.0$ & 7.60 & 12.00 & 12.0 & 93 & 99 \\
\hline
\end{tabular}


Table A-4. SA533B TMI-2 VIP creep test results.

\begin{tabular}{|c|c|c|c|}
\hline Country/specimen & $\begin{array}{c}\text { Temperature } \\
(\mathrm{K})\end{array}$ & $\begin{array}{l}\text { Stress } \\
(\mathrm{MPa})\end{array}$ & $\begin{array}{l}\text { Time to rupture } \\
\text { (h) }\end{array}$ \\
\hline Belgium/K-13 & 873.0 & 240.01 & 0.20 \\
\hline Belgium/K-13 & 873.0 & 225.00 & 1.00 \\
\hline Belgium/K-13 & 873.0 & 155.00 & 23.10 \\
\hline Belgium/K-13 & 873.0 & 115.00 & 128.00 \\
\hline U.S.A./H-8 & 973.0 & 95.10 & 1.34 \\
\hline U.S.A./H-8 & 973.0 & 80.00 & 3.27 \\
\hline U.S.A./H-8 & 973.0 & 52.10 & 27.60 \\
\hline U.S.A./H-8 & 973.0 & 41.60 & 46.00 \\
\hline U.S.A./H-8 & 973.0 & 34.50 & 81.60 \\
\hline Belgium/F-5 & $1,073.0$ & 70.00 & 0.95 \\
\hline Belgium/F-5 & $1,073.0$ & 50.00 & 5.40 \\
\hline Belgium/F-5 & $1,073.0$ & 40.00 & $15.50^{\circ}$ \\
\hline Belgium/F-5 & $1,073.0$ & 30.00 & 27.00 \\
\hline Belgium/F-5 & $1,073.0$ & 23.70 & 111.00 \\
\hline U.S.A./H-5 & $1,173.0$ & 35.00 & 1.09 \\
\hline U.S.A./H-5 & $1,173.0$ & 26.00 & 4.55 \\
\hline U.S.A./H-5 & $1,173.0$ & 19.00 & 18.10 \\
\hline U.S.A./H-5 & $1,173.0$ & 14.80 & 42.30 \\
\hline U.S.A./H-5 & $1,173.0$ & 9.51 & 159.50 \\
\hline Spain/K-7 & $1,273.0$ & 16.90 & 1.90 \\
\hline Spain/K-7 & $1,273.0$ & 11.50 & 7.54 \\
\hline Spain/K-7 & $1,273.0$ & 8.70 & 29.64 \\
\hline Spain/K-7 & $1,273.0$ & 6.30 & 152.80 \\
\hline U.S.A./M-8 & $1,473.0$ & 9.00 & 0.98 \\
\hline U.S.A./M-8 & $1,473.0$ & 6.00 & 7.26 \\
\hline U.S.A.M-8 & $1,473.0$ & 4.00 & 48.20 \\
\hline U.S.A./M-8 & $1,473.0$ & 3.40 & 55.10 \\
\hline
\end{tabular}




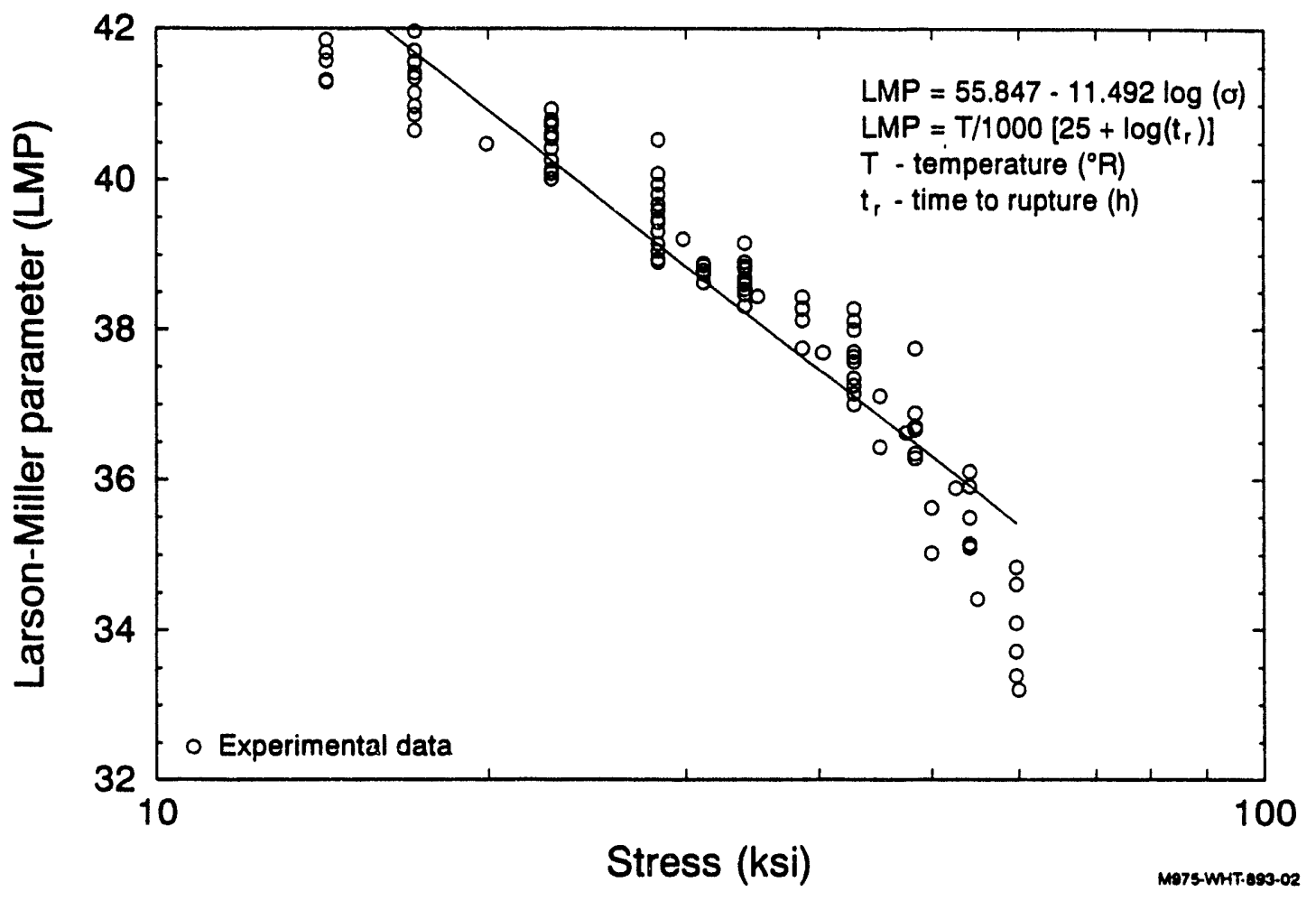

Figure A-41. SA533B Larson-Miller parameter versus log (stress) for tests between $723 \mathrm{~K}$ and $823 \mathrm{~K}$, based on published data. ${ }^{\mathrm{A}-16, \mathrm{~A}-17}$ 
Table A-5. Power law coefficients used in creep strain relations.

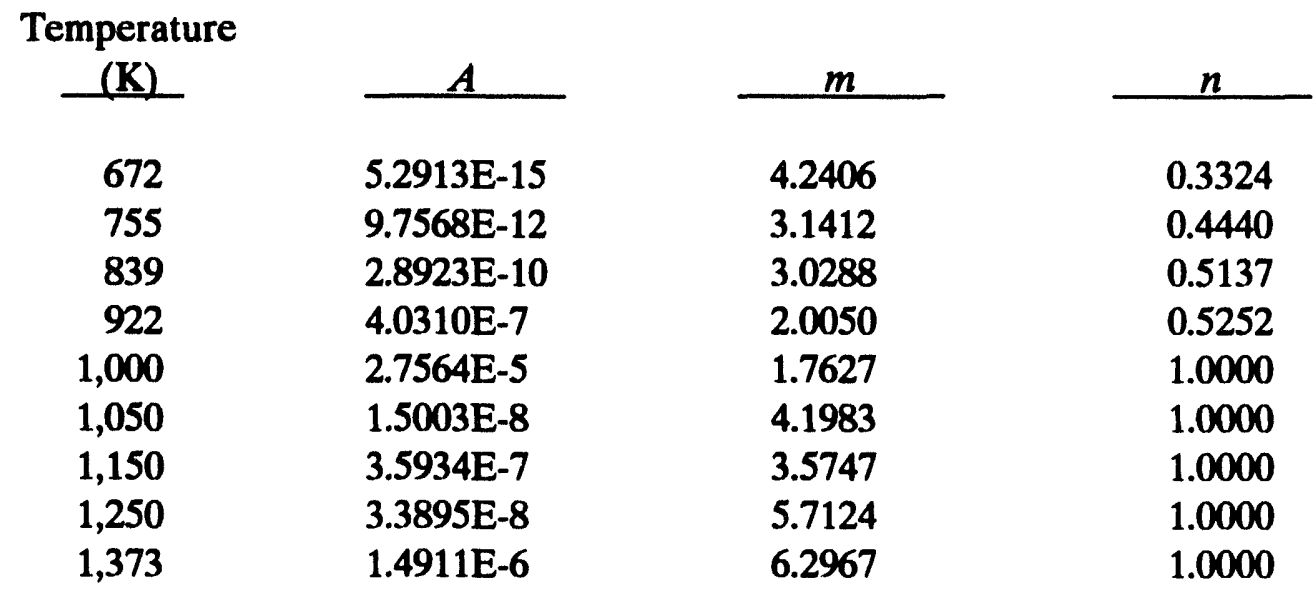

The high temperature creep strain behavior for the scoping calculations in Secton 4.5.2 used data provided from the USNRC-sponsored lower head failure program. TMI-2 VIP data was not available at the time that these calculations were performed. The data was fit to the following power law (or Bailey-Norton) form:

$$
\tilde{\varepsilon}_{c r}=A(T) \tilde{\sigma}^{m(T)} t^{n(T)} \text {. }
$$

Table A-5 lists the values of the coefficients $A, m$, and $n$ as functions of temperature. The first four entries are fits to the relations of Reddy and Ayres and are used as a backup for obtaining creep strain rates when combinations of stress and temperature render unacceptable ratios of $\tilde{\sigma} / \sigma_{m}$.

The Bailey-Norton constants for primary and secondary creep listed in Table A-6 are from testing of the TMI-2 vessel material and were used in Section 5.1 calculations to investigate enhanced cooling. As with the data used to derive Larson-Miller parameters, creep data for tests conducted at temperatures below the transition temperature $(1,000 \mathrm{~K})$ only include specimens which did not reach $1,000 \mathrm{~K}$ during the accident. Some of the data listed in the tables (e.g., \% total elongation in Table A-3) were not actually used in the analysis, but are included for completeness.

Table A-7 contains equation fits for primary and secondary creep, as well as tertiary creep, used in Section 5.2 comparisons of stress-based versus strain-based failure criteria. The primary/secondary fits were used until the tertiary point (also listed in Table A-7) was reached, at which point the tertiary fits were used. Primary/secondary fits for Tables A-6 and A-7 are not identical because the fits in Table A-6 attempted to use as much of the curves as possible, whereas the fits for Table A-7 do not include data beyond the tertiary point. In addition, a more accurate least squares fit was used to obtain the constants in Table A-7. 
Table A-6. SA533B TMI-2 VIP creep test results, Bailey Norton constants used in Section 5.1 slow and rapid cooling analysis.

\begin{tabular}{cccc}
\hline $\begin{array}{c}\text { Temperature } \\
(\mathrm{K})\end{array}$ & \multicolumn{1}{c}{$\boldsymbol{A}$} & $m$ & $n$ \\
\hline 873.0 & $7.8163 \mathrm{E}-14$ & 5.0287 & 0.98760 \\
973.0 & $4.9614 \mathrm{E}-10$ & 4.1548 & 1.16840 \\
$1,073.0$ & $6.2661 \mathrm{E}-08$ & 3.5945 & 0.79562 \\
$1,173.0$ & $5.6481 \mathrm{E}-08$ & 4.4051 & 1.04690 \\
$1,273.0$ & $1.8897 \mathrm{E}-06$ & 3.9414 & 0.93976 \\
$1,473.0$ & $1.0505 \mathrm{E}-04$ & 3.4700 & 0.91029
\end{tabular}

a. Constants are used in Equation A-2.

\section{A.2.3 Structural Failure Criterion}

A stress-based failure criterion was defined by consensus of the Structural Mechanics Peer Review Group. ${ }^{\mathrm{A}-22}$ The procedure includes converting a multi-dimensional stress state to an effective stress, interpolating the time to failure for constant stress and temperature using the Larson-Miller parameter and predicting time to failure for the actual stress and temperature history using a time damage model. The Huddleston criterion for calculating effective stress is described below, followed by a brief discussion of the Larson-Miller parameter and the time damage rule.

A.2.3.1 Huddleston Criterion for Effective Stress. The effective (or equivalent) stress used in the Larson-Miller parameter is a measure suggested by Reference A-21 and based on biaxial creep tests of steel. The stress measure for ferritic steels may be written using

$$
\tilde{\sigma}=\sigma_{v m} \exp \left[0.2\left(J_{1} / S_{s}-1\right)\right]
$$

where

$$
\tilde{\sigma}=\text { the effective stress. }
$$


Table A-7. SA533B TMI-2 VIP creep test results, Bailey-Norton constants used to compare Section 5.2 creep failure criteria."

Primary and secondary curves

Temperature

(K)

\begin{tabular}{rllll}
$(\mathrm{K})$ & \multicolumn{1}{c}{$A$} & \multicolumn{1}{c}{$m$} & \multicolumn{1}{c}{$n$} & \multicolumn{1}{c}{ Notes } \\
\hline 873 & $1.6672 \mathrm{E}-12$ & 4.47023 & 0.71308 & \\
973 & $1.3925 \mathrm{E}-12$ & 5.4352 & 1.21024 & $34.5 \mathrm{MPa}$ omitted $^{\mathrm{b}}$ \\
1,073 & $2.5619 \mathrm{E}-08$ & 3.81621 & 0.79783 & \\
1,173 & $1.4268 \mathrm{E}-08$ & 4.71562 & 1.08466 & \\
1,273 & $1.1152 \mathrm{E}-06$ & 4.15893 & 0.97798 & $\begin{array}{l}2 \text { unphysical data points } \\
\text { removed from 6.3 MPa }\end{array}$ \\
1,473 & $8.9176 \mathrm{E}-05$ & 3.5891 & 0.70114 & $3.4 \mathrm{MPa}$ omitted $^{\mathrm{c}}$
\end{tabular}
-

Tertiary curves

Temperature

\begin{tabular}{rccll}
$(\mathrm{K})$ & $A$ & $m$ & \multicolumn{1}{c}{$n$} & Notes \\
\hline 873 & $8.3387 \mathrm{E}-12$ & 4.47023 & 3.946 & $225 \mathrm{MPa}$ only \\
973 & $3.5818 \mathrm{E}-28$ & 13.4311 & 2.53973 & $\begin{array}{l}\text { 80.0 and 95.1 MPa only } \\
\mathbf{c}\end{array}$ \\
1,073 & $4.2601 \mathrm{E}-08$ & 3.81621 & 2.4084 & $\begin{array}{l}70 \mathrm{MPa} \text { only } \\
\text { use I\&II fit }\end{array}$ \\
1,173 & & & & $\begin{array}{l}\text { use I\&II fit } \\
1,273\end{array}$ \\
1,473 & $5.7553 \mathrm{E}-08$ & 7.25974 & 1.5341 & 6.0 and $9.0 \mathrm{MPa}$ only
\end{tabular}

Tertiary points

Temperature.

\begin{tabular}{rlcc}
$(\mathrm{K})$ & $\tilde{\sigma}(\mathrm{MPa})$ & $t(h)$ & $\tilde{\varepsilon}_{c-}(\%)$ \\
\hline \multicolumn{4}{c}{} \\
873 & 225 & 0.66 & 5.30 \\
873 & 155 & 15.0 & 7.49 \\
973 & 95.1 & 0.674 & 4.88 \\
973 & 80 & 1.907 & 6.71 \\
973 & 52.1 & 15.0 & 7.31 \\
1,073 & 70 & 0.729 & 21.9 \\
1,073 & 50 & 4.58 & 23.3 \\
1,173 & \multicolumn{4}{c}{ no tert. curves } \\
1,273 & no tert. curves & \\
1,473 & 9.0 & 0.4215 & 12.94 \\
1,473 & 6.0 & 2.51664 & 10.57 \\
1,473 & 4.0 & 35.3 & 26.41
\end{tabular}


Table A-7. (continued).

a. Constants are used in Equation A-2.

b. Removing the curve at $34.5 \mathrm{MPa}$ results in much better fits for the remaining curves. The remaining curves are at $41.6 \mathrm{MPa}, 52.1 \mathrm{MPa}, 80 \mathrm{MPa}$, and $95.1 \mathrm{MPa}$.

c. Removing the curve at $3.4 \mathrm{MPa}$ results in much better fits for the remaining curves. The remaining curves are at $4.0 \mathrm{MPa}, 6.0 \mathrm{MPa}$ and $9.0 \mathrm{MPa}$.

d. Only the $225 \mathrm{MPa}$ curve was fit for tertiary. The remaining curves did not exhibit tertiary within 15 hours.

e. Only the $80 \mathrm{MPa}$ and 95.1 curves were fit for tertiary. The remaining curves did not exhibit tertiary behavior within 15 hours.

f. Only the $70 \mathrm{MPa}$ curve was fit for tertiary. The remaining curves did not exhibit tertiary within 15 hours (23.7 and $30 \mathrm{MPa}$ ) or had a reasonably good fit to the primary and secondary curves throughout their history (40 and $50 \mathrm{MPa}$ ).

g. The constants listed for primary and secondary behavior fit the entire history reasonably well. A tertiary fit was attempted with $11.5 \mathrm{MPa}$ and $16.9 \mathrm{MPa}$, but the fit was not good.

h. Only the 6.0 MPa and 9.0 MPa curves were fit for tertiary. The remaining curve at 4.0 MPa did not exhibit tertiary behavior within 15 hours.

$$
\begin{aligned}
& \sigma_{v m}=\text { the von Mises stress } \\
& J_{1}=\text { the first stress invariant } \\
& S_{s}=\text { a modulus of principal stresses. } \\
& J_{1}=\sigma_{1}+\sigma_{2}+\sigma_{3} \\
& S_{s}=\sigma_{1}^{2}+\sigma_{2}^{2}+\sigma_{3}^{2} .
\end{aligned}
$$

A.2.3.2 Time Damage Rule and the Larson-Miller Parameter. At each Gauss point (for localized vessel failure model) or vessel wall segment (for vessel global rupture model), the damage was evaluated by calculating an equivalent, or effective, stress $(\tilde{\sigma})$ and finding the Larson-Miller parameter (LMP) for SA533B vessel steel from 
where $\tilde{\sigma}$ is in ksi, (see Figure A-36). Time to rupture $\left(t_{r}\right)$, for SA533B vessel steel, was obtained at that stress and a known temperature $(T)$ from

$t_{r}=10^{[L M P(1000) / T-11]}$

where $t_{r}$ is in hours and $T$ is in Rankine.

Equations (A-6) and (A-7) were fit from TMI-2 VIP data where testing temperatures were above $873 \mathrm{~K}$. Implemented in the simple global vessel calculations, they were found to give very conservative results when extrapolated to lower temperatures. Supplementing the TMI-2 VIP data with lower temperature data from other sources, ${ }^{\mathrm{A}-16, \mathrm{~A}-17}$ the following relationships were found to apply. These were used in the localized vessel failure calculations. (Note: Using these equations in the simple global vessel calculations would not change the conclusions of that analysis).

For $723 \leq T<850 \mathrm{~K}$,

$$
\begin{aligned}
& L M P=55.847-11.492 \log (\sigma) \\
& t_{r}=10^{[L M P(1,000) / T \cdot 25]}
\end{aligned}
$$

For $850 \leq T<1,473 \mathrm{~K}$,

$$
\begin{aligned}
& L M P=30.014-12.127 \log (\sigma)+5.1831[\log (\sigma)]^{2}-1.8394[\log (\sigma)]^{3} \\
& t_{\mathrm{r}}=10^{[L M P(1,000) / T \cdot 11]}
\end{aligned}
$$

The damage within a time step $\Delta t$ is $\Delta t / t_{r}$ and the accumulated damage at a Gauss point or wall segment from all time steps $i$ is

$D=\Sigma\left(\Delta t_{i} / t_{r}\right)$

This procedure is also discussed in Reference A-23. 


\section{A.3 Geometrical Data}

This section contains dimensions used in the TMI-2 margin-to-failure analyses. Dimensioned diagrams of the vessel, instrument nozzle, cavity configuration, and reactor vessel insulation placement are included in Figures A-42 through A-45. 


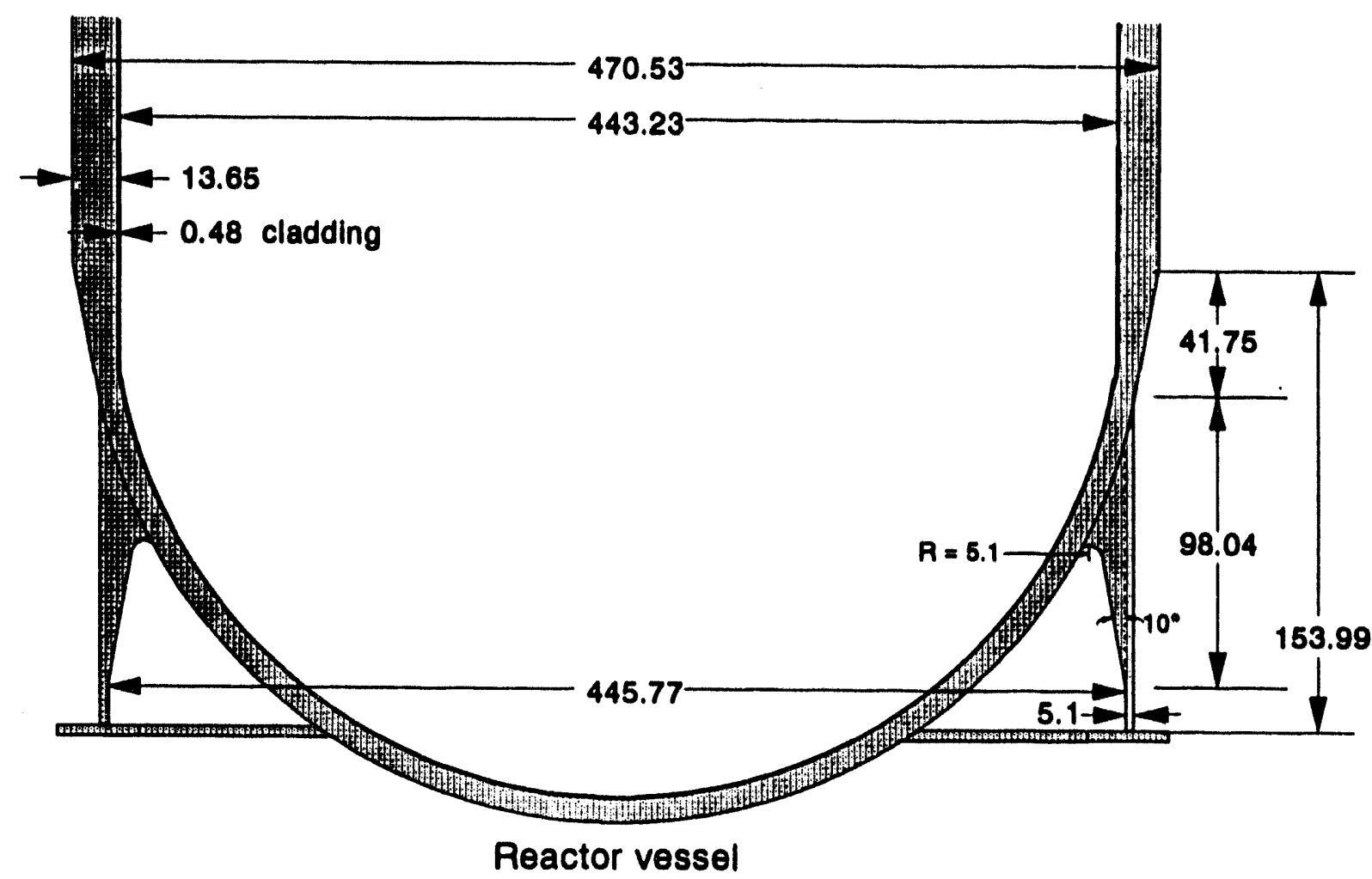

(Dimensions in centimeters)

MQ12-WHT-203-12

Figure A-42. Dimensioned drawing of TMI-2 lower head (see Table A-8 for references for dimensions). 
Table A-8. References for TMI-2 lower head dimensions shown in Figure A-42.

Vessel

Material

Thickness-reference

Thickness-minimum

Inner diameter (to base metal)

Outer diameter

Claddins

Material

Thickness-nominal

Thickness-minimum

Skirt

Material

Inner diameter

$44.77 \mathrm{~cm}$

$5.1 \mathrm{~cm}$

$41.75 \mathrm{~cm}$

Point of attachment (distance from hemisphere to point where skirt attaches to outer surface)

Length (from hemisphere to end of skirt)

Radius for junction between skirt and vessel

Distance between hemisphere and point where skirt angles in at 10 degrees

SA533B1

$13.65 \mathrm{~cm}$

$12.7 \mathrm{~cm}$

$443.23 \mathrm{~cm}$

$470.53 \mathrm{~cm}$

SS304

$0.48 \mathrm{~cm}$

$0.32 \mathrm{~cm}$$$
41.75 \mathrm{~cm}
$$

$153.99 \mathrm{~cm}$

$5.1 \mathrm{~cm}$

98.04
B\&W Drawing 126970, Rev. 4 "Vessel Head and Suppt Assy \& Details," 1/20/75.

B\&W Drawing 126970, Rev. 4 "Vessel Head and Suppt Assy \& Details," 1/20/75.

B\&W Drawing 126970, Rev. 4 "Vessel Head and Suppt Assy \& Details," 1/20/75.

B\&W Drawing 126970, Rev. 4 "Vessel Head and Suppt Assy \& Details," 1/20/75.

B\&W Drawing 126971 E, Rev. 6 " Inst. Nozzle Det. \& Assy.," 12/6/74.

B\&W Drawing 126970, Rev. 4 "Vessel Head and Suppt Assy \& Details," 1/20/75.

Thickness
B\&W Drawing 126970, Rev. 4 "Vessel Head and Suppt Assy \& Details," 1/20/75.

B\&W Drawing 126970, Rev. 4 "Vessel Head and Suppt Assy \& Details," 1/20/75.

B\&W Drawing 126963 E, Rev. 11 "Arrgt. Reactor Vessel Long. Sec.," 6/18/75.

B\&W Drawing 126970, Rev. 4 "Vessel Head and Suppt Assy \& Details," 1/20/75.

B\&W Drawing 126970, Rev. 4 "Vessel Head and Suppt Assy \& Details," 1/20/75. 


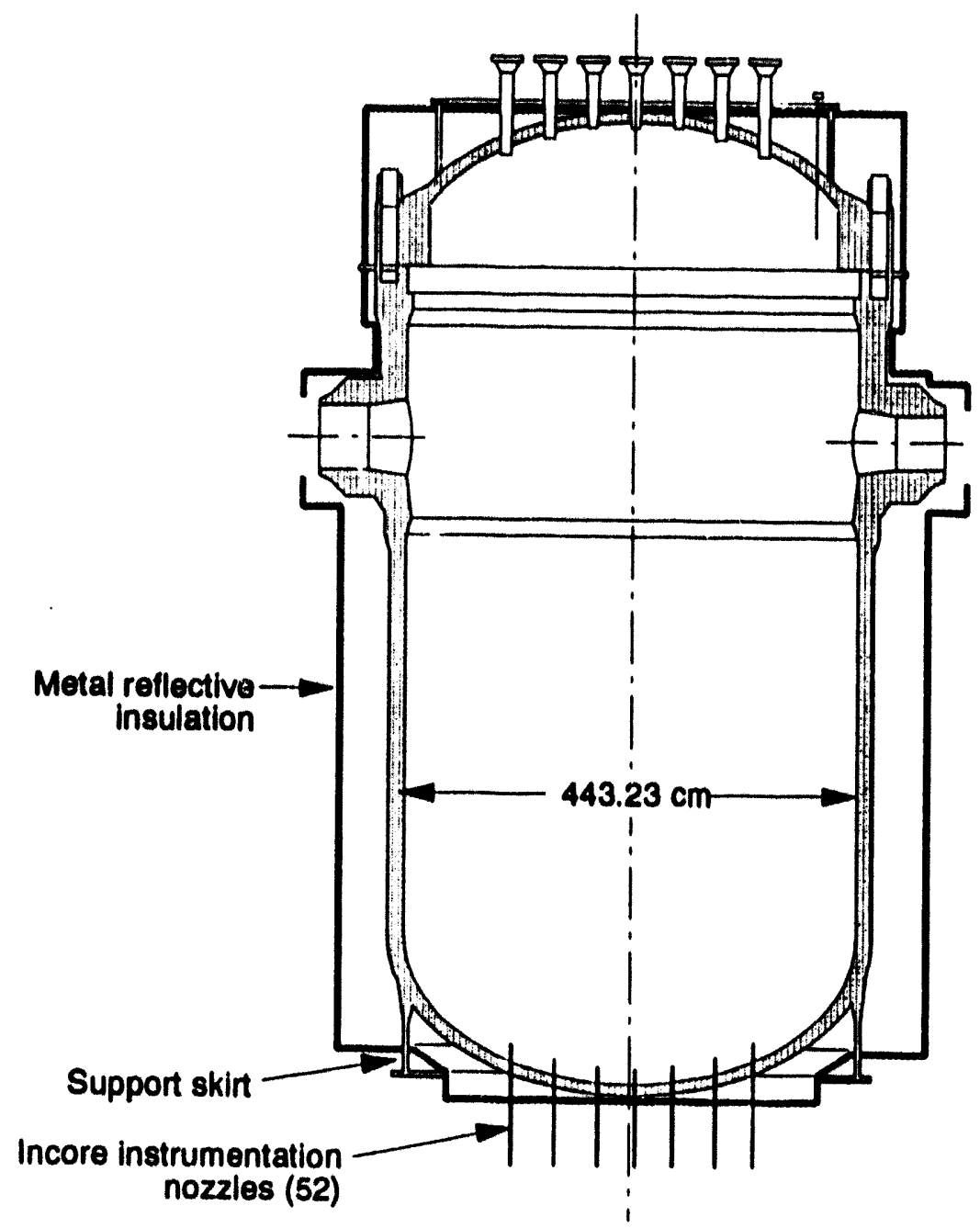

M757.WHT-1192-07

Figure A-43. Drawing illustrating insulation placement around TMI-2 reactor vessel. ${ }^{\mathrm{A}-24}$ 


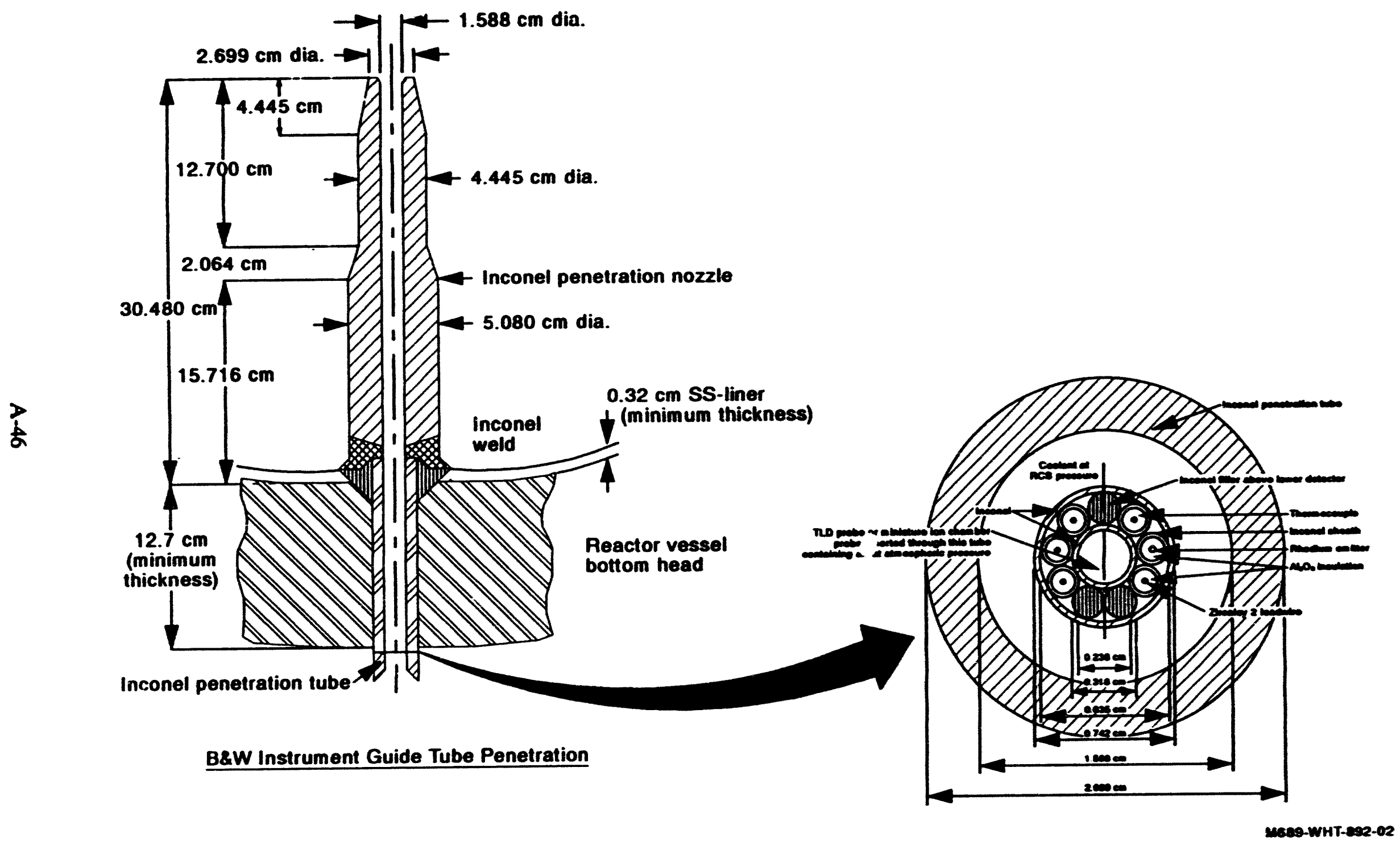

Figure A-44. Dimensioned drawing of TMI-2 instrument nozzle. A-25 


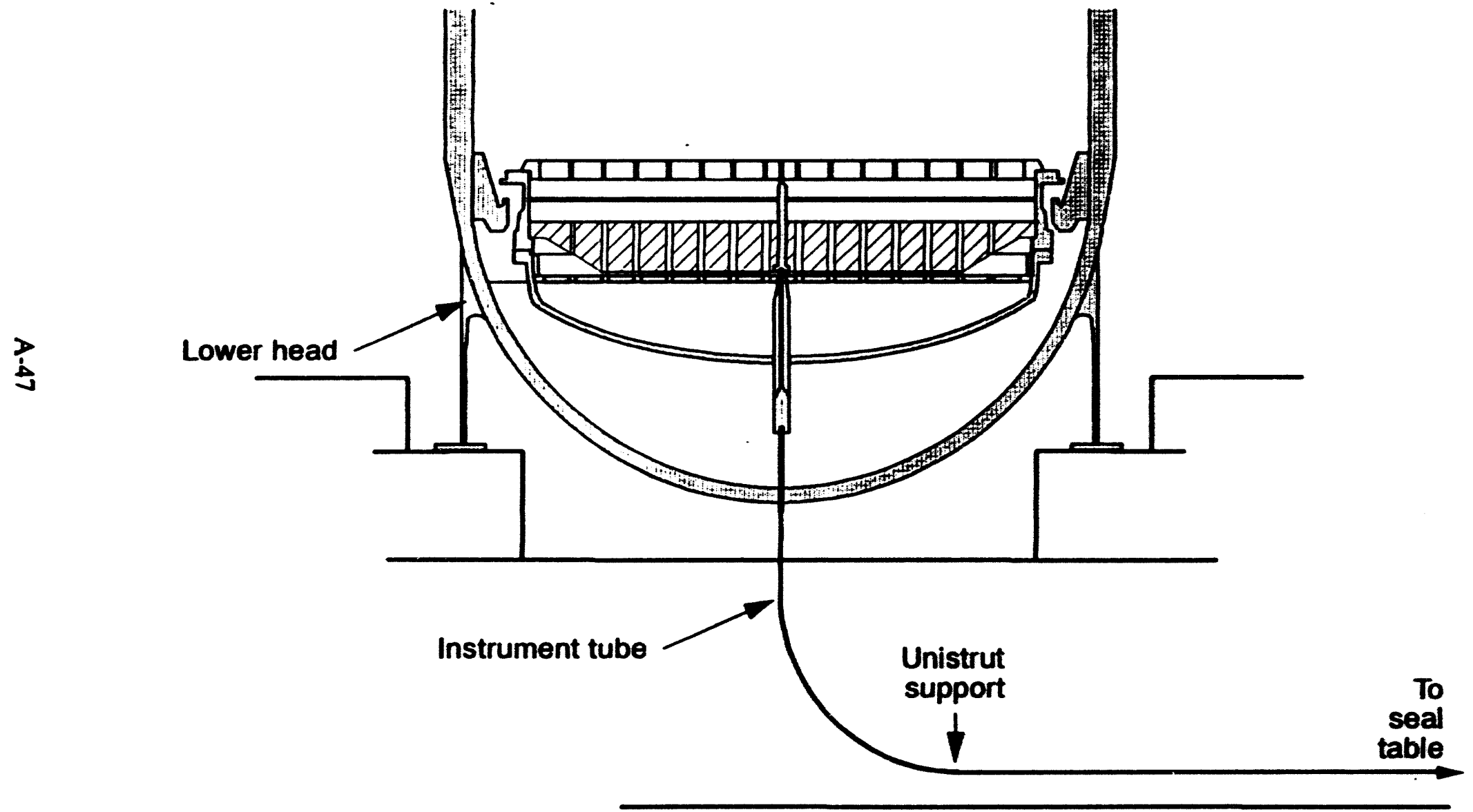

Mrse sect $1002-0$

Figure 4-45. Drawing illustrating instrument tube arrangement below $\mathbf{T M I}-2$ reactor vessel. ${ }^{\text {A-25. }}$ a. Personal communication with B\&W personnel, September 1992. 


\section{A.4 Roferences}

A-1. J. K. Hohorst, SCDAP/RELAPS/MOD2 Code Manual, Volume 4: MATPRO - A Library of Materials Properties for Light-Water-Reactor Accident Analysis, NUREG/CR-5273, EGG2555, February 1990.

A-2. D. W. Akers, et al., Companion Sample Examinations, OECD-NEA-TMI-2 VIP TMIV(92)EG10, July 1992.

A-3. Sandia Laboratories, Core Meltdown Experimental Review, SAND74-0382, August, 1992.

A-4. Air Force Materials Laboratory, Aerospace Structural Metals Handbook, 1990 Edition, Revised 1989, Air Force Materials Laboratory.

A-5. Huntington Alloy, Inconel-600, Technical Bulletin of the International Nickel Company, Inc., now Inco Alloys International, Inc., Huntington Alloy Products Division, Seventh edition, Huntington, West Virginia, 1987.

A-6. R. E. Bolz and G. L. Tuve, (eds.), CRC Handbook of Tables for Applied Engineering Science, Second Edition, Boca Raton, Florida: The Chemical Rubber Company Press, 1976.

A-7. D. L. Timrot, Determination of Thermal Conductivity and Heat Capacity of Steels, Zhurnal Tekhinicheskoi Fizinki, 5, 1935, pp. 1011-1036.

A-8. R. W. Powell, and M. J. Hickman, "Thermal Conductivity and Electrical Resistivity of a Series of Steels," Journal of the Iron Steel Institute, Special Report No. 24, Part 3, London, 1939, pp. 242-251.

A-9. B. E. Neimark, and V. E. Lynsternik, "Effect of Chilling on the Thermal Diffusivity of Carbon Steels," Teploenergetika, 7, pp. 16-18, 1960.

A-10. J. H. Awbery, A. R. Calloner, P. R. Pallister, and R. W. Powell, "The Physical Properties of a Series of Steels - Part II," Journal of the Iron Steel Institute, 154(2), London, 1946, pp. 83-111.

A-11. P. R. Pallister, "Specific Heat and Resistivity of Mild Steel," Joumal of the Iron Steel Institute, 185(4), London, 1957, pp. 474-482.

A-12. British Iron and Steel Research Association, Physical Constants of Some Commercial Steels at Elevated Temperatures, London: Butterworth's Scientific Publication, Ltd., 1957, p. 38.

A-13. E. Griffiths, R. W. Powell, and M. J., Hickman, "The Physical Properties of a Series of Steels-I," Journal of the Iron Steel Institute, Special Report No., 24, London, pp. 215-251. 
A-14. E. G. Shuidkovskii, "Measurement of the Thermal Conductivity of Metals by the Method of Angstrom," Journal Tech. Phys., 8, USSR, 1938, pp. 935-947.

A-15. J. L. Rempe, et al., Light Water Reactor Lower Head Failure Analysis, NUREG/CR-5642, EGG-2618, October 1993, Appendix B.

A-16. G. V. Smith, Evaluations of the Elevated Temperature Tensile and Creep Rupture Properties of C-Mo, Mn-Mo and Mn-Mo-Ni Steels, Metal Properties Council, American Society for Testing and Materials, ASTM Data Series Publication DS47, 1971.

A-17. National Research Institute for Metals, Data Sheets on the Elevated-Temperature Properties of 1.3 Mn-0.5 Mo-0.5 Ni Steel Plates for Boilers and Other pressure Vessels (SBV 2), NRIM Creep Data Sheet No. 18B, Japan, December 1987.

A-18. G. B. Reddy and D. J. Ayres, High Temperature Elastic-Plastic Creep Properties for SAS33 Grade B Class 1 and SA508 Materials, EPRI-NP-2763, December 1982.

A-19. Y. Takeuti, et al., "Thermal-Stress Problems in Industry. 3: Temperature Dependency of Elastic Moduli for Several Metals at Temperatures from $196^{\circ} \mathrm{C}$ to $1000^{\circ} \mathrm{C}$," Journal of Thermal Stresses, 2: 1979, pp. 233-250.

A-20. R. A. Moen, Thermophysical Properties of Ferrous Structural Alloys, HEDL-TME-78-47, April 1978.

A-21. R. L. Huddleston, "An Improved Multiaxial Creep-Rupture Strength Criterion," American Society of Mechanical Engineers, Joumal of Pressure Vessel Technology, 107, 1985, pp. 421-429.

A-22. J. Strosnider, "Summary Record of the TMI-VIP Structural Mechanics Peer Review Group Meeting," OECD TMI Vessel Investigation Project, Idaho Falls, Idaho, May 11, 1992, NEA.TMIVIMAN(92)09, July 20, 1992.

A-23. H. Kraus, Creep Analysis, New York, New York: John Wiley and Sons, 1980, pp. 98-106.

A-24. Sacramento Municipal Utility District, Rancho Seco Final Safety Analysis Report, Docket No. 50-312, Sacramento Municipal Utility District, 1971.

A-25. MPR Associates, Phase 4 Status Report, Removal of Test Specimens from the TMI-2 Reactor Vessel Bottom Head, Project Summary, MPR-1195, October 1, 1990, Drawing no. F-80-107-89, July 1990. 


\section{Appendix B}

\section{Supporting Information for Melt}

Penetration Calculations

B-1 


\section{Appendix B}

\section{Supporting Information for Melt Penetration Calculations}

\section{B.1 Compllation of Instrumentation Nozzle Data}

In the information below, cut elevations and ablation elevations reported by MPR Associates ${ }^{\mathrm{B}-1}$ should be considered as nominal distances. Elevations are given from the nadir of the lower head inside the pressure vessel. Figure B-1 illustrates the relative positions of the various elevations given in the information below for several of the nozzles. A discrepancy of $1.27 \mathrm{~cm}$ in the total length of nozzles D10 and E11 exists. The missing length might be attributed to uneven cutting. In the dimensions presented below the missing length was assumed to exist between the nozzle cut and the sample and was added into the fuel penetration elevation and nozzle ablation elevation. Fuel penetration measurements were based on gamma scans.

\section{Nozzle D10}

Examining Lab: ANL

Length: $23.5 \mathrm{~cm}$

Elevation of nozzle at cut: $28.8 \mathrm{~cm}$

Fuel penetration elevation in nozzle: $42.8 \mathrm{~cm}$ min., $29.9 \mathrm{~cm} \max$.

Debris penetration elevation in instrument probe tube: $28.8 \mathrm{~cm}$

Debris composition in instrument probe tube: ceramic

Nozzle ablation elevation: $53.6 \mathrm{~cm}$

Comments: A gamma scan for fuel depth indicated a small amount of fuel at the nozzle tip and fuel throughout the nozzle, with the highest concentration at an elevation of $21.6 \mathrm{~cm}$. The instrument probe tube in the center of the instrument string had collapsed. (Surface temperatures of $1,673 \mathrm{~K}$ were estimated at the $21.6 \mathrm{~cm}$ elevation.)

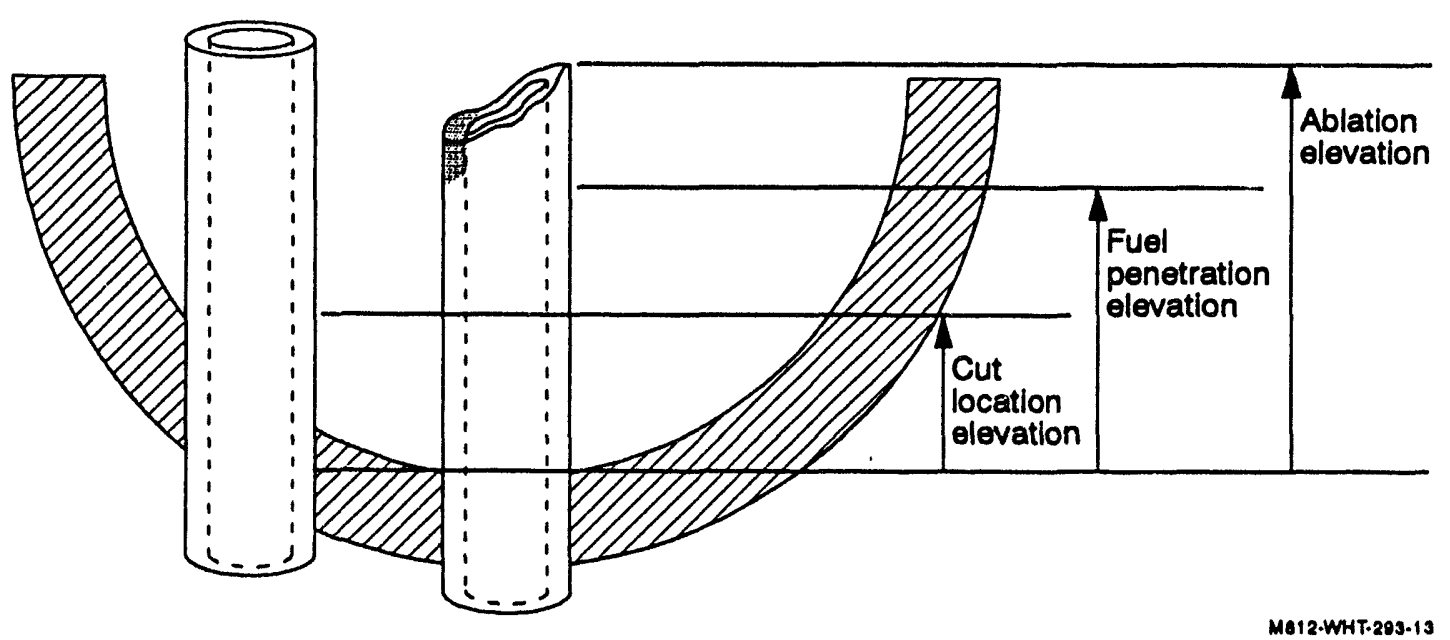

Figure B-1. Relative positioning of elevational data. 


\section{Nozzle E7}

Examining Lab: INEL

Length: $1.3-1.6 \mathrm{~cm}$

Comments: Nozzle was severely damaged. A crack extends through one wall of the nozzle. Due to the short length, a gamma scan was not performed. The instrument string was removed from the sample. No blockages were encountered with a wire probe test.

\section{Nozzle E11}

Examining Lab: ANL

Length: $22.5 \mathrm{~cm}$

Elevation of nozzle at cut: $28.4 \mathrm{~cm}$

Fuel penetration elevation in nozzle: $42.5 \mathrm{~cm}$

Debris penetration elevation in instrument probe tube: $28.4 \mathrm{~cm}$

Debris composition in instrument probe tube: ceramic and metallic

Nozzle ablation elevation: $52.3 \mathrm{~cm}$

Comments: Undamaged nozzle was cut to allow access to vessel sample. Gamma scan for fuel depth showed a large concentration of fuel at the nozzle tip and a smaller amount inside the nozzle approximately $7.6 \mathrm{~cm}$ from the tip. The instrument string was loose but intact and was pulled out. The outer surface of the nozzle tip appeared thermally ablated by aluminum. Debris in the center of the nozzle consisted of fuel shards and oxidized instrument lead conduit. (Surface deposits appear non-adherent below the $27.2 \mathrm{~cm}$ elevation, indicating temperatures less than $1,273 \mathrm{~K}$.)

\section{Nozzle G5}

Examining Lab: INEL

\section{Length: $4.4 \mathrm{~cm}$}

Comments: The nozzle was heavily damaged and too short to be gamma scanned. A wire probe test indicated the nozzie was completely plugged with melt. There are insufficient data to determine if melt penetration ends above or below the cut.

\section{Nozzle H5}

Examining Lab: ANL

Length: $14.6 \mathrm{~cm}$

Elevation of nozzle at cut: $10.7 \mathrm{~cm}$

Fuel penetration elevation in nozzle: $22.4 \mathrm{~cm}$ min., $19.6 \mathrm{~cm}$ max.

Debris penetration elevation in instrument probe tube: $10.7 \mathrm{~cm}$

Debris composition in instrument probe tube: ceramic and metallic

Nozzle ablation elevation: $25.3 \mathrm{~cm}$

Comments: The nozzle was cut off flush with the vessel. About $15.9 \mathrm{~cm}$ was ablated from the top of the nozzle. A gamma scan for fuel depth was performed. Debris appeared to cover the outside tip of the nozzle. A slug of Inconel was present in the annulus, extending to the bottom of the nozzle. (Temperatures varied from $1,673 \mathrm{~K}$ at $36.6 \mathrm{~cm}$ elevation to less than $1,033 \mathrm{~K}$ at the bottom of the nozzle, $29.0 \mathrm{~cm}$ elevation). 


\section{Nozzle $\mathbf{H 8}$}

Examining Lab: ANL

Length: $7.0 \mathrm{~cm}$

Elevation of nozzle at cut: $5.1 \mathrm{~cm}$

Fuel penetration elevation in nozzle: $<6.4 \mathrm{~cm}$

Debris penetration elevation in instrument probe tube: $5.1 \mathrm{~cm}$

Debris composition in instrument probe tube: ceramic and metallic

Nozzle ablation elevation: $12.1 \mathrm{~cm}$

Comments: Nozzle was approximately $15.2 \mathrm{~cm}$ long postaccident. About $5.1 \mathrm{~cm}$ was broken off during lower head defueling. After cutting the nozzle, the length was $7.0 \mathrm{~cm}$. A gamma scan for fuel depth indicated fuel throughout the nozzle, with the highest concentration at the nozzle tip. Molten Inconel was found inside the nozzle within $1.3 \mathrm{~cm}$ of the bottom of the nozzle. The temperature of the Inconel was estimated to be approximately $1,223 \mathrm{~K}$.

Nozzle $\mathbf{H 9}$

Examining Lab: INEL

Length: $24.1 \mathrm{~cm}$

Comments: Nozzle sustained very little visual damage. The instrument string was still intact. Gamma scans show high fuel concentrations at two positions in the nozzle, $5.1 \mathrm{~cm}$ and $14.0 \mathrm{~cm}$ from the point where the nozzle was cut. Probe testing revealed no blockage.

\section{Nozzle K11}

Examining Lab: INEL

Length: $23.5 \mathrm{~cm}$

Comments: Nozzle was badly damaged 7.6 to $20.3 \mathrm{~cm}$ above the vessel surface, with one-half the wall thickness melted away. This was the only nozzle where melt ablated the outside of the nozzle wall. The top $15.2 \mathrm{~cm}$ was leaning at an angle of 10-20 degrees. Gamma scans showed fuel over the entire length of the nozzle, but complete blockage was not encountered by a wire probe. MPR Associates reported that melt filled the cross sectional area of the remaining $5.1 \mathrm{~cm}$ nozzle stub in the vessel. ${ }^{B-2}$

\section{Nozzle K12}

Examining Lab: INEL

Length: $25.7 \mathrm{~cm}$ with instrument string, $24.4 \mathrm{~cm}$ without instrument string

Comments: This was a relatively undamaged nozzle, but gamma scans showed a high, steady concentration of fuel throughout the entire nozzle. No blockages were detected from a wire probe test.

\section{Nozzle 16}

Examining Lab: ANL

Length: $24.1 \mathrm{~cm}$

Elevation of nozzle at cut: $15.7 \mathrm{~cm}$

Fuel penetration elevation in nozzle: $16.9 \mathrm{~cm}$

Debris penetration elevation in instrument probe tube: $15.7 \mathrm{~cm}$

Debris composition in instrument probe tube: ceramic and metallic

Nozzle ablation elevation: $39.9 \mathrm{~cm}$ 
Comments: The nozzle had minor damage to the upper $0.5 \mathrm{~cm}$ wall section. A gamma scan for fuel depth was performed. Control materials entered the nozzle prior to fuel. No significant axial temperature gradient was present in the nozzle.

\section{Nozzle L11}

Examining Lab: INEL

Length: $22.9 \mathrm{~cm}$

Comments: This was a relatively undamaged nozzle except for a $5.1 \mathrm{~cm}$ region at the shoulder of the nozzle, extending 5.1 to $10.2 \mathrm{~cm}$ from the bottom end. A gamma scan showed high fuel activity present $7.6 \mathrm{~cm}$ from the base. No blockage of the nozzle was found from a probe test.

\section{Nozzle M9}

Examining Lab: ANL

Length: $25.4 \mathrm{~cm}$

Elevation of nozzle at cut: $14.5 \mathrm{~cm}$

Fuel penetration elevation in nozzle: $36.0 \mathrm{~cm}$

Debris penetration elevation in instrument probe tube: $33.0 \mathrm{~cm}$

Debris composition in instrument probe tube: ceramic and metallic

Nozzle ablation elevation: $39.9 \mathrm{~cm}$

Comments: There was minor damage to the top of nozzle, believed to be caused by molten fuel as opposed to a solid crust of fuel. A gamma scan for fuel depth showed fuel only in the top $5.1 \mathrm{~cm}$ of nozzle.

\section{Nozzle M10}

Examining Lab: INEL

Length: $16.2 \mathrm{~cm}$

Comments: There was severe melt damage to the top $6.4 \mathrm{~cm}$ of the nozzle. The upper portion of the nozzle appears to have been melted. A gamma scan showed higher concentration of fuel near the base end of the nozzle than at the tip. Wire probe tests indicated melt plugged the nozzle to within $5.7 \mathrm{~cm}$ of the bottom end.

\section{Nozzle R7}

Examining Lab: INEL

Length: $23.2 \mathrm{~cm}$

Comments: Fuel adhered to the top of the nozzle and protruded approximately $2.5 \mathrm{~cm}$ above the nozzle. The instrument string was partially molten at the tcp end. A gamma scan showed high fuel concentration at the tip of the nozzle, with a smaller concentration halfway down the nozzle. No blockages were determined from a wire probe test. 


\section{B.2 Derlvation of Modifled Bulk-Freezing Model Equations}

The derivation begins with a heat balance on the debris,

$m_{d} c_{p d}\left(T_{d}-T_{m p}\right)+m_{d} L_{d}=h_{t d} A_{t d}\left(T_{d}-T_{t}\right) t_{s o l}+h_{w d} A_{w d}\left(T_{d}-T_{c}\right) t_{s o l}$

The heat transfer coefficient between the debris and the coolant can be replaced by terms accounting for the energy change of the coolant, derived from a separate heat balance around the coolant in azimuthal contact with the debris. The heat balance is dependent upon the coolant state. For example, assume the coolant is saturated liquid at the time the debris solidifies, then

$h_{w d} A_{w d}\left(T_{d}-T_{c}\right) t_{\text {sol }}=m_{\text {sat }} c_{p_{l}}\left(T_{\text {sat }}-T_{i}\right)$

Substituting this expression into Equation (B-1),

$m_{d}\left\{c_{p d}\left(T_{d}-T_{m p}\right)+L_{d}\right\}=h_{t d} A_{t d}\left(T_{d}-T_{t}\right) t_{s o l}+m_{\text {sat }} c_{p_{l}}\left(T_{s a t}-T_{i}\right)$

In the above equations, $t_{\text {sol }}$ is the time required for debris of length $x_{p}$ to solidify while traveling at a constant velocity $v_{d}$, such that $t_{s o l}=x_{p} / v_{d}$. The mass of debris and coolant are given as

$m_{d}=\rho_{d} x \frac{\pi}{4} d_{e}^{2} x_{p}$

$m_{\text {sat }}=P_{\text {sat }}(1-x) \frac{\pi}{4} d_{e}^{2} x_{p}$

where $x$ is the fraction of the effective cross-sectional area covered by debris. The $A_{t d}$ in the heat transfer coefficient term is the circumferential contact area between the debris and the nozzle wall,

$A_{t d}=x \pi\left(d_{i}+d_{s o}\right) x_{p}$

Substituting Equations (B-4) through (B-6), the heat balance, Equation (B-3), becomes

$$
\rho_{d} x \frac{\pi}{4} d_{e}^{2} x_{p}\left\{c_{p d}\left(T_{d}-T_{m p}\right)+L_{d}\right\}=h_{t d} x \pi\left(d_{i}+d_{s o}\right) x_{p}\left(T_{d}-T_{t}\right) \frac{x_{p}}{v_{d}}+\rho_{s a t l}(1-x) \frac{\pi}{4} d_{e}^{2} x_{p} c_{p l}\left(T_{s a t}-T_{i}\right)
$$

After simplification and rearrangement, the dimensionless peretration distance is 
$\frac{x_{p}}{\left(d_{i}-d_{s o}\right)}=\frac{.25 v_{d}}{h_{t d}\left(T_{d}-T_{t}\right)}\left[\rho_{d}\left\{c_{p d}\left(T_{d}-T_{m p}\right)+L_{d}\right\}-\left(\frac{1}{x}-1\right) \rho_{s a t} c_{p l}\left(T_{s a t}-T_{i}\right)\right]$

The definition of the effective diameter, $d_{c}^{2}=d_{i}^{2}-d_{s o}^{2}$, was used in the simplification. The heat transfer coefficient may be replaced by a Nusselt number correlation. A Nusselt number correlation for liquid metals in concentric annuli ${ }^{\mathrm{B}-2}$ was used. The correlation is

$N u=5.25+0.0188 P e^{0.8}\left(\frac{d_{i}}{d_{s 0}}\right)^{0.3}$.

The Peclet number in Equation (B-9) is defined as

$P e=\frac{d_{e} v_{d} \rho_{d} c_{p d}}{k_{d}}$

Inserting Equation (B-9), the dimensionless distance for debris in contact with saturated coolant becomes

$$
\frac{x_{p}}{\left(d_{i}-d_{s o}\right)}=.25 P e \frac{\left[\rho_{d}\left\{c_{p d}\left(T_{d}-T_{m p}\right)+L_{d}\right\}-\left(\frac{1}{x}-1\right)\left\{\rho_{s a t} c_{p l}\left(T_{s a t}-T_{i}\right)\right\}\right]}{\rho_{d} c_{p d}\left(T_{d}-T_{t}\right)\left(5.25+0.0188 P e^{0.8}\left(\frac{d_{i}}{d_{s o}}\right)^{0.3}\right)} .
$$

As observed from Equation (B-11), several variations of the modified bulk-freezing equation are possible. The form of the equation depends upon the Nusselt number correlation and the final coolant conditions. Equations incorporating Nusselt numbers for annular nozzles will be presented. Two cases of coolant state are implemented. At the time of solidification, the coolant in radial contact with the debris is modeled as either subcooled liquid or saturated liquid. If the coolant remains subcooled, but at a temperature above the initial temperature, the penetration distance is

$$
x_{p}=0.25 P e\left(d_{i}-d_{s o}\right) \frac{\left[\rho_{d}\left\{c_{p d}\left(T_{d}-T_{m p}\right)+L_{d}\right\}-\left(\frac{1}{x}-1\right) \rho_{s u b} c_{p l}\left(T_{s u b}-T_{i}\right)\right]}{\rho_{d} c_{p d}\left(T_{d}-T_{t}\right)\left(5.25+0.0188 P e^{0.8}\left(\frac{d_{i}}{d_{s o}}\right)^{0.3}\right)}
$$

For the case in which the coolant in contact with the debris becomes saturated liquid, the relation is 


$$
x_{p}=0.25 P e\left(d_{i}-d_{s o}\right) \frac{\left[\rho_{d}\left\{c_{p d}\left(T_{d}-T_{m p}\right)+L_{d}\right\}-\left(\frac{1}{x}-1\right)\left\{\rho_{s a t} c_{p l}\left(T_{s a t}-T_{i}\right)\right\}\right]}{P_{d} \mathcal{C}_{p d}\left(T_{d}-T_{t}\right)\left(5.25+0.0188 P e^{0.8}\left(\frac{d_{i}}{d_{s o}}\right)^{0.3}\right)} .
$$

For the case in which no coolant is present and the debris fills the nozzle, a heat balance yields

$$
x_{p}=0.25 \operatorname{Pe}\left(d_{i}-d_{s o}\right) \frac{\left[\left(T_{d}-T_{m p}\right)+L_{d} / c_{p d}\right]}{\left(T_{d}-T_{t}\right)\left(5.25+0.0188 \mathrm{Pe}^{\left.0.8\left(\frac{d_{i}}{d_{s o}}\right)^{0.3}\right)}\right.} .
$$

One of the six nozzles examined at ANL was found to contain debris in a ring formation around the inside of the nozzle wall. The above equations were modified for this variation in shape and are presented below for the specific case of saturated coolant. The equation for the case of subcooled liquid can be discerned from the equation above. For this debris shape, a more general equation may be written where any thickness of the debris can be input:

$$
\begin{aligned}
x_{p}= & \frac{0.25 P e}{\rho_{d} c_{p d} d_{i}\left(T_{d}-T_{t}\right)\left(5.25+0.0188 P e^{0.8}\left(\frac{d_{i}}{d_{s o}}\right)^{0.3}\right)} \\
& {\left[\rho_{d}\left(d_{i}^{2}-d_{d}^{2}\right)\left\{c_{p d}\left(T_{d}-T_{m p}\right)+L_{d}\right\}-\left(d_{d}^{2}-d_{s o}^{2}\right)(1 / x-1)\left\{\rho_{s a t} c_{p l}\left(T_{s a t}-T_{i}\right)\right\}\right] }
\end{aligned}
$$

\section{B.3 References}

B-1. MPR Associates, Inc., Removal of Test Specimens from the TMI-2 Reactor Vessel Bottom Head, MPR-1195, October 1, 1990.

B-2. N.E. Todreas and M.S. Kazimi, Nuclear Systems I: Thermal Hydraulic Fundamentals, New York: Hemisphere Publishing Corp, 1990. 


\section{Appendix C}

\section{TMI Model Description}

C-1 


\section{Appendix C}

\section{TMI Model Description}

\section{C.1 TMI Model Description}

Heat transfer to the pressure vessel is modelled using an overall heat transfer coefficient, which is obtained by assuming that the energy transferred through the crust equals the energy transferred to the pressure vessel. The heat transfer coefficient through the crust, $\boldsymbol{h}_{\text {crust }}$ is given by a value which represents steady state conduction through the crust thickness, $\delta_{\text {crust }}{ }^{a}$

$h_{\text {cus }}=\frac{k_{\text {crus }}}{\delta_{\text {crus }}}$.

The pressure vessel heat transfer coefficient, $h_{p p}$, is given by the maximum of the following two values.

$h_{p v}=M A X\left[\frac{k_{v}}{\sqrt{\pi \alpha_{n} t}}\right.$ or $\left.\frac{k_{v}}{t_{v} / 2.0}\right]$.

An overall heat transfer coefficient, $U_{\text {down }}$ which represents heat transfer to the pressure vessel is therefore given by

$$
\frac{1}{U_{\text {down }}}=\frac{1}{h_{c n u s t}}+\frac{1}{h_{p v}}+\frac{1}{h_{i n t}} .
$$

Note that an interfacial heat transfer coefficient, $h_{i n s}$ is included in the overall heat transfer coefficient to account for the interfacial thermal resistance that may be present due to surface roughness between the crust and the vessel. Using the method suggested by Garnier, ${ }^{C-1}$ values for the gap resistance between the vessel and crust were estimated to range from 150 to $10,000 \mathrm{~W} / \mathrm{m}^{2} \mathrm{~K}$.

The heat fluxes to the fuel crust surface next to the pressure vessel at short times ( $\sim 1$ minute) are dominated by the impinging jet, while at long times the heat fluxes are controlled by natural convection due to internal heat generation in the melt pool. Heat transfer coefficients due to the jet, $h_{\text {din }}$, for the impingement region and the laminar boundary layer region around it are exponentially reduced to the coefficients resulting from internal natural convection over a

a. A complete list of variables is found in the Nomenclature 
time period that is longer than the time it takes the jet to drain, $t_{\text {drain }}$. This relationship is shown below.

\section{Stagnation Region:}

$h_{d n}=h_{d c}+\exp \left[\frac{-1}{t_{d r a i n} / 8}\right]\left[\frac{N u_{\text {seas }} k_{j e t}}{D_{j e r}}-h_{d c}\right]$.

Laminar Boundary Layer Region:

$h_{d i n}=h_{d c}+\exp \left[\frac{-t}{t_{\text {drain }} / 8}\right]\left[\frac{N u(r) k_{j n}}{D_{j e r}}-h_{d c}\right]$.

The Nusselt number for the jet stagnation region and for the laminar boundary layer region were modeled based on simulated experiments ${ }^{\mathrm{C}-2}$ and analysis ${ }^{\mathrm{C}-3}$ of the impingement of liquid jets on a wall with possible simultaneous melting and freezing. The complete formulations are provided in Reference C-4.

The transition from jet impingement stagnation heat transfer to the natural convection regime assumes that there is no substantial period over which the melt pool would be completely stagnant. This assumption is based upon the assumptions: (a) that most of the melt arrives in a molten state, and (b) that the characteristic time for the onset of natural convection is short compared to the time of interest (several hours). The first assumption is based upon TEXAS calculational results discussed in Section 3.2. The second assumption is based on results from dimensional analyses, which indicate that the timescale for the onset of natural convection is much less than one hour. ${ }^{\mathrm{C}-4}$

Internal heat generation resulting from fission products causes some of the pool to remain molten and can cause significant internal natural convection. The only appropriate correlation for the heat transfer coefficient to the lower crust, $h_{d c}$, for a hemispheric molten zone with internal heat generation, $\boldsymbol{Q}_{h g}$, was found from the work of Jahn and Reineke:c-s

$$
h_{d c}=f(\varphi) 0.54 R a^{0.18} \frac{k_{p}}{R_{m}}
$$

where

$$
R a=\frac{g \beta_{p} Q_{n g} R_{m}^{s}}{\alpha_{p} v_{p} k_{p}}
$$


while

$R_{m}=\frac{R_{\text {crum }}+h}{2}$

and

$f(p)=0.2$

$f(\varphi)=0.2+1.8 \frac{\varphi-20}{55}$

if $\varphi<20$ degrees

$f(\varphi)=2.0$

if $20<\varphi<75$ degrees

if $\varphi^{\prime}>75$ degrees.

The variation of the heat flux as a function of the angle, $\varphi$, is given by the experimental and theoretical work done by Jahn and Reineke. ${ }^{\text {C.S }}$ (See Figure C-1 for the definitions of $\varphi, R_{\text {crurr }}$, and $h$.)

The overall heat transfer coefficient for heat transferred from the pressure vessel to its surroundings is represented by a heat transfer coefficient through the outer half of the pressure vessel thickness, $\boldsymbol{h}_{\text {cond }}$, and a heat transfer coefficient on the outside of the pressure vessel, $\boldsymbol{h}_{p \text { o }}$. The heat transfer coefficient through the half thickness of the pressure vessel is represented by

$h_{\text {cond }}=\frac{k_{p v}}{t_{v} / 2.0}$

and the overall heat transfer coefficient representing heat transfer to the surroundings is given by

$\frac{1}{U_{\text {out }}}=\frac{1}{h_{\text {cond }}}+\frac{1}{h_{p v o}}$

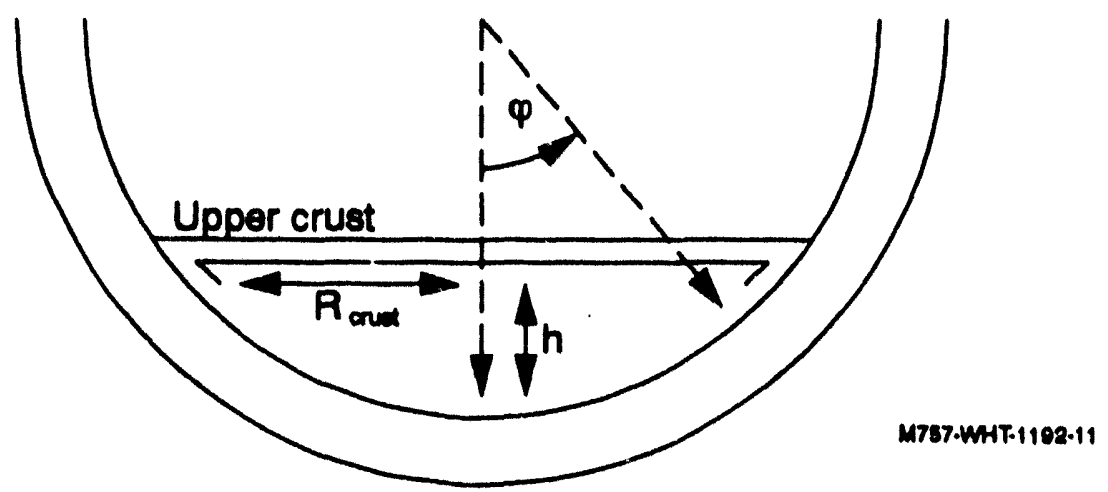

Flgure C-1. Definition of geometrical parameters for estimating convective heat transfer from a molten pool. ${ }^{\text {C.S }}$ 
Now that the heat transfer aspects surrounding the lower crust are defined, an energy ' balance can be written which determines the growth of the crust:

$$
\begin{aligned}
& \rho_{\text {cruor }} L_{\text {cruor }} A_{\text {derust }} \frac{d \delta_{\text {denus }}}{d t}=U_{\text {down }} A_{p v}\left(T_{\text {mpp }}-T_{\text {mall }}\right) \\
& -h_{\text {divo }} A_{\text {dcruor }}\left(T_{p}-T_{m p p}\right)-q^{\prime \prime \prime} V_{\text {dcrus }} \text {. }
\end{aligned}
$$

This balance is done for each control volume section of the pressure vessel, therefore allowing for variable lower crust thickness. A major assumption in this energy balance for the crust is that the change in sensible heat of the crust during its growth is small compared to the latent heat released during its growth; i.e., $L_{\text {crus }}>>c_{p d}$, where $L_{\text {cruss }}$ is the latent heat of fusion, and $c_{p} \Delta T$ is the change in the average crust thermal energy over the time period of interest. For calculations in Section 3.2, this inequality holds, and the assumption is reasonable.

For the upper energy loss, the heat transferred from the upper surface of the melt pool to the saturated water $(584 \mathrm{~K}, 10 \mathrm{MPa})$ is now examined. Film boiling and radiation are the initial heat transfer modes expected. This is based on the fact that the interface temperature is above the critical temperature of water and nucleate boiling would not occur in such a circumstance. Total heat flux up from the pool is determined by an overall energy balance based on two-phase flow $\mathrm{C}-6, \mathrm{C}-7, \mathrm{C}-\mathrm{B}$ and is given by

$$
q^{\prime \prime} f_{r}=q{ }^{\prime \prime} f_{s, s u b}+0.75 q ",
$$

The film boiling heat transfer from the upper surface of the melt pool while the jet is still draining is given by the correlation ${ }^{\mathrm{C}-\mathrm{8}}$

$$
\begin{aligned}
& q_{f b}^{\prime \prime}=0.425\left[\frac{g\left(\rho_{f}-\rho_{g}\right) \rho_{g} k_{g}^{3} h_{f g}}{\mu_{g}\left[\frac{\sigma_{f}}{g\left(\rho_{f}-\rho_{g}\right)}\right]^{0.25}\left(T_{p}-T_{\text {sat }}\right)^{0.75}}\right. \\
& q_{f b_{\text {sub }}}^{\prime \prime}=q_{\text {fo }}^{\prime \prime}\left[1.0+0.98 \frac{\left(T_{\text {sat }}-T_{\text {bulk }}\right)^{4}}{\left(T_{p}-T_{\text {sas }}\right)^{4}}\right]^{0.25} .
\end{aligned}
$$

The heat transfer to the water due to radiation is given by

$q^{\prime \prime} r=\sigma_{s b} \varepsilon_{\text {crust }}\left[T_{p}^{A}-T_{b u l k}^{A}\right]$.

An emissivity of 0.8 was assumed for the debris crust based on known properties. These correlations are used directly for the heat transfer from the melt pool until the jet stops draining, at which time it is assumed that a stable crust can form on the surface of the melt pool. Once the crust forms, an overall heat transfer coefficient representing the heat transfer to the water 
must be obtained. Again, the overall heat transfer coefficient can be used because it is assumed that the heat transfer through the crust is equal to the heat transferred into the coolant. Noting from Equation $\mathrm{C}-1$ that the heat transfer coefficient through the crust is given by

$$
h_{\text {crust }}=\frac{k_{\text {crust }}}{\delta_{\text {crust }}}
$$

while the heat transfer coefficient for film boiling and radiation from the crust to the water is given by

$$
h_{f b r}=\frac{q^{\prime \prime} f b r}{T_{i n t}-T_{s a t}}
$$

where $q$ " $f \circ$, is calculated using Equation C-13 with $T_{p}$ replaced by $T_{i m s}$, the interface temperature at the upper surface of the crust. The overall heat transfer coefficient from the pool to the water is a combination of the heat transfer through the crust and the heat transfer coefficient from the crust to the water:

$$
\frac{1}{U_{u p}}=\frac{1}{h_{c r u s t}}=\frac{1}{h_{f b, r}} .
$$

As the upper crust thickens and the interface temperature decreases, it is expected that film boiling will cease. Experience indicates that the minimum film boiling point would occur at this critical temperature $(647 \mathrm{~K})$, and eventually nucleate boiling will occur on the upper crust surface. In order to be consistent (i.e., keep the heat flux through the crust equal to that removed from the crust), the interface temperature was calculated by equating the heat flux through the crust and the heat flux given by nucleate boiling, $q$ " $N B$

$$
q_{N B}^{\prime \prime}=\frac{\mu_{f} h_{f g}}{0.014^{3.03}} \frac{1.0}{\sqrt{\frac{\sigma_{f}}{g\left(\rho_{f}-\rho_{g}\right)}}}\left[\frac{c_{p f}\left(T_{p}-T_{s a t}\right)}{h_{f f} \operatorname{Pr}_{f}^{1.7}}\right]^{3.03}
$$

with $T_{p}$ replaced by the interface temperature. This modeling approach results in the instantaneous removal of energy from the upper crust resulting in a steeper temperature gradient in the crust. The heat flux increases correspondingly to the representative heat flux given by the nucleate boiling correlation. As the interface temperature continues to decrease, the heat transfer due to natural convection becomes important. Therefore, the heat flux is now given by

$q^{\prime \prime}{ }_{t}=q^{\prime \prime}{ }_{N B}+q^{\prime \prime} N C-q^{\prime \prime}$ ONB 
where $q$ " ONB is the heat flux at the onset of nucleate boiling (negligible) and the heat flux due to natural convection $q^{\prime \prime}{ }_{N C}$ is given by Collier: ${ }^{\mathrm{C}-6}$

$q_{N C}^{\prime \prime}=\left[\frac{g \rho_{f}^{3} c_{p f} \beta}{\mu k_{f}}\right]^{0.33} 0.14 k_{f}\left[T_{i n t}-T_{s a t}\right]^{4 / 3}$

The heat transfer to the upper crust from the molten pool due to convection from internal heat generation is given by $\mathrm{C}$-5

$h_{u c}=0.36 R a^{0.23} \frac{k_{p}}{R_{m}}$

where the above variables were defined during the discussion of the heat transfer to the lower crust.

The energy balance to determine the growth of the upper crust is very similar to that of the lower crust:

$$
\begin{aligned}
\rho_{u c r u s t} L_{u c r u s t} A_{u c r u s t} \frac{d \delta_{u c r u s t}}{d t} & =U_{u p} A_{\text {top }}\left(T_{m p p}-T_{\text {bulk }}\right) \\
& -h_{u c} A_{u c r u s s}\left(T_{p}-T_{m p p}\right)-q^{\prime \prime \prime} V_{u c r u s t} .
\end{aligned}
$$

As noted above in the discussion about the energy balance for the lower curst [Equation (C-12)], these energy balances assume that the change in sensible heat of the crust during its growth is small compared to the latent heat released during its growth.

In order to put the model together, an energy balance centered around the heat in and out of the melt pool is used. Two differe $\cdots$, balances are needed, the following energy balance is applied while the jet is still draining,

$$
\begin{aligned}
\Delta T_{p} M_{p} c_{p}= & \dot{m} c_{j e t}\left(T_{j e t}-T_{p}\right) \Delta t+q^{\prime \prime \prime} \frac{M_{p}}{\rho_{p}} \Delta t \\
& -h_{\text {dirt }} A_{d c r u s t}\left(T_{p}-T_{m p p}\right) \Delta t-h_{u c} A_{u c r u s t}\left(T_{p}-T_{m p p}\right) \Delta t
\end{aligned}
$$

while this balance is applied after the jet has ended: 


$$
\Delta T_{p} M_{p} c_{p}=q^{\prime \prime \prime} \frac{M_{p}}{p_{p}} \Delta t-h_{\text {dir }} A_{d c n u s}\left(T_{p}-T_{m p p}\right) \Delta t-h_{u c} A_{u c r u s}\left(T_{p}-T_{m p p}\right) \Delta t
$$

The temperatures in the pressure vessel are incremented appropriately according to the equation

$$
\Delta T_{v} M_{v} c_{p v}=U_{\text {down }} A_{p v i}\left(T_{m p p}-T_{\text {wall }}\right) \Delta t-U_{\text {our }} A_{p v o}\left(T_{\text {wall }}-T_{\text {bulk }}\right) \Delta t
$$

One should remember that this energy balance follows the average temperature of the vessel wall, $T_{v}$, as it changes with time due to heat flow in from the melt pool and heat flow out to the ambient. The continuity of heat fluxes at the inner and outer vessel surfaces were then used to determine the through-wall vessel temperatures, such as shown in Figures 3-14(a) and 3-15(a).

Other aspects of the TMI model that should be mentioned are the effect of the freezing temperature range on the solid fraction and, consequently, its effect on the viscosity of the molten pool and the effect of the porosity on the thermal conductivity of the crust. When the temperature of the melt pool falls below the liquidus temperature of the debris $(2,850 \mathrm{~K})$, the solid fraction in the molten pool will become a factor in the analysis. The solid fraction to temperature relationship in the freezing range has been taken to be linear. That is, at $2,850 \mathrm{~K}$, the solid fraction of the melt pool is equal to zero; at $2,750 \mathrm{~K}$, the solid fraction is equal to 0.5 ; and at $2,650 \mathrm{~K}$ (i.e., the solidus temperature), the solid fraction is equal to 1.0 . The viscosity change due to the increase in solid fraction is important, as it plays a role when calculating the $\mathrm{Ra}$ number for the heat fluxes due to internal heat generation. The relationship between solid fraction, $X_{s}$, viscosity of the pool, $\mu_{p}$, and viscosity of the jet, $\mu_{\text {jet }}$, is shown below: ${ }^{C-9}$

$$
\mu_{p}=\mu_{j e 1} 1.5\left[\frac{1-1 / 3\left(1-X_{s}\right)}{\left(1-X_{s}\right)^{4}}\right] \text {. }
$$

The porosity in the crust will decrease the thermal conductivity. The relationship between porosity, $P_{c n u s t}$, and thermal conductivity of a solid with and without porosity, $k_{p o r}$, and $k_{s}$, respectively, was obtained from Olander ${ }^{\mathrm{C}-10}$

$$
\frac{k_{\text {por }}}{k_{s}}=\frac{1-P_{\text {crust }}}{1+\left(\alpha_{s f}-1\right) P_{\text {crust }}}
$$

where $\alpha_{3 f}$ is the shape factor equal to 1.5 for equal size spherical pores.

Heat transfer from the vessel at temperature, $T_{v}$, to the containment at temperature, $T_{a}$, is modeled using a heat transfer coefficient, $h_{p v o}$, that considers losses via natural convection and radiation (i.e., $h_{\text {pvo }}=h_{\text {conv }}+h_{\text {rad }}$ ). The convective component of this coefficient, $h_{\text {conv }}$, was estimated to range from 6 to $30 \mathrm{~W} / \mathrm{m}^{2} \mathrm{~K}$, based upon typical values cited in Reference $C-11$ for 
natural convection. The radiative component, $h_{\text {rad }}$, was calculated to range from 20 to $65 \mathrm{~W} / \mathrm{m}^{2} \mathrm{~K}$ using the following equation: ${ }^{\mathrm{C}-12}$

$h_{\text {rad }}=\frac{\sigma_{s b} \varepsilon_{v e s}\left(T_{v}^{A}-T_{a}^{A}\right)}{T_{v}-T_{a}}$.

Hence, the heat transfer coefficient on the outer surface of the vessel is estimated to range from 30 to $100 \mathrm{~W} / \mathrm{m}^{2} \mathrm{~K}$.

\section{C.2 References}

C-1. J. Garnier, Ex-Reactor Determination of Thermal and Contact Conductance, NUREG/CR-0330, April 1979.

C-2. M. Epstein et. al., "Simultaneous Melting and Freezing in the Impingement Region of a Liquid Jet," AIChE Journal, 26, September 1980, p. 743.

C-3. X. Liu, J. H. Lienhard, and J. S. Lombara, "Convective Heat Transfer for Impingement of Circular Liquid Jets," Joumal of Heat Transfer, 113, 1991, p. 571.

C-4. J. A. Kos, Model of Fuel-Melt Quenching in the Lower Plenum of the RPV, Master of Science thesis, University of Wisconsin, Madison, Wisconsin, August 1992.

C-5. M. Jahn, and H. H. Reineke, "Free Convection Heat Transfer with Internal Heat Sources Calculations and Measurements," Proceedings of the Fifth International Heat Transfer Conference, Tokyo, Japan, 3, Paper NC2.8, 1974, pp. 74-78.

C-6. J. G. Collier, Convective Boiling Condensation, New York: McGraw-Hill, 1972.

C-7. V. J. Dhit, and G. P. Purohit, "Subcooled Film-Boiling Heat Transfer from Sphere," Nuclear Engineering and Design, 47, 1978, p. 49.

C-8. J. G. Collier, Convective Boiling Condensation, Chapter 4, New York: McGraw-Hill, 1972.

C-9. M. Epstein, and H. K. Fauske, "Steam Film Instability and the Mixing of Core Melt Jets and Water," American Nuclear Society Proceedings of the National Heat Transfer Conference, Denver, Colorado, August 4-7, 1985 p. 277.

C-10. D. R. Olander, Fundamental Aspects of Nuclear Reactor Fuel Elements, University of California-Berkeley, published by the Technical Information Center Energy Research and Development Administration, (TID-26711-P1), November 1977.

C-11. Todreas, N. E. and M. S. Kazimi, Nuclear Systems I-Thermal Hydraulic Fundamentals, New York: Hemisphere Publishing, 1990.

C-12. Welty, J. R., C. E. Wicks, and R. E. Wilson, Fundamentals of Momentum, Heat and Mass Transfer, New York: Y. Wiley \& Sons, 1976. 


\section{Appendix D}

\section{Best Estimate Calculations for Tube Weld Failure}

D-1 


\section{Appendix D}

\section{Best Estimate Calculations \\ for Tube Weld Fallure}

\section{LOADS}

Pressure loads, $F_{p}$

$O D=0.0254 m(1.0 \text { in })^{D-1}$

$P=15 E 6 \mathrm{~Pa}$ D.2

where $O D$ is the outer diameter of the instrument tube and $P$ is the system pressure.

$F_{p}=(15 E 6 \mathrm{~Pa})(\pi / 4)(0.0254 m)^{2}=7601 \mathrm{~N}$

Deadweight loads, $\boldsymbol{F}_{d}$

$I D=0.01554 m^{\mathrm{D}-1}$

$O D=0.0254 m^{\mathrm{D}-1}$

$L_{t}=5.47 \mathrm{~m}^{\mathrm{D}-3, \mathrm{a}}$

$\rho=8400 \mathrm{~kg} / \mathrm{m}^{3}$

where $I D$ is the inner diameter, $O D$ is the outer diameter, $L$ is the length of the instrument tube to the nearest unistrut support, and $\rho$ is the density of Inconel-600.

$F_{d}=(5.47 \mathrm{~m})(\mathrm{p} / 4)\left[(0.0254 \mathrm{~m})^{2}-(0.01554 \mathrm{~m})^{2}\right]\left(8400 \mathrm{~kg} / \mathrm{m}^{3}\right)\left(9.8 \mathrm{~m} / \mathrm{s}^{2}\right)$

$F_{d}=143 \mathrm{~N}$

Total force on weld, $F_{\text {total }}$

$F_{\text {total }}=F_{p}+F_{d}=7744 N$

SHEAR AREA OF THE WELD, $A_{s}$

$O D=0.0254 \mathrm{~m}$

$L_{w}=0.01365 \mathrm{~m}^{\mathrm{b}}$

where $O D$ is the outer diameter of the instrument tube and $L_{w}$ is the length of the weld below the vessel cladding.

$A_{s}=\pi(0.0254 \mathrm{~m})(0.01365 \mathrm{~m})=1.089 E-3 \mathrm{~m}^{2}$

a. Personal communication with Babcock \& Wilcox personnel, September 1992.

b. Babcock \& Wilcox drawing \# 126971E6, October 1991. 
APPLIED SHEAR STRESS $\tau$ AND EFFECTTVE STRESS, $\sigma_{\mathbf{m}}$

$\tau=F_{\text {total }} / A_{s}=(7744 \mathrm{~N}) /\left(1.089 E-3 \mathrm{~m}^{2}\right)=7.11 E 6 \mathrm{~Pa}$

$\sigma_{v m}=1.737 \tau=12.32 E 6 \mathrm{~Pa}(1.786 \mathrm{ksi})$

ULTMMATE STRENGTH MARGIN TO FAILURE, MF

$M F=1-\sigma_{v m} / S_{u}=1-12.32 E 6 / 30.78 E 6=0.60=60 \%$

where $\sigma_{v m}$ is the von Mises effective stress, and $S_{u}$ is the ultimate strength (30.78 MPa) of Inconel- 600 at $1,348 \mathrm{~K}\left(2,450^{\circ} \mathrm{R}\right)$ obtained from high temperature tensile tests. ${ }^{\mathrm{D}-4}$

Note: At $1,348 \mathrm{~K}, S_{\mu}$ is $35 \mathrm{MPa}$; at $1,373 \mathrm{~K}, S_{\mu}$ is $27 \mathrm{MPa}$.

TIME TO CREEP FAILURE USING LARSON-MIILER PARAMETER, $t_{r}$

$L M P=36.196-8.9433\left[\log \left(\sigma_{v m}\right)\right]$

$\log \left(t_{r}\right)=(L M P)(1000) / T-13$

where $L M P$ is the Larson-Miller parameter, $\sigma_{v m}$ is the effective stress (in ksi), and $T$ is the temperature $\left({ }^{\circ} \mathrm{R}\right)$. These equations are fit from high temperature creep rupture experiments. ${ }^{\mathrm{D}-4}$

$L M P=36.196-8.9433[\log (1.786 \mathrm{ksi})]=33.943$

$\log \left(t_{r}\right)=(33.943)(1000) /\left(2450^{\circ} R\right)-13$

$t_{r}=7.2 \mathrm{~h}$

95\% CERTAINTY LMMTS FOR LARSON-MILLER PARAMETER

$L M P(95 \%)=L M P \pm 2.069 S D$

$S D=0.42691\left[0.90909+\left\{\log \left(\sigma_{v m}\right)-0.86372\right\}^{2} / 1.09944\right]^{0.5}$

where $\sigma_{v m}$ is the Mises effective stress (in ksi). ${ }^{\text {D-4,D-S }}$

\section{D.1 References}

D-1. MPR Associates, Inc., Removal of Test Specimens from the TMI-2 Reactor Vessel Bottom Head, MPR-1195, October 1, 1990, Drawing No. F-73-30-328, July 24, 1990.

D-2. G. L. Thinnes, TMI-2 Lower Head Creep Rupture Analysis, EGG-TMI-8133, August, 1988, p. 10.

D-3. MPR Associates, Inc., Removal of Test Specimens from the TMI-2 Reactor Vessel Bottom Head, MPR-1195, October 1, 1990, Drawing No. F-80-107-89 July 22, 1988.

D-4. J. L. Rempe, et al., Light Water Reactor Lower Head Failure Analysis NUREG/CR-5642, EGG-2618, October 1993.

D-5. N. R. Draper and H. Smith, Applied Regression Analysis, second edition, New York: John Wiley \& Sons, Inc., 1981, pp. 20-29. 


\section{Appendix E}

\section{Results from Verification Calculations for Locallzed Effects Model}




\section{Appendlx E}

\section{Results from Verification Calculations for Localized Effects Model}

\section{E.1 Summary}

The verification of the shell model (TSM) used to evaluate the potential for localized vessel failure has provided several insights into the applicability of this program for use in lower head severe accident structural response calculations. First of all, it must be remembered that the purpose for developing this program was to provide a fast-running solution to predict the collapse of a localized portion of the vessel wall, resulting from hot spots in a debris bed resting on the lower head. Thus, the program would be appropriate for scoping parameter studies in various accident scenarios. Results of the benchmark problems used in this verification effort indicate that TSM performs well for its intended purpose.

TSM was benchmarked against an $\mathrm{ABAQUS} \mathrm{S}^{\mathrm{E}-1}$ axisymmetric solid finite element model using two hot spot load cases. One load case consisted of a moderate thermal gradient in the hot spot region and an internal pressure of $45 \mathrm{MPa}$, and the second case represented a more severe temperature gradient in the hot spot region and an applied pressure of $55 \mathrm{MPa}$. These pressures were selected to enhance plastic deformation through the thickness of the wall and are several times greater than the $15.5 \mathrm{MPa}$ expected in reactor operations. The choice of these pressures did help to identify a portion of the disagreement between ABAQUS and TSM.

In the cooler boundary areas of the hot spot and the cooler portion of the vessel wall under the hot spot, which was basically that portion outside the vessel midsurface, hoop and meridional stresses were within $4 \%$ of the ABAQUS model results. TSM generally underpredicted the strains in both of these benchmark hot spot cases. Because TSM is based on shell model assumptions, which neglect radial stresses through the vessel wall, it underpredicted stresses and strains in the hoop and meridional components in the very hottest areas of the model. This was because the vessel material was relatively soft in these areas at the load case temperatures and the radial stresses, as calculated in the ABAQUS model, were of the same order as the hoop and meridional stresses. Thus, the Poisson effect from the radial stresses would significantly affect the hoop and meridional components. TSM underpredicted hoop and meridional stresses by as much as $60 \%$ in these hottest areas, where the stresses were typically two orders of magnitude lower than the peak values on the shell outer surface. Total strain comparisons ranged from underpredictions of $24 \%$ on the inside surface to $11 \%$ on the outside surface in the hot spot region for the severe thermal gradient load case. In the cooler boundary areas strain comparisons ranged from underpredictions of $13 \%$ on the inner surface to $7 \%$ on the outer surface.

Examinations of the plastic strains indicated that plasticity of the wall had propagated from the outside inward one Gauss point further in the ABAQUS model than in the TSM model for the two hot spot load cases.

It should be noted, however, that the cooler outer portions of the vessel wall carry the majority of the pressure load in these cases and that vessel wall material yielding eventually begins at the 
outer surface and propagates inward to final failure. Hoop and meridian stress levels are typically 35 times higher in the outer portions than the inner regions of the vessel wall. Thus, model accuracy in these high stress areas is most crucial to accurate predictions of vessel failure margins.

The benchmark thermal load cases included a maximum internal pressure of 45 to $55 \mathrm{MPa}$, while an accident condition would result in maximum pressures no greater than around $15 \mathrm{MPa}$. Therefore, additional cases were examined where the thermal loadings of both hot spot load cases were applied to TSM and ABAQUS models with an internal pressure load of $15 \mathrm{MPa}$. For the moderate thermal load case, TSM calculater stresses in the inside third of the wall $13 \%$ lower than those of ABAQUS, while the remaining portion of the wall was within $3 \%$. The severe thermal load case stresses were an average of $4 \%$ lower than the ABAQUS model results throughout the wall. Total meridian and hoop strains ranged from underpredictions of $16 \%$ on the inside to $2 \%$ on the outside portions of the vessel wall in the hot spot region and within $5 \%$ in areas away from the hot spot. This represents a substantially better agreement than the same thermal conditions at elevated pressures and indicates TSM assumption of negligible radial stress is acceptable for loading histories representative of accident conditions.

\section{E.2 Introduction}

Verification calculations were undertaken to compare results from the localized creep rupture model, described in Section 4.2.2 and Appendix D of Reference E-2, and a finite element model developed with the ABAQUS code. ${ }^{\mathrm{E}-1}$ As described in Reference E-2, Section 4.2 .2 and Appendix D, the localized creep rupture model, which was developed at the University of Wisconsin, Madison, is a finite difference shell theory model. Several benchmark problems have been performed to compare results from TSM (see Figure E-1) and the ABAQUS finite element code, which used an axisymmetric continuum model (see Figure E-2). The remainder of this appendix is divided up as follows: Section E-3 details the four benchmark problems, Section E-4 describes TSM and ABAQUS models, Section E-5 discusses the results from the first two (spherically symmetric) benchmark problems, Section E-6 includes the results from the remaining two (localized thermal loading) benchmark problems, and Section E-7 gives conclusions.

Variables used in this section are defined in the Nomenclature.

\section{E.3 Descriptlon of Benchmark Problems and Material Properties}

Four benchmark problems were suggested ${ }^{a}$ as verification calculations for TSM. The suggested problems were refined during the analysis to reach required final states; specifically, the relative contributions of thermal and pressure loadings were modified to achieve plasticity one-quarter of the way through the thickness at some location along the shell. The purpose of the problems was to determine the ability of TSM to accurately resolve the spatial variation of displacement, stress, and strain fields in the vicinity of a localized thermal loading (hot spot). None of the problems included creep in the material response; creep introduces complexities in the material model and

a. Professor R. H. Dodds, member of the TMI-2 Structural Mechanics Peer Review Group, University of Illinois at Champaign-Urbana, letter to S. A. Chávez, INEL, regarding benchmarking calculations of model for predicting localized rupture (Consulting Agreement 94-160236-HRS-284-92), July 20, 1992. 


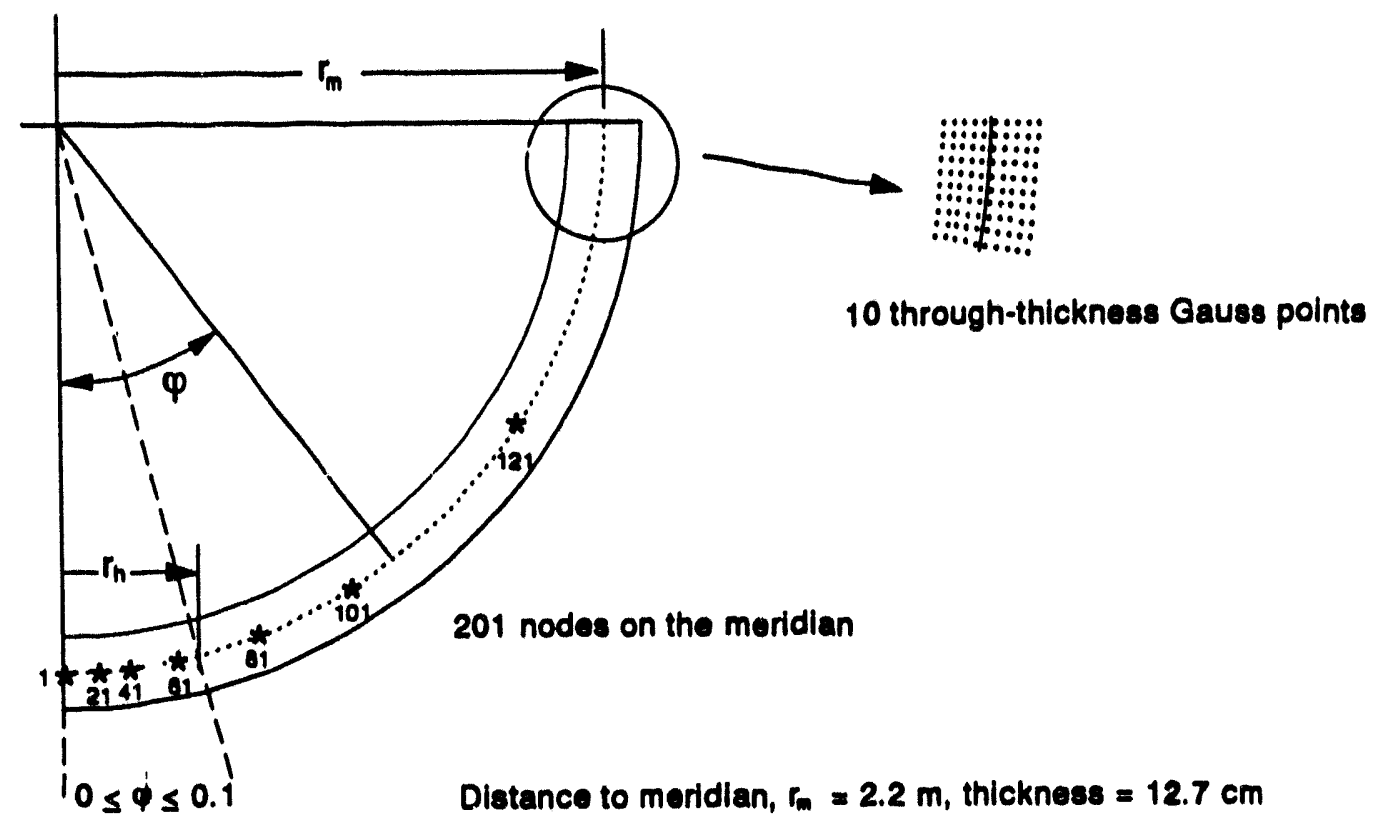

Figure E-1. The shell model (TSM).

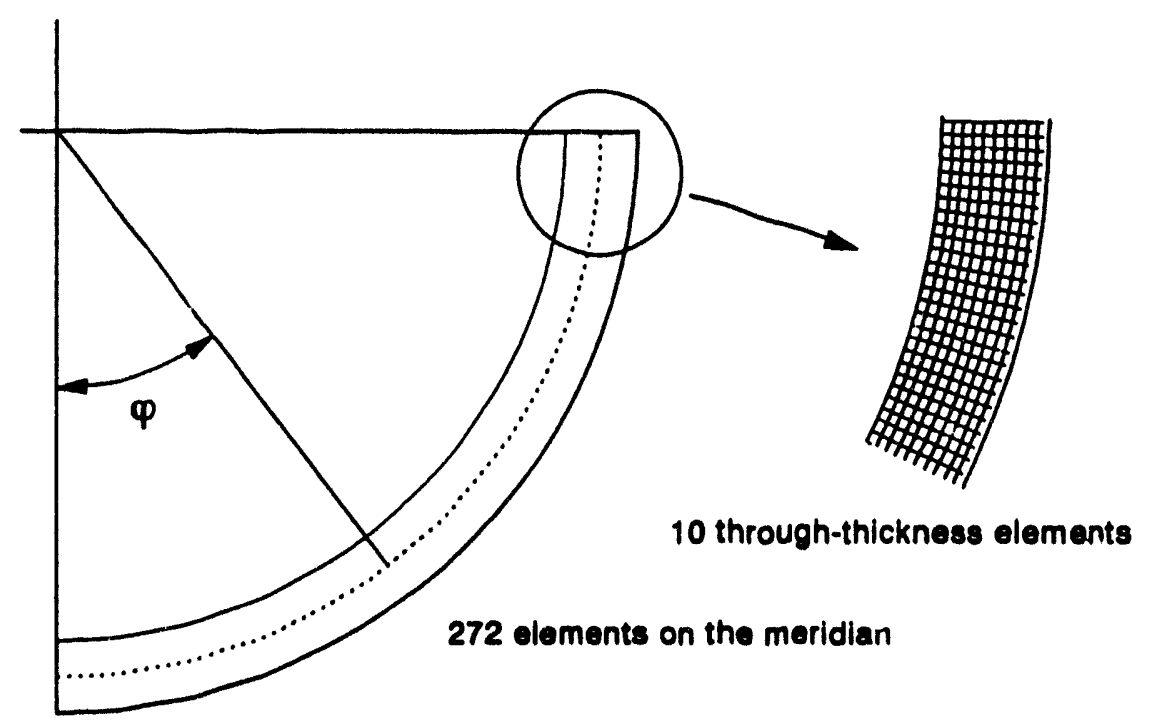

8-node, isoparametric elements (axisymmetric)

Mo12 1000390-10 
global solution algorithms but not in the ability to represent the spatial variation of the computed fields. The four problems considered were:

1. Internal Pressure Only: This problem tested the elastic response of TSM by ramping an internal pressure load to $10 \mathrm{MPa}$ while employing material properties at $300 \mathrm{~K}$. The problem was essentially one-dimensional with no variation along the meridian. This problem is shown as Case I in Figure E-3.

2. Internal Protsure, Background Temperature: This problem tested the elastic-plastic response by employing an internal pressure and a background temperature profile. The response was one-dimensional. The desired final state must show plasticity penetrating one-quarter of the wall. The problem was run by taking the initial state as $0 \mathrm{MPa}$ internal pressure, and inside and outside surface temperatures $\left(T_{\text {in }} T_{\text {out }}\right)$ at $300 \mathrm{~K}$. The subsequent state of $10 \mathrm{MPa}, T_{\text {in }}$ at $900 \mathrm{~K}$ and $T_{\text {ouf }}$ at $700 \mathrm{~K}$ (and a linear temperature gradient through-thickness) was reached by linearly ramping both pressure and temperature. This second state corresponded to the background state for Problems 3 and 4. At this point, yielding initiated at the outer surface of the shell in TSM. Continued ramping of both temperatures and pressure to reach the desired final state was found to be unacceptable because of the progressive softening of the shell at elevated temperatures (above $1,000 \mathrm{~K}$ ). The desired final state was reached by ramping the pressure to $35 \mathrm{MPa}$ while holding $T_{\text {in }}$ and $T_{\text {out }}$ at 900 and $700 \mathrm{~K}$, respectively. This problem is shown as Case II in Figure E-3.

3. Internal Pressure, Moderate Localized Thermal Loading: This problem tested the elastic-plastic response by employing a moderate localized thermal loading onto a background internal pressure and temperature profile, producing a two-dimensional loading with modest gradients along the meridian directly underneath the hot spot. The desired final state must show plasticity penetrating one-quarter of the wall. The problem first established the spherically symmetric state described in Problem 2 (10 MPa pressure, temperature field of $T_{\text {in }}$ at $900 \mathrm{~K}$ and $T_{\text {out }}$ at $700 \mathrm{~K}$, linear through-thickness temperature gradient). At this point, a moderate localized thermal loading was applied. This loading consisted of ramping the temperature at the bottom inner surface to $1,400 \mathrm{~K}$ (at $\varphi=0$ ), with a linear gradient to the outside surface and to the background profiic at $\varphi=0.1$ (see Figure E-1). Then the internal pressure was increased to $45 \mathrm{MPa}$ to reach the final state. This problem is shown as Case III in Figure E-3.

4. Internal Pressure, Severe Localized Thermal Loading: This problem tested the elastic-plastic response by employing a severe localized thermal loading onto a background internal pressure and temperature profile, representing a two-dimensional problem with pronounced gradients along the meridian. The desired final state must show plasticity penetrating one-quarter of the wall directly underneath the hot spot. The problem first established the spherically symmetric state described in Problem 2 (10 MPa internal pressure, temperature field of $T_{\text {in }}$ at $900 \mathrm{~K}$ and $T_{\text {out }}$ at $700 \mathrm{~K}$, linear through-thickness temperature gradient). At this point, a Type 2 (hot lump defined by Equation 4-54, Ref. E-2) temperature distribution was applied over $0<\varphi<0.1$, with a peak temperature of $1,400 \mathrm{~K}$. This temperature profile was more severe than that of Problem 3 due to the nonlinearity of the distribution. Then the internal pressure was increased to $55 \mathrm{MPa}$ to reach the final state. This problem is shown as Case IV in Figure E-3. 


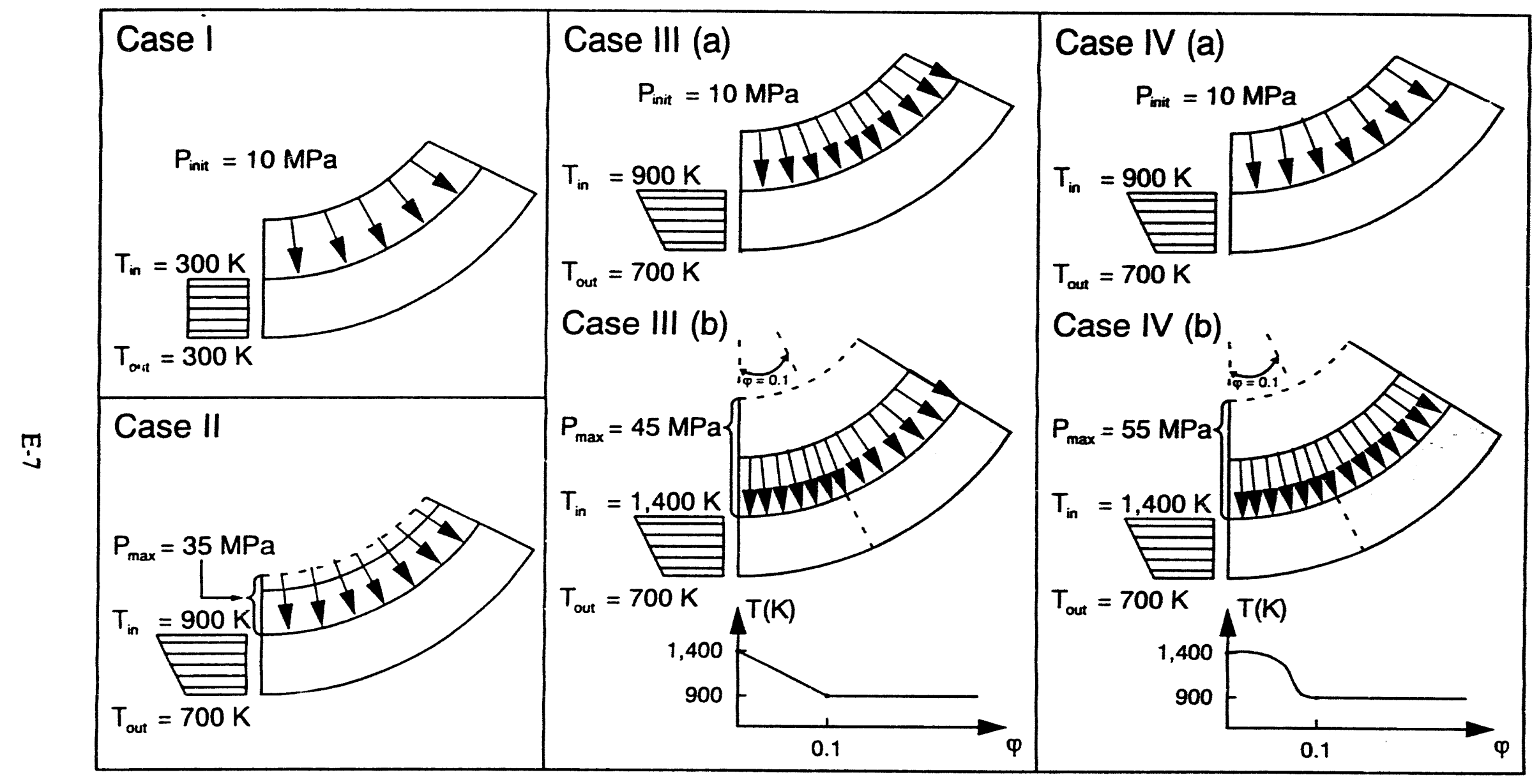

M757-W-T-1192-14

Figure E-3. Benchmark problem loadings. 
The material properties required for these analyses included Young's modulus as a function of temperature, mean thermal expansion coefficient as a function of temperature, and yield strength and plastic deformation characteristics as independent of temperature. The material properties used were taken from Reference E-2 (Appendices B and E) and Reference E-3. Poisson's ratio was taken as independent of temperature as $v=0.29$.

\section{E.4 TSM and ABAQUS Models}

The spatial model for TSM calculations was made using the axisymmetric representation $r_{h} / r_{m}=\xi^{2}$ with 201 nodes, where $r_{h}$ is the horizontal distance from the vertical axis and $r_{m}$ is the initial radius of the vessel middle surface (see Figure E-1). The model represented a spherical head with a mean radius, $r_{m}$, of $2.2 \mathrm{~m}$ and a uniform thickness of $12.7 \mathrm{~cm}$.

The ABAQUS model consisted of a quarter sphere that utilized axisymmetric solid (8-node, isoparametric with reduced integration) elements. The model was meshed with 10 elements through the thickness and 272 along the meridian (uniformly spaced), giving approximately square elements. The free ends of the quarter sphere were restrained for symmetry, the loading conditions and geometry being symmetric about the two global axes. A second ABAQUS model was prepared with 15 elements through the thickness and 408 along the meridian. Both ABAQUS models were evaluated using ABAQUS, a multi-purpose finite element solution package, for all four benchmark problems. The output data (stress, strain and displacement) for the two ABAQUS models were compared, and the results showed that the data were within less than $1 \%$. This indicated that the mesh refinement of the first ABAQUS model was sufficient to accurately describe the response for the benchmark problems. Only the results of the first ABAQUS model were compared to those of TSM in the following sections. Figure E-2 outlines the ABAQUS model.

Note that the ABAQUS model was developed so that nodes in both TSM and ABAQUS models overlapped at $\xi=0,0.1,0.2,0.3,0.4,0.5$ and 0.6 , corresponding to TSM node numbers 1 (shell bottom), 21, 41, 61, 81, 101 and 121 (see Figure E-1). The through-thickness location of information differed in the two models, with TSM providing information at ten Gauss points through the thickness, while ABAQUS calculated information at element integration points, then interpolated (and averaged) that information at the nodes. This latter difference required interpolation of results from the ABAQUS nodes to TSM Gauss points in order for the comparison of results to be made. All comparisons using average data weighted each data point equally, unless specified differently in the discussion. In the spherically symmetric problems (Benchmark Problems 1 and 2 only) the results were identical on all radial lines and only one set of output information was given.

\section{E.5 Results of Benchmark Problems 1 and 2}

Benchmark Problems 1 and 2 were spherically symmetric problems. A separate means of evaluating TSM exists in that closed-form solutions are available for infinitesimal deformation, constant elastic property problems with arbitrary temperature distributions through thickness. Since some insight into the shortcomings of TSM can be gained by obtaining closed-form 
solutions, the results are summarized below. In a spherically symmetric problem, the meridian and hoop strains and stresses become identical and the radial equilibrium equation is:

$$
\frac{d o_{r}}{d r}+\frac{2\left(o_{r}-o_{d}\right)}{r}=0
$$

The Hooke's Law relationships are

$$
\begin{aligned}
& \sigma_{r}=\frac{E\left(\varepsilon_{r}-\varepsilon_{T}\right)}{1+v}+\frac{\left[v E\left(\varepsilon_{r}-\varepsilon_{T}+2\left(\varepsilon_{r}-\varepsilon_{T}\right)\right)\right]}{(1+v)(1-2 v)} \\
& \sigma_{\varphi}=\frac{E\left(\varepsilon_{\varphi}-\varepsilon_{T}\right)}{1+v}+\frac{\left[v E\left(\varepsilon_{r}-\varepsilon_{T}+2\left(\varepsilon_{r}-\varepsilon_{T}\right)\right)\right]}{(1+v)(1-2 v)} .
\end{aligned}
$$

Using the strain/displacement relationships:

$\varepsilon_{r}=\frac{d u}{d r} \quad$ and $\quad \varepsilon_{\varphi}=\frac{u}{r}$

the Hooke's Law form of the stress/displacement relationship may be substituted into the equilibrium equation to obtain a second-order equation for $u$ :

$\frac{d^{2} u}{d r^{2}}+\frac{2}{r}\left[\frac{d u}{d r}-\frac{u}{r}\right]=\frac{1+v d \varepsilon_{T}}{1-v} \frac{1}{d r}$

The complete solution of which is

$u(r)=C_{1} r-\frac{C_{2}}{r^{2}}+\frac{1+v}{r^{2}(1-v)} \int_{a}^{b} e_{T} r^{2} d r^{\prime}$

subject to the resolution of constants $C_{1}$ and $C_{2}$. If the requirements are that $\sigma_{r}=-p$ at $r=a$ and $\sigma_{r}=0$ at $r=b$, then the strains can be shown to be

$$
\varepsilon_{\varphi}=\frac{1-2 v}{1-(a / b)^{3}} \frac{p}{E}\left[(a / b)^{3}+\frac{(1+v)(a / r)^{3}}{2(1-2 v)}\right]+\frac{2(1-2 v) e_{T a v}}{3(1-v)}\left[1+\frac{(1+v)(a / r)^{3}}{2(1-2 v)}\right]
$$




$$
\begin{aligned}
& +\frac{1+v}{(1-v) r^{2}} \int_{a}^{b} \varepsilon_{T} r^{\prime 2} d r^{\prime} \\
\varepsilon_{r}= & \frac{1-2 v}{1-(a / b)^{3}} \frac{p}{E}\left[(a / b)^{3}-\frac{(1+v)(a / r)^{3}}{2(1-2 v)}\right]+\frac{2(1-2 v) \varepsilon_{T a v}}{3(1-v)}\left[1-\frac{(1+v)(a / r)^{3}}{2(1-2 v)}\right] \\
& +\frac{(1+v) \varepsilon_{T}}{(1-v)}-\frac{2(1+v)}{(1-v)^{2}} \int_{a}^{b} e_{T} r^{\prime 2} d r
\end{aligned}
$$

where $\varepsilon_{T a v}$ is the average thermal strain, defined as

$$
\varepsilon_{T a v}=\frac{3}{b^{3}-a^{3}} \int_{a}^{b} \varepsilon_{T} r^{2} d r
$$

In Benchmark Problem 1 (see Figure E-3), a purely elastic response showed that stresses and strains varied through the thickness for the exact solution (from closed form equations) and ABAQUS. The stress and strain results of the exact and ABAQUS solutions were within $1 \%$. TSM stress and strain results were constant throughout the thickness at the calculated average for the shell.

For an internal pressure of $10 \mathrm{MPa}$ with the inner surface temperature brought to $900 \mathrm{~K}$ and the outer surface temperature brought to $700 \mathrm{~K}$ (from initially $300 \mathrm{~K}$ ), a purely elastic analysis produced TSM stresses that varied throughout the thickness. Those stresses were within $2 \%$ of the values for the exact solution. However, TSM strains were constant throughout the thickness at the calculated average for the shell. The most obvious shortcoming of TSM is in the isothermal problem. With the strains formulated as, for instance,

$$
\varepsilon_{\varphi}=\varepsilon_{m}\left(1+\xi / R_{\varphi}\right)+\xi\left[1 / R_{\varphi}-1 / R_{\varphi}+\left(\gamma^{\prime} / \alpha_{o}\right) \sec ^{2} \gamma\right]
$$

and the deformed radius of curvature related to the initial radius of curvature through

$$
R_{\varphi}=\frac{R_{\varphi}\left(1+\varepsilon_{m}\right)}{\left(1+\beta^{\prime} / \varphi_{o}^{\prime}\right)}
$$

then in spherically symmetric problems $(\beta=\varphi=0)$, substitution of $R_{\varphi}=R_{\varphi \infty}\left(1+\varepsilon_{m}\right)$ into the strain measure [see Equation (E-10)] yields

$$
\varepsilon_{\varphi}=\varepsilon_{m}
$$


i.e., no through-thickness dependence. The exact result shows the strain measure has a constant component and a component that scales inversely to distance cubed. The shortcoming is of less consequence in the problem with a temperature gradient through the thickness because the gradient in thermal strain provides a much larger bending component of stress than is obtained from the finite thickness of the shell.

In Benchmark Problem 2 (see Figure E-3), yielding occurred approximately $1 / 4$ way through the thickness after ramping the internal pressure to $35 \mathrm{MPa}$. The ABAQUS data was interpolated to coincide with TSM Gauss point data. Since TSM results varied somewhat from ABAQUS, a comparison of the difference was in order. The comparison used the ABAQUS results as the baseline. TSM values for meridional stress were on the average $1.0 \%$ below ABAQUS in the outer two-thirds of the wall. In the inner one-third of the wall the meridional stress levels predicted by TSM were an average of $50 \%$ below those given by ABAQUS. That underprediction was due to the radial stresses in the area, whose magnitudes were on the same order as those of the meridional stresses. TSM assumes that the radial component of stress was negligible throughout the model. That assumption was not true in the inner third of the wall, and TSM meridional stress levels reflected that error. Benchmark Problems 3 and 4 discuss that assumption in detail.

TSM values for total meridional strain averaged $1 \%$ below ABAQUS. The ABAQUS plastic strains began one Gauss point location closer to the inside surface than those of TSM. However, TSM meridional plastic strains were an average of $1 \%$ above those of ABAQUS.

\section{E.6 Results of Benchmark Problems 3 and 4}

A far greater amount of output information was associated with Benchmark Problems 3 and 4 because the hoop and meridian stresses and strains were not generally identical and those states varied along the shell meridian. In Problem 3, the inner surface temperature was raised to $1,400 \mathrm{~K}$ (over the defined local area), then the pressure was raised to $45 \mathrm{MPa}$ to get yielding $1 / 4$ way through the thickness in the vicinity of $\varphi=0$. Yielding occurred to a greater extent under these conditions at positions away from the bottom (edge of shell at $\varphi=0$ ) of the shell. In Problem 4, the inner surface temperature was raised to $1,400 \mathrm{~K}$ (over the defined local area), then the pressure was raised to $55 \mathrm{MPa}$ to get yielding $1 / 4$ way through the thickness at the shell bottom. Again, yielding was more severe away from $\varphi=0$ in this case.

\section{E.6.1 Problem 3 Results}

The moderate localized thermal loading applied in this problem is shown in Figure E-3. The pressure was raised to $45 \mathrm{MPa}$ to get yielding $1 / 4$ way through the thickness in the vicinity of $\varphi=0$. It is of interest that yielding occurred to a greater extent under these conditions at positions away from the bottom (edge of shell at $\varphi=0$ ) of the shell. Due to the volume of data and locations available in the models, the evaluation was limited to 7 specific meridional points and their 10 associated through-thickness Gauss point locations. Four of the meridional points were within the hot spot, one on the inside edge (near $\varphi=0$ ), two in the middle, and one near the outside edge. The fifth through seventh points were outside of the hot spot, the fifth being near the outside edge of the spot, the sixth and seventh being well away from it (see Figure E-1). 
A graphical representation of the comparison between TSM and ABAQUS meridian and hoop stresses is given in Figures E-4 through E-10. Note that TSM meridian and hoop stresses inside the midplane in the hot spot underpredicted those calculated by ABAQUS. This portion of the wall was very soft because of the temperature profile and the material definition. A small percentage of the total load was carried by this half of the wall. It is noted that because of the softness of the wall the radial component of stress up to the midplane maintained a magnitude higher than that of the hoop and meridian stresses. The underprediction of hoop and meridian stresses by TSM was largely due to the absence of a radial stress component in TSM model. This was confirmed by comparing the ABAQUS and TSM results at the same thermal conditions at a lower pressure (discussed below). As discussed in Reference E-2, Section 4.2.2 and Appendix D, TSM solution scheme assumed that radial stresses were negligible. This was true beyond the midplane in the hot spot since the radial stresses quickly decreased to zero at the outside surface while the hoop and meridian stresses increased by a factor of 50 to 100. TSM meridian and hoop stresses in this area underpredicted those calculated by ABAQUS by about $2 \%$. This portion of the wall carried the majority of the load, and shell yielding propagated from the outer surface inward. Near the outside edge of the hot spot (point 61) and far-field (points 81 through 121), meridian and hoop stresses were about $18 \%$ lower in the inner $30 \%$ of the wall than predicted by ABAQUS, while the stresses over the outer $70 \%$ of the wall were within $3 \%$.

TSM solution' scheme and model were prepared for the purpose of predicting a particular failure mechanism (a bulging/shear-through type due to a local hot spot) in a reactor vessel lower head during an accident scenario. It is important to note that Benchmark Problem 3 included a maximum internal pressure of $45 \mathrm{MPa}$ where an accident condition would specify maximum pressures closer to $15 \mathrm{MPa}$. Therefore, the moderate localized thermal loading of Problem 3 was applied to TSM and ABAQUS models with a maximum internal pressure load of $15 \mathrm{MPa}$.

Figure E-11 shows the comparison of the hoop and meridian stresses of the two models for node point 41 (located in the middle of the hot spot). TSM stresses in the inside third of the wall were $13 \%$ (or less) lower than those of ABAQUS while the remaining portion of the wall was within 3\%. These levels of agreement are representative of all points examined along the meridian $(1,21, \ldots 121)$ and indicate that the discrepancies in Figures E-4 through E-10 are rooted largely in the absence of a radial stress in TSM and not the severity of the temperature gradient.

TSM total meridian and hoop strain results for Benchmark Problem 3 underpredicted the values calculated by ABAQUS on an average of 3.6\%. Figure E-12 gives the comparison of total hoop and meridian strains for node 41 , which is typical of all node locations.

TSM Benchmark Problem 3 results at the middle of the hot spot (nodes 21 and 41) showed that plastic strains (meridian and hoop) began at the seventh Gauss point location (of 10 total) from the inside surface and increased to the outer surface. ABAQUS results identified plastic strains beginning at the sixth location and increasing to the outside surface. The difference was $100 \%$ for the seventh location (where plastic strains were smallest), then decreased for each successive location to an average of $8 \%$ at the outside surface (where plastic strains reached a maximum). Outside of the hot spot (nodes 81 through 121), the plastic strain in both models began one Gauss point location closer to the inside surface. The difference in plastic strains was $100 \%$ for the fourth location (where plasticity began in the ABAQUS model) but averaged $9 \%$ or less for the entire outer half of the wall. 


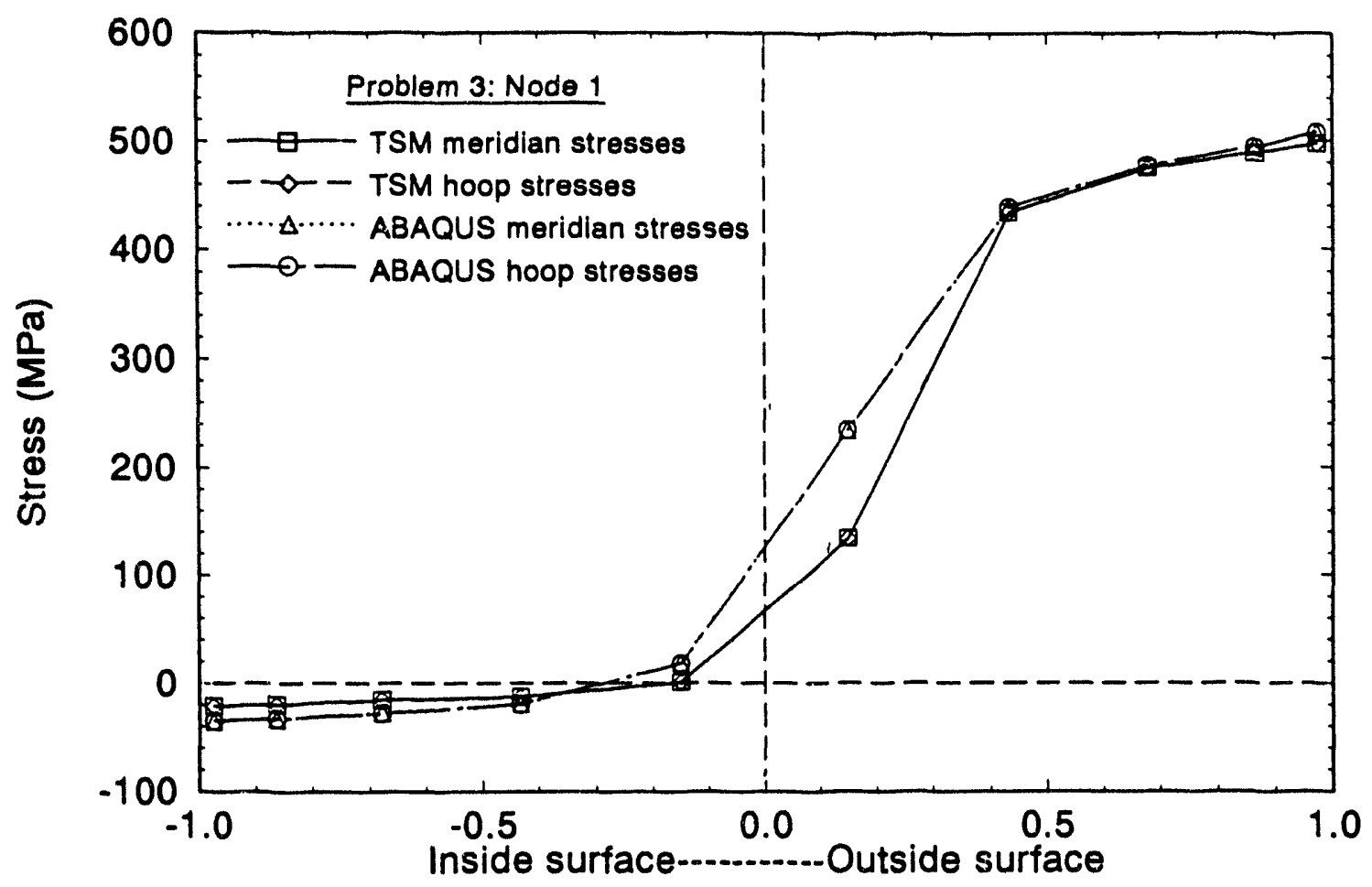

Figure E-4. Problem 3: node 1 stresses.

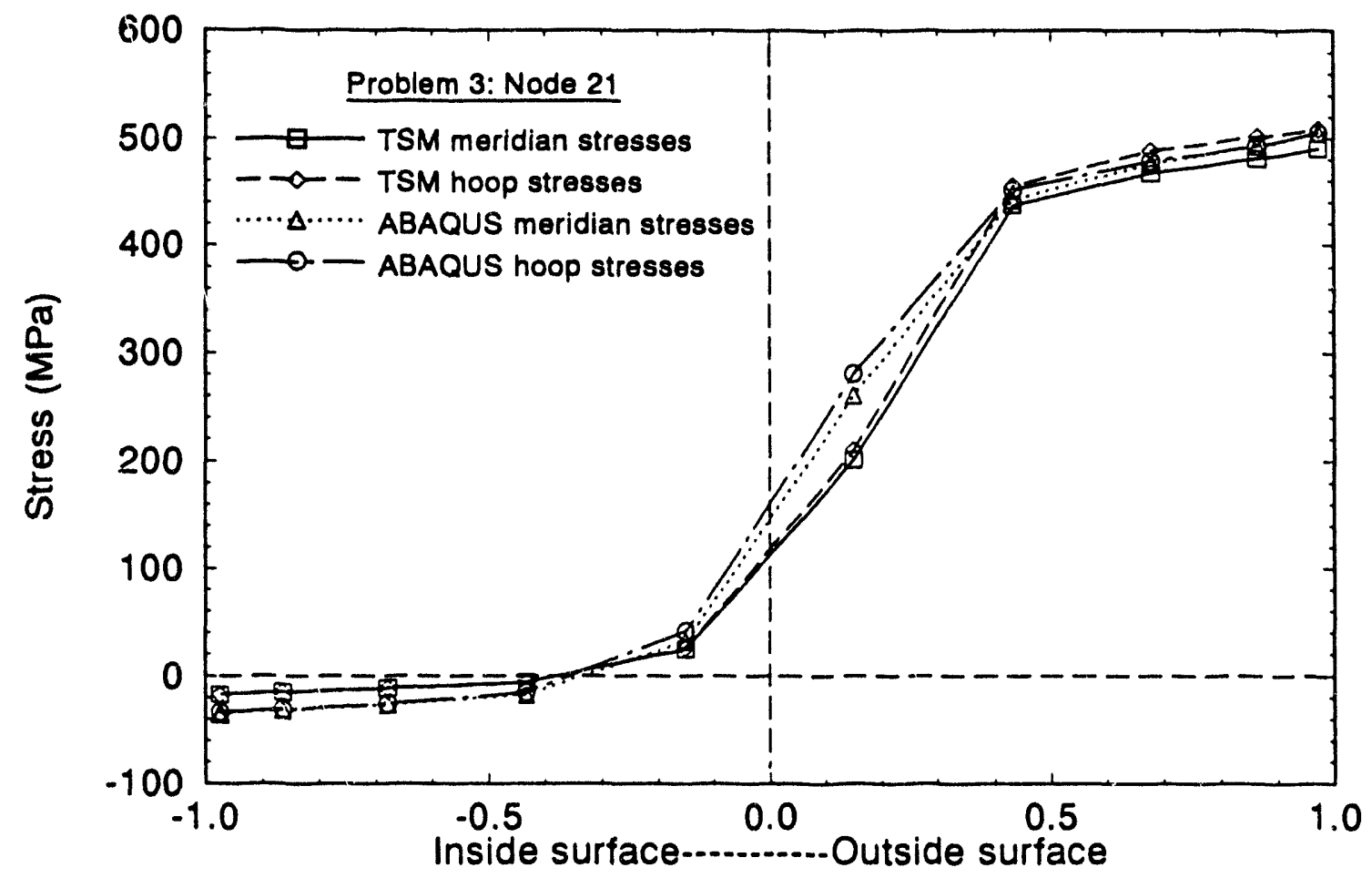

M756 $2 \cdot 1102.02$

Figure E-5. Problem 3: node 21 stresses. 


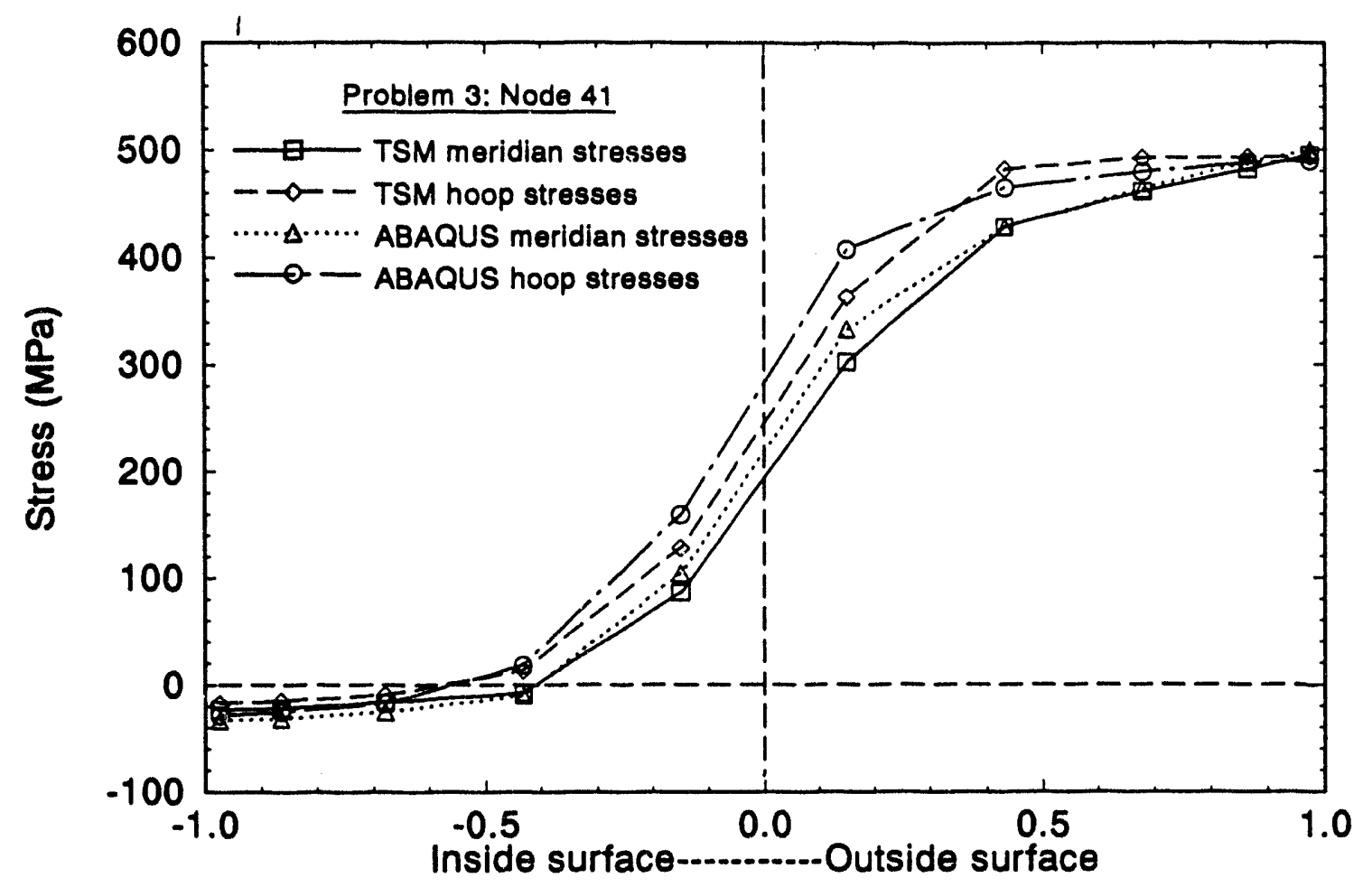

M7se $=-1192-03$

Figure E-6. Problem 3: node 41 stresses.

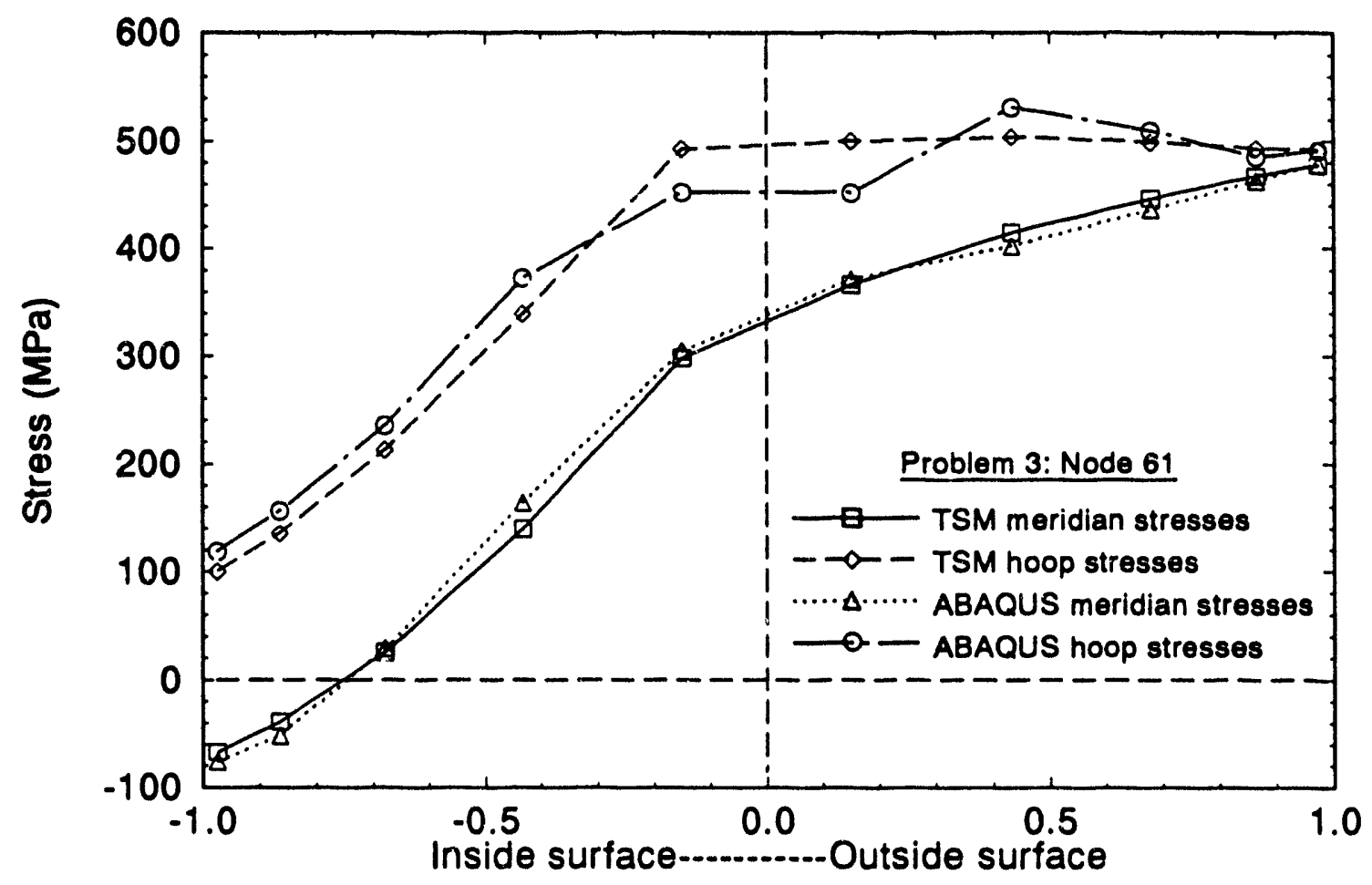

Figure E-7. Problem 3: node 61 stresses. 


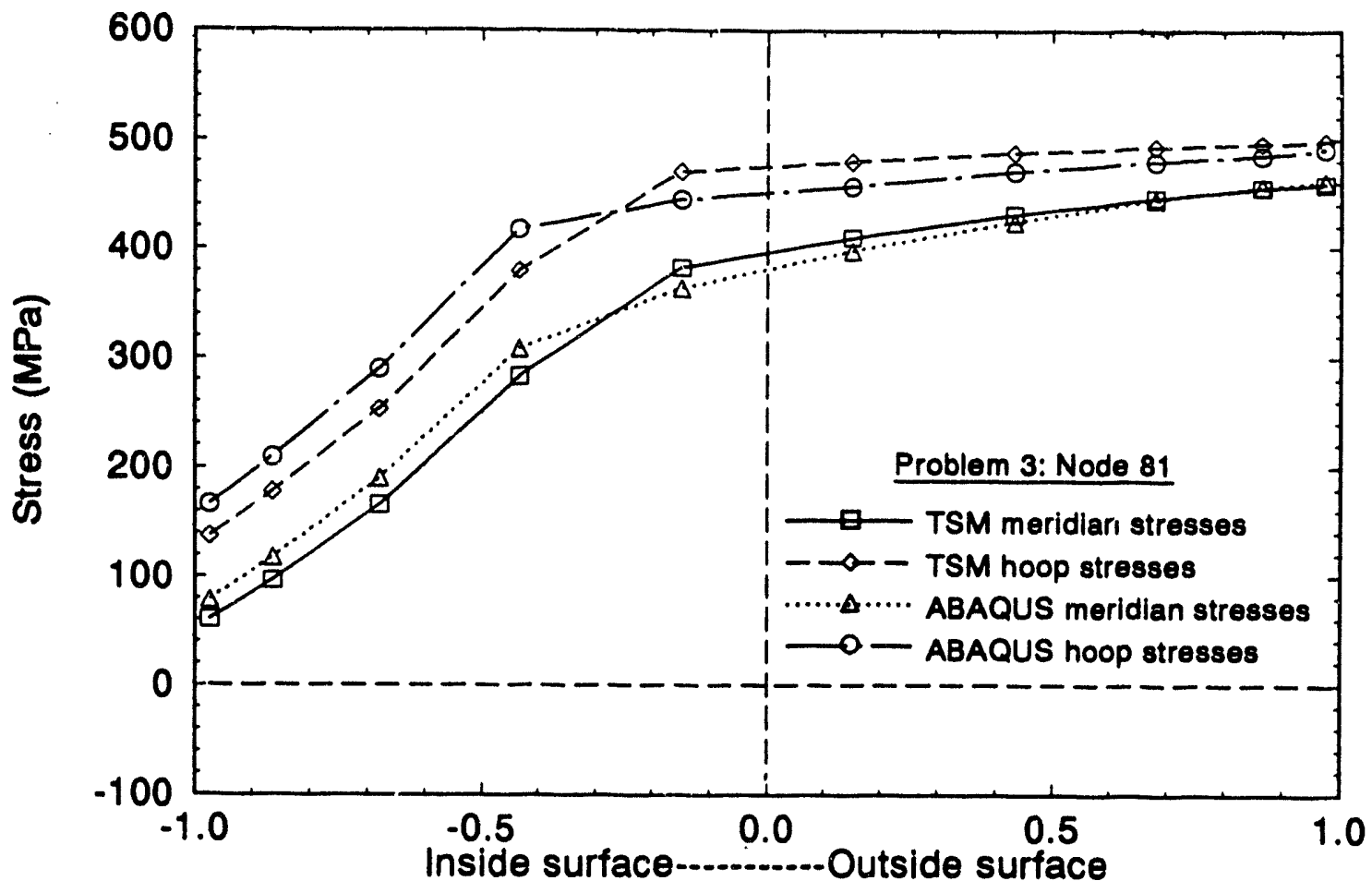

M7s0 $=-1102-03$

Figure E-8. Problem 3: node 81 stresses.

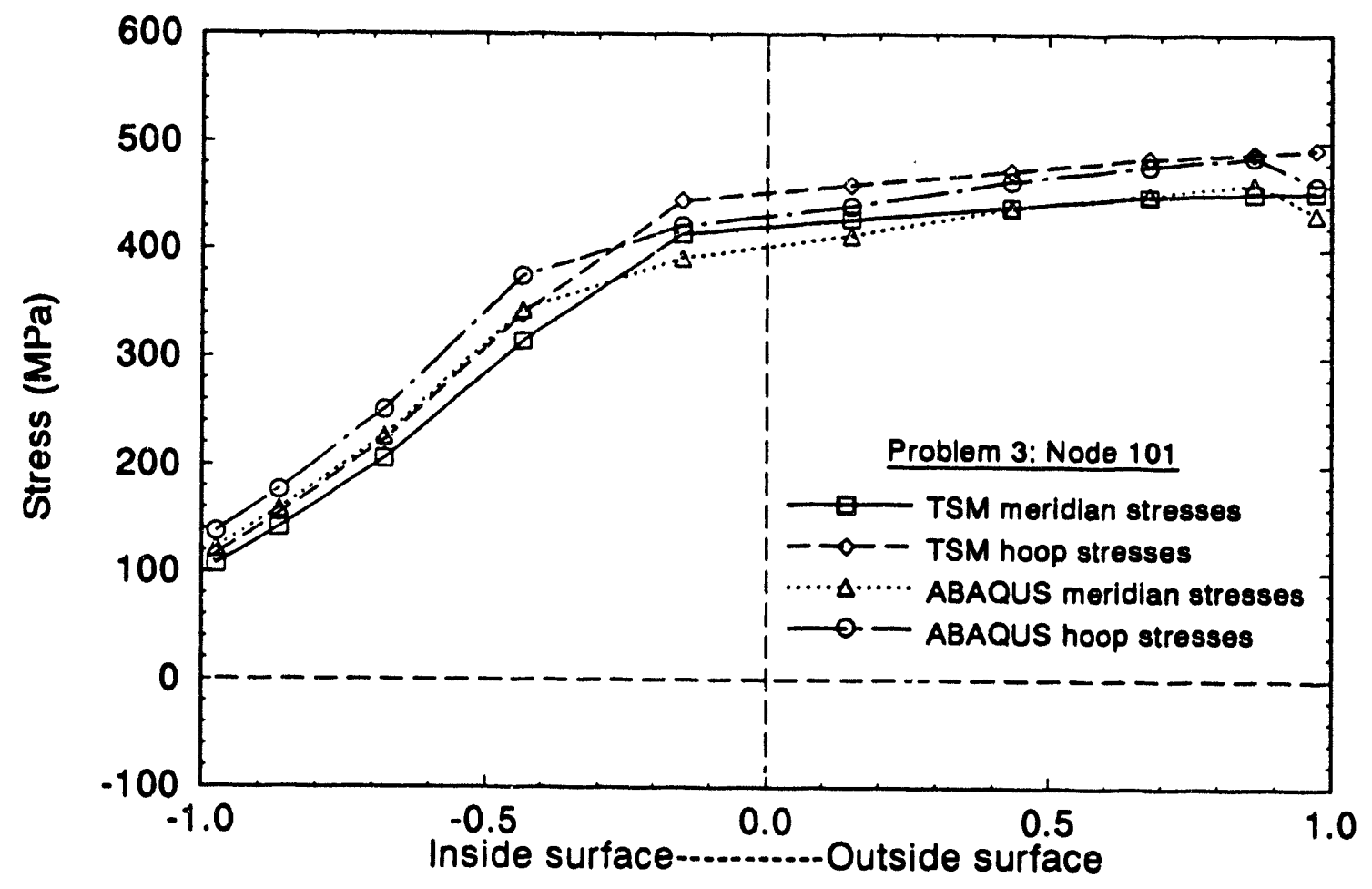

M7se $=1102.00$

Figure E-9. Problem 3: node 101 stresses. 


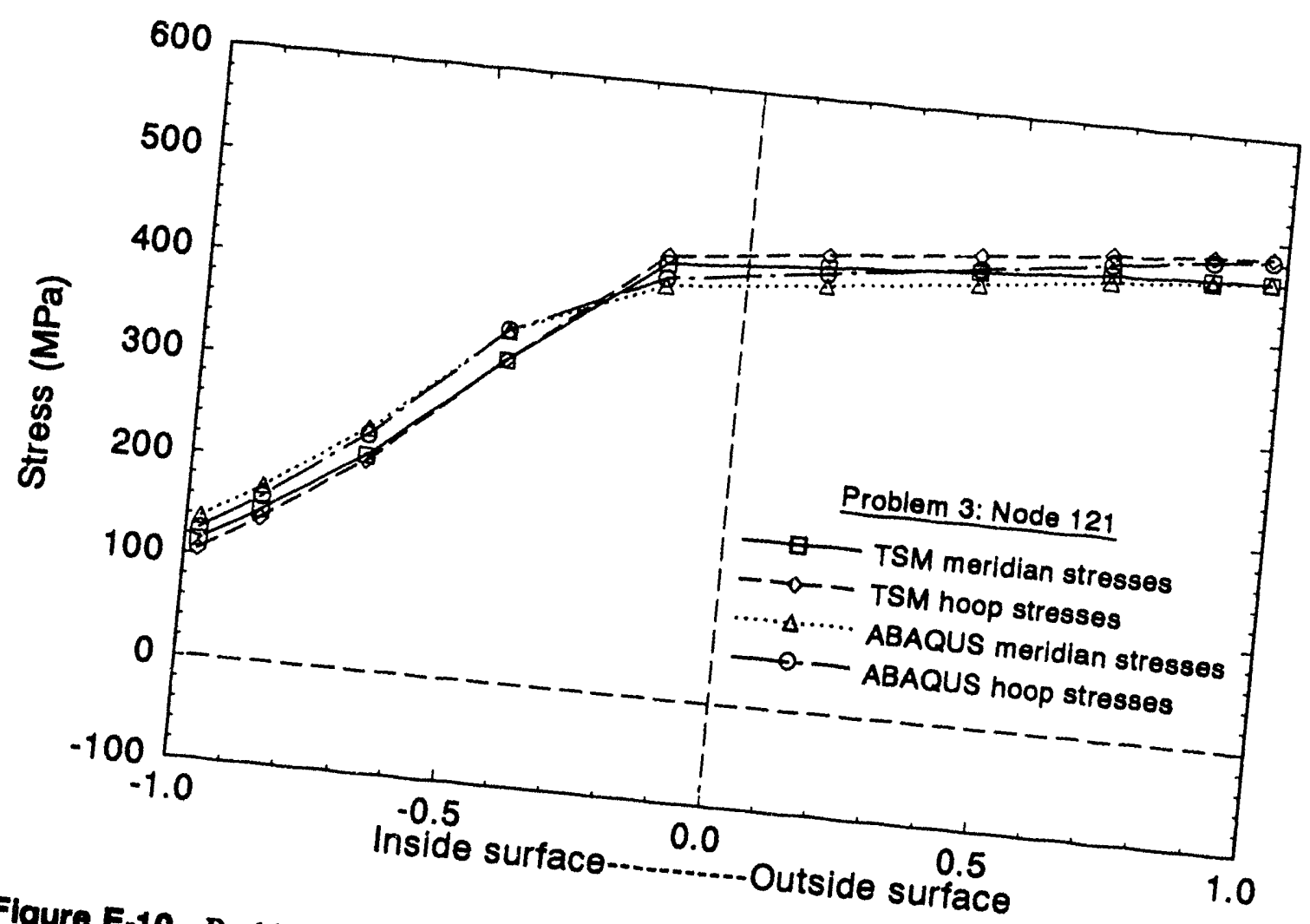

Figure E-10. Problem 3: node 121 stresses.

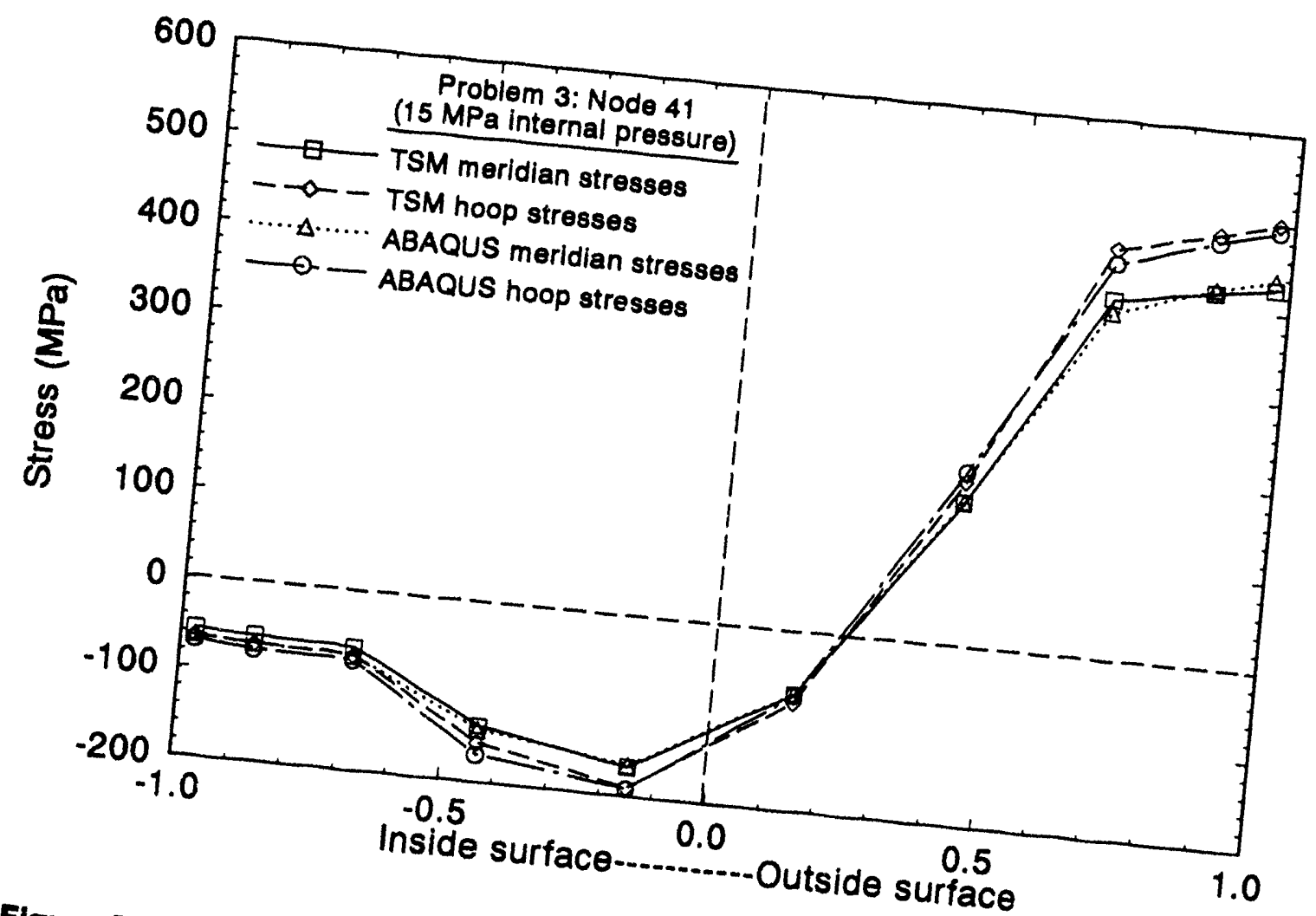

Figure E-11. Problem 3 thermal loading with only $15 \mathrm{MPa}$ internal pressure: E-16 


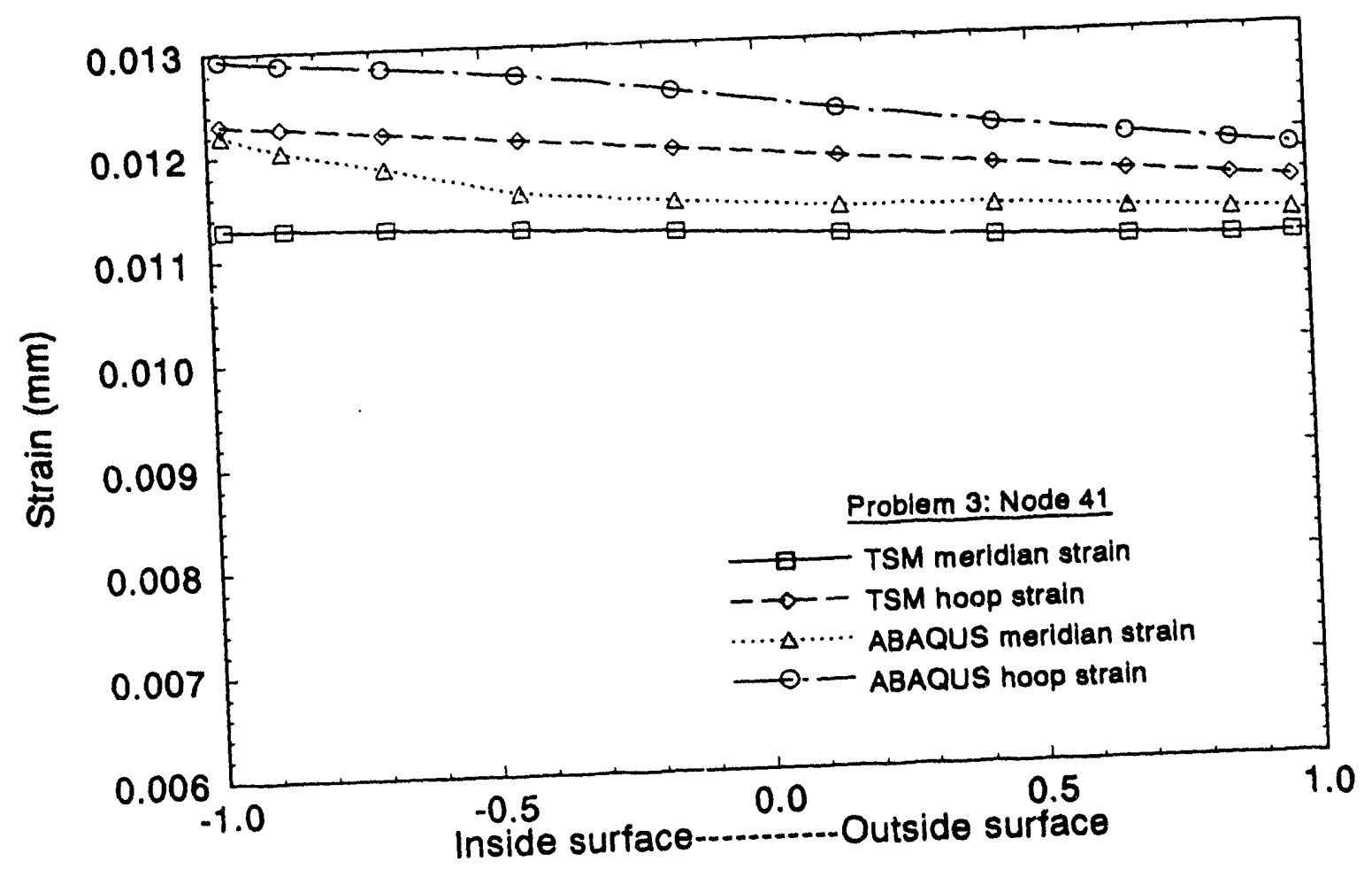

M750 $=1192 \cdot 15$

Figure E-12. Problem 3: node 41 strains.

\section{E.6.2 Problem 4 Results}

The severe localized thermal loading for this problem involved a nonlinear temperature distribution (see Figure E-3). The pressure was raised to $55 \mathrm{MPa}$ to get yielding $1 / 4$ way through the thickness at the shell bottom. Again, yielding was more severe away from $\varphi=0$. The same meridian points and their associated through-thickness Gauss point locations were evaluated as in Problem 3.

A graphical representation of the comparison between TSM and ABAQUS meridian and hoop stresses is given in Figures E-13 through E-19. Note that TSM meridian and hoop stresses up to the sixth Gauss point location (just beyond the midplane) in the middle of the hot spot underpredicted those calculated by ABAQUS. This area of underprediction was larger than the underpredicted area in Problem 3. This portion of the wall was very soft because of the temperature profile and the material definition. A small percentage of the total load was carried by this portion of the wall. Because of the softness of the wall, the radial component of stress up to the fourth Gauss point location from the inside surface maintained a magnitude higher than that of the hoop and meridian stresses. As in Problem 3, the underprediction of hoop and meridian stresses by TSM was largely due to neglecting the radial stress component in the calculations. 


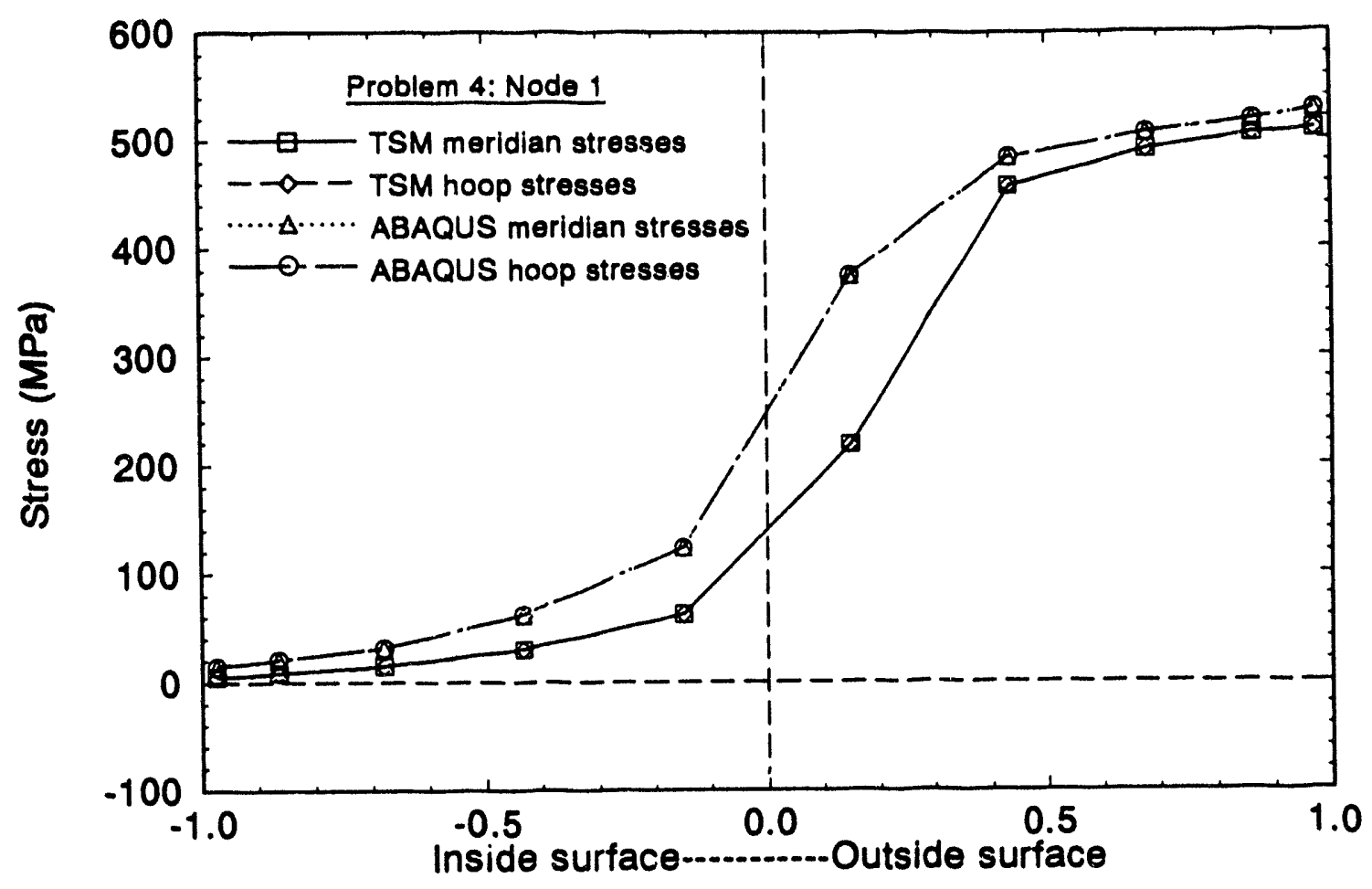

M7se $2-1102-00$

Figure E-13. Problem 4: node 1 stresses.

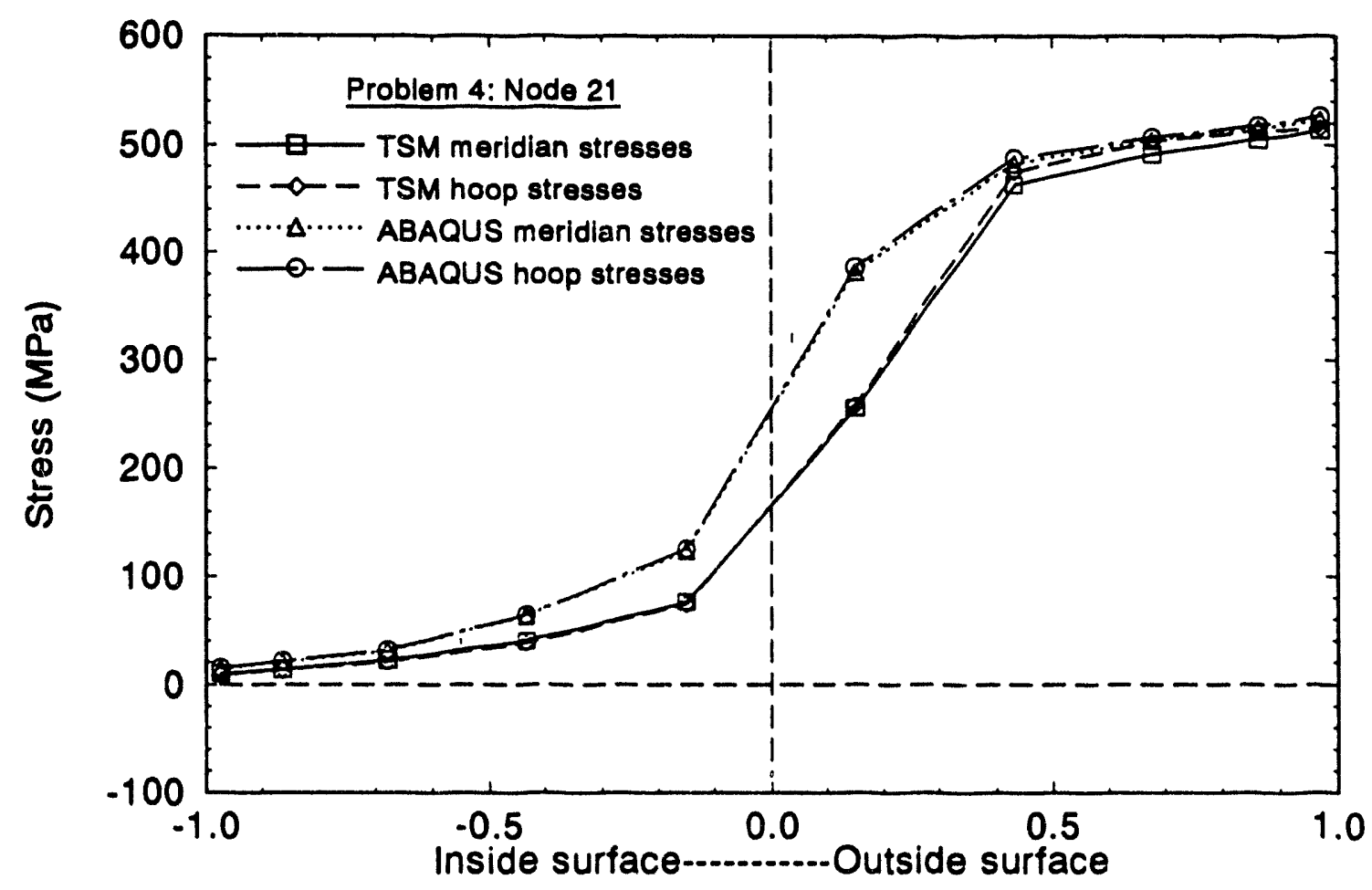

Figure E-14. Problem 4: node 21 stresses. 


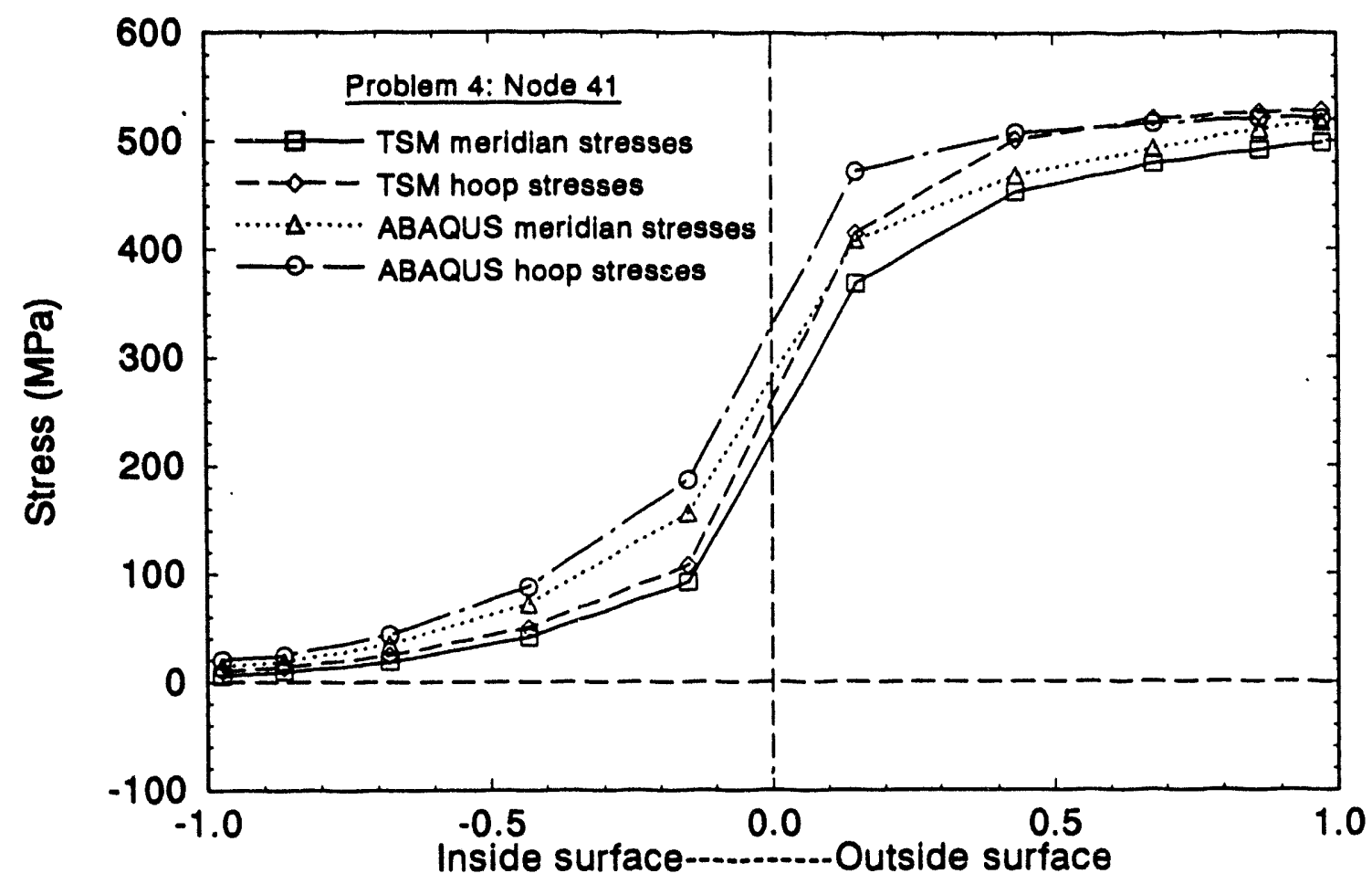

M7se $\approx-1192 \cdot 10$

Figure E-15. Problem 4: node 41 stresses.

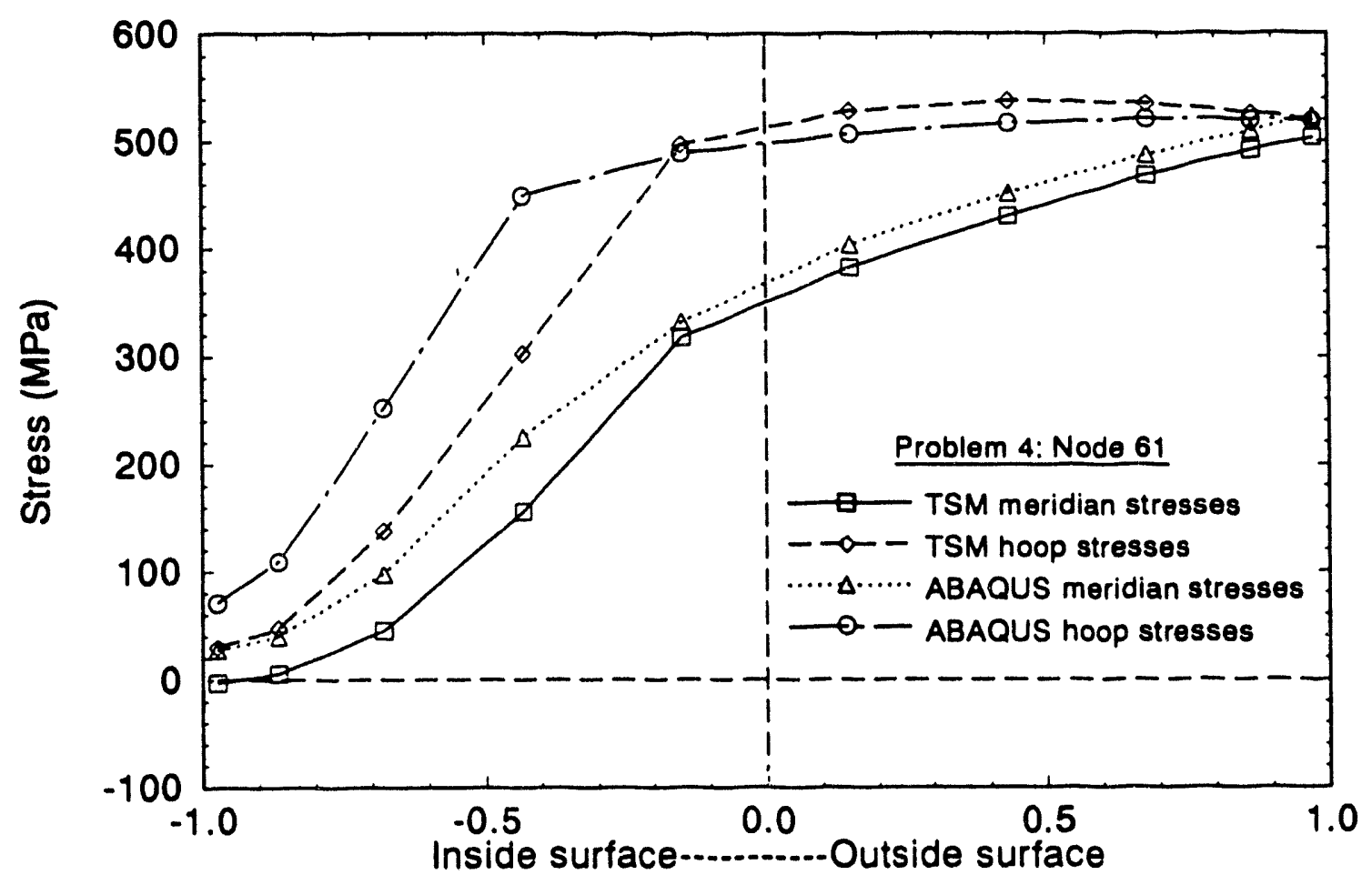

M7s0 - 1102.11

Figure E-16. Problem 4: node 61 stresses. 


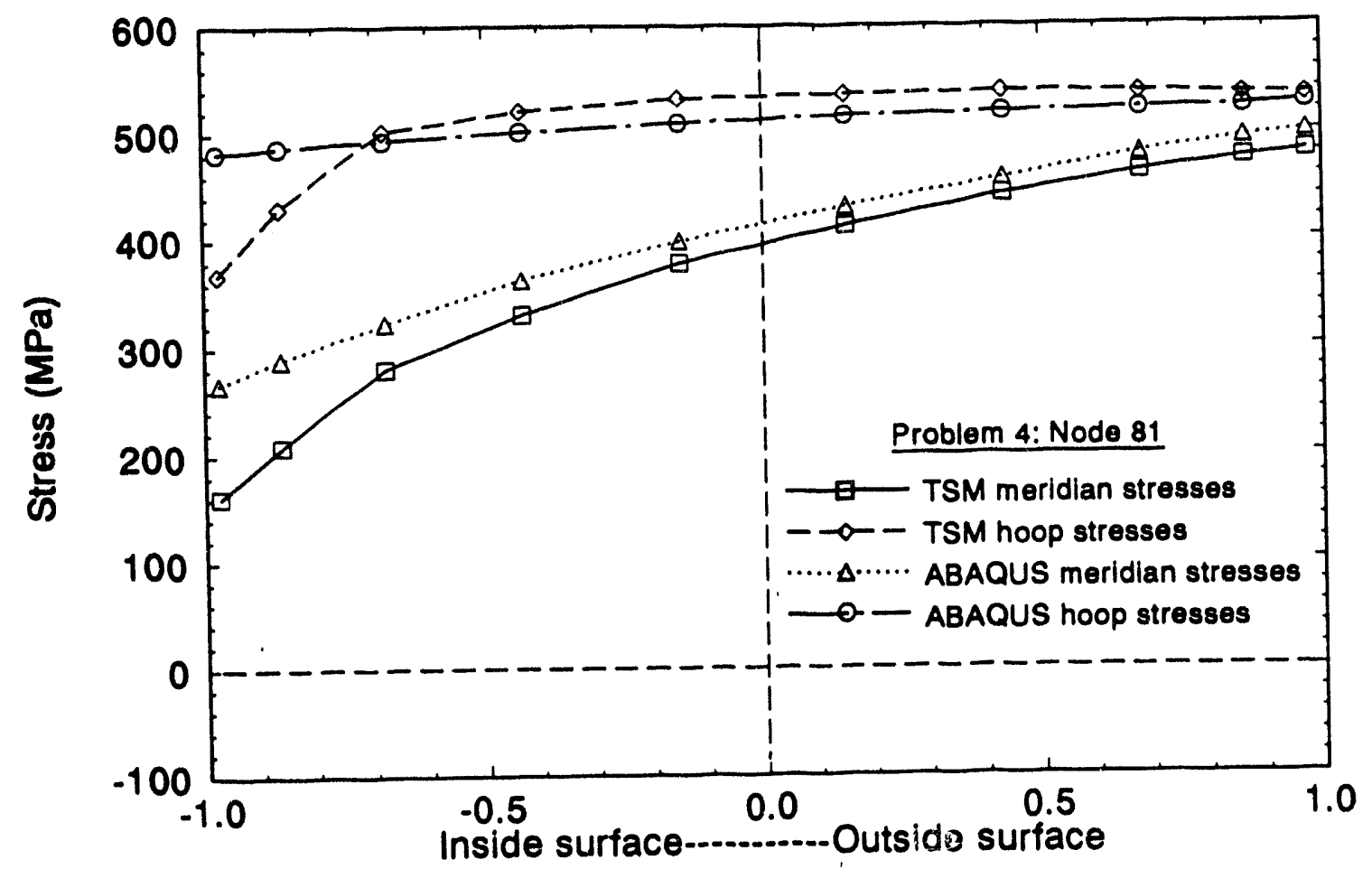

M7s $\approx-1192 \cdot 12$

Figure E-17. Problem 4: node 81 stresses.

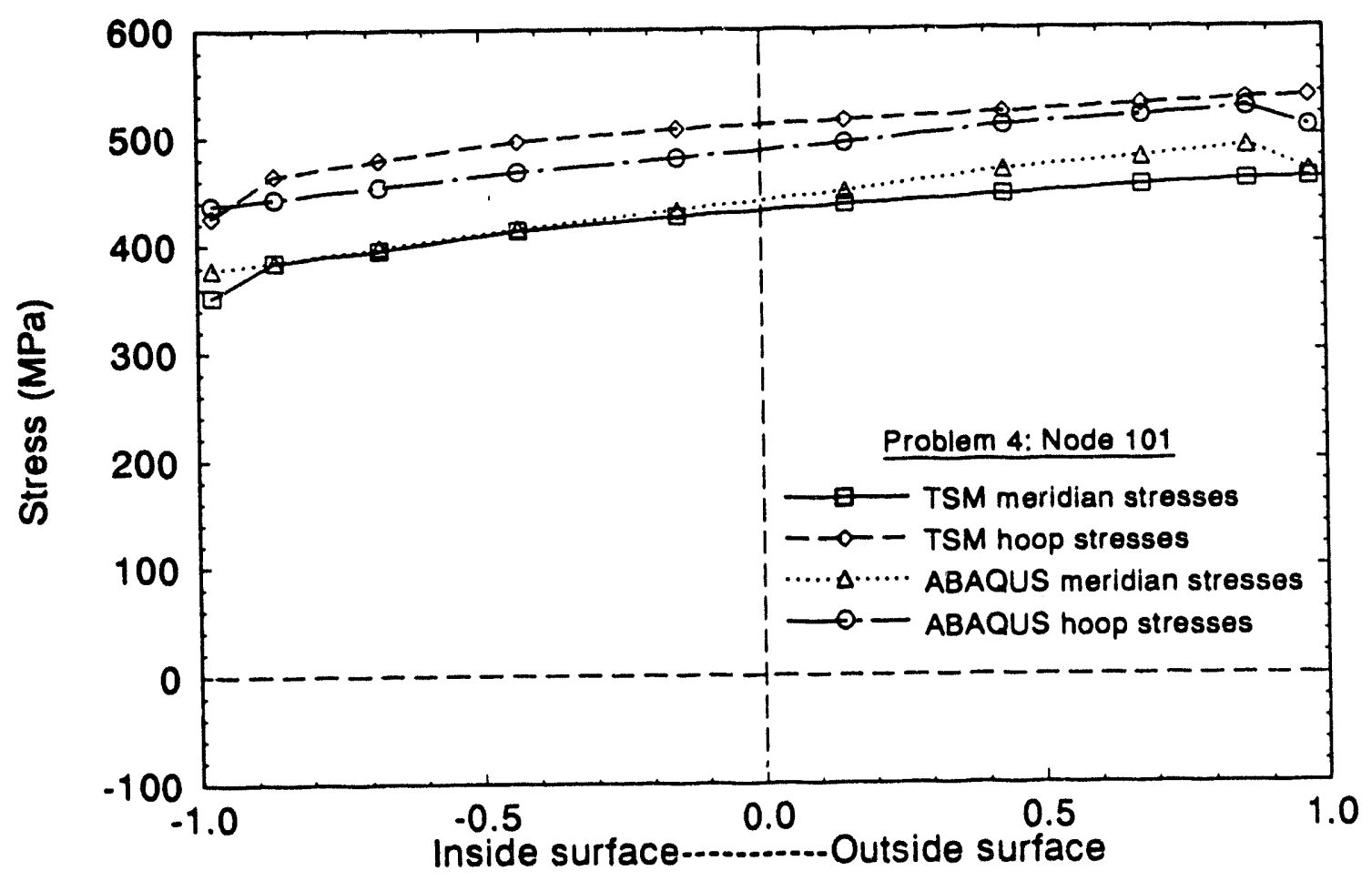

Figure E-18. Problem 4: node 101 stresses. 


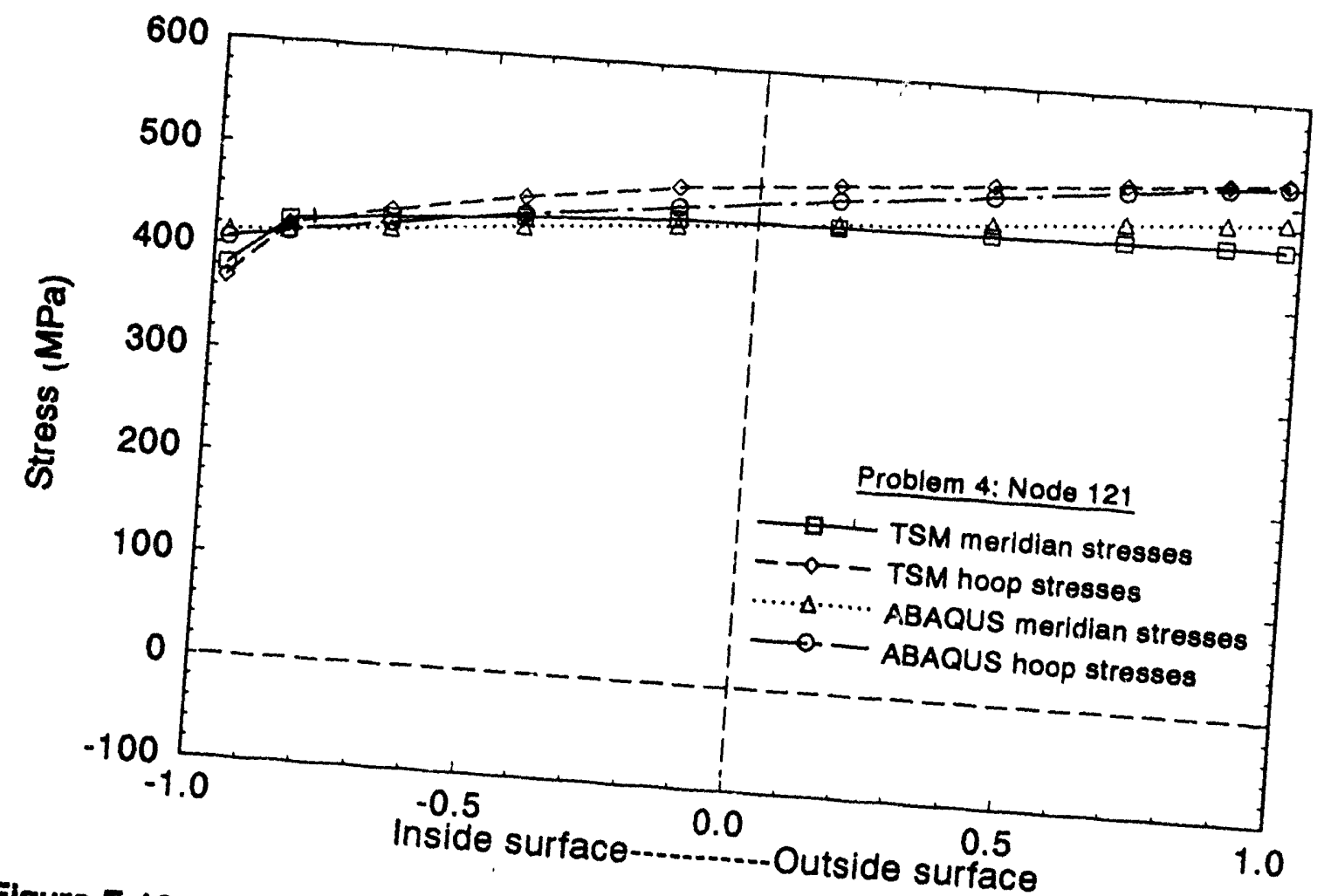

Figure E-19. Problem 4: node 121 stresses. the radial stresses quickly dropped off to zero at the outside surface while the hoo spot, since stresses rose by a factor of 50 to 100 . TSM meridian and hoop stre while the hoop and meridian majority of thed those calculated by ABAQUS by about $4 \%$. (points 101 and 121 ) and shell yielding propagated from the outer portion of the wall carried the values for the entire meridian and hoop stresses were within an surface inward. The far-field

Next, TSM and ABAQUS m

of Problem 4 applied with a maximum inte evaluated with the severe localized thermal loading comparison of the hoop and meridian stresses of the of $15 \mathrm{MPa}$. Figure E-20 shows the middle of the hot spot). TSM stesses tresses of the two models for node those of ABAQUS. The agreesses throughout the wall were an node point 41 (located in the temperature gradient at 15 agreement between ABAQUS and TSM in the of $4 \%$ lower than models in a moderate $15 \mathrm{MPa}$ pressure is comparable to the agreeme more severe of radial stress in TSM is rature gradient at $15 \mathrm{MPa}$ pressure, indicating again the two elevated pressures. locations within the hot spot at elevated the inside surface to near $10 \%$ on the outside for reduced to $12 \%$ on the inside and $7 \%$ on the outsides from the hot spot those values were 


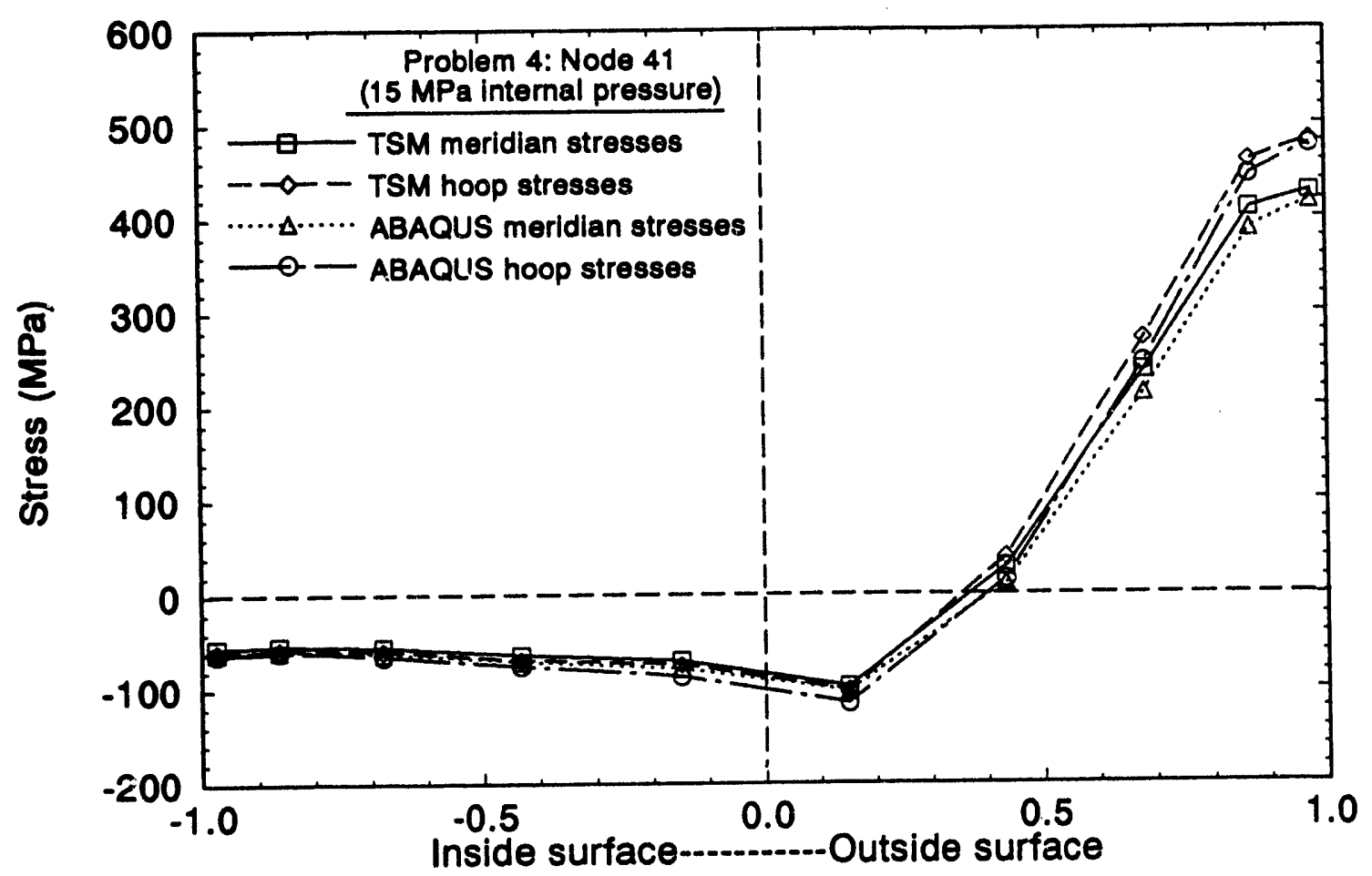

M750 ש.1102-17

Figure E-20. Problem 4 thermal loading with only $15 \mathrm{MPa}$ internal pressure: node 41 stresses.

Problem 4 thermal loading with a maximum pressure of $15 \mathrm{MPa}$, the total meridian and hoop strains in the hot spot were at most $16 \%$ lower than ABAQUS on the inside surface and within $2 \%$ on the outside. Outside of the hot spot all TSM total strains were within 5\% of ABAQUS values. Figure E-21 compares the total strains of the two models for the Problem 4 thermal loading with an internal pressure of $15 \mathrm{MPa}$.

TSM results for Problem 4 showed that all plastic strains (meridian and hoop) occurred one or two Gauss point locations closer to the outer surface than ABAQUS. Those plastic strains increased towards the outer surface. As in Problem 3, TSM plastic meridian and hoop strains started at $\mathbf{1 0 0 \%}$ lower values (at the smallest plastic strains), and steadily increased to, at most, $1 \%$ lower values than ABAQUS (where the plastic strains reached maximum values).

\section{E.7 Conclusions}

The verification of TSM has provided several insights into the applicability of this program for use in lower head severe accident structural response calculations. First of all, it must be remembered that the purpose for developing this program was to provide a fast-running solution to predict the collapse of a localized portion of the vessel wall resulting from hot spots in a debris bed resting on the lower head. Thus, the program would be appropriate for scoping parameter studies in various accident scenarios. Results of the benchmark problems used in this verification effort indicate that TSM performs well for its intended purpose. 


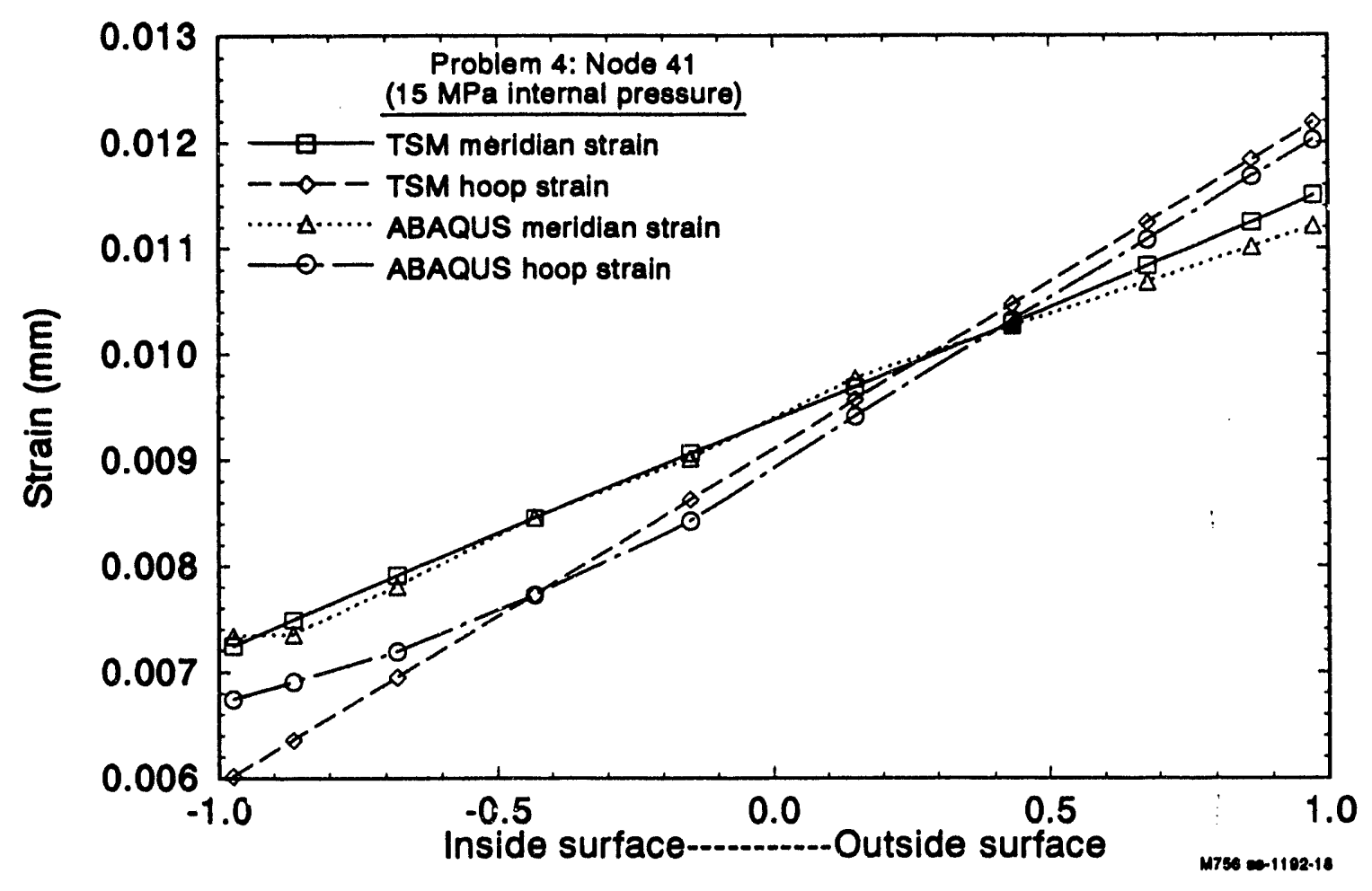

Figure E-21. Problem 4 thermal loading with only $15 \mathrm{MPa}$ internal pressure: node 41 strains.

The two benchmark problems that applied a localized hot spot (Problems 3 and 4) with an internal pressure of 45 to $55 \mathrm{MPa}$ identified that TSM does not accurately predict the stresses in the hottest regions. This was due to TSM assumption that the radial component of stress was negligible. However, it was pointed out that the hottest areas carry a very small percentage of the total pressure load. The assumption of negligible radial stresses was shown to be valid in the cooler regions under the hot spot, which is essentially the portion beyond the midplane and away from the hot spot. That portion of the wall carried the majority of the pressure load in these cases. It was noted that vessel wall material yielding eventually begins at the outer surface and propagates inward to final frilure. Hoop and meridian stress levels are typically $\mathbf{3 5}$ times higher in the outer portions than the inner regions of the vessel wall. Thus, model accuracy in these areas is most crucial to accurate predictions of vessel failure margins.

Two additional load cases were evaluated that employed the thermal hot spot definitions from Problems 3 and 4 with a pressure of $15 \mathrm{MPa}$. This lower pressure was more representative of accident conditions on a reactor vessel. The evaluation of these two cases verified that TSM assumption of negligible radial stresses was acceptable for the more representative accident conditions.

TSM total strain comparisons ranged from underpredictions of $24 \%$ on the inside surface to $11 \%$ on the outside surface in the hot spot region for the severe thermal gradient load case at elevated pressures. In the cooler boundary areas, strain comparisons ranged from underpredictions of $13 \%$ on the inner surface to $7 \%$ on the outer surface. Examinations of the 
plastic strains indicated that plasticity of the wall had propagated from the outside inward one Gauss point further in the ABAQUS model than in TSM model for the two hot spot load cases. The magnitude of total strains for Benchmark Problems 3 and 4 were 3 to 5 times lower than the plastic strain values. Use of TSM for predicting vessel response is considered acceptable for pressure levels at or below $15 \mathrm{MPa}$.

\section{E.8 References}

E-1. ABAQUS, Version 4-8-5, Providence Rhode Island: Hibbit, Karlsson, and Sorenson, Inc. 1990.

E-2. J. L. Rempe et al., Light Water Reactor Lower Head Failure Analysis, NUREG/CR-5642, EGG-2618, October 1993.

E-3. R. H. Bogaard et al., Thermophysical Properties of Selected Manganese and Nickel Steels and High Nickel Iron, CINDAS Special Report (Part VI), Center for Information and Numerical Data Analysis and Synthesis, Purdue University, January 1978. 


\begin{tabular}{|c|c|}
\hline 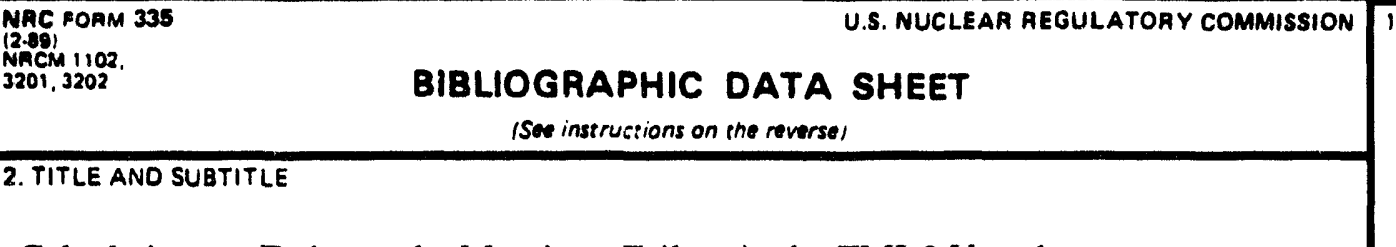 & 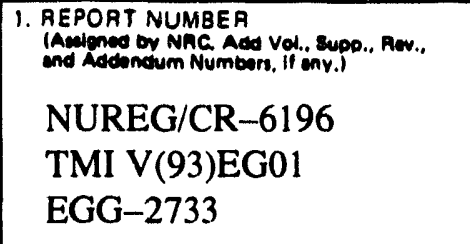 \\
\hline \multirow[t]{3}{*}{ Calculations to Estimate the Margin to Failure in the TMI-2 Vessel } & 3. DATE REPORT PUBLISHED \\
\hline & \begin{tabular}{|l|l} 
MONTH & YEAR \\
March & 1994 \\
\end{tabular} \\
\hline & $\begin{array}{l}\text { 4. FIN OR GAANT NUMBEA } \\
\text { A6899 }\end{array}$ \\
\hline L. A. Stickler, J. L. Rempe, S. A. Chávez, G. L. Thinnes, S. D. Snow, & $\begin{array}{l}\text { 6. TYPE OF REPOAT } \\
\text { Technical }\end{array}$ \\
\hline $\begin{array}{l}\text { L. A. Stickler, J. L. Rempe, S. A. Chávez, G. L. Thinnes, S. D. Snow, } \\
\text { R. J. Witt," M. L. Corradini," J. A. Kos* }\end{array}$ & 7. PERIOD COVERED InClusive Dates/ \\
\hline \multicolumn{2}{|l|}{ 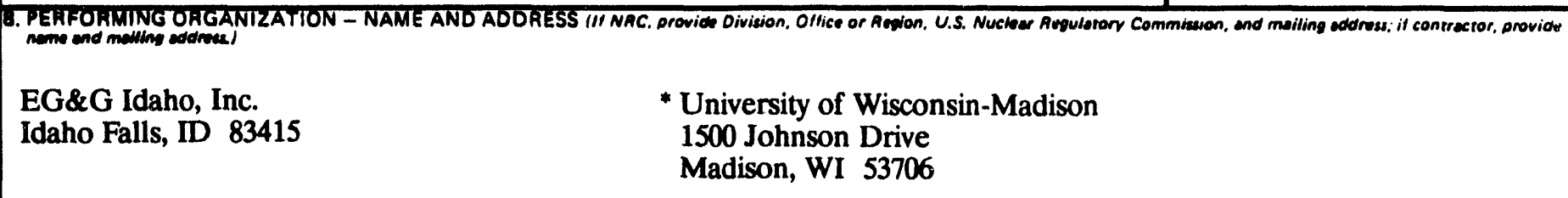 } \\
\hline \multicolumn{2}{|c|}{ 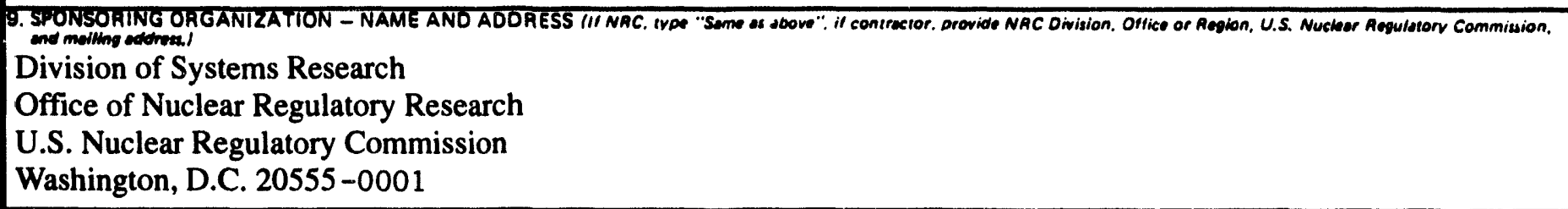 } \\
\hline \multicolumn{2}{|l|}{ 10. SUPPLEMENTARY NOTES } \\
\hline \multicolumn{2}{|c|}{$\begin{array}{l}\text { As part of the OECD-sponsored Three Mile Island Unit } 2 \text { (TMI-2) Vessel Investigation Project (VIP), } \\
\text { margin-to-failure calculations for mechanisms having the potential to threaten the integrity of the vessel were } \\
\text { performed to improve understanding of events that occurred during the TMI-2 accident. Analyses considered four } \\
\text { failure mechanisms: tube rupture, tube ejection, global vessel failure, and localized vessel failure. Calculational } \\
\text { input was based on data from the TMI-2 VIP examinations of the vessel steel samples, the instrument tube nozzles, } \\
\text { and samples of the hard layer of debris found on the TMI-2 vessel lower head. Sensitivity studies were performed } \\
\text { to investigate the uncertainties in key parameters for these analyses. }\end{array}$} \\
\hline 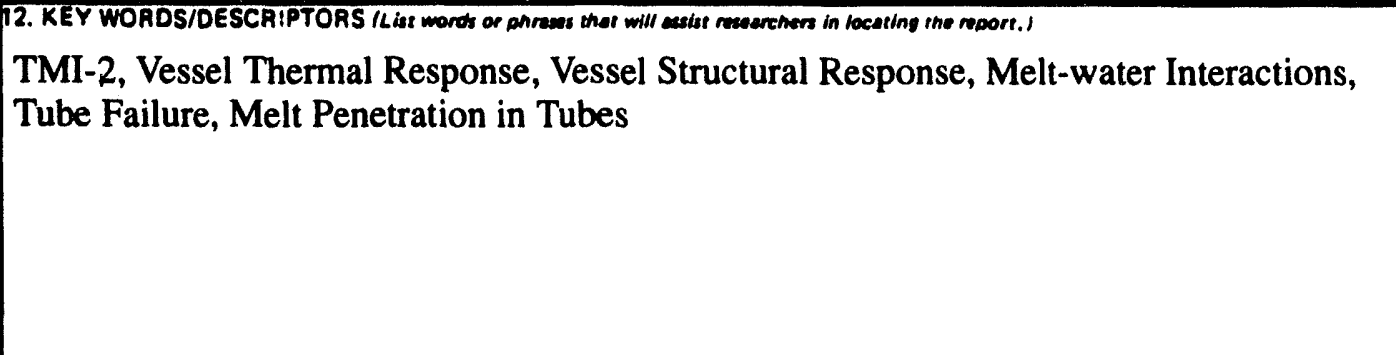 & 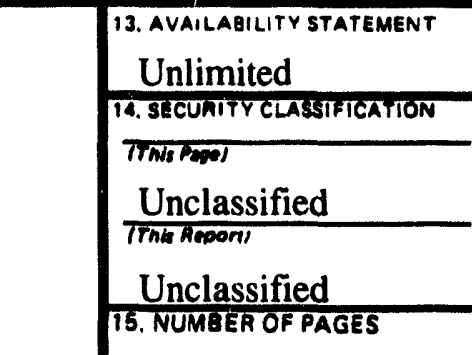 \\
\hline & 16. PAICE \\
\hline
\end{tabular}



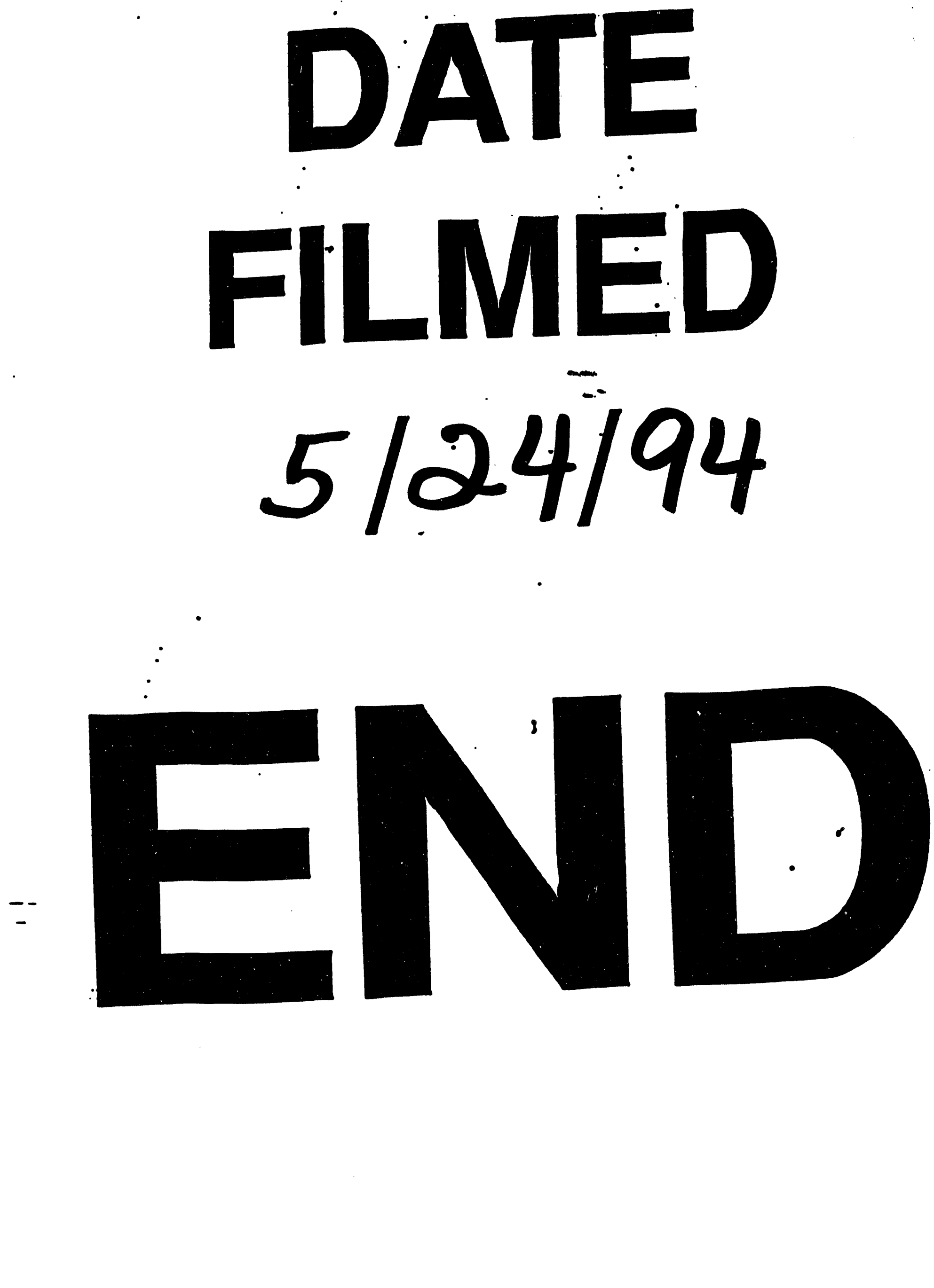
